Universidade de São Paulo

Instituto de Física

\title{
Caracterização estrutural de sistemas biológicos de diferentes classes: Um estudo pela técnica de SAXS
}

\author{
Pedro Leonidas Oseliero Filho
}

Orientador: Prof. Dr. Cristiano Luis Pinto de Oliveira

Tese de doutorado apresentada ao Instituto de Física como requisito parcial para a obtenção do título de Doutor em Ciências.

Banca Examinadora:

Prof. Dr. Cristiano Luis Pinto de Oliveira (IFUSP)

Prof. Dr. Leandro Ramos Souza Barbosa (IFUSP)

Profa. Dra. Marcia Carvalho de Abreu Fantini (IFUSP)

Prof. Dr. Emerson Rodrigo da Silva (UNIFESP)

Profa. Dra. Lucimara Gaziola de la Torre (UNICAMP) 
FICHA CATALOGRÁFICA

Preparada pelo Serviço de Biblioteca e Informação do Instituto de Física da Universidade de São Paulo

Oseliero Filho, Pedro Leonidas

Caracterização estrutural de sistemas biológicos de diferentes classes: um estudo pela técnica de SAXS. São Paulo, 2018.

Tese (Doutorado) - Universidade de São Paulo. Instituto de Física. Depto. de Física Experimental.

Orientador: Prof. Dr. Cristiano Luis Pinto de Oliveira Área de Concentração: Biofísica.

Unitermos: 1. Modelagem de dados; 2. Espalhamento de raios $\mathrm{X}$ a baixos ângulos; 3. Proteínas; 4. Surfactantes; 5. Lipossomos. 
Para a minha amada Babige... 



\section{AGRADECIMENTOS}

Agradeço

-A Deus, por tudo aquilo que já aconteceu na minha, pois é graças a isso que sou quem eu sou. -À minha mãe, Cilene, por todo o amor e carinho que sempre me proveu e continua me provendo apesar de eu ser um filho relapso, que não telefona muito depois que saí da sua casa (mas mudarei isso...). Saiba que te amo muito e que foi somente por sua causa e por causa do pai que pude estudar, iniciando um caminho que posteriormente me levaria a onde estou hoje.

-Ao meu falecido pai, Pedro, que por vias pouco "ortodoxas" me ensinou sobre caráter, honra e verdades da vida. Sei que o senhor cometeu alguns erros (que espero não cometer), mas ninguém é perfeito, tampouco diminui o homem que você foi em vida. Saiba que, de onde estiver, te agradeço por todos os momentos que passamos juntos. Te amo muito.

-Aos meus irmãos, Marcos e Camila, por estarem sempre presentes, mesmo depois que cada um trilhou seu caminho. Sempre que nos encontramos conversamos e rimos muito. Saibam que, mesmo distante, amo muito vocês e sempre poderão contar comigo.

-À minha linda e amada esposa Barbara (também chamada por mim de Babige, Boy, e outros pseudônimos...), com quem compartilho a vida a quase uma década na ocasião da escrita desta tese. Se tem algo que aprendi ao longo de todo esse tempo é que ela sempre possui razão! É incrível! Acreditem quando digo que ela já me impediu de fazer várias burradas, da mesma forma que por causa dela já fui bem-sucedido inúmeras vezes. Se minha mãe e meu pai foram os responsáveis pela minha educação básica, que culminou na minha graduação, foi por influência positiva da Barbara que iniciei minha pós-graduação. Além disso, também aprendi que ela sempre estará ao meu lado, principalmente nos momentos difíceis, assim como eu estarei ao seu lado. Sei que sou muito chato várias vezes, e por isso eu te agradeço, Barbara, por toda a paciência e compreensão. Assim como no meu mestrado, grande parte desse atual trabalho somente se concretizou porque você ficou ao meu lado, como sempre... Te amo um montão, com ... no final.

-Ao Bacon, meu cachorrinho cuja única tarefa na vida, aparentemente, além de comer, dormir e brincar/bagunçar, é o de nos trazer alegria. Foi por sua causa, e o que aprendemos com você, que Barbara e eu, até o momento desta tese, ainda não tivemos um bebê... rsrsrsr 
-À família Gerbelli/Voltarelli, por serem também minha família. Clara, Junior, Iduílio, Denise, muito obrigado por tudo. Em especial, agradeço à minha sogra, Roseli, por ser ter sido minha segunda mãe e uma grande amiga desde o início do meu relacionamento com sua filha. Sempre que nos encontramos damos várias risadas juntos. Obrigado por todos os ensinamentos, em particular sobre persistir nos seus sonhos. E se algo der errado, o Juninho rezará por nós...

-Ao meu orientador, Prof. Cristiano, por ter aceitado me orientar mais uma vez e ter sido ainda mais paciente e compreensivo comigo do que foi no mestrado, ao mesmo tempo sempre me estimulando e abrindo meus olhos para as várias possibilidades futuras. Obrigado por toda a experiência, conhecimento e oportunidades que me foram concedidos ao longo desses anos.

-Às colaborações estabelecidas com a Profa. Samantha e o Matheus, com a Profa. Iolanda e a Laura Farkuh, e com a Profa. Monica, cuja amizade, troca de experiências e informações tornaram a minha formação ainda mais rica e única;

-Ao pessoal do CRPP, na França, que recebeu a mim e minha esposa muitíssimo bem, em especial ao Rafael Rubim, que nos ajudou tanto na parte acadêmica quanto na parte pessoal, sempre nos fornecendo dicas e informações valiosas;

-Ao Prof. Nallet, do CRPP, com quem tive a honra de trabalhar por alguns dias e que me relembrou porque eu entrei na área acadêmica e porque devo continuar. Nesse sentido, novamente agradeço ao Prof. Cristiano porque foi graças a ele que esse encontro foi possível.

-Aos colegas do GFCx, do INCTFCx e do Laboratório de Cristalografia, que direta ou indiretamente contribuíram muitíssimo para minha formação ao longo do mestrado e doutorado;

-A todos da USP, incluindo a CPG, secretarias, recepções, bandeijão, com quem tenho contato e que sempre me trataram muitíssimo bem;

-Ao CNPq pelo auxílio financeiro;

-A todos que, direta ou indiretamente, que foram ou não mencionados aqui, só tenho a agradecer por tudo o que me proporcionaram. Muitíssimo obrigado por tudo!

Pedro 
"Talvez não tenha conseguido fazer o melhor, mas lutei para que o melhor fosse feito. Não sou o que deveria ser, mas Graças a Deus, não sou o que era antes."

Marthin Luther King

“O mundo não é um grande arco-íris. É um lugar sujo,é um lugar cruel, que não quer saber o quanto vocêé durão, vai botar você de joelhos e você vai ficar para sempre se você deixar. Você, eu, ninguém vai bater tão duro quanto a vida. Mas não se trata de quão forte ela bate. Se trata de quanto você aguenta apanhar e seguir em frente, o quanto você é capaz de aguentar e continuar tentando. É assim que se consegue vencer."

Rocky Balboa 



\section{RESUMO}

Esta tese apresenta resultados da caracterização estrutural de três sistemas de classes diferentes por meio, principalmente, da modelagem de dados de espalhamento de raios $\mathrm{X}$ a baixos ângulos (SAXS). No sistema surfactante-surfactante as micelas mistas são formadas por dodecil sulfato de sódio (SDS) e um dos surfactantes da série Tween ${ }^{\circledR}\left(\right.$ Tween $^{\circledR} 20,40,60$ e 80). A modelagem adotada impôs vínculos moleculares uma vez que os dados de SAXS estavam em escala absoluta. Isso reduziu a ambiguidade nos valores dos parâmetros ajustáveis e permitiu verificar que os dados de SAXS são satisfatoriamente descritos considerando-se que as micelas são elipsoides de revolução core-shell, podendo ser prolatas ou oblatas dependendo do tipo de Tween ${ }^{\circledR}$ empregado.

Para o sistema proteína-surfactante, a metodologia experimental utilizada permitiu um estudo estrutural e termodinâmico dos complexos formados por meio do acompanhamento do processo de ligação de SDS às proteínas lisozima e alfa-lactalbumina. A técnica de calorimetria de titulação isotérmica (ITC) forneceu um panorama geral sobre a desnaturação proteica e norteou os experimentos seguintes de SAXS e dicroísmo circular (CD). Por meio da análise dos dados de CD concluiu-se que as proteínas perdem quase totalmente sua estrutura terciária, mas não a secundária (esse estado é conhecido como "molten globule"). Já a modelagem de SAXS em escala absoluta com imposição de vínculos permitiu concluir que os complexos proteínasurfactante podem ser entendidos micelas decoradas, isto é, a proteína está distribuída sobre a superfície de uma micela de SDS. Esse modelo, aliado à abordagem experimental empregada, permitiu a caracterização sistemática dos complexos durante a desnaturação proteica.

Em relação ao sistema lipossomas-(bio)ativos, a análise dos dados de SAXS por meio do Método da Deconvolução Gaussiana usando bicamadas simétricas, para os sistemas Phospholipon ${ }^{\circledR} 90 \mathrm{H}$ - curcumina/vitamina $\mathrm{D}_{3}$ e dipalmitoilfosfatidilcolina de soja (DPPC) ácido láurico (LA), e assimétricas, para o caso fosfatidilcolina de ovo (EPC) - sumatriptano (SMT), permitiu acompanhar mudanças na estrutura das mesmas ocasionadas pela presença dos (bio)ativos. Verificou-se em todos os casos que a espessura da bicamada se mantém praticamente constante. A flexibilidade membranar aumenta, seja em função da temperatura, para o sistema Phospholipon ${ }^{\circledR} 90 \mathrm{H}$ - curcumina/ vitamina $\mathrm{D}_{3}$, seja em função da concentração de (bio)ativos, como nos outros dois casos. Para estes, concluiu-se pela análise dos perfis de contraste de densidade eletrônica que os (bio)ativos interagem preferencialmente com as cabeças polares dos fosfolipídeos que constituem os lipossomas, possivelmente causando defeitos topológicos nessa região e ocasionando o aumento da flexibilidade membranar mencionada antes. LA, diferentemente de SMT, induz uma transição de lipossomas multilamelares para unilamelares, e esse fenômeno é grandemente influenciado pelo $\mathrm{pH}$ do meio.

Palavras-chave: Espalhamento de Raios X a Baixos Ângulos, Calorimetria de Titulação Isotérmica, micelas mistas, lipossomas, complexos proteína-surfactante 



\section{ABSTRACT}

This thesis presents a structural characterization of three systems of different classes through, mainly, the small angle X-ray scattering (SAXS) technique. In the surfactant-surfactant system the mixed micelles are composed by sodium dodecyl sulfate (SDS) and one of the Tween ${ }^{\circledR}$ surfactants (Tween ${ }^{\circledR} 20,40,60$ and 80). The adopted modeling imposed molecular constraints since the SAXS data was in absolute scale. This procedure reduced the ambiguity in the values of the adjustable parameters and allowed to verify that SAXS data is satisfactorily described considering that the micelles are core-shell revolution ellipsoids which can be prolate or oblate depending on the type of Tween ${ }^{\circledR}$ used in the micelle.

For the protein-surfactant system, the applied experimental methodology allowed a structural and thermodynamic study of the complexes formed through monitoring the binding of SDS to the proteins lysozyme and alpha-lactalbumin. Isothermal titration calorimetry (ITC) technique provided an overview of proteic denaturation and guided the following experiments of SAXS and circular dichroism (CD). From CD data analysis it was concluded that the proteins lose almost totally their tertiary structure, but not the secondary one (this state is known as "molten globule"). On the other hand, SAXS data modeling in absolute scale with molecular constraints leaded to the conclusion that protein-surfactant complexes can be considered decorated micelles in which the protein is distributed over a SDS micelle surface. This model, combined to the adopted experimental procedure, allowed the systematic characterization of the complexes along the protein denaturation.

In the liposome-(bio)actives system, the SAXS data analysis using the Gaussian Deconvolution Method assuming symmetric bilayers, for the systems Phospholipon ${ }^{\circledR} 90 \mathrm{H}-$ curcumin /vitamin $\mathrm{D}_{3}$ and soybean dipalmitoyl phosphatidylcholine (DPPC) - lauric acid (LA), and asymmetric bilayers, in the case of egg phosphatidylcholine (EPC) - sumatriptan (SMT) system, allowed to follow changes in the lipid bilayer structure induced by the presence of the (bio)actives. It has been found, in all cases, that the bilayer thickness remains approximately. Membrane flexibility increases, depending on the temperature, for the Phospholipon ${ }^{\circledR} 90 \mathrm{H}-$ curcumin /vitamin $\mathrm{D}_{3}$ system, or as a function of the (bio)actives concentrations, as in the other two cases. For those, it was concluded, by the analysis of electron density contrast profiles, that the (bio)actives preferentially interact with the polar heads of the phospholipids forming the liposomes, possibly causing topological defects in that region and leading the membrane flexibility increase. LA, unlike SMT, induces a transition from multilamellar to unilamellar liposomes, and this phenomenon is greatly influenced by the $\mathrm{pH}$ of the medium.

Key words: Small Angle X-ray Scattering, Isothermal Titration Calorimetry, mixed micelles, liposomes, protein-surfactant complexes 



\section{LISTA DE FIGURAS}

Figura 1: A) As ligações de hidrogênio (representadas pelas retângulos tracejados) sempre acontecem entre um aceptor e um doador. Em biomoléculas, esse tipo de ligação pode ocorrer, por exemplo, entre B) bases complementares de DNA, C) entre o grupo hidroxila de um álcool e água, D) entre o grupo carbonila de uma cetona e água e E) entre grupos peptídicos em polipeptídeos. Adaptada de [34].

Figura 2: Esquema representando a interação hidrofóbica. Em A) a molécula de surfactante está rodeada de água, incluindo a parte não polar. Essa situação, desfavorável termodinamicamente, é substituída por aquela mostrada em B). Extraído de [62].

Figura 3: A) Acima, estrutura genérica de um $\alpha$-aminoácido (com exceção da prolina, um aminoácido cíclico). Abaixo, exemplos de $\alpha$-aminoácidos com grupos laterais contendo anéis aromáticos. B) Esquema da ligação peptídica. C) Esquema da ligação dissulfeto. Adaptado de [34].

Figura 4: A) Estrutura primária. B) Estrutura secundária. C) Estrutura terciária. D) Estrutura quaternária. Adaptado de [34].

Figura 5: A) Fórmula estrutural da molécula anfifílica aniônica SDS. B) Representação esquemática da molécula SDS. Extraído de [62].

Figura 6: A) Solução com concentração abaixo da CMC do surfactante. A maior parte das moléculas encontra-se nas interfaces. B) Solução com concentração acima da CMC, onde formam-se agregados. Extraído de [62].

Figura 7: Comportamento de algumas propriedades físicas em função da concentração de surfactante. Retirado de [62].

Figura 8: A) Exemplos de compostos frequentemente usados na preparação de lipossomas com suas respectivas cargas e temperatura de transição. B) Estrutura geral de um fosfolipídeo. C) Estrutura da molécula DPPC, um fosfolipídeo. Adaptado de [68].

Figura 9: A) Esquema do aparato experimental usado na técnica de SAXS. B) Exemplo de difratograma. C) A partir do difratograma obtém-se uma curva unidimensional de intensidade espalhada $I q$ versus o módulo do vetor de transferência de momento no espaço recíproco $q$.

Figura 10: A) Esquema de um equipamento de ITC. B) Exemplo de dado experimental bruto obtido com o experimento (fluxograma). C) Exemplo de dado experimental final (entalpograma), o qual poderá ser analisado e comparado com modelos teóricos (linha azul) se disponíveis.

Figura 11: A) Esquema do aparato experimental usado na técnica de CD. B) O processamento dos dados é feito de modo a levar em conta informações da amostra, como concentração, para o cálculo da elipticidade, que é a grandeza que se relaciona com o ângulo de rotação do plano de luz em relação ao plano da luz incidente. C) Como saída, obtém-se um gráfico de elipticidade versus comprimento de onda (região far-UV ou nearUV).

Figura 12: A) Feixe de raios $X$ espalhado por uma partícula, fixa no espaço, formando um ângulo $2 \theta$ em relação ao feixe incidente. B) A partir de considerações geométricas, escreve-se o módulo do vetor de transferência de momento no espaço recíproco $q$ em função do ângulo de espalhamento e do módulo do vetor de onda $k$. Retirado de [62].

Figura 13: Cada estrutura mostrada à direita (esfera, cilindro, prisma...) possui um único perfil de intensidade assim como um único perfil de $p(r)$. Conhecendo-se esses perfis, pode-se em uma análise inicial dar palpites sobre a forma das partículas em um sistema qualquer assim como o tamanho máximo envolvido ( $r m a ́ x)$, informação esta relacionada com a curva $p(r)$. Adaptado de [62].

Figura 14: A) Exemplo de partícula do tipo core-shell. B) A partir da curva de intensidade é possível obter a função $p(r)$ via Transformada Inversa de Fourier (IFT). Adaptado de [75]

Figura 15: A) Esquema simplificado de uma micela com forma elipsoidal. B) Modelo usado para descrever a micela, um elipsoide de revolução core-shell. A revolução se dá em torno eixo perpendicular ao eixo principal passando pelo centro do elipsoide. O significado de cada termo mostrado na figura encontra-se no texto. 
Figura 16: Diferença entre um elipsoide de revolução prolato (A) e oblato (B).

Figura 17: A) Esquema simplificado de uma micela decorada. B) Modelo usado para descrever a micela decorada, um elipsoide de revolução core-shell. A revolução se dá em torno eixo perpendicular ao eixo principal passando pelo centro do elipsoide. O significado de cada termo mostrado na figura encontra-se no texto. 55

Figura 18: A) Esquema de duas bicamadas adjacentes de espessura $\delta m$, separadas por uma cada aquosa de espessura $\delta w$. A periodicidade lamelar $D$ é tal que $D=\delta m+\delta w$. B) Perfil de contraste de densidade eletrônica $\Delta \rho$ ao longo do eixo $z$, que é a direção perpendicular ao plano da membrana. C) Fator de forma $P q$ obtido por meio da Transformada de Fourier de $\Delta \rho$. .58

Figura 19: Estrutura molecular dos surfactantes $\operatorname{Tween}^{\circledR}$ (A) e SDS (B) 64

Figura 20: A) Dados experimentais de SAXS para as micelas puras (símbolos abertos), ajustados pelo procedimento IFT (linhas contínuas). Nos ajustes, os pontos atrás da linha vertical tracejada (na posição $q=$ $0,05 \AA-1$ ), representados pelo símbolo de cruz, foram desconsiderados por terem relação com o fator de estrutura. B) Funções $p(r)$ obtidas a partir dos ajustes. As setas indicam os tamanhos máximos das partículas em solução.

Figura 21: A) Dados experimentais de SAXS para as micelas mistas (símbolos abertos), ajustados pelo procedimento IFT (linhas contínuas). Nos ajustes, os pontos atrás da linha vertical tracejada (na posição $q=$ $0,05 \AA-1$ ), representados pelo símbolo de cruz, foram desconsiderados por terem relação com o fator de estrutura. B) Funções $p(r)$ obtidas a partir dos ajustes. As setas indicam os tamanhos máximos das partículas em solução.

Figura 22: A) e B) correspondem aos dados experimentais (símbolos abertos) para as micelas puras e mistos, respectivamente, ajustados pelo modelo de elipsoide de revolução core-shell (linha contínua). 71

Figura 23: A) Estrutura primária da lisozima (sequência de letras, cada uma representando um resíduo). Retirado de [131]. B) Estrutura secundária e terciaria da lisozima gerada no website https://www.rcsb.org com a entrada 6LYZ.pdb.

Figura 24: A) Entalpogramas obtidos para a titulação de SDS em diferentes concentrações de lisozima. B) Pontos selecionados para a determinação da estequiometria de ligação.

Figura 25: Concentração total de surfactante $[\mathrm{S}]$ em função da concentração total de proteína $[\mathrm{P}]$ para cada um dos 11 pontos selecionados, para cada entalpograma. As linhas contínuas correspondem aos ajustes feitos com a Eq. 7.

Figura 26: A) Curvas de SAXS (símbolos abertos) obtidas para as soluções de lisozima, SDS e para as amostras P1-P11, com exceção das amostras P3 e P9. As linhas contínuas representam os ajustes IFT. B) Funções $p r$ obtidas para as curvas apresentadas em A).

Figura 27: A) Curvas de SAXS (símbolos abertos) obtidos para as amostras P3 e P9. As linhas contínuas representam os ajustes IFT. B) Funções $p r$ obtidas para as curvas apresentadas em A).

Figura 28: A) Espectros de $\mathrm{CD}$ na região $F a r-U V$, que fornecem informações sobre a estrutura secundária da proteína, coletados para diferentes razões $S: P$. B) Porcentagem de três conformações da estrutura secundária da lisozima em função da razão $S: P$, obtida a partir do ajuste das curvas de CD usando-se o programa DICHROWEB

Figura 29: Espectros de CD na região Near-UV, o qual fornece informações sobre a estrutura terciária da proteína, coletados para diferentes razões $S: P$.

Figura 30: A) Dados de SAXS (símbolos abertos) ajustados com o modelo de micelas decoradas (linhas contínuas) para todos os pontos exceto P3 e P9. B) Ajuste (linhas contínuas) dos dados de P3 e P9 (símbolos abertos) com o modelo de micelas decoradas acrescido do fator de estrutura da pela Eq. 69.

Figura 31: Representação esquemática dos diferentes estágios da ligação de SDS na lisozima, dando origem aos complexos estudados nessa seção. Figura adaptada de [45].

Figura 32: A) Estrutura primária da alfa-lactalbumina (sequência de letras, cada uma representando um resíduo). Retirado de [131]. B) Estrutura secundária e terciaria da alfa-lactalbumina gerada no website https://www.rcsb.org com a entrada 1AV4.pdb. As pequenas esferas representam íons $C a 2+$.

Figura 33: A) Entalpogramas obtidos para a titulação de SDS em diferentes concentrações de alfa-lactalbumina. B) Pontos selecionados para a determinação da estequiometria de ligação. 
Figura 34: Concentração total de surfactante [S] em função da concentração total de proteína [P] para cada um dos 11 pontos selecionados, para cada entalpograma. As linhas contínuas correspondem aos ajustes feitos com a Eq. 7 .

Figura 35: A) Curvas de SAXS (símbolos abertos) obtidas para as soluções de alfa-lactalbumina, SDS e para as amostras P1-P11. As linhas contínuas representam os ajustes IFT. B) Funções pr obtidas para as curvas apresentadas em A).

Figura 36: A) Espectros de $\mathrm{CD}$ na região $F a r-U V$, que fornecem informações sobre a estrutura secundária da proteína, coletados para diferentes razões $S: P$. B) Porcentagem de três conformações da estrutura secundária da alfa-lactalbumina em função da razão $S: P$, obtida a partir do ajuste das curvas de CD usandose o programa DICHROWEB.

Figura 37: Espectros de CD na região Near-UV, o qual fornece informações sobre a estrutura terciária da proteína, coletados para diferentes razões $S: P$.

Figura 38: Dados de SAXS (símbolos abertos) ajustados com o modelo de micelas decoradas (linhas contínuas).

Figura 39: Representação esquemática dos diferentes estágios da ligação de SDS na lisozima, dando origem aos complexos estudados nessa seção. Figura adaptada de [105]. 102

Figura 40: Estrutura química do Phospholipon ${ }^{\circledR} 90 \mathrm{H}$ (A), da vitamina $\mathrm{D}_{3}$ (B) e da curcumina (C) 106

Figura 41: A) Dados de SAXS (símbolos abertos) correspondentes a dispersões de lipossomas contendo apenas curcumina (FC), apenas vitamina $\mathrm{D}_{3}$ na concentração $50000 \mathrm{UI}$ (F5V), apenas vitamina $\mathrm{D}_{3}$ na concentração 80000 UI (F8V), curcumina + vitamina $\mathrm{D}_{3}$ na concentração $50000 \mathrm{UI}$ (FC5V), curcumina + vitamina $\mathrm{D}_{3}$ na concentração 80000 UI (FC8V), em diferentes temperaturas. As curvas de SAXS relativas às temperaturas $30{ }^{\circ} \mathrm{C}$ e $50^{\circ} \mathrm{C}$ estão ausentes pois são muito semelhantes às curvas para $20^{\circ} \mathrm{C} \mathrm{e} 40{ }^{\circ} \mathrm{C}$. As linhas sólidas correspondem aos ajustes usando o Método de Deconvolução Gaussiana. B) Perfis de contraste de densidade eletrônico obtidos a partir dos ajustes dos dados experimentais. 108

Figura 42: Valores dos parâmetros obtidos para as composições FC, F5V, F8V, FC5V e FC8V em função da temperatura.

Figura 43: Estrutura química da dipalmitoilfosfatidilcolina de soja (A) e do ácido láurico (B). 113

Figura 44: A) Dados experimentais (símbolos abertos) correspondentes a vesículas em presença de LA em diferentes pH's. As linhas sólidas correspondem aos ajustes usando o Método da Deconvolução Gaussiana. B) Perfil de contraste de densidade eletrônico obtido a partir dos ajustes dos dados experimentais. 114

Figura 45: Estrutura química da fosfatidilcolina de ovo (A) e do sumatriptano (B). 118

Figura 46: A) Dados experimentais (símbolos abertos) para lipossomas de EPC com SMT em diferentes razões molares. As linhas sólidas correspondem aos ajustes usando o Método da Deconvolução Gaussiana (seção Fundamentos Teóricos do Capítulo 2). B) Perfis de contraste de densidade eletrônica obtidos a partir dos ajustes das curvas experimentais.

Figura 47: Valores dos parâmetros da Tabela 9 em função do valor numérico da razão STM:EPC.

Figura 48 - Resultados do Teste 02 para todos os conjuntos de dados analisados. 136

Figura 49 - Comparação entre os valores dos parâmetros apresentados no artigo original [194] (círculos pretos) e os valores obtidos via procedimento automático de ajuste (círculos vermelhos). 



\section{LISTA DE TABELAS}

Tabela 1: Informações moleculares dos surfactantes. Massa molecular (MW), concentração micelar crítica (CMC) determinadas entre $23^{\circ} \mathrm{C}$ e $25^{\circ} \mathrm{C}$, em água deionizada, volume da cabeça polar $(V h)$ e da cauda apolar $(V t)$, número de elétrons na cabeça polar (Nelh) e na cauda apolar (Nelt)

Tabela 2: Valores dos parâmetros número de agregação $(N a g g)$, anisotropia $(\varepsilon)$, volume da cabeça polar do Tween $^{\circledR}(V h T W)$, raio de esfera rígida $(R H S)$, fração volumétrica de micelas $(\phi)$ e carga elétrica superficial para micelas carregadas $(Z)$ obtidos a partir do ajuste dos dados experimentais das micelas puras. As incertezas dos valores nos últimos algarismos significativos, quando existem, estão mostradas entre parêntesis.

Tabela 3: Valores dos parâmetros número de agregação $(N a g g)$, anisotropia $(\varepsilon)$, raio de esfera rígida $(R H S)$, fração volumétrica de micelas $(\phi)$ e carga elétrica superficial para micelas carregadas $(Z)$ obtidos a partir do ajuste dos dados experimentais das micelas mistas. Os parâmetros fração molar de SDS na micela $(x S D S)$ e concentração micelar crítica da micela mista $(C M C M)$ foram obtidos pela Teoria de Clint para misturas ideais e foram mantidos fixos nos ajustes. As incertezas dos valores nos últimos algarismos significativos, quando existem, estão mostradas entre parêntesis.

Tabela 4: Valores dos parâmetros Nagg e Sfree obtidos a partir do ajuste da Eq. 7 para cada conjunto de pontos mostrado na Figura 25.

Tabela 5: Valores dos parâmetros do modelo de micela decorada obtidos a partir dos ajustes dos dados experimentais de SAXS. Os valores entre parêntesis indicam a incerteza nos últimos algarismos significativos.

Tabela 6: Valores dos parâmetros Nagg e Sfree obtidos a partir do ajuste da Eq. 7 para cada conjunto de pontos mostrado na Figura 25.

Tabela 7: Valores dos parâmetros do modelo de micela decorada obtidos a partir dos ajustes dos dados experimentais de SAXS. Os valores entre parêntesis indicam a incerteza no último algarismo significativo.

Tabela 8: Valores dos parâmetros obtidos a partir dos ajustes das curvas experimentais (Figura 44A) usando o Método da Deconvolução Gaussiana. Para vesículas unilamelares (valor de $N$ próximo de 1), os parâmetros relativos ao fator de estrutura ( $D$ e $\eta$ ) não se aplicam ("NA"). Os valores entre parêntesis indicam a incerteza no último algarismo significativo.

Tabela 9: Valores dos parâmetros obtidos a partir do ajuste dos dados experimentais de SAXS (Figura 46). Os valores entre parêntesis indicam a incerteza no último algarismo significativo.

Tabela 10: Parâmetros de SAXS obtidos a partir do ajuste das curvas experimentais das dispersões de lipossomas (Figura 41A) usando o Método de Deconvolução Gaussiana. Os valores entre parêntesis indicam a incerteza no último algarismo significativo. 



\section{LISTA DE SIGLAS}

CD - Circular Dichroism (Dicroísmo Circular)

CMC - Concentração Crítica Micelar

DNA - DeoxyriboNucleic Acid (ácido desoxirribonucleico)

DPPC - Dipalmitoilfosfatidilcolina de Soja

EPC - Fosfatidilcolina de Ovo

GIFT - Generalized Indirect Fourier Transform (Transformada Indireta de Fourier Generalizada)

IFT - Indirect Fourier Transform (Transformada Indireta de Fourier)

ITC - Isothermal Titration Calorimetry (Calorimetria de Titulação Isotérmica)

LA - Ácido Láurico

PBS - Tampão Fosfato de Sódio Salino

PC - Fosfatidilcolina

SAXS - Small Angle X-Ray Scattering (Espalhamento de Raios-X a Baixos Ângulos)

SDS - Dodecil Sulfato de Sódio

SMT - Sumatriptano ou Sumatriptana 



\section{ÍNDICE}

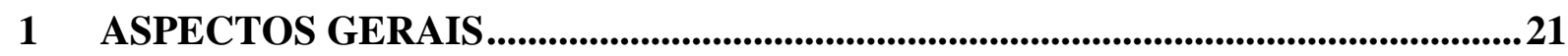

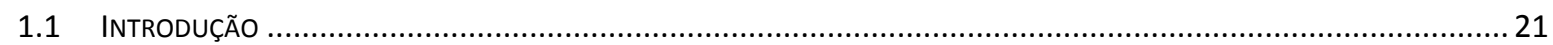

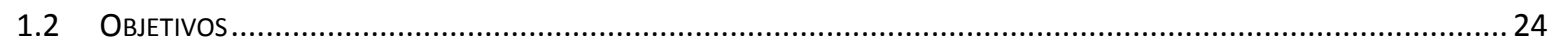

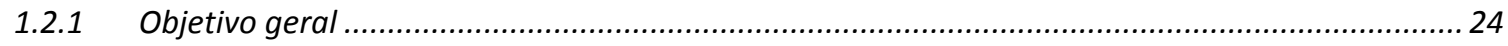

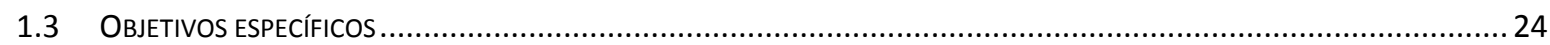

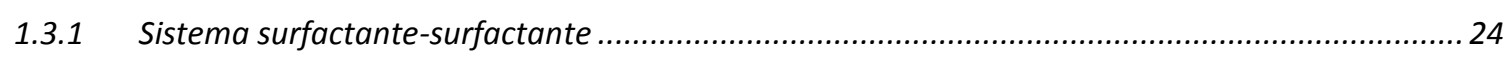

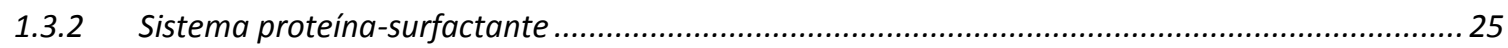

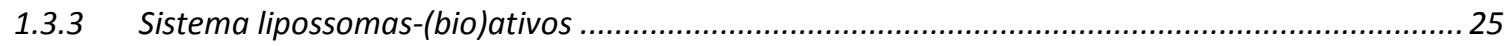

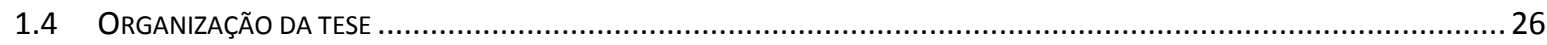

2 FUNDAMENTOS TEÓRICOS E EXPERIMENTAIS ...................................................2

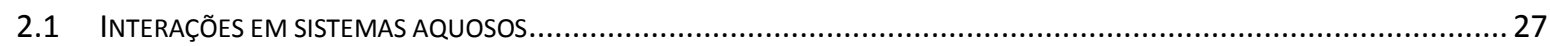

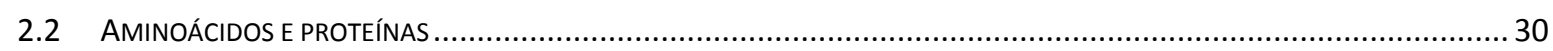

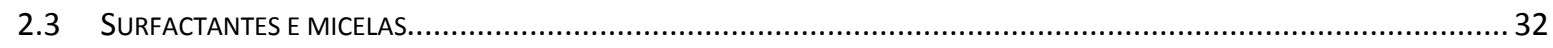

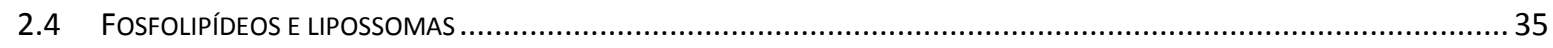

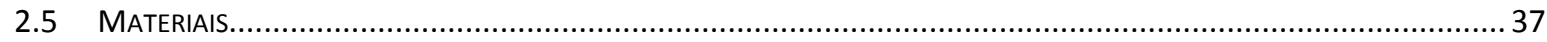

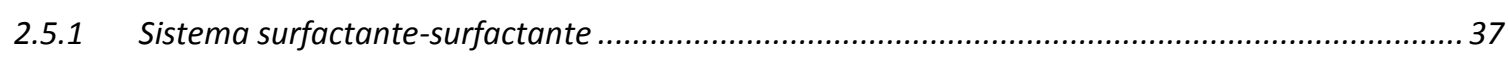

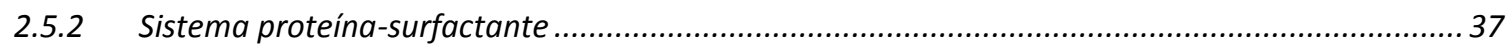

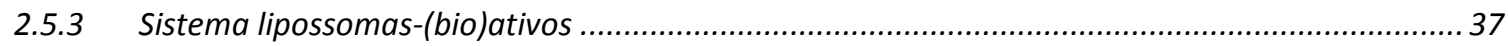

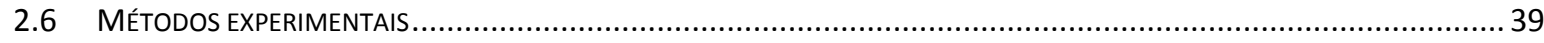

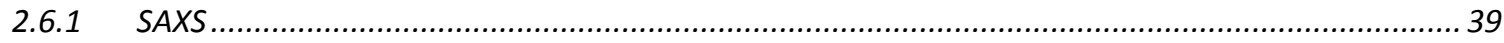

2.6.2 ITC

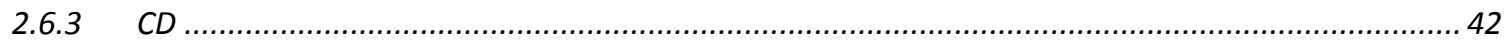

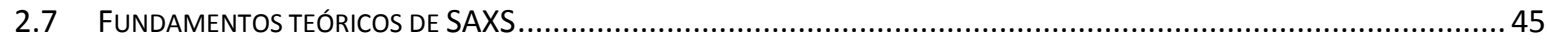

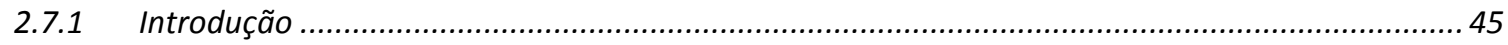

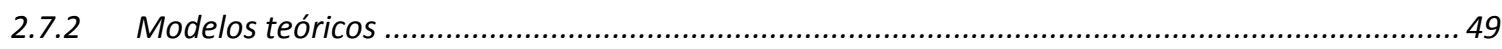

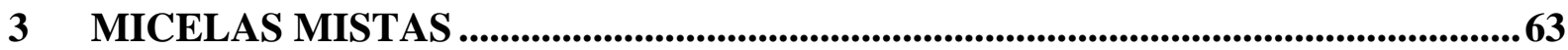

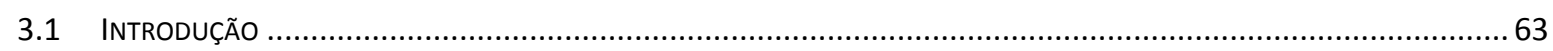

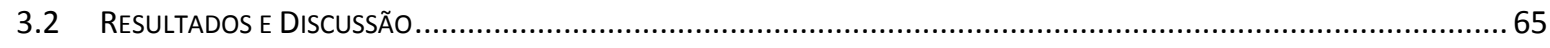

3.3 CONCLUSÃO

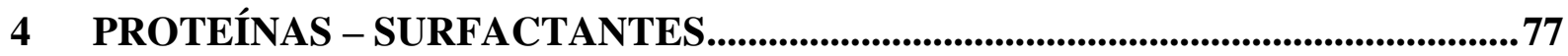

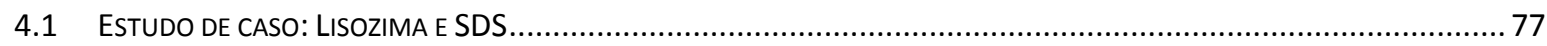

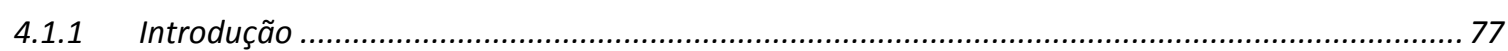




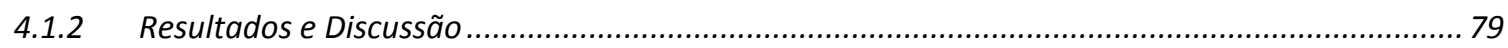

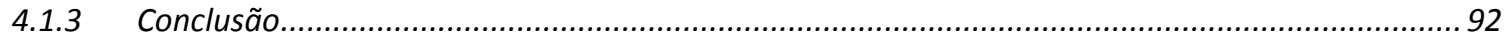

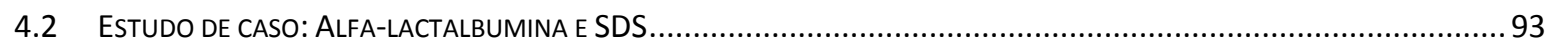

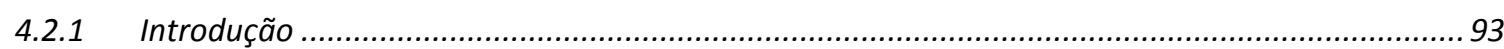

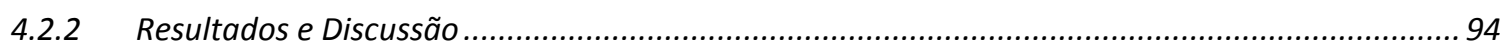

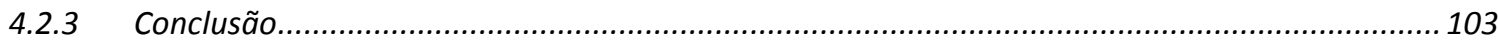

$5 \quad$ LIPOSSOMAS - (BIO)ATIVOS.....................................................................................105

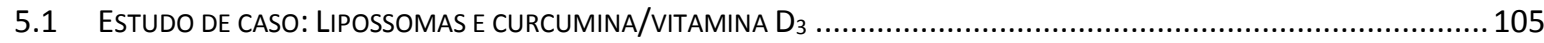

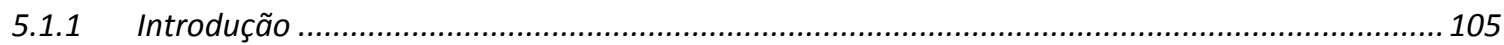

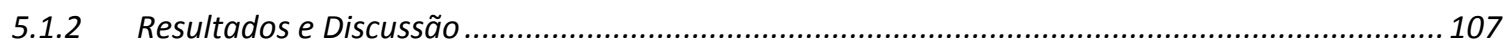

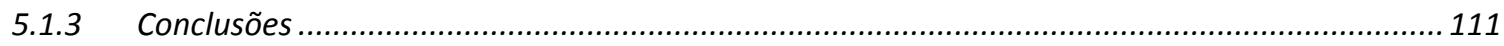

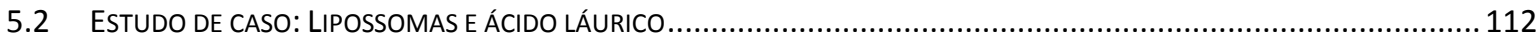

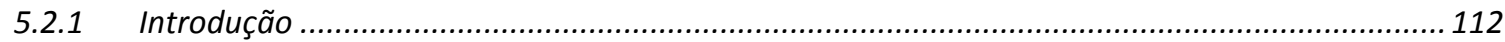

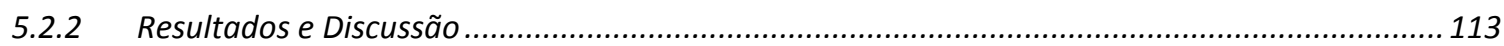

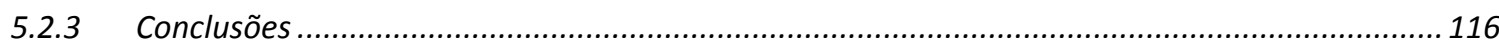

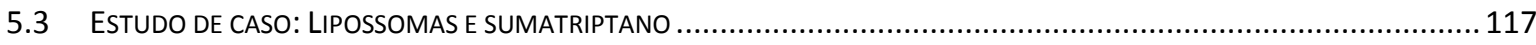

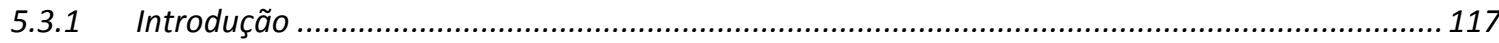

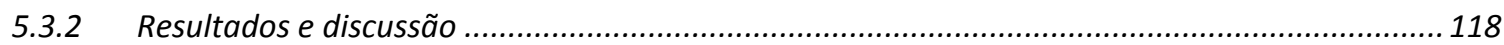

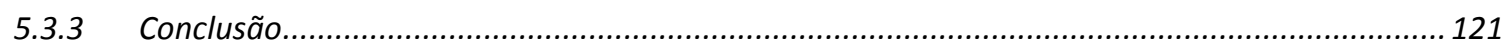

6 CONCLUSÕES E PERSPECTIVAS ..............................................................................123

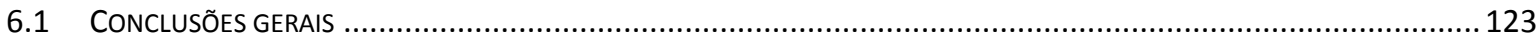

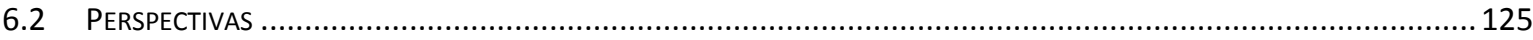

$7 \quad$ APÊNDICE 1 .......................................................................................................127

8 APÊNDICE 2 ................................................................................................................129

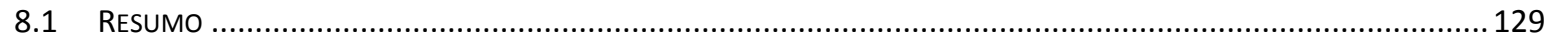

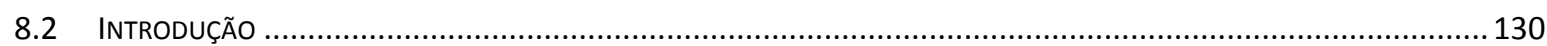

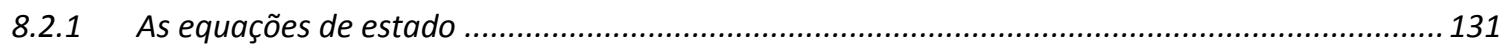

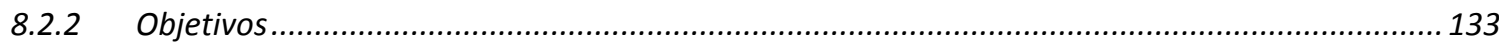

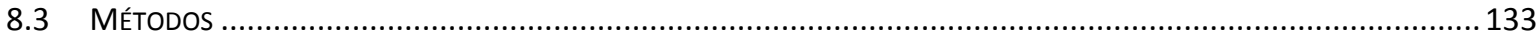

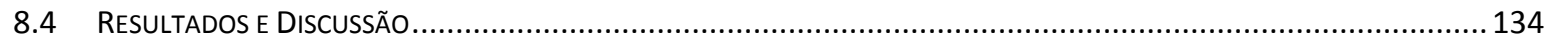

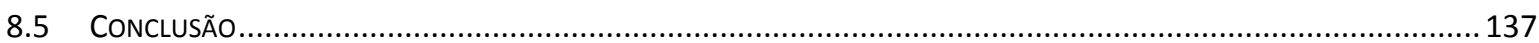

$9 \quad$ REFERÊNCIAS BIBLIOGRÁFICAS ............................................................................139 


\section{ASPECTOS GERAIS}

Neste capítulo será feita a apresentação geral dos sistemas estudados bem como dos objetivos e da estrutura desta tese.

\subsection{Introdução}

O fenômeno da auto-organização é essencial para a vida, uma vez que muitos cientistas propõem que a origem da mesma se deve ao aumento espontâneo da complexidade e especificidade molecular [1]. Nesse contexto, dentro de um organismo, ocorrem a cada instante milhares de reações, coordenadas, reguladas e interconectadas, cada uma cumprindo propósitos específicos. Entre as moléculas que participam desse intrincado processo estão os surfactantes, as proteínas e os lipídeos, as quais exibem propriedades de auto-organização e interagem entre si seguindo mecanismos que ainda não são totalmente conhecidos e/ou caracterizados.

O uso pelo homem de substâncias com propriedades de auto-organização data da época dos babilônios, cerca de 2200 a.C., porém o interesse econômico em relação a elas bem como o seu estudo científico só se iniciou no final do século XVIII, com a Revolução Industrial [2]. Descobriu-se que essas substâncias são formadas por um grupo de moléculas, nomeadas hoje anfifílicas, que exibem simultaneamente características de substâncias polares e apolares. Como essas moléculas atuam na superfície e interface entre substâncias, reduzindo a tensão superficial, elas passaram também a ser chamadas de surfactantes ou tensoativos [3], sendo usadas na composição de produtos de higiene pessoal, de limpeza doméstica e industrial, agroquímicos, extração de petróleo, tratamento de superfícies de metal, indústria alimentícia, entre outras [2]. Isso se deve às propriedades de detergência, emulsificação, lubrificação, capacidade espumante e molhante bem como de solubilização, que dependem de fatores intrínsecos ao surfactante (estrutura e composição química) e extrínsecos a ele, estes últimos dependendo das características do meio (temperatura, força iônica, $\mathrm{pH}$, etc.) [4,5]. 
Adicionalmente, moléculas de surfactante podem formar micelas, aglomerados de formas e tamanhos variados que possuem diversas propriedades físico-químicas interessantes. Para estes sistemas em solução são necessárias técnicas que permitam o estudo de suas características dessa maneira. Dentre os métodos experimentais mais comumente usados para tal finalidade, estão a condutimetria [6-9], tensiometria [7,10], a calorimetria de titulação isotérmica [8,9], o espalhamento de luz [6,8-10], o espalhamento de raios X a baixos ângulos [11-14] e o espalhamento de nêutrons $[10,14,15]$. Tendo em vista ampliar as propriedades de tais sistemas para além do controle sobre fatores extrínsecos e intrínsecos de surfactantes e micelas, é comum se misturar dois ou mais surfactantes [16-18]. Isso abre a possibilidade de aplicação desses sistemas como nanocarreadores em drug delivery [19,20], onde a micela formada acaba encapsulando o fármaco uma vez que a parte apolar das moléculas do surfactante possui afinidade pelos ativos, que em geral são hidrofóbicos.

Outro nanocarreador frequentemente usado para tal fim é o lipossoma, uma estrutura supramolecular formada por lipídeos, que compreendem um grande grupo de moléculas dentre as quais podemos citar os fosfolipídeos, constituintes majoritários das membranas celulares. Esses sistemas complexos se organizam em bicamada e desempenham o papel de uma barreira semipermeável que delimita o meio externo celular e o citoplasma. Além desta função de fronteira para a maquinaria intracelular, elas também atuam como substrato para uma variedade de biomoléculas incluindo glicolipídeos, proteínas e sequências curtas de aminoácidos [21-23]. Tais biomoléculas podem ocupar ambas as interfaces da membrana ou podem ser hospedadas no interstício hidrofóbico da fase lipídica, onde desempenham papel fundamental na comunicação e regulação de vários processos biológicos [24]. Por isso, lipossomas, além de serem usados em drug delivery no processo de encapsulação tradicional, são também excelentes escolhas para o processo denominado coencapsulação [25].

Diversos modelos têm sido propostos ao longo das últimas quatro décadas com vistas a ampliar nossa compreensão acerca de membranas biológicas [26]. Entre esses modelos, um dos mais antigos e bem sucedidos é o chamado "modelo do mosaico fluido" [21] segundo o qual espécies lipídicas organizadas em bicamadas servem de suporte para os grupos proteicos. Ainda de acordo com esta proposição, as biomoléculas estão em movimento contínuo com lipídeos e proteínas "fluindo" ao longo da superestrutura membranar. A grande maioria dos desenvolvimentos posteriores são aperfeiçoamentos desta representação pioneira e, mais recentemente, o papel exercido por domínios proteicos intercalados tem sido intensamente revisitado [22,26-28]. Particularmente, tem sido observado que a presença de proteínas em 
membranas biológicas é muito maior do que imaginado inicialmente e, mais que isso, esses grupos introduzem modificações estruturais locais na matriz lipídica se relacionando de maneira íntima com as funções desempenhadas por diferentes domínios da membrana [26]. Observou-se ainda que não apenas proteínas, mas uma série de outras biomoléculas, modulam as propriedades estruturais e elásticas da bicamada lipídica [29]. Portanto, o estudo da interação entre elas e as membranas é uma questão altamente relevante tanto para a compreensão de muitos processos biológicos [30] quanto para aplicações em biotecnologia [23,24,31-33].

As proteínas, formadas pela ligação de aminoácidos por meio dos processos de transcrição e tradução [34], desempenham um papel essencial na atividade celular dos organismos ao participarem de diversas funções biológicas, ditadas ambas por sua estrutura particular e pela interação que elas fazem com outras moléculas, geralmente chamadas de ligantes, que podem ser outras proteínas, ácidos nucléicos, carboidratos, lipídeos, íons, e também surfactantes [35]. Complexos proteína-surfactante têm sido utilizados pelo homem desde 100 a.C., época em que os egípcios usavam sabão para realização da higiene pessoal. Como é conhecido hoje, as moléculas de sabão (que são surfactantes) são levadas em contato com a superfície da pele e do cabelo e interagem com a proteína queratina da pele morta, removendo dejetos. O estudo científico dos complexos proteína-surfactante, embora tenha começado no final do século XIX, somente ganhou força na década de 1930 com estudos sobre a interação entre SDS e o vírus mosaico do tabaco e sobre a interação entre detergentes comerciais e sais da bile com metahemoglobina e albumina de ovo [36]. Desde então esses complexos têm sido estudados extensivamente, embora os mecanismos de interação entre proteína e surfactante, bem como suas propriedades biofísicas, ainda hoje não sejam completamente entendidos [37]. Mesmo sendo possível hoje, por modelagens computacionais, reproduzir alguns aspectos dos processos de auto-organização de surfactantes [38] e predizer, com base na estrutura primária de uma proteína, estruturas tridimensionais proteicas pequenas [39], não existe na literatura abordagens desse tipo para um estudo completo dos complexos proteína-surfactante que seja capaz de revelar suas características estruturais e termodinâmicas. Nesse sentido, somente abordagens experimentais podem acessar e fornecer informações energéticas e estruturais. Uma vez dispondo delas, é possível usá-las de forma bem-sucedida para refinamento das modelagens computacionais [40]. Partindo do pressuposto de que ambos proteína e surfactante estarão em solução, o desafio, do ponto de vista prático, é o de definir técnicas que permitam, primeiro, um estudo não invasivo já que o equilíbrio termodinâmico pode ser facilmente desfeito e, segundo, que possibilitem a obtenção de parâmetros termodinâmicos e estruturais visando a 
caracterização mais completa possível dos complexos. Atualmente são usadas técnicas como condutimetria [39], ressonância magnética nuclear [41], espectroscopia de infravermelho por transformada de Fourier [42], calorimetria de titulação isotérmica [40,42-45], dicroísmo circular [40,45-48], espalhamento de raios X a baixo ângulo [39,40,45,49], espalhamento estático de luz [50], espalhamento dinâmico de luz [47,50], tensão superficial [47,49,51], fluorescência [44,48,52,53] dentre outras. Essas técnicas ou fornecem informações de cunho estrutural ou termodinâmico, sendo esse o motivo para se buscar relacioná-las durante o estudo destes sistemas. Existem trabalhos na literatura que lançam mão apenas da abordagem termodinâmica $[2,43]$ ou estrutural $[38,47,48]$, mas também existem aqueles que se propõem a fazer um estudo envolvendo ambas as abordagens [40,44,51]. Dentre estes últimos, alguns propõem modelos esquemáticos para os estágios de ligação dos surfactantes na proteína [42,44] mas sem verificação/comprovação deles.

\subsection{Objetivos}

\subsubsection{Objetivo geral}

O objetivo desta tese é o de caracterizar estruturalmente os sistemas surfactante-surfactante, proteína-surfactante e lipossomas-(bio)ativos, contemplando:

- Design adequado de experimentos de espalhamento de raios X a baixos ângulos (SAXS) e, para o caso do sistema proteína-surfactante, de calorimetria de titulação isotérmica (ITC) e de dicroísmo circular (CD);

- Desenvolvimento de métodos de análise de dados de espalhamento, o que inclui a construção de modelos e a implementação computacional dos mesmos;

- Interpretação dos resultados e correlação com informações oriundas da literatura ou de outras técnicas para o caso dos sistemas proteína-surfactante e lipossomas-(bio)ativos.

\subsection{Objetivos específicos}

\subsubsection{Sistema surfactante-surfactante}

Os surfactantes comerciais da série Tween ${ }^{\circledR}$ são, entre outras aplicações, muito utilizados na indústria alimentícia [54,55]. Por esse motivo, várias de suas propriedades físico-químicas, incluindo as propriedades de suas micelas, já foram investigadas na literatura. Contudo, essas 
propriedades podem ser convenientemente moduladas pela presença de um co-surfactante [56]. Nesse sentido, escolheu-se o SDS por se tratar de um surfactante modelo cujas propriedades também são bem conhecidas. Já existem na literatura investigações acerca do sistema SDSTween ${ }^{\circledR}$ utilizando, por exemplo, as técnicas condutimetria e tensão superficial [16,57], mas até o presente momento não existe uma caracterização estrutural das micelas mistas pela técnica de SAXS. Portanto, nessa parte da tese, o objetivo é o de caracterizar estruturalmente as micelas mistas de SDS-Tween ${ }^{\circledR}$ por meio da análise de dados de SAXS em escala absoluta.

\subsubsection{Sistema proteína-surfactante}

A desnaturação das proteínas lisozima e alfa-lactalbumina por efeito do surfactante SDS já foi investigada na literatura. Entre as técnicas empregadas, está o ITC, que fornece um panorama termodinâmico geral da interação [41,58]. Adicionalmente, estudos estruturais em razões molares surfactante:proteína pontuais também já haviam sido feitos [59,60]. Contudo, não existia na literatura uma caracterização estrutural sistemática dos complexos formados durante a desnaturação. Nesse contexto, o objetivo da tese nesta parte é o de propor uma metodologia que permite acompanhar, sistematicamente, a ligação de SDS nas proteínas lisozima e alfalactalbumina, tanto do ponto de vista estrutural (usando SAXS e CD) quanto do ponto de vista termodinâmico (ITC).

\subsubsection{Sistema lipossomas-(bio)ativos}

Lipossomas podem ser usados como nanocarreadores para várias moléculas, tanto hidrofílicas e quanto hidrofóbicas, com potencial de aplicação, por exemplo, na indústria farmacêutica e alimentícia. Contudo, a interação dos lipossomas com essas moléculas pode levar a alterações estruturais importantes na bicamada lipídica, de maneira que a quantificação dessas variações é um ponto importante para a viabilidade do uso dos lipossomas nas suas respectivas aplicações. O objetivo nesta parte da tese consiste na caracterização, pela técnica de SAXS, das mudanças estruturais de lipossomas formados pelos fosfolipídeos fosfatidilcolina de soja hidrogenada (Phopholipon ${ }^{\circledR}$ 90H), dipalmitoilfosfatidilcolina e fosfatidilcolina de ovo, causadas pela presença dos (bio)ativos curcumina/vitamina $\mathrm{D}_{3}$, ácido láurico e sumatriptano, respectivamente. Esses sistemas são oriundos de colaborações com grupos de pesquisa 
nacionais e internacionais e as análises desenvolvidas complementarão estudos mais amplos que utilizam outros procedimentos experimentais.

\subsection{Organização da tese}

Neste Capítulo 1 foi feita uma introdução geral aos assuntos que serão tratados ao longo do manuscrito. No Capítulo 2 apresentam-se os materiais e métodos experimentais além da discussão sobre os fundamentos teóricos da análise dos dados de SAXS e a posterior modelagem de cada um dos sistemas investigados nesta tese. Optou-se, para fins de clareza, tendo em vista as especificidades dos sistemas, apresentar cada um deles em capítulos separados, com introdução, resultados e discussão e conclusão. Nesse sentido, o Capítulo 3 é dedicado ao estudo do sistema surfactante-surfactante. Já o sistema proteína-surfactante é tratado no Capítulo 4, enquanto o Capítulo 5 é destinado à investigação do sistema lipossomas(bio)ativos que foram estudados em colaboração com grupos de pesquisa nacionais e internacionais. Finaliza-se a tese no Capítulo $6 \mathrm{com}$ as conclusões gerais obtidas a partir dos expostos nos capítulos anteriores. Em seguida, apresentam-se as perspectivas para trabalhos futuros, seja dando continuidade aos trabalhados discutidos neste manuscrito, seja iniciando estudos em outras linhas correlatas. 


\title{
2 FUNDAMENTOS TEÓRICOS E EXPERIMENTAIS
}

\author{
Nesse capítulo serão apresentados os conceitos teóricos e experimentais \\ fundamentais para as discussões a serem realizadas nos capítulos seguintes \\ de resultados. São abordados os temas sobre interações fundamentais em \\ sistemas aquosos, proteínas, micelas, lipossomas, além de informações sobre \\ materiais e técnicas utilizados bem como modelos teóricos empregados na \\ análise dos dados de SAXS.
}

\subsection{Interações em sistemas aquosos}

A água é um solvente polar que possui afinidade por moléculas polares. Isto quer dizer que tais moléculas se dissolvem com facilidade no meio aquoso porque podem substituir as interações pré-existentes entre as moléculas de água (interações “água-água”) por outras entre a água e o soluto (interações "água-soluto") que são energeticamente tanto quanto mais favoráveis que as primeiras. Se, entretanto, as moléculas a serem dissolvidas forem apolares, elas interferirão nas interações água-água mas não formarão interações água-soluto energeticamente favoráveis. As interações água-água e água-soluto, responsáveis por esse e outros fenômenos, poder ser, principalmente, ligações de hidrogênio, interações iônicas, hidrofóbicas e de van der Waals.

Ligações de hidrogênio têm sua origem na geometria da molécula de água, que possui dois dipolos elétricos, cada um ao longo da ligação $O-H$. Como resultado, existe uma atração eletrostática entre o átomo de oxigênio de uma molécula e o hidrogênio da outra. Nas condições normais de pressão e temperatura, cada molécula de água constitui, em média, 3,4 ligações de hidrogênio com moléculas adjacentes, ao passo que esse número aumenta para 4 no estado sólido, espacialmente mais ordenado e com menos energia térmica. Vale ressaltar que esse tipo de interação não é exclusiva entre moléculas de água, e ocorrerá sempre entre um átomo eletronegativo (chamado aceitador de hidrogênio, como oxigênio e nitrogênio) e um átomo de hidrogênio ligado covalentemente a outro átomo eletronegativo (chamado doador de hidrogênio) na mesma molécula ou em outra (Figura 1). 

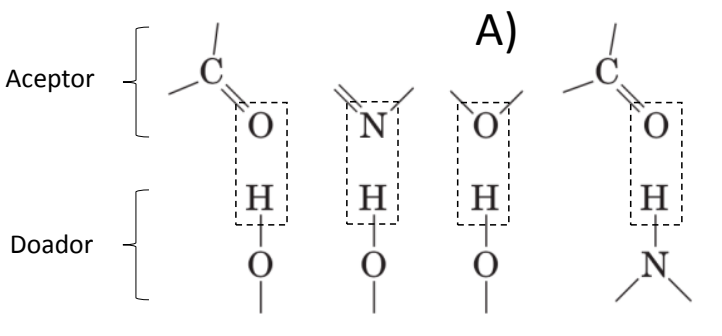

C) D)

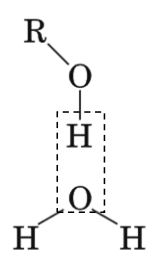<smiles></smiles>

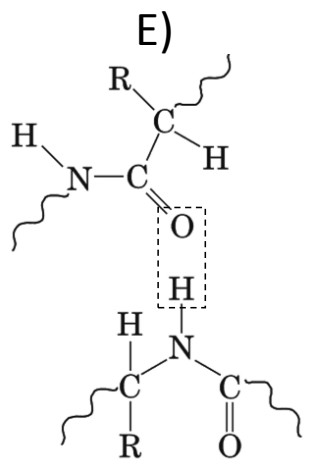

B)<smiles>[R]n1c([2H])c(C)c(=O)[nH]c1=O</smiles><smiles></smiles>

Figura 1: A) As ligações de hidrogênio (representadas pelas retângulos tracejados) sempre acontecem entre um aceptor e um doador. Em biomoléculas, esse tipo de ligação pode ocorrer, por exemplo, entre B) bases complementares de DNA, C) entre o grupo hidroxila de um álcool e água, D) entre o grupo carbonila de uma cetona e água e E) entre grupos peptídicos em polipeptídeos. Adaptada de [34].

Associadas também a interações eletrostáticas estão as interações iônicas, que acontecem necessariamente entre grupos carregados, e as interações de van der Waals, que ocorrem entre átomos neutros. Neste último caso, quando dois átomos não carregados são colocados próximos $(\sim 0,1 \mathrm{~nm})$, as suas nuvens eletrônicas influenciam uma a outra. Em particular, movimentos aleatórios dos elétrons ao redor do núcleo atômico geram dipolos elétricos transientes que induzem dipolos de carga oposta no átomo mais próximo. Como resultado, os núcleos se atraem e a aproximação acontece até que as nuvens eletrônicas passam a repelir uma a outra. A distância interatômica para a transição atração/repulsão é característica de cada elemento, chamado raio de van der Waals.

O último tipo de interação fundamental, denominada hidrofóbica, é diferente das anteriores por não se tratar de uma interação de fundo eletrostático. Considerando um soluto anfifílico em solução, como surfactantes e fosfolipídeos, ambas as porções polares e apolares são solvatadas pelas moléculas de água que formam algo parecido como uma "gaiola" (Figura 2A). Contudo, como essa configuração é energeticamente desfavorável, seja porque água não possui afinidade pelas porções apolares, seja porque a entropia do sistema diminui devido à estruturação das moléculas do solvente, há a tendência das partes apolares se aproximarem com a consequente 
expulsão das moléculas de água da camada de solvatação. Neste processo conhecido como dessolvatação, a entropia do sistema aumenta e, como as partes polares tendem a maximizar o contato com o solvente por causa da afinidade, o resultado é a formação de aglomerados mais estáveis numa configuração agora energeticamente favorável (Figura 2B). As "forças" que mantêm as porções apolares juntas resultam das chamadas interações hidrofóbicas, que têm sua origem associada à estabilização termodinâmica [61]. A formação desses aglomerados também seria observada caso as moléculas a serem dissolvidas fossem puramente apolares, como ocorre no sistema água-óleo.

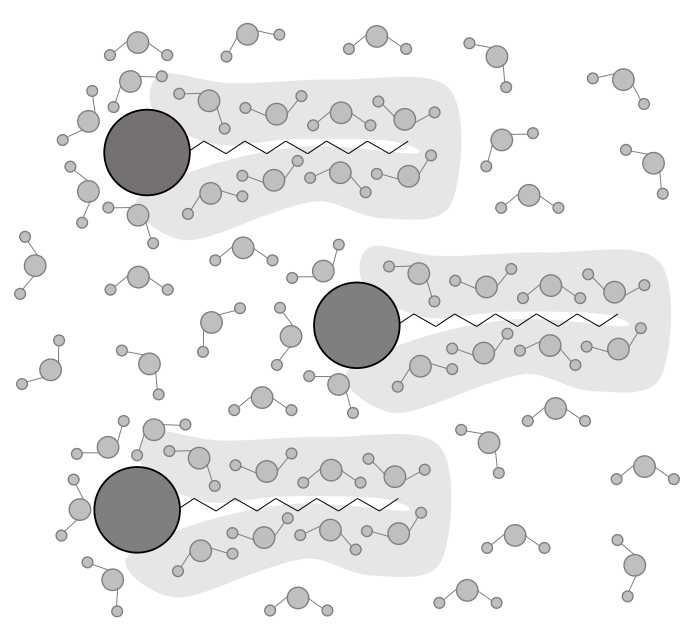

A)

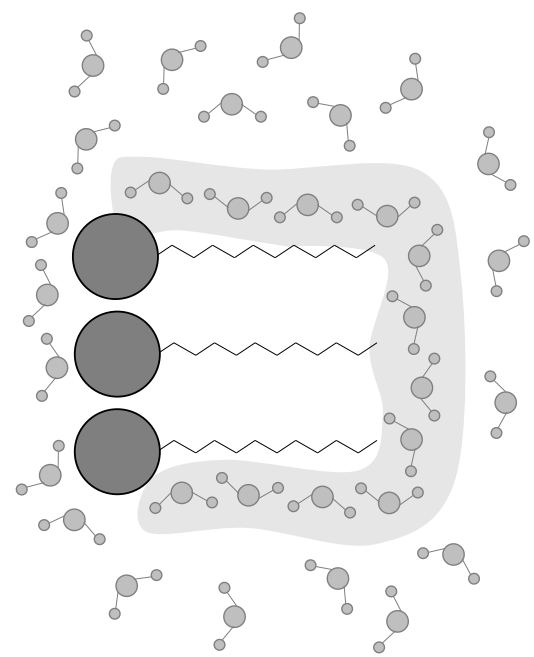

B)

Figura 2: Esquema representando a interação hidrofóbica. Em A) a molécula de surfactante está rodeada de água, incluindo a parte não polar. Essa situação, desfavorável termodinamicamente, é substituída por aquela mostrada em B). Extraído de [62].

Todas as interações mencionadas, sem exceção, são individualmente muito fracas comparadas às interações covalentes ${ }^{1}$, mas coletivamente possuem influência significativa na estruturação de aminoácidos em proteínas, surfactantes em micelas e fosfolipídeos em lipossomas, por exemplo.

\footnotetext{
${ }^{1}$ Para fins de comparação, são necessários $410 \mathrm{~kJ}$ para quebrar 1 mol de ligações $C-H$, mas apenas $4 \mathrm{~kJ}$ para romper 1 mol de interações de van der Waals típicas (Nelson e Cox, 2011).
} 


\subsection{Aminoácidos e proteínas}

Proteínas são macromoléculas presentes em todos os organismos vivos conhecidos e são formadas a partir da junção de apenas 20 moléculas menores, os aminoácidos ${ }^{2}$ [34] (Figura 3A, acima). A diferença entre os aminoácidos está na cadeia lateral, também denominado grupo $R$, o qual pode ser um anel aromático (Figura 3A, abaixo), uma região apolar ou uma região polar. No último caso, os grupos polares podem ser neutros ou carregados positivamente ou negativamente. Os grupos laterais contendo anéis aromáticos são de extrema importância para a investigação de proteínas pelo uso de técnicas espectroscópicas como dicroísmo circular, fluorescências, entre outras (ver seção Métodos Experimentais).

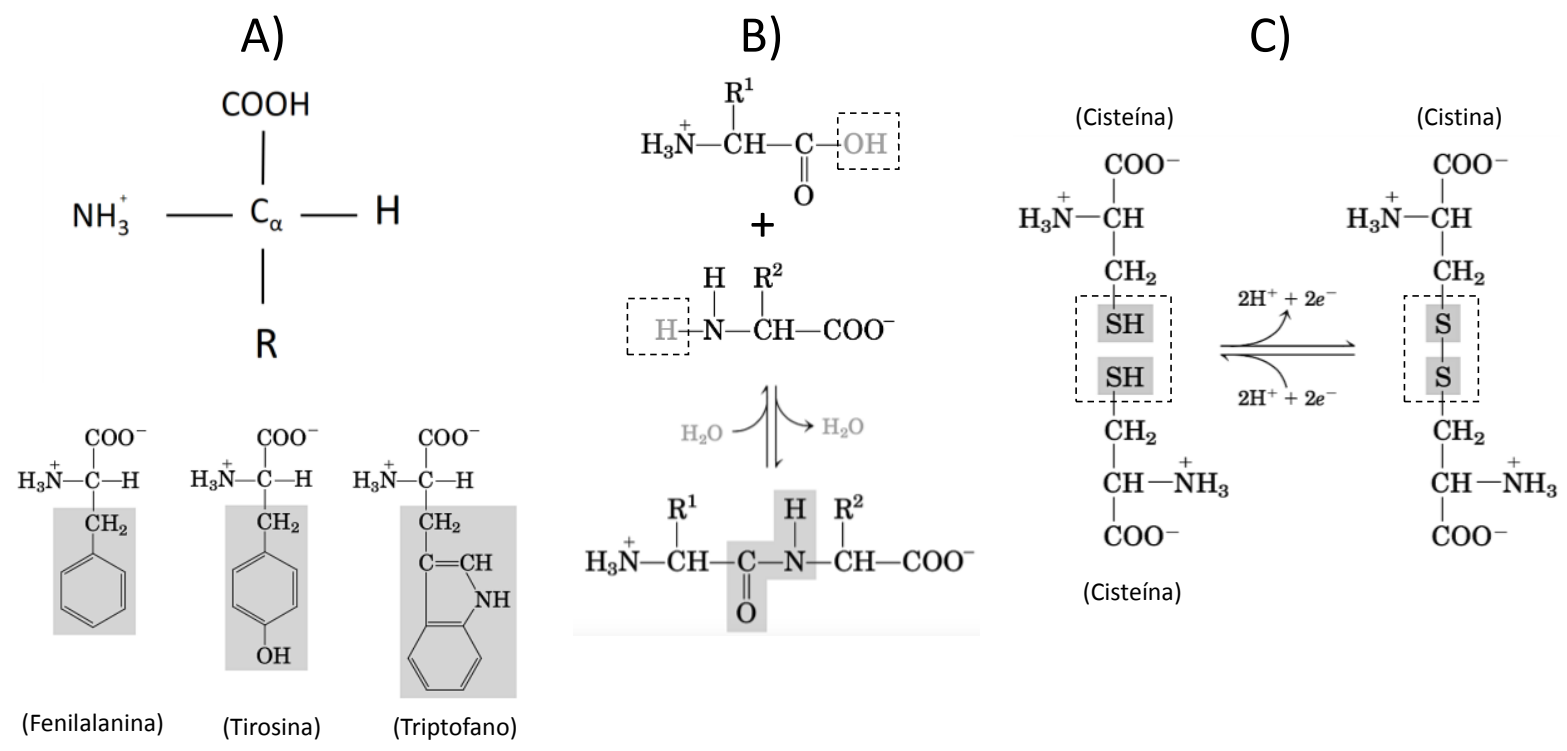

Figura 3: A) Acima, estrutura genérica de um $\alpha$-aminoácido (com exceção da prolina, um aminoácido cíclico). Abaixo, exemplos de $\alpha$-aminoácidos com grupos laterais contendo anéis aromáticos. B) Esquema da ligação peptídica. C) Esquema da ligação dissulfeto. Adaptado de [34].

A ligação entre os aminoácidos é denominada ligação peptídica, do tipo covalente, e ocorre entre o grupo $\alpha$-carboxila de um aminoácido e o grupo $\alpha$-amino de outro, com liberação de água (Figura 3B). Devido a essa alteração química, os aminoácidos que participam da ligação peptídica passam a ser chamadas de resíduos. Por exemplo, as proteínas lisozima e alfalactalbumina, ambas usadas nesta tese, possuem 129 e 123 resíduos, respectivamente. Além da ligação peptídica existe também a ligação dissulfeto, que ocorre particularmente entre dois $\alpha$ aminoácidos cisteína originando o dímero cistina (Figura 3C) e é muito importante na estrutura

\footnotetext{
${ }^{2}$ Eles também são chamados de $\alpha$-aminoácidos por serem formados por um grupo $\alpha$-carboxila e um grupo $\alpha$ amino ligados no mesmo carbono $\alpha$.
} 
de várias proteínas já que é cerca de 10 vezes mais forte do que as interações fracas mencionadas na seção anterior [34].

A partir da ligação peptídica são formados (di-, tri-, oligo-, poli-) peptídeos e proteínas. É considerada proteína uma macromolécula que possui mais de 100 resíduos ou um peso molecular maior que $10 \mathrm{kDa}$ (onde $1 \mathrm{Da}$ é a massa molecular de um átomo de hidrogênio). A sequência de resíduos que forma a proteína (incluindo as ligações dissulfeto) recebe o nome de estrutura primária da proteína (Figura 4A). Contudo, esses aminoácidos podem ser hidrofóbicos ou hidrofílicos, com carga elétrica ou não. Por conta disso, quando a proteína está em meio aquoso, existirão interações aminoácido-aminoácido e aminoácido-solução, como aquelas mencionadas na seção anterior, que serão responsáveis pelo enovelamento (também conhecido como dobramento) da proteína. Do ponto de vista de uma organização hierárquica, serão formadas, num primeiro momento, organizações locais denominadas estrutura secundária da proteína (Figura 4B), que podem ser hélices $\alpha$, folhas $\beta$ (paralelas ou antiparalelas) e as voltas $\beta$. Há também trechos da sequência que não se dobram, sendo chamados de laços (random coils, em inglês).

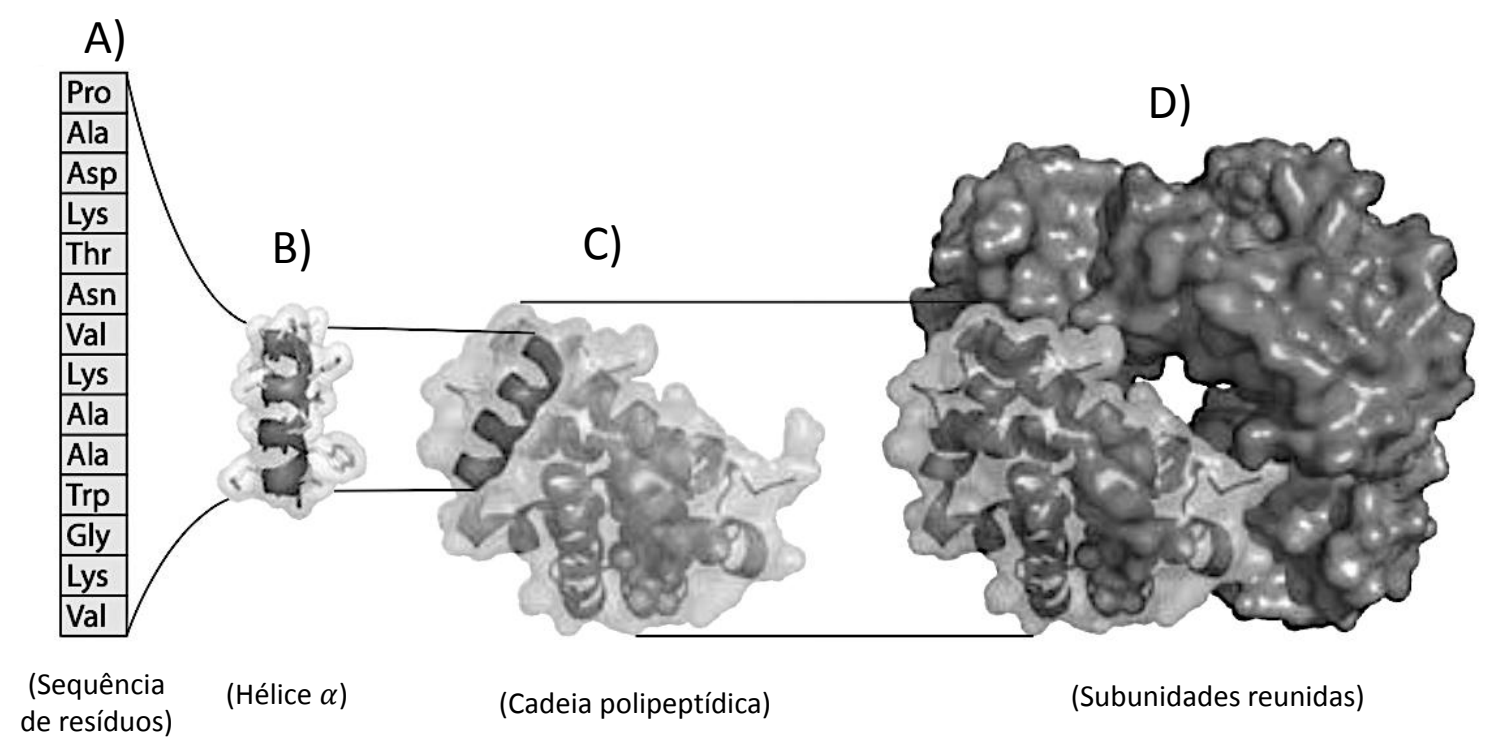

Figura 4: A) Estrutura primária. B) Estrutura secundária. C) Estrutura terciária. D) Estrutura quaternária. Adaptado de [34].

A partir da interação dessas estruturas locais com o solvente, via principalmente interação hidrofóbica/van der Waals e ligações de hidrogênio, serão formadas organizações de um nível maior que recebem o nome de estrutura terciária da proteína (Figura 4C). Proteínas com mais de duas sequências de resíduos, como insulina (duas sequências) e hemoglobina (quatro 
sequências) possuem ainda a estrutura quaternária (Figura 4D), onde cada domínio corresponde a uma estrutura terciária.

A função e atividade da proteína são ditadas pelo sequenciamento de aminoácidos (estrutura primária) e por sua forma (estrutura secundária e terciária), oriunda do processo de enovelamento. A desnaturação proteica, que pode ser influenciado por diversos fatores, ocorre quando há a perda da função da proteína devido à alteração de sua forma tridimensional. Solventes orgânicos miscíveis em água (como álcool), solutos (como ureia) e surfactantes atuam principalmente rompendo as interações hidrofóbicas que mantêm o núcleo de proteínas globulares estável. A ureia, assim como a elevação de temperatura, também é capaz de romper as ligações de hidrogênio. Por outro lado, a alteração do $\mathrm{pH}$ promove mudança na carga líquida da proteína, causando desestabilização eletrostática da estrutura, além de também romper ligações de hidrogênio.

A desnaturação proteica não significa perda completa da estrutura secundária e terciária (e em alguns casos da estrutura quaternária), isto é, o desenovelamento total da proteína. Desse modo, é perfeitamente possível a proteína estar desnaturada, sem função, e ainda possuir hélices $\alpha$ e/ou folhas $\beta$. A desnaturação de proteínas globulares pode originar o estado conhecido como "molten globule" ("globular fundido", em tradução livre), isto é, as proteínas apresentam pouca ou nenhuma estrutura terciária e alguma estrutura secundária $[2,58,63]$.

É importante mencionar que a estrutura secundária e terciária de uma proteína são ditadas por sua estrutura primária. Como consequência, em grande parte dos casos, se os agentes desnaturantes forem removidos, pode acontecer o processo de renaturação ou reenovelamento. Recentemente isso foi demostrado por Kaspersen et al. [64] que, usando surfactantes nãoiônicos, foi capaz de extrair moléculas de SDS de proteínas desnaturadas e permitiu assim que as proteínas passassem pelo processo de reenovelamento total ou parcial.

\subsection{Surfactantes e micelas}

Surfactantes pertencem a uma classe de moléculas conhecidas como anfifílicas ou anfipáticas [3], e como mencionado no Capítulo 1, tais moléculas possuem duas regiões muito distintas. Parte dela tem afinidade com a água (e em geral com qualquer solvente polar), sendo chamada região hidrofílica, liofílica ou lipofóbica. A outra região não possui afinidade com a água (e em geral com qualquer solvente não polar) é chamada parte hidrofóbica, liofóbica ou lipofílica 
(Holmberg, Jönsson and Kronberg 2003, Moroi 1992). Na literatura, a parte polar do surfactante é frequentemente referenciada como "cabeça", enquanto a parte não polar, que corresponde a uma ou mais cadeias hidrocarbonadas, é chamada de "cauda" (Figura 5).

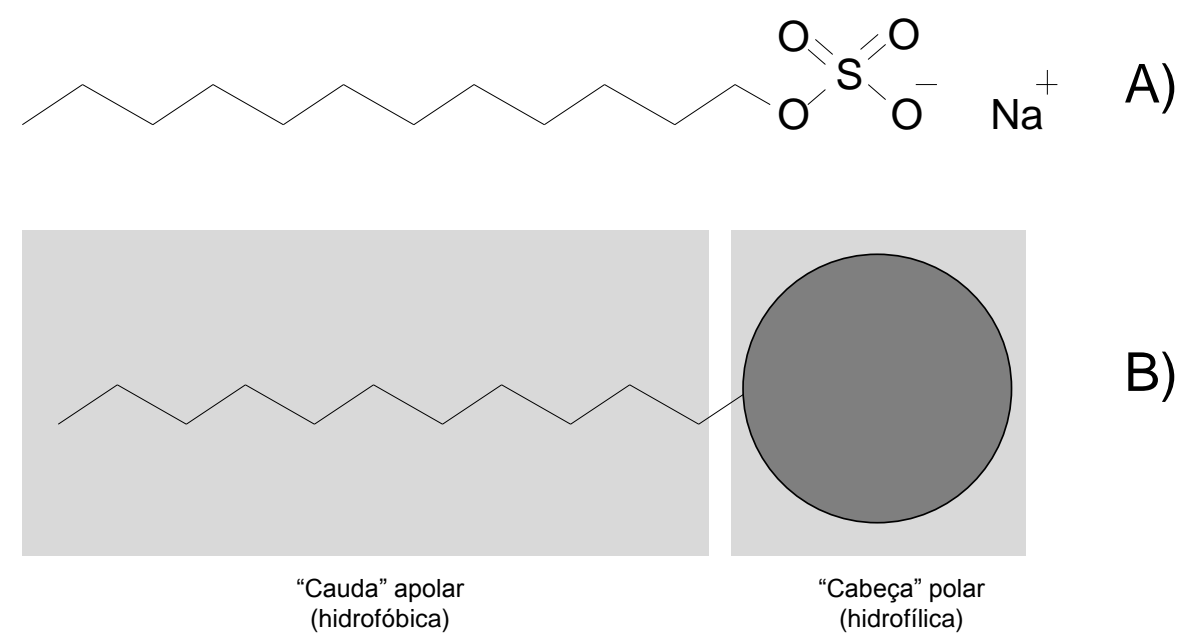

Figura 5: A) Fórmula estrutural da molécula anfifílica aniônica SDS. B) Representação esquemática da molécula SDS. Extraído de [62].

De acordo com a natureza do grupo polar na cabeça, o surfactante poderá ser classificado em iônico, podendo ser aniônico ou catiônico, dependendo se íon na cabeça é positivo ou negativo, respectivamente, ou não-iônico, podendo ser zwiteriônico ou neutro, dependendo se existe ou não um dipolo elétrico na cabeça [65].

Devido às interações hidrofóbicas, as moléculas de surfactante tendem a minimizar o contato das caudas com o solvente polar. O contrário ocorre para as cabeças polares, que tendem a maximizar o contato com o solvente polar. Nesse sentido, em concentrações abaixo da concentração micelar crítica (CMC), as moléculas de surfactante encontram-se em sua maioria em alguma interface (Figura 6A). Já em concentrações acima da CMC (Figura 6B) é mais favorável energeticamente as moléculas se organizarem em agregados que podem ser micelas, bicamadas e vesículas [4,61]. Cada uma dessas morfologias dependerá das características geométricas das moléculas por meio do chamado fator de empacotamento [66], $p$, definido como $p=\frac{V_{t}}{A_{h} \ell_{t}}$, onde $V_{t}$ e $\ell_{t}$ correspondem ao volume e comprimento da cauda apolar e $A_{h}$ é a área da cabeça polar. Dessa forma, se $p<\frac{1}{3}$, as moléculas tenderão a formar micelas globulares. Se $\frac{1}{3}<p<\frac{1}{2}$, as micelas tenderão a ser cilíndricas. Contudo, se $\frac{1}{2}<p<1$, haverá a tendência 
de formação de bicamadas. Já para $p>1$, as moléculas provavelmente formarão micelas reversas.

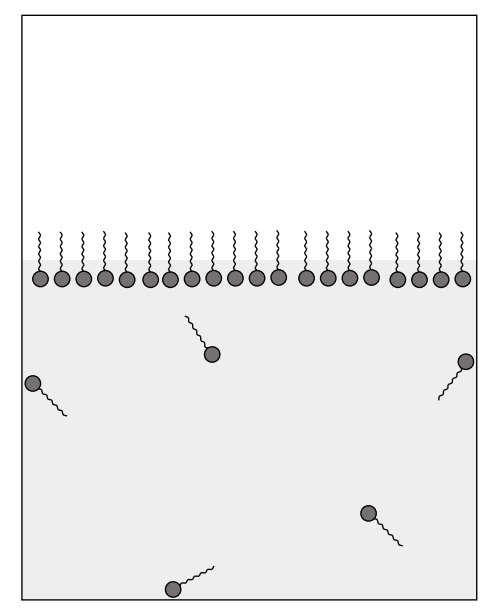

A)

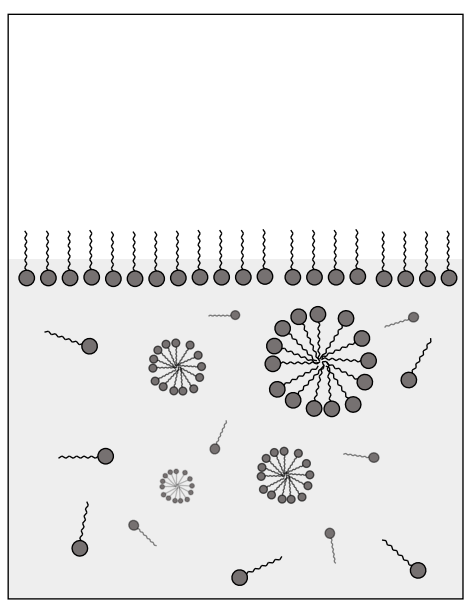

B)

Figura 6: A) Solução com concentração abaixo da CMC do surfactante. A maior parte das moléculas encontra-se nas interfaces. B) Solução com concentração acima da CMC, onde formam-se agregados. Extraído de [62].

Assim como forma e tamanho das micelas dependem de fatores intrínsecos e extrínsecos ao meio, a CMC também é influenciada pelo tamanho da cauda e da cabeça do surfactante, da quantidade de caudas, do grupo iônico/não-iônico na cabeça, temperatura, presença de eletrólitos, presença de co-surfactantes, entre outros [4]. Na CMC, várias propriedades físicas da solução são modificadas, tais como detergência, pressão, condutividade e outras [67]. Usando técnicas apropriadas que quantifiquem a variação dessas propriedades, é possível se determinar a CMC para diferentes sistemas. Além disso, é interessante observar que a CMC determinada por qualquer método físico não se restringe a um único ponto, mas a sua ocorrência abrange uma faixa de concentração (Figura 7).

Para surfactantes iônicos, a formação micelar também dependerá do equilíbrio eletrostático dos monômeros constituintes da micela. Em solução aquosa ocorre a dissociação iônica: um íon da cabeça polar, chamado contra-ion, passa para a solução, enquanto a cabeça polar e a cauda formam um único íon de carga oposta à do contra-íon. Por exemplo, o SDS em solução aquosa liberará o contra-íon $\mathrm{Na}^{+}$, enquanto a cabeça ficará negativa com o íon $\mathrm{SO}_{4}^{-}$(Figura $5 \mathrm{~A}$ ). $\mathrm{Na}$ micela, por sua vez, ocorreria repulsão elétrica entre os monômeros se não fossem os contraíons que se colocam entre eles, ajudando na estabilização elétrica do agregado. Entretanto, 
como nem todos os contra-íons se associam à micela, define-se o parâmetro $\alpha$ como sendo o grau de ionização micelar ou, equivalentemente, $\beta=1-\alpha$, que é a fração de carga neutralizada na micela. Ambas as grandezas são expressas como uma porcentagem [67].

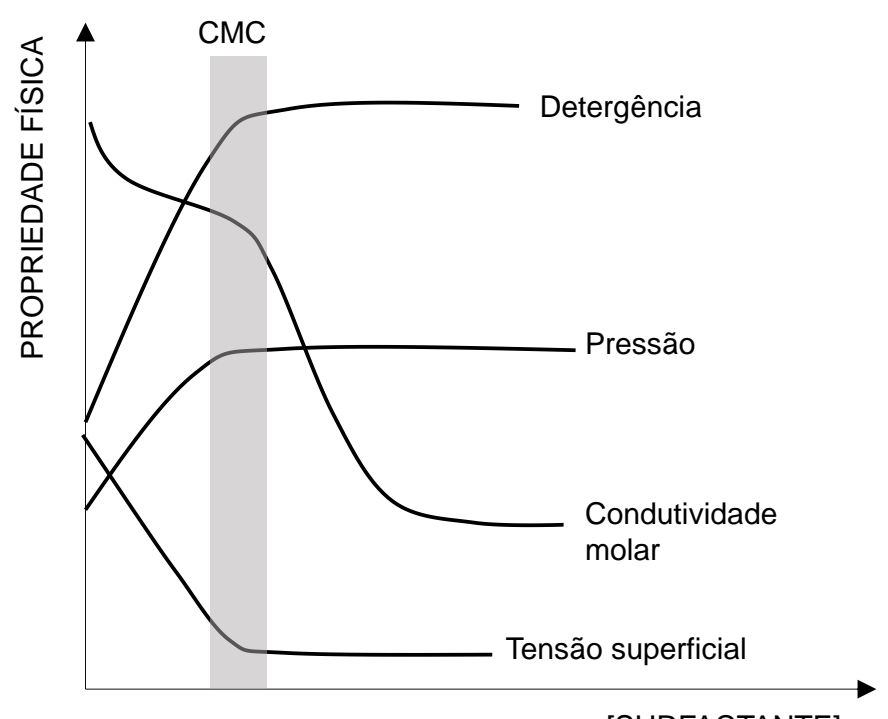

Figura 7: Comportamento de algumas propriedades físicas em função da concentração de surfactante. Retirado de [62].

\subsection{Fosfolipídeos e lipossomas}

As moléculas lipídicas fazem parte de uma classe abrangente de materiais biológicos e são compostos de ácidos graxos, podendo ser solúveis ou não em água. Alguns lipídeos, chamados de fosfolipídios, são também surfactantes e apresentam em sua constituição um grupo glicerol e um grupo fosfato, sendo muito utilizados em estudos fundamentais uma vez que compõem cerca $80 \%$ da membrana celular [68]. Sua estrutura geral encontra-se na Figura 8B, e um exemplo de estrutura particular encontra-se na Figura 8C.

Por causa de suas características geométricas, fosfolipídeos tendem a formar bicamadas. Além disso, cada fosfolipídeo pode ser caracterizado pela presença de carga ou não na cabeça polar, da mesma forma que os surfactantes, e por uma temperatura de transição de fase $\left(T_{c}\right)$, na qual a bicamada passa de uma fase gel, chamada também de $L_{\beta \prime}$, onde a cauda do lipídeo está estendida em estado compacto e ordenado e, portanto, a membrana é mais rígida, para uma fase líquido-cristalina ou fase fluida, chamada também de $L_{\alpha}$, onde as caudas estão randomicamente 
orientadas e mais fluidas e, portanto a membrana se torna mais flexível. A Figura 8A mostra valores de $T_{c}$ para alguns fosfolipídeos comumente usados nessa área.

\begin{tabular}{|c|c|c|c|c|}
\hline Fosfolipídeos $\left(R_{3}\right)$ & Cadeia hidrofóbica do ácido graxo $\left(R_{1}, R_{2}\right)$ & Nomenclatura e abreviatura & $\boldsymbol{T}_{c}\left({ }^{\circ} \mathrm{C}\right)$ & Carga \\
\hline Fosfatidilcolina (PC) & $\mathrm{CH}_{3}-\left(\mathrm{CH}_{2}\right)_{7}-\mathrm{CH}=\mathrm{CH}-\left(\mathrm{CH}_{2}\right)_{7}-(\mathrm{O})-$ & Dioleilfosfatidilcolina (DOPC) & $<0$ & zwieteriônico \\
\hline \multirow[t]{3}{*}{$\mathrm{CH}_{2} \mathrm{CH}_{2} \mathrm{~N}^{+}\left(\mathrm{CH}_{3}\right)_{3}$} & $\mathrm{CH}_{3}-\left(\mathrm{CH}_{2}\right)_{12}-\mathrm{C}(\mathrm{O})-$ & Dimiristoilfosfatidilcolina (DMPC) & 23 & zwieteriônico \\
\hline & $\mathrm{CH}_{3}-\left(\mathrm{CH}_{2}\right)_{14}-\mathrm{C}(\mathrm{O})-$ & Dipalmitoilfosfatidilcolina (DPPC) & 42 & zwieteriônico \\
\hline & $\mathrm{CH}_{3}-\left(\mathrm{CH}_{2}\right)_{16}-\mathrm{C}(\mathrm{O})-$ & Diestearoilfosfatidilcolina (DSPC) & 55 & zwieteriônico \\
\hline Fosfatidiletaloamina (PE) & $\mathrm{CH}_{3}-\left(\mathrm{CH}_{2}\right)_{7}-\mathrm{CH}=\mathrm{CH}-\left(\mathrm{CH}_{2}\right)_{7}-(\mathrm{O})-$ & Dioleilfosfatidiletaloamina (DOPE) & $<0$ & zwieteriônico \\
\hline $\mathrm{CH}_{2} \mathrm{CH}_{2} \mathrm{NH}_{3}^{+}$ & $\mathrm{CH}_{3}-\left(\mathrm{CH}_{2}\right)_{16}-\mathrm{C}(\mathrm{O})-$ & Diestearoilfosfatidiletaloamina (DSPE) & 74 & zwieteriônico \\
\hline Fosfatidilglicerol (PG) & $\mathrm{CH}_{3}-\left(\mathrm{CH}_{2}\right)_{12}-\mathrm{C}(\mathrm{O})-$ & Dimiristoilfosfatidilglicerol (DMPG) & 13 & Aniônico \\
\hline $\mathrm{CH}_{2} \mathrm{CHOHCH}_{2} \mathrm{OH}$ & $\mathrm{CH}_{3}-\left(\mathrm{CH}_{2}\right)_{14}-\mathrm{C}(\mathrm{O})-$ & Dipalmitoilfosfatidilglicerol (DPPG) & 35 & Aniônico \\
\hline Fosfatidilserina (PS) & $\mathrm{CH}_{3}-\left(\mathrm{CH}_{2}\right)_{14}-\mathrm{C}(\mathrm{O})-$ & Dipalmitoilfosfatidilserina (DPPS) & 79 & Aniônico \\
\hline $\mathrm{CH}_{2} \mathrm{CHNH}_{3}^{+} \mathrm{COO}^{-}$ & $\mathrm{CH}_{3}-\left(\mathrm{CH}_{2}\right)_{16}-\mathrm{C}(\mathrm{O})-$ & Diestearoilfosfatidilserina (DSPS) & 79 & Aniônico \\
\hline
\end{tabular}

B)
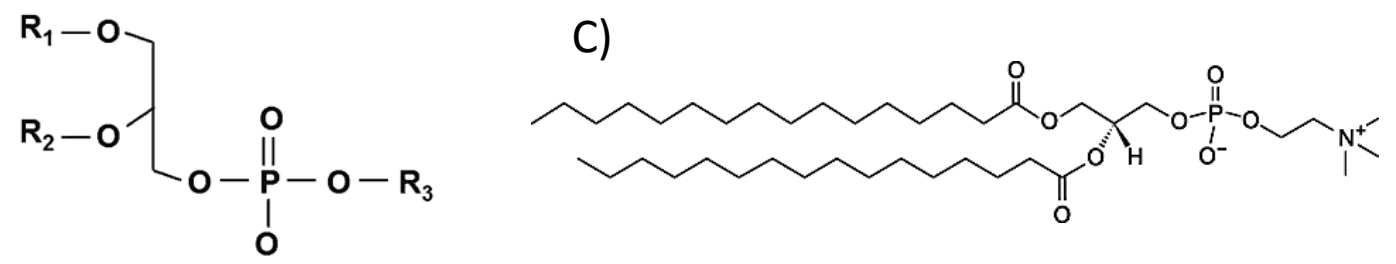

Figura 8: A) Exemplos de compostos frequentemente usados na preparação de lipossomas com suas respectivas cargas e temperatura de transição. B) Estrutura geral de um fosfolipídeo. C) Estrutura da molécula DPPC, um fosfolipídeo. Adaptado de [68].

Fosfolipídios podem ainda estar ligados a outro grupo, chamado de colina, sendo denominados fosfatidilcolinas (PC) ou lecitinas (Figura 8C). Assim como os surfactantes, são moléculas anfifílicas cuja cauda apolar pode apresentar de 4 a 36 carbonos, além de insaturações que influenciarão na flexibilidade da membrana [69]. Além disso, as fosfatidilcolinas são moléculas zwitteriônicas devido ao arranjo molecular dos átomos presentes no grupo colina, o que origina um dipolo elétrico fraco [70].

Dependendo da hidratação, as bicamadas podem originar fases lamelares e lipossomas. No primeiro caso, apresentam-se regularmente espaçadas ao longo do eixo perpendicular ao plano que as contém (embora as bordas desses planos sejam instáveis), enquanto no plano elas se comportam como um fluido, podendo variar os tipos de orientação das caudas hidrocarbônicas em função das condições de temperatura e hidratação. Já os lipossomas são vesículas compostas de uma ou mais bicamadas lipídicas concêntricas, separadas por um meio aquoso. Aqueles formados por uma bicamada são chamados unilamelares. Do contrário, são multilamelares [71]. 


\subsection{Materiais}

\subsubsection{Sistema surfactante-surfactante}

SDS e a série Tween ${ }^{\circledR}$ 20/40/60/80 (referenciados no texto como “T20”, “T40”, "T60”, "T80”) foram adquiridos da Sigma-Aldrich (Brasil) e usados sem purificação adicional. As soluções estoque foram preparadas usando-se água deionizada e consistiu essencialmente na mistura entre o surfactante e o solvente, com a posterior homogeneização por meio da elevação de temperatura (até $50^{\circ} \mathrm{C}$ ) e leve agitação manual. Para a preparação das amostras foi feita a mistura entre as soluções estoque de modo que a razão molar entre os surfactantes SDS:Tween ${ }^{\circledR}$ fosse 3:2 e a concentração total de surfactante fosse $50 \mathrm{mM}$ (acima das CMC's dos surfactantes individuais). Ambas as soluções estoque e amostras foram armazenadas sob refrigeração até o momento de sua utilização. O intervalo de tempo entre a preparação das amostras e a posterior medida foi de 24 horas.

\subsubsection{Sistema proteína-surfactante}

Lisozima, alfa-lactalbumina bovina e SDS foram adquiridos da Sigma-Aldrich (Brasil) e usados sem purificação adicional. As soluções estoque $(0,15 \mathrm{mM}$ de lisozima, 0,10 $\mathrm{mM}$ de alfalactalbumina e $100 \mathrm{mM}$ de SDS) foram preparadas em tampão fosfato salino (PBS) $10 \mathrm{mM}$, pH 6,9. Ambas soluções estoque e amostras foram mantidas sob refrigeração até sua utilização. O intervalo de tempo entre a preparação das amostras e a posterior medida foi de 24 horas.

\subsubsection{Sistema lipossomas-(bio)ativos}

\subsubsection{Sistema Phopholipon ${ }^{\circledR} 90 \mathrm{H}$ - curcumina/vitamina $D_{3}$}

Esse sistema foi investigado em colaboração com o grupo da Profa. Samantha Cristina de Pinho, da FZEA-USP (Campus Pirassununga), e as amostras foram recebidas prontas. Curcumina e vitamina $\mathrm{D}_{3}$ foram adquiridos da Sigma-Aldrich (St. Louis, EUA) e usados sem purificação adicional. Fosfatidilcolina de soja hidrogenada (Phopholipon ${ }^{\circledR} 90 \mathrm{H}$ ) foi obtida da Lipoid GmbH (Ludwigshafen, Alemanha), goma xantana (Grindsted ${ }^{\circledR}$ Xanthan 80) foi doada pela Du Pont (Cotia, SP, Brasil) e a goma guar foi adquirida da Êxodo Científica (Hortolândia, SP, Brasil). As amostras foram preparadas segundo o método de hidratação de prolipossomas [72], que correspondem fundamentalmente a uma mistura sólida obtida a partir da solubilização em 
etanol de Phopholipon ${ }^{\circledR} 90 \mathrm{H}$, curcumina e vitamina $\mathrm{D}_{3}$ com a posterior evaporação à vácuo do solvente orgânico. Os prolipossomas são então hidratados com água deionizada e uma mistura de goma xantanta e guar, na razão molar 1:9, é adicionada à solução de modo a aumentar a estabilidade da amostra. Para detalhes do processo, consultar [73].

\subsubsection{Sistema DPPC - LA}

Esse sistema foi investigado em colaboração com o grupo da Profa. Iolanda Midea Cuccovia, do IQ-USP (Campus São Paulo), e as amostras foram recebidas prontas. Nesse caso, o fosfolipídeo dipalmitoilfosfatidilcolina (DPPC) foi obtido da Avanti Polar Lipids (Alabaster, EUA), enquanto ácido láurico (LA) foi adquirido da Sigma Aldrich (St. Louis, EUA). Os tampões Tris- $\mathrm{HCl} 50 \mathrm{mM}$ pH 7,4 e acetato $50 \mathrm{mM} \mathrm{pH} \mathrm{5,0} \mathrm{foram} \mathrm{preparados} \mathrm{com} \mathrm{materiais}$ oriundos da Sigma Aldrich (Tris Base) e da Merck (ácidos clorídrico e acético, hidróxido de sódio), além da utilização de água deionizada. Para a preparação dos lipossomas foram utilizados os solventes clorofórmio e metanol (J. T. Baker Chemicals).

As amostras foram preparadas segundo o método de hidratação do filme lipídico [74], onde DPPC e LA foram pesados em quantidades desejadas e solubilizados com uma mistura de clorofórmio:metanol na razão 3:2. Em seguida, os solventes foram evaporados usando-se um fluxo de $N_{2}$. O filme seco ficou aderido à parede do tubo de ensaio. Para garantir que todos os solventes orgânicos fossem removidos, o tubo de ensaio contendo o filme foi colocado em uma câmara de vácuo por 1 hora. Para ressuspender o filme e formar os lipossomas, adicionou-se o volume desejado do tampão com pH de interesse $(5,0$ ou 7,4), agitando-se a suspensão em vórtex. Desta maneira foram obtidas vesículas que foram submetidas ao processo de extrusão a fim de reduzir sua polidispersidade, e a concentração de LA nas amostras variou de 0 a $50 \%$ da concentração molar total de lipídio (fixa em $10 \mathrm{mM}$ ). Vale ressaltar que todo o processo de extrusão foi realizado à $60^{\circ} \mathrm{C}$, acima da temperatura de transição do DPPC, $\sim 42^{\circ} \mathrm{C}$ (Figura $8 \mathrm{~A})$.

\subsubsection{Sistema EPC - SMT}

Esse sistema foi investigado em colaboração com o grupo da Profa. Monica Pickholz, da Universidade de Buenos Aires, e as amostras foram recebidas prontas. O lipídeo fosfatidilcolina 
de ovo (EPC) foi adquirido da Avanti Polar Lipids (Alabaster, EUA) enquanto o sumatriptano 3 (SMT), também chamado de sumatriptana, foi doado pelo laboratório LAFEDAR S.A., na Argentina, sob a forma do medicamento succinato de sumatriptano, um sal que em solução aquosa se ioniza dando origem ao bioativo sumatriptano e ao ácido succínico. Fosfolipídeo e fármaco foram usados sem purificação adicional.

As amostras foram preparadas segundo o método de hidratação do filme lipídico, como no caso anterior, nas razões SMT:EPC 0:1, 1:3, 1:2, 9:10, 9:5, 3:1, mantendo-se a concentração de EPC sempre igual a $20 \mathrm{mM}$.

\subsection{Métodos experimentais}

\subsubsection{SAXS}

A principal técnica usada nesta tese foi a de espalhamento de raios $\mathrm{X}$ a baixos ângulos (SAXS, do inglês Small Angle X-ray Scattering), que permite a determinação da forma e tamanho de estruturas biológicas diretamente em solução. Entre essas estruturas estão proteínas, DNA, micelas, lipossomas, etc. [75]. A ideia básica por trás da técnica de SAXS consiste no espalhamento de raios $\mathrm{X}$ a partir da interação deles com a $\operatorname{amostra}^{4}$ (Figura 9A). O registro desse espalhamento pode ser feito usando-se um detector uni- ou bidimensional. A partir do tratamento da informação registrada (Figura 9B) obtém-se uma curva unidimensional da intensidade espalhada $I(q)$ em função do módulo do vetor de transferência de momento no espaço recíproco $\vec{q}$ (Figura 9C). Essa curva conterá informações particulares sobre a estrutura do sistema estudado. Algumas delas podem ser acessadas pela análise de ordem inicial (por exemplo, via Transformada Indireta de Fourier - IFT $^{5}$ ), mas outras somente com uma modelagem apropriada. Levando-se em consideração que SAXS é uma técnica de "baixa resolução", visto que o processo de obtenção da curva unidimensional $I(q) \times q$ a partir do espalhamento de estruturas tridimensionais randomicamente orientadas no espaço é acompanhado de grande perda de informação, pode-se ter casos em que modelos diferentes acabam por ajustar satisfatoriamente os dados experimentais. A fim de se reduzir essa ambiguidade inerente dos dados, é uma prática frequente empregar na modelagem os chamados

\footnotetext{
3 1-[3-(2-dimetilaminoetil)-1H-indol-5-il]-N-metil-metanosulfonamida.

${ }^{4}$ Ver seção Fundamentos Teóricos.

${ }^{5}$ Ver seção Fundamentos Teóricos.
} 
vínculos moleculares e/ou utilizar informações oriundas de outras técnicas. De um modo geral, quanto maior a quantidade de informações disponíveis sobre o sistema estudado, mais confiável será o modelo escolhido para descrever os dados.

As medidas de SAXS apresentadas nesta tese foram feitas ou no equipamento Xeuss ${ }^{\circledR}$ (adquirido da empresa Xenocs) ou no equipamento NanoStar ${ }^{\circledR}$ (adquirido da empresa Bruker), ambos localizados no Instituto de Física da Universidade de São Paulo. Em todos os casos, as amostras foram colocadas em capilares de quartzo reutilizáveis de diâmetro 1,5 $\mathrm{mm}$ colados em cases de aço e vedados com tampas removíveis. Dessa forma, as medidas das amostras do tampão foram feitas nas mesmas condições. A distância amostra-detector foi $0,70 \mathrm{~m}$, fornecendo um intervalo em $q$ aproximado de $0,02<q<0,35 \AA^{-1}$. Para o tratamento dos dados foi usado o pacote SUPERSAXS [76], o qual corrigiu as intensidades pelo espalhamento de background, do tampão, do capilar vazio e posteriormente as normalizou para a escala absoluta de intensidade usando-se como padrão a água.

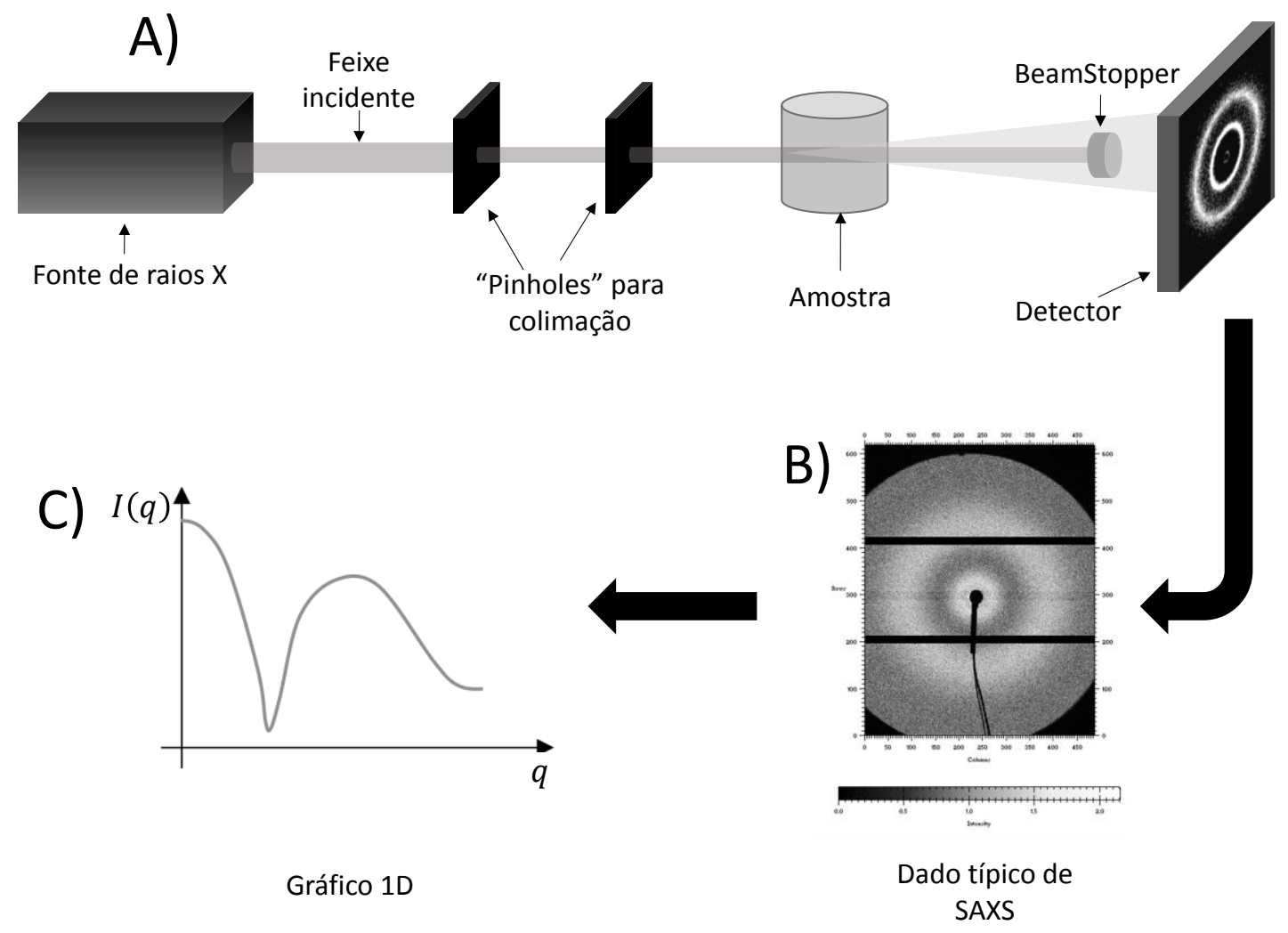

Figura 9: A) Esquema do aparato experimental usado na técnica de SAXS. B) Exemplo de difratograma. C) A partir do difratograma obtém-se uma curva unidimensional de intensidade espalhada $I(q)$ versus o módulo do vetor de transferência de momento no espaço recíproco $\vec{q}$. 


\subsubsection{ITC}

A sigla ITC vem de Isothermal Titration Calorimetry, que significa calorimetria de titulação isotérmica, e é uma técnica que visa a medida do calor liberado ou absorvido pelo sistema durante um experimento de titulação (tipicamente, envolvendo a titulação de um ligante no substrato). No experimento a temperatura é mantida constante e observada por meio de sensores ligados às duas células, uma de referência (a qual é preenchida sempre com água) e a outra de amostra (onde é colocada a amostra e ocorre a titulação), como está mostrado na Figura 10A. Ambas as células estão dentro de uma armadura adiabática que evita trocas de calor das células com o ambiente externo. A informação sobre calores trocados vem da medida do fluxo de calor necessário para manter o equilíbrio térmico entre as células. Se a titulação não gera calor, então o fluxo se mantém constante, correspondendo à chamada linha de base. Contudo, se o processo libera ou absorve calor, eles são chamados exotérmico e endotérmico, respectivamente, e o equipamento reage diminuindo ou aumentando o fluxo de calor a fim de manter a temperatura constante. Isso corresponde, respectivamente, a picos abaixo e acima da linha de base.

O fluxo de calor é observado ao longo do tempo do experimento e o resultado é um gráfico de fluxo de calor x tempo, chamado de fluxograma (Figura 10B). Uma vez tratados os dados, a interpretação do gráfico está diretamente ligada a medidas de mudanças de energia no sistema. A entalpia $H$ corresponde à Transformada de Legendre da energia interna $U$ do sistema, que substitui o volume pela pressão como uma variável independente [77]. Ela é definida por

$$
H=U+P V
$$

onde $P$ é a pressão e $V$ o volume. Pode-se mostrar que num sistema onde o calor é trocado à pressão constante e não há troca de matéria, a variação de entalpia $\Delta H$ corresponde ao próprio calor trocado [77]. Portanto, partindo-se do fluxograma obtém-se o chamado de entalpograma (Figura 10C), que traz informações sobre as variações de entalpia do sistema.

Cada ponto no entalpograma corresponde a um pico do fluxograma que foi integrado em relação ao tempo. Para casos mais simples, é possível construir um modelo que será usado para ajustar os dados experimentais (linha contínua na Figura 10B) o qual permitirá obter informações sobre parâmetros termodinâmicos como constante de equilíbrio, variações de energias livre e de entropia. Do contrário, podem ser empregados métodos gráficos para a avaliação de parâmetros termodinâmicos ou mesmo ser feita uma análise qualitativa que dependerá de cada sistema estudado [78,79]. 
As medidas de ITC apresentadas nesta tese, relacionadas particularmente ao sistema proteínasurfactante, foram realizadas em um MicroCal ${ }^{\mathrm{TM}} \mathrm{iTC}_{200}$ (adquirido da GE Heathcare Life Sciences) localizado no Instituto de Física da Universidade de São Paulo. A cela de referência sempre foi preenchida com água deionizada, enquanto a cela de amostra foi preenchida com $200 \mu L$ de solução de proteína em concentrações que variaram de tipicamente de 0,02 a 0,15 mM. Já a seringa foi preenchida com $39 \mu L$ de solução de SDS $100 \mathrm{mM}$. Os experimentos, todos realizados a $25^{\circ} \mathrm{C}$ e em duplicata (a fim de checar a reprodutibilidade), consistiram tipicamente de 80 injeções: a primeira foi de $0,1 \mu L$ e as demais foram de $0,5 \mu L$ cada. O tempo entre uma injeção e outra foi $400 \mathrm{~s}$, suficiente para o sinal retornar para a linha de base. Os fluxogramas obtidos foram integrados em relação ao tempo pelo programa Origin ${ }^{\circledR}$, fornecido juntamente com o equipamento.

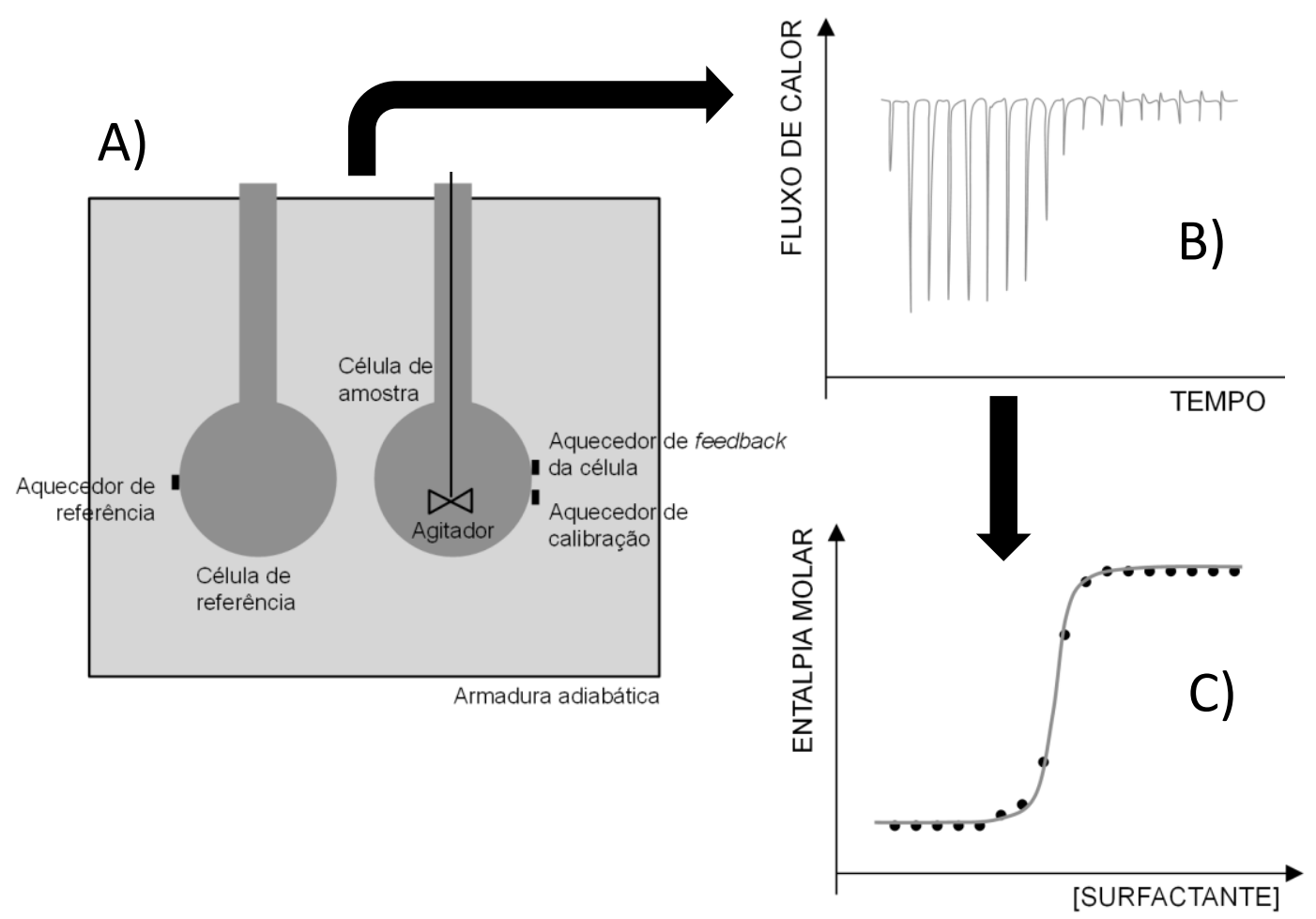

Figura 10: A) Esquema de um equipamento de ITC. B) Exemplo de dado experimental bruto obtido com o experimento (fluxograma). C) Exemplo de dado experimental final (entalpograma), o qual poderá ser analisado e comparado com modelos teóricos (linha azul) se disponíveis.

\subsubsection{CD}

Quando um feixe de luz passa através de um meio, dois fenômenos básicos podem ocorrer: Refração e absorção. O primeiro se relaciona com a mudança da velocidade de propagação da 
luz quando ela passa de um meio para outro. Essa mudança pode ser caracterizada pelo índice de refração $\varrho$, definido por:

$$
\varrho=\frac{v_{v a ́ c u o}}{v}
$$

onde $v_{v a ́ c u o}$ é a velocidade de propagação da luz no vácuo e $v$ é a velocidade dela em outros meios. A absorção consiste na redução da intensidade original $I_{0}$ de luz ao passar por uma amostra de coeficiente de absorção molar $\mu$ e concentração molar $c$, percorrendo um caminho ótico $\ell$. A diminuição da intensidade da luz é bem caracterizada pela lei de Beer-Lambert:

$$
I=I_{0} 10^{-\mu \ell c}
$$

Se, entretanto, a luz incidente for linearmente polarizada, e se a substância contida na amostra for oticamente ativa (por exemplo, cromóforos quirais), então o plano de polarização da luz transmitida "gira". Esse fenômeno é conhecido como polarização circular.

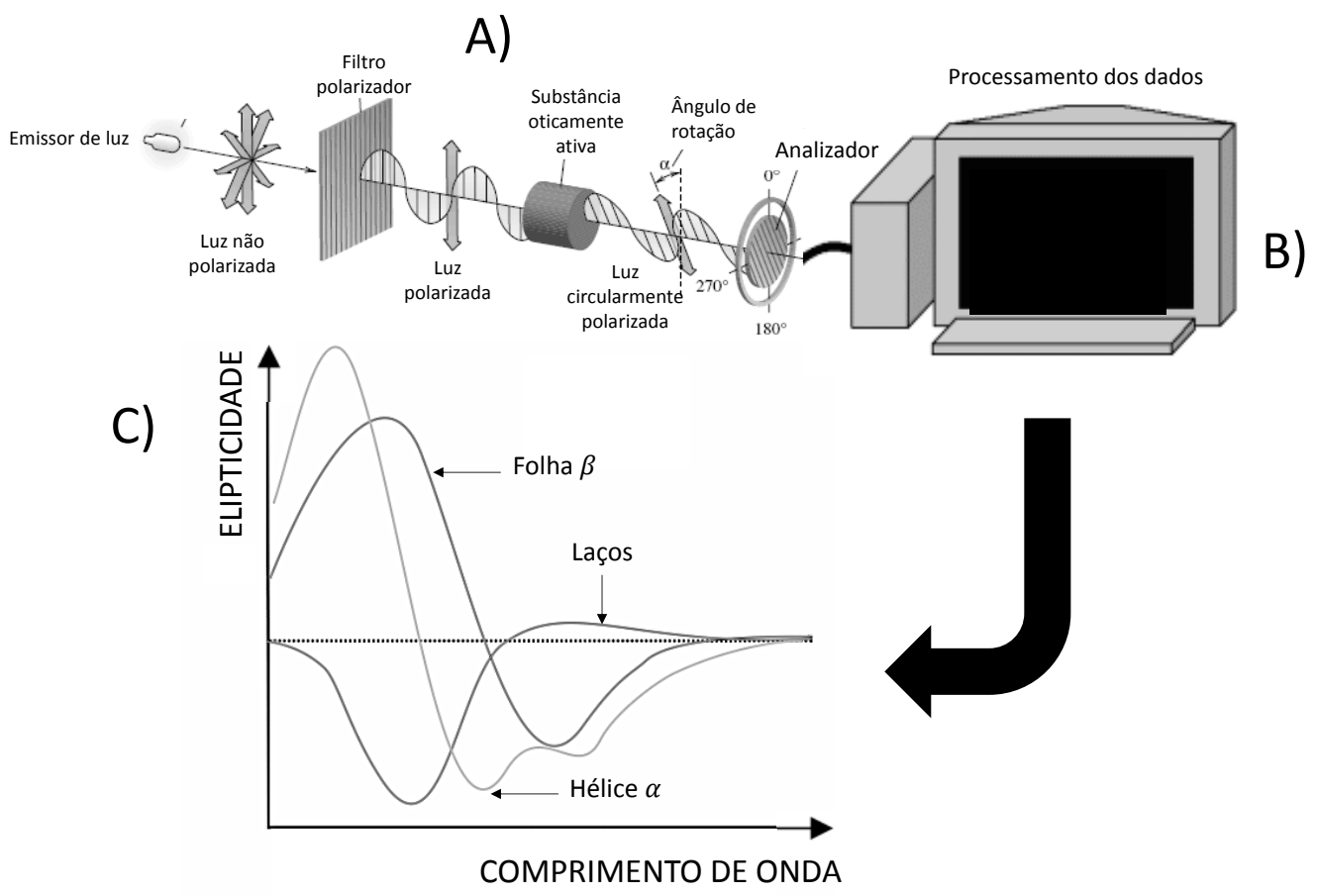

Figura 11: A) Esquema ${ }^{6}$ do aparato experimental usado na técnica de CD. B) O processamento dos dados é feito de modo a levar em conta informações da amostra, como concentração, para o cálculo da elipticidade, que é a grandeza que se relaciona com o ângulo de rotação do plano de luz em relação ao plano da luz incidente. C) Como saída, obtém-se um gráfico de elipticidade versus comprimento de onda (região far-UV ou near-UV).

\footnotetext{
${ }^{6}$ Adaptado de http://www.lookfordiagnosis.com/mesh info.php?term=Dicro\%C3\%ADsmo+Circular\&lang=3, acessado em Setembro/2016.
} 
Verifica-se também que as componentes da luz circularmente polarizada (esquerda e direita) diferem não apenas nas velocidades de propagação, mas também nos coeficientes de absorção. Esse fenômeno é chamado de dicroísmo circular. É possível definir a diferença entre os coeficientes de absorção molares como:

$$
\Delta \mu=\mu_{e}-\mu_{d}
$$

onde os índices " $e$ " e " $d$ " estão relacionados com "esquerda" e "direita", respectivamente. Em geral é mais conveniente escrever essa diferença em termos da grandeza elipticidade $\theta$, definida por:

$$
\theta=\frac{\ln 10}{4} c\left(\mu_{e}-\mu_{d}\right)
$$

onde $c$ é a concentração molar. Como resultado, a elipticidade será dada em mdeg (miligraus). É possível converter para a elipticidade molar, $\theta^{\prime}$ (em unidades $d e g \cdot \mathrm{cm}^{2} \cdot d \mathrm{~mol}^{-1}$ ), usandose a relação:

$$
\theta^{\prime}=\frac{100 \theta}{\ell c^{\prime}}
$$

onde $c^{\prime}=\mathcal{N} c, \operatorname{com} \mathcal{N}$ sendo o número de resíduos na macromolécula investigada.

A técnica de CD é muito utilizada para o estudo estrutural de proteínas e macromoléculas afins, e fornece informação em dois níveis [2] chamados Far-UV e Near-UV. O primeiro abrange o intervalo de comprimento de onda de $260-190 \mathrm{~nm}$, tornando possível acessar informações sobre a estrutura secundária. Por meio de programas de análise adequados [80], é possível calcular a porcentagem de hélices $\alpha$, folhas $\beta$ e laços em determinada proteína. Por outro lado, Near-UV lida com o intervalo de comprimento de onda de 320-260 nm, permitindo assim o acesso a informações sobre a estrutura terciária [64]. Vale ressaltar que, no texto desta tese, as análises nesse intervalo de comprimento de onda foram qualitativas via inspeção direta das curvas experimentais.

A Figura 11 fornece uma visão geral sobre o aparato experimental. Essencialmente, uma fonte emite luz que passa por um filtro polarizador. A luz polarizada incide na amostra oticamente ativa e seu plano gira (Figura 11A). Um analisador conectado ao sistema de processamento (Figura 11B) permite determinar a elipticidade, fornecendo assim curvas como aquelas mostradas em Figura 11C. 
As medidas de CD apresentadas nesta tese, relacionadas particularmente ao sistema proteínasurfactante, foram feitas no espectropolarímetro J-715 (da empresa Jasco), localizado no Instituto de Química da Universidade de São Paulo. Foram utilizadas cubetas de quartzo de 1 e $5 \mathrm{~mm}$ para medidas nas regiões espectrais Near-UV e Far-UV, respectivamente. A velocidade de varredura no comprimento de onda foi de $20 \mathrm{~nm} /$ minuto (com tempo de resposta de $4 \mathrm{~s}$ ) e o dado final correspondeu à média de 4 varreduras completas. As contribuições do tampão para o background foram subtraídas dos dados.

\subsection{Fundamentos teóricos de SAXS}

\subsubsection{Introdução}

Quando um feixe colimado de raios $\mathrm{X}$ incide na amostra, parte desse feixe interage com os elétrons de cada molécula, podendo gerar vários processos possíveis (espalhamento Rayleigh, efeito Compton, produção de pares e outros). Para energias de 7 à $12 \mathrm{keV}$, o espalhamento é bem descrito pela primeira aproximação de Born, que considera que o feixe espalhado é resultado do espalhamento primário dos objetos espalhadores (elétrons, átomos, partículas), isto é, não existem espalhamentos múltiplos [81].

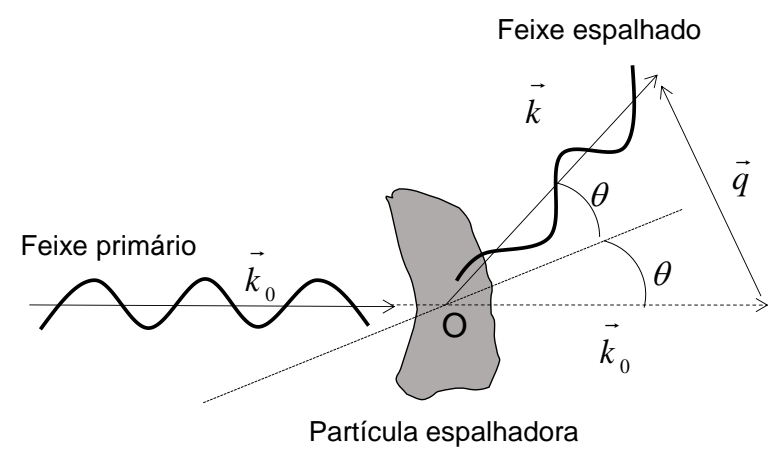

A)

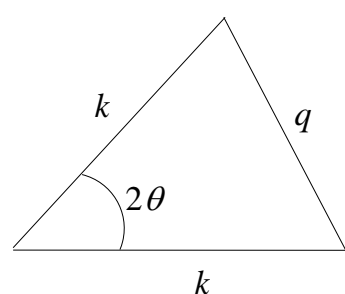

B)

Figura 12: A) Feixe de raios $X$ espalhado por uma partícula, fixa no espaço, formando um ângulo $2 \theta$ em relação ao feixe incidente. B) A partir de considerações geométricas, escreve-se o módulo do vetor de transferência de momento no espaço recíproco $q$ em função do ângulo de espalhamento e do módulo do vetor de onda $k$. Retirado de [62].

Na Figura 12A está esquematizado uma situação de espalhamento. Seja $\vec{k}_{0}$ o vetor de onda do feixe incidente e $\vec{k}$ o vetor de onda do feixe espalhado. Define-se: 


$$
\vec{q}=\vec{k}-\vec{k}_{0}
$$

como sendo o vetor de transferência de momento no espaço recíproco. Já que, pela primeira aproximação de Born, a onda incidente possui mesma energia que a onda espalhada, isto é, o espalhamento é elástico, então:

$$
|\vec{k}|=\left|\vec{k}_{0}\right|=k=\frac{2 \pi}{\lambda}
$$

onde $\lambda$ é o comprimento de onda usado na radiação. Com este fato, podemos escrever o módulo de $\vec{q}$ usando-se a lei dos cossenos no triângulo mostrado na Figura 12B:

$$
q^{2}=k^{2}+k^{2}-2 k^{2} \cos 2 \theta
$$

Resolvendo, encontra-se a relação entre $q$ e $k$, a saber:

$$
q=2 k \sin \theta
$$

Substituindo Eq. 8 em Eq. 10, vem:

$$
q=\frac{4 \pi}{\lambda} \sin \theta
$$

Se a partícula está fixa no espaço e possui densidade eletrônica $\rho(\vec{r})$, então a amplitude de espalhamento $F(\vec{q})$ será dada pela Transformada de Fourier da densidade eletrônica [82,83]:

$$
F(\vec{q})=\frac{1}{4 \pi} \int_{V} \rho(\vec{r}) e^{-i \vec{q} \cdot \vec{r}} d \vec{r}
$$

a qual está relacionada com a intensidade espalhada $I_{1}(\vec{q})$, mensurável, por meio de:

$$
I_{1}(\vec{q})=F(\vec{q}) \cdot F(\vec{q})^{*}
$$

Em sistemas reais as partículas não estão fixas no espaço. Logo, deve-se tomar a média sobre todas as orientações da partícula (essa operação será representada com "brackets", 〈 〉). No espaço recíproco isso é feito facilmente tomando-se a média sobre o ângulo sólido $\Omega$ [84]: 


$$
I_{1}(q)=\left\langle F(\vec{q}) \cdot F(\vec{q})^{*}\right\rangle=4 \pi \int_{0}^{\infty} p(r) \frac{\sin q r}{q r} d r
$$

onde $p(r)$, chamada função distribuição de pares de distâncias, é uma função no espaço real que fornece informações sobre a forma das partículas a partir da intensidade espalhada $I_{1}(q)$. Para acessá-la partindo-se de $I_{1}(q)$ utiliza-se a Transformada Inversa de Fourier [84]:

$$
p(r)=\frac{r}{2 \pi^{2}} \int_{0}^{\infty} q^{2} I_{1}(q) \frac{\sin q r}{q r} d q
$$

Como, experimentalmente, não é possível avaliar $q$ no intervalo $[0 ; \infty[$, obtém-se $p(r)$ por meio da Transformada Indireta de Fourier - IFT [82,83]. A Figura 13 mostra a intensidade espalhada por algumas formas geométricas comuns assim como a função $p(r)$ correspondente. Nos casos tratados nesta tese, utilizou-se o programa WIFT [76] para esse tipo de análise.

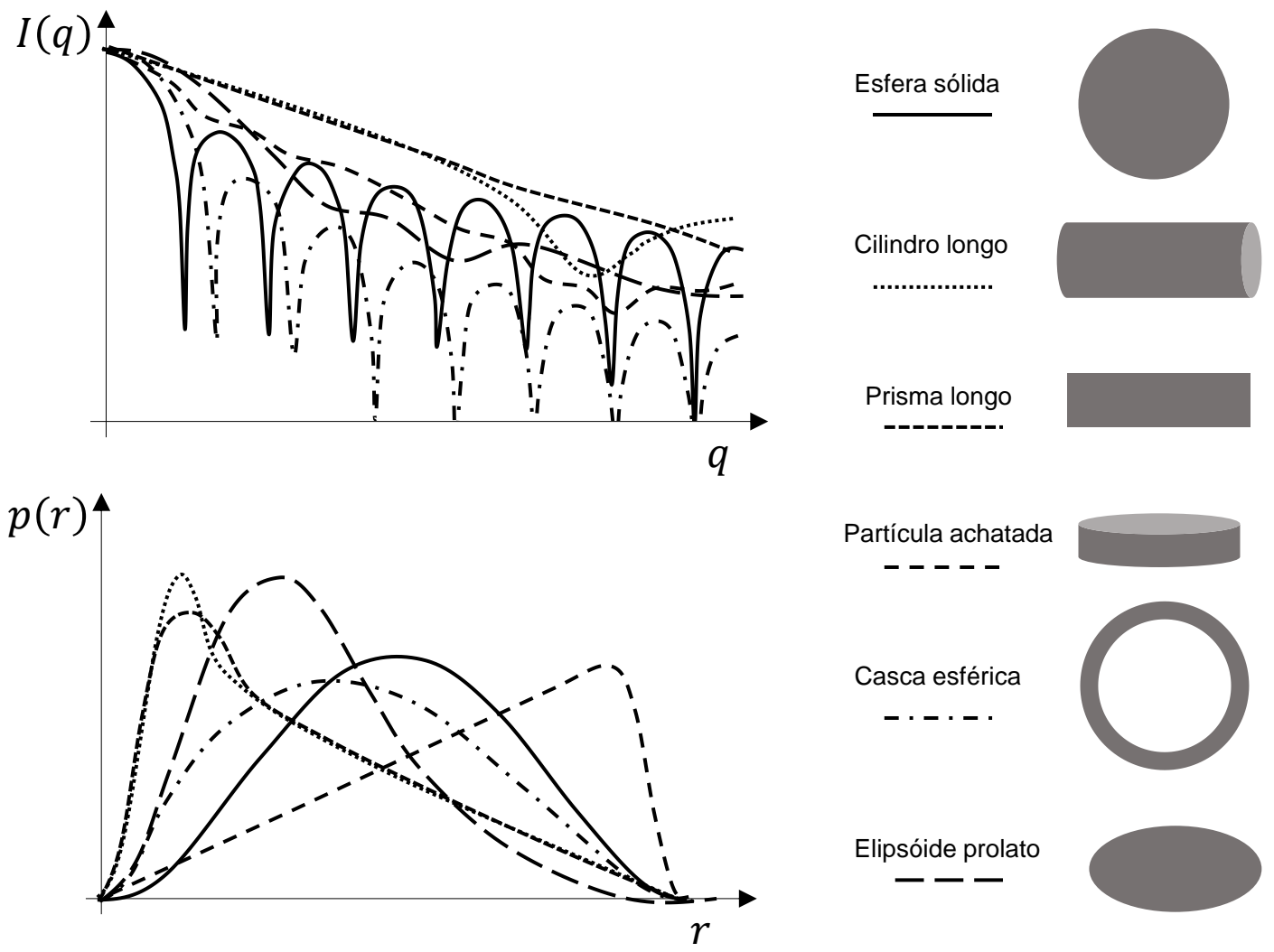

Figura 13: Cada estrutura mostrada à direita (esfera, cilindro, prisma...) possui um único perfil de intensidade assim como um único perfil de $p(r)$. Conhecendo-se esses perfis, pode-se em uma análise inicial dar palpites sobre a forma das partículas em um sistema qualquer assim como o tamanho máximo envolvido $\left(r_{\text {máx }}\right)$, informação esta relacionada com a curva $p(r)$. Adaptado de [62]. 
Um caso especial corresponde a partículas do tipo core-shell, isto é, formadas por um núcleo e uma casca concêntricos, de contrastes eletrônicos $\Delta \rho$ de sinais opostos (Figura 14A). Nessa situação a função $p(r)$ típica (Figura 14B) possuirá “oscilações". Um sistema formado por micelas, por exemplo, possui essa característica.

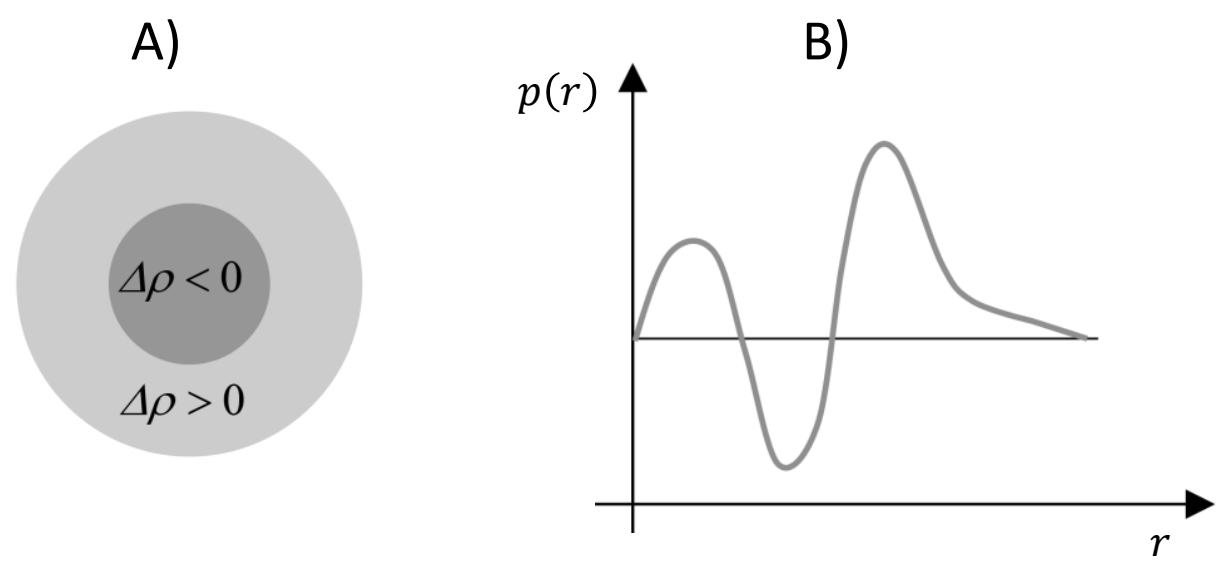

Figura 14: A) Exemplo de partícula do tipo core-shell. B) A partir da curva de intensidade é possível obter a função $p(r)$ via Transformada Inversa de Fourier (IFT). Adaptado de [75].

Até agora foi considerado o espalhamento de uma única partícula. Para um sistema de $n$ partículas por unidade de volume, randomicamente orientadas, a intensidade espalhada passa a ser descrita por [85]:

$$
I(q)=n \cdot\left\langle F(\vec{q})^{2}\right\rangle \cdot\langle S(\vec{q})\rangle
$$

onde $\left\langle F(\vec{q})^{2}\right\rangle=P(q)$ é o chamado fator de forma das partículas e $\langle S(\vec{q})\rangle=S(q)$ é o chamado fator de estrutura do sistema. O fator de forma depende unicamente da forma das partículas. Se o sistema for monodisperso, a forma das partículas não muda e $P(q)=I_{1}(q)$. Se o sistema for polidisperso, o fator de forma incluirá a média sobre todas as possíveis formas, tamanhos e densidades eletrônicas das partículas. $\mathrm{O}$ fator de estrutura depende das interações entre as partículas e das possíveis estruturas que elas podem formar devido a isso. Para sistemas diluídos, $S(q) \rightarrow 1$ e a intensidade espalhada só dependerá do fator de forma das partículas. Para sistemas concentrados, $S(q)$ deve ser levado em conta a fim de que a intensidade espalhada seja perfeitamente descrita. 


\subsubsection{Modelos teóricos}

\subsubsection{Micelas simples e mistas}

O modelo teórico descrito a seguir será usado para a modelagem das micelas mistas no Capítulo 3. Partindo-se da hipótese de que o sistema micelar (simples ou misto) é monodisperso ou pouco polidisperso e formado por partículas levemente anisotrópicas, é possível usar a aproximação de desacoplamento [85] onde a intensidade espalhada $I(q)$ é modelada por meio de:

$$
I(q)=n\left\{\left\langle F(\vec{q})^{2}\right\rangle+\langle F(\vec{q})\rangle^{2}[S(q)-1]\right\}
$$

Modelos core-shell são bastante usados para descrever micelas uma vez que elas possuem um core, formado pelas caudas apolares do surfactante, e um shell, formado pelas cabeças polares. Mesmo que a geometria da molécula do surfactante e/ou as condições do meio favoreçam a formação de micelas globulares (ou também cilíndricas), é sabido que elas não são perfeitamente esféricas, mas sim elipsoidais $[85,86]$.

A)

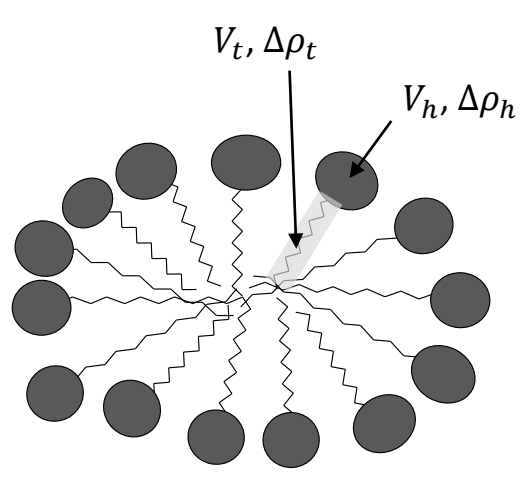

B)

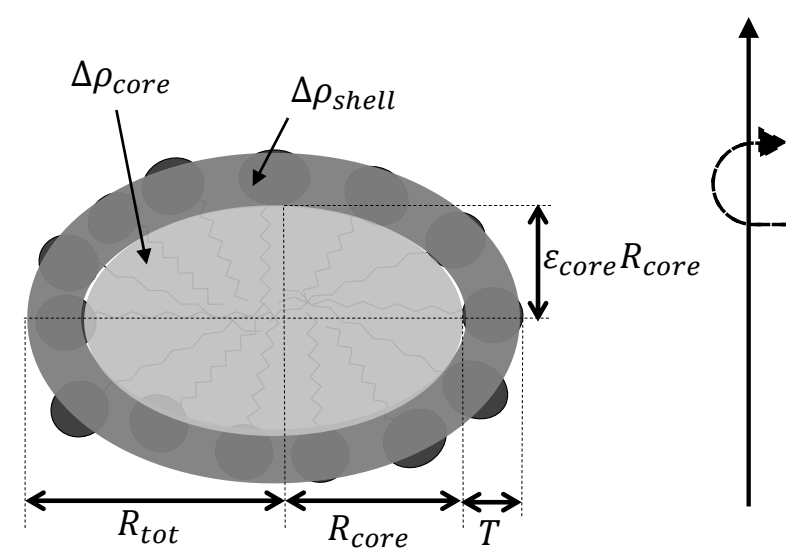

Figura 15: A) Esquema simplificado de uma micela com forma elipsoidal. B) Modelo usado para descrever a micela, um elipsoide de revolução core-shell. A revolução se dá em torno eixo perpendicular ao eixo principal passando pelo centro do elipsoide. O significado de cada termo mostrado na figura encontra-se no texto.

A Figura 15 mostra um modelo elipsoidal de revolução core-shell que pode ser usado para interpretar os dados de SAXS das micelas simples e mistas dos surfactantes usados nesta tese. Para este caso, o fator de forma $P(q)$ será dado por [87]: 


$$
\begin{aligned}
P(q)=\left\langle F(\vec{q})^{2}\right\rangle & \\
= & \int_{0}^{\frac{\pi}{2}}\left[\Delta \rho_{\text {shell }} \cdot V_{\text {tot }} \cdot \phi\left(q r_{\text {tot }}\right)+\left(\Delta \rho_{\text {core }}-\Delta \rho_{\text {shell }}\right) \cdot V_{\text {core }}\right. \\
& \left.\cdot \phi\left(q r_{\text {core }}\right)\right]^{2} \sin \alpha d \alpha
\end{aligned}
$$

onde $\Delta \rho$ e $V$ correspondendo ao excesso de comprimento de espalhamento e volume, respectivamente, enquanto $r_{\text {core }}=R_{\text {core }}\left(\sin \theta^{2}+\varepsilon_{\text {core }}^{2} \cos \theta^{2}\right)^{\frac{1}{2}}$ e $r_{\text {tot }}=R_{\text {tot }}\left(\sin \theta^{2}+\right.$ $\left.\varepsilon_{\text {tot }}^{2} \cos \theta^{2}\right)^{\frac{1}{2}}$, sendo $\theta$ o ângulo entre o vetor $\vec{q}$ e o eixo principal do elipsoide. O raio total do elipsoide, $R_{\text {tot }}$, está relacionado com o raio do core, $R_{\text {core }}$, por meio de $R_{\text {tot }}=R_{\text {core }}+T$, onde $T$ é a espessura do shell. O parâmetro $\varepsilon$ é chamado anisotropia ou excentricidade e informa o achatamento do elipsoide. Se $\varepsilon>1$, então o elipsoide é prolato (Figura 16A). Se $\varepsilon<1$, então o elipsoide é dito oblato (Figura 16B). Se $\varepsilon=1$, então o elipsoide é na verdade uma esfera. Decorre dessas definições que $\varepsilon_{\text {tot }}=\frac{\varepsilon_{\text {core }} R_{\text {core }}+T}{R_{\text {core }}+T}$. A existência de duas anisotropias diferentes, $\varepsilon_{\text {tot }}$ e $\varepsilon_{\text {core }}$, garante que a espessura do shell será constante. Contudo, para o caso das análises referentes ao sistema surfactante-surfactante (Capítulo 3), ambas as anisotropias serão consideradas iguais a fim de se reduzir a quantidade de parâmetros ajustáveis.

A)

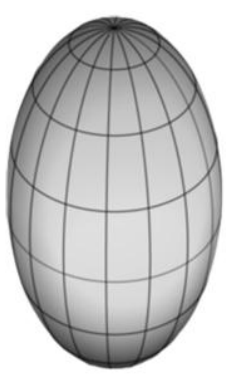

(elipsoide prolato, $\varepsilon>1$ )
B)

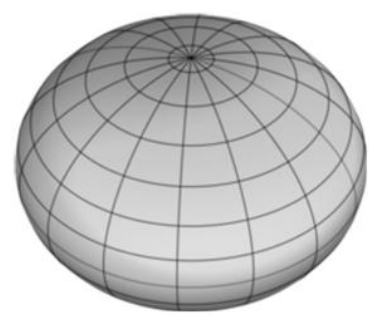

(elipsoide oblato, $\varepsilon<1$ )

Figura 16: Diferença entre um elipsoide de revolução prolato (A) e oblato (B).

A função $\phi(x)$ é a amplitude de espalhamento normalizada para uma esfera, dada por [88]:

$$
\phi(x)=3 \frac{\sin x-x \cos x}{x^{3}}
$$


Similarmente à equação Eq. 18, pode-se escrever:

$$
\begin{gathered}
\langle F(\vec{q})\rangle^{2}=\left[\int _ { 0 } ^ { \frac { \pi } { 2 } } \left[\Delta \rho_{\text {shell }} \cdot V_{\text {tot }} \cdot \phi\left(q r_{\text {tot }}\right)+\left(\Delta \rho_{\text {core }}-\Delta \rho_{\text {shell }}\right) \cdot V_{\text {core }}\right.\right. \\
\left.\left.\cdot \phi\left(q r_{\text {core }}\right)\right] \sin \alpha d \alpha\right]^{2}
\end{gathered}
$$

As interfaces core/shell e shell/solvente podem ser deixadas difusas multiplicando-se cada termo nas equações Eq. 18 e Eq. 20 pelo fator $e^{-\frac{\sigma^{2} q^{2}}{2}}$, onde $\sigma$ é a largura da distribuição gaussiana usada para fazer o smearing das interfaces.

Se as micelas são neutras e aproximadamente esféricas, a interação entre elas pode ser descrita pelo fator de estrutura de esfera rígida [89]:

$$
S_{H S}(q)=\frac{1}{1+\frac{24 \phi G\left(q R_{H S}\right)}{q R_{H S}}}
$$

onde $\phi$ é a fração de volume de esferas rígidas, $R_{H S}$ é o raio das esferas e a função $G(x)$ é dada por:

$$
\begin{array}{r}
G(x)=\alpha \frac{(\sin x-x \cos x)}{x^{2}}+\beta \frac{\left[2 x \sin x+\left(2-x^{2}\right) \cos x-2\right]}{x^{3}} \\
+\gamma \frac{\left[-x^{4} \cos x+4\left|\left(3 x^{2}-6\right) \cos x+\left(x^{3}-6 x\right) \sin x+6\right|\right]}{x^{5}}
\end{array}
$$

com:

$$
\begin{gathered}
\alpha=\frac{(1+2 \phi)^{2}}{(1-\phi)^{4}} \\
\beta=(-6 \phi) \frac{\left(1+\frac{\phi}{2}\right)^{2}}{(1-\phi)^{2}} \\
\gamma=\frac{\phi \alpha}{2}
\end{gathered}
$$

Já para sistemas carregados eletricamente e diluídos, a interação entre elas pode ser representada pelo fator de estrutura de sistemas diluídos de partículas coloidais carregadas [90]. 


\subsection{Vínculos moleculares para micelas simples}

Considerando-se o modelo core-shell elipsoidal descrito acima, o volume do core será dado por:

$$
V_{\text {core }}=\frac{4}{3} \pi \varepsilon_{\text {core }} R_{\text {core }}^{3}
$$

Assumindo que a micela possua número de agregação $N_{a g g}$, isto é, que seja formada, em média, por $N_{\text {agg }}$ moléculas de surfactante, então:

$$
V_{\text {core }}=V_{t} \cdot N_{a g g}
$$

onde $V_{t}$ é o volume da cauda de cada surfactante. Logo, igualando Eq. 26 e Eq. 27 teremos:

$$
R_{\text {core }}=\left(\frac{N_{a g g} V_{t}}{\frac{4}{3} \pi \varepsilon_{\text {core }}}\right)^{\frac{1}{3}}
$$

Da mesma forma é possível escrever que:

$$
R_{t o t}=\left(\frac{N_{a g g} V_{t o t}}{\frac{4}{3} \pi \varepsilon_{t o t}}\right)^{\frac{1}{3}}=\left[\frac{N_{a g g}\left(V_{t}+V_{h}\right)}{\frac{4}{3} \pi \varepsilon_{t o t}}\right]^{\frac{1}{3}}
$$

Sabendo o número de elétrons $N_{e l}$ e o volume da cauda e da cabeça do surfactante utilizado, é possível calcular a densidade eletrônica $\rho$ da cabeça e da cauda por meio, respectivamente, de:

$$
\begin{gathered}
\rho_{h}=\frac{N_{e l_{h}}}{V_{h}} \\
\rho_{t}=\frac{N_{e l_{t}}}{V_{t}}
\end{gathered}
$$

Tomando como referência a densidade eletrônica do tampão $\left(\rho_{b u f}\right)$, é possível se obter o contraste de densidade eletrônica da cabeça e da cauda por meio, respectivamente, de: 


$$
\begin{gathered}
\Delta \rho_{h}=\rho_{h}-\rho_{\text {buf }} \\
\Delta \rho_{t}=\rho_{t}-\rho_{\text {buf }}
\end{gathered}
$$

Os excessos de comprimento de espalhamento podem ser escritos como:

$$
\begin{gathered}
\Delta \rho_{\text {shell }}=\Delta \rho_{h} \cdot r_{T} \\
\Delta \rho_{\text {core }}=\Delta \rho_{t} \cdot r_{T}
\end{gathered}
$$

onde $r_{T}=2,82 \times 10^{-13} \mathrm{~cm}$ é o raio clássico do elétron (raio de Thomson) [75]. A expressão final da intensidade espalhada modelada será:

$$
I(q)=S c \cdot \frac{c-C M C}{N_{a g g}} \cdot\left\{\left\langle F(\vec{q})^{2}\right\rangle+\langle F(\vec{q})\rangle^{2}[S(q)-1]\right\}+\text { back } \quad \text { Eq. } 36
$$

onde os termos $\left\langle F(\vec{q})^{2}\right\rangle$ e $\langle F(\vec{q})\rangle^{2}$ são dados pelas equações Eq. 18 e Eq. 20, respectivamente, e $S(q)$ é o fator de estrutura (escolhido de acordo com as características elétricas das partículas). O parâmetro $c$ é a concentração total de surfactante e $C M C$ é a concentração micelar crítica que coincide com a concentração de monômeros livres (isto é, que não formam micelas). Assim, $C=c-C M C$ é a concentração de surfactantes que formam micelas. Portanto, o fator $\frac{c-C M C}{N_{a g g}}$ corresponde ao número de micelas por unidade de volume. O parâmetro $S c$ é um fator de escala geral que é útil para corrigir eventuais erros de concentração dos surfactantes (em geral seu valor é próximo de 1 nos ajustes), enquanto o parâmetro back corrige efeitos gerais background (seu valor inicial para fins de ajuste é 0). O modelo foi implementado em linguagem Fortran 77 com rotina de minimização baseada no método de Levenberg-Marquardt [85] e a execução dos programas levou um tempo da ordem de segundos.

\subsection{Vínculos moleculares para micelas mistas}

Para os sistemas mistos nos quais as micelas são formadas pelos surfactantes genéricos A e B, o parâmetro $N_{a g g}$ corresponderá ao número total de surfactantes A e B que compõem a micela mista. Definindo o parâmetro $x_{A}$ como sendo a fração molar do surfactante A presente na micela mista, decorre que o número de moléculas de A na micela é $x_{A} N_{a g g}$, enquanto o número de 
moléculas de B na mesma micela é $\left(1-x_{A}\right) N_{a g g}$. Logo, os excessos de comprimento de espalhamento do shell e do core serão dados por:

$$
\begin{gathered}
\Delta \rho_{\text {shell }}=\left[x_{A} \Delta \rho_{h(A)}+\left(1-x_{A}\right) \Delta \rho_{h(B)}\right] \cdot r_{T} \\
\Delta \rho_{\text {core }}=\left[x_{A} \Delta \rho_{t(A)}+\left(1-x_{A}\right) \Delta \rho_{t(B)}\right] \cdot r_{T}
\end{gathered}
$$

onde $\Delta \rho_{h(A)}$ e $\Delta \rho_{h(B)}$ são os contrastes eletrônicos das cabeças polares e $\Delta \rho_{t(A)}$ e $\Delta \rho_{t(B)}$ são os contrastes eletrônicos das caudas, dados pelas equações Eq. 32 e Eq. 33. Redefinindo também os raios, tem-se:

$$
R_{\text {core }}=\left[\frac{x_{A} N_{a g g} V_{t(A)}+\left(1-x_{A}\right) N_{a g g} V_{t(B)}}{\frac{4}{3} \pi \varepsilon_{\text {core }}}\right]^{\frac{1}{3}}
$$

Da mesma forma é possível escrever que

$$
R_{t o t}=\left[\frac{x_{A} N_{a g g}\left(V_{t(A)}+V_{h(B)}\right)+\left(1-x_{A}\right) N_{a g g}\left(V_{t(A)}+V_{h(B)}\right)}{\frac{4}{3} \pi \varepsilon_{t o t}}\right]^{\frac{1}{3}}
$$

Usando-se como aproximação que a mistura entre os surfactantes A e B seja ideal, pode-se empregar a Teoria de Clint para misturas ideais de surfactantes [91] e escrever que:

$$
x_{A}=\frac{\tau c-c_{A}}{c-c_{B}-c_{A}}
$$

onde $c$ é a concentração total de surfactante, $\tau$ é a fração molar de A na amostra, $c_{A}$ e $c_{B}$ são as concentrações monoméricas de A e B, respectivamente, calculadas a partir de:

$$
\begin{gathered}
c_{A}=\frac{1}{2}\left\{(\Delta-c)+\left[(\Delta-c)^{2}+4 \tau c \Delta\right]^{\frac{1}{2}}\right\}\left(\frac{C M C_{B}}{C M C_{A}}-1\right) \\
c_{B}=\left(1-\frac{c_{A}}{C M C_{A}}\right) C M C_{B}
\end{gathered}
$$

Onde $\Delta=C M C_{B}-C M C_{A}$ e os parâmetros $C M C_{A}$ e $C M C_{B}$ são as concentrações críticas micelares de A e B, respectivamente. A expressão final da intensidade espalhada modelada será: 


$$
I(q)=S c \cdot \frac{c-C M C_{M}}{N_{a g g}} \cdot\left\{\left\langle F(\vec{q})^{2}\right\rangle+\langle F(\vec{q})\rangle^{2}[S(q)-1]\right\}+b a c k
$$

onde os termos $\left\langle F(\vec{q})^{2}\right\rangle$ e $\langle F(\vec{q})\rangle^{2}$ são dados pelas equações Eq. 18 e Eq. 20, respectivamente, e novamente $S(q)$ será escolhido de acordo com as características elétricas das partículas. O parâmetro $C M C_{M}$ é a concentração micelar crítica das micelas mistas. Algumas vezes fica difícil obtê-lo experimentalmente. Nesse sentido, assumindo novamente que a mistura dos surfactantes é ideal, a Teoria de Clint fornece [91]:

$$
\frac{1}{C M C_{M}}=\frac{\tau}{C M C_{A}}+\frac{1-\tau}{C M C_{B}}
$$

\subsubsection{Complexos proteína-surfactante}

O modelo que será usado para descrever os dados de SAXS referentes aos complexos proteínasurfactante estudados no Capítulo 4 considera que os complexos são micelas decoradas [40]. Nesse caso, o core é formado pelas cadeias carbônicas do surfactante e o shell é constituído pelas cabeças polares dos surfactantes e pela proteína que está distribuída sobre a superfície da micela (Figura 17).

\section{A)}

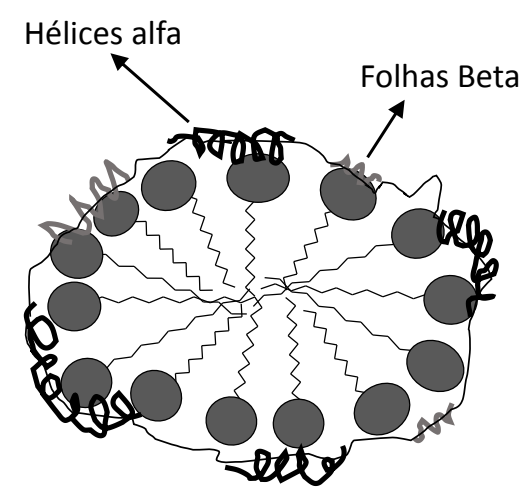

B)

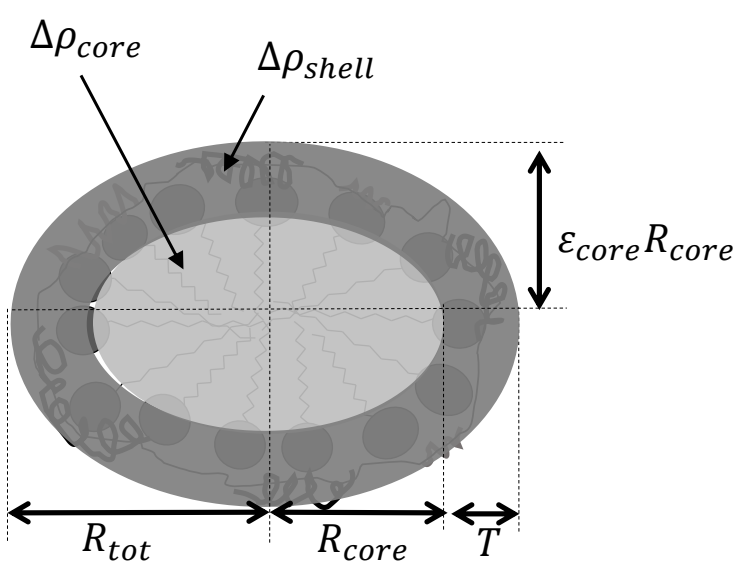

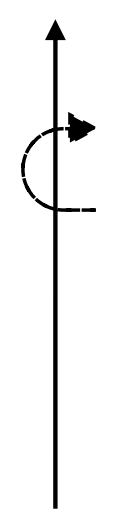

Figura 17: A) Esquema simplificado de uma micela decorada. B) Modelo usado para descrever a micela decorada, um elipsoide de revolução core-shell. A revolução se dá em torno eixo perpendicular ao eixo principal passando pelo centro do elipsoide. O significado de cada termo mostrado na figura encontra-se no texto. 
As equações básicas Eq. 18, Eq. 20 e Eq. 36 continuam válidas. Contudo, será necessário modificar alguns parâmetros que caracterizam o shell das micelas de maneira a incluir as informações da proteína. Assumindo que todas as proteínas do sistema formam complexos com as micelas, a massa de proteína por micela (g/micela) será:

$$
m_{\text {prot }}=\frac{c_{\text {prot }}}{n_{\text {mic }}}
$$

onde $c_{\text {prot }}$ é a concentração de proteína (em $\frac{\mathrm{g}}{\mathrm{cm}^{3}}$ ). Para proteínas, o constraste de comprimento de espalhamento por massa de proteína é $\Delta \rho_{m}=2,0 \times 10^{10} \frac{\mathrm{cm}}{\mathrm{g}}$ [92]. Dividindo esse resultado pelo raio clássico do elétron (raio de Thomson), $r_{T}=2,82 \times 10^{-13} \mathrm{~cm}$, teremos $\frac{\Delta \rho_{m}}{r_{T}}$, ou seja, a quantidade de elétrons por massa de proteína (em elétrons/g). Logo, o excesso de elétrons em cada micela devido à proteína será dada por (elétrons/micela):

$$
N_{e l(p r o t)}=\frac{\Delta \rho_{m}}{r_{T}} m_{\text {prot }}
$$

Assumindo que as proteínas permanecem na superfície da micela, o número total de elétrons na casca será:

$$
N_{e l(\text { shell })}=N_{a g g} V_{h} \Delta \rho_{h}+N_{e l(p r o t)}
$$

O volume total do complexo será:

$$
V_{t o t}=\frac{4}{3} \pi \varepsilon_{t o t} R_{t o t}^{3}
$$

O volume total da casca será:

$$
V_{\text {shell }}=V_{\text {tot }}-V_{\text {core }}
$$

Um parâmetro bastante útil é a fração molar de água no shell, calculado por:

$$
x_{w t}=\frac{V_{\text {shell }}-N_{\text {agg }} V_{H}-m_{\text {prot }} \bar{v}}{V_{\text {shell }}}
$$

onde $\bar{v}$ é o volume específico da proteína, que em geral é $0,72 \frac{\mathrm{cm}^{3}}{\mathrm{~g}}$ [40]. O novo contraste de comprimento de espalhamento o shell será: 


$$
\Delta \rho_{\text {shell }}=S c_{\text {shell }} \frac{N_{\text {el }(\text { shell })} \cdot r_{T}}{V_{\text {shell }}}
$$

onde $S c_{\text {shell }}$ é um fator de escala que corrige possíveis diferenças entre o $\Delta \rho_{\text {shell }}$ do sistema teórico e o experimental, levando em consideração também hidratação e possível presença de contra-íons no shell devido ao surfactante. Novamente, o modelo foi implementado em linguagem Fortran 77 com rotina de minimização baseada no método de Levenberg-Marquardt [85] e a execução dos programas levou um tempo da ordem de segundos.

\subsubsection{Lipossomas}

O forma de análise descrita a seguir será usado para a modelagem de dados de SAXS de lipossomas no Capítulo 5 e se baseia Método de Deconvolução Gaussiana [93], apresentado a seguir, e que permite lidar tanto com bicamadas simétricas quanto assimétricas.

A intensidade de espalhamento de um conjunto de bicamadas lipídicas é dada por [94]:

$$
I(q)=n \frac{P(q) \cdot S(q)}{q^{2}}
$$

que é semelhante à equação Eq. 16, onde o fator $q^{2}$ no denominador corresponde a uma correção para espalhadores altamente anisotrópicos em relação aos quais as dimensões transversais são muito maiores do que a perpendicular (como é o caso de sistemas planares e grandes vesículas). O fator de estrutura transversal para um sistema multilamelar, com periodicidade lamelar $D$, pode ser descrito pela Teoria de Caillé Modificada [95]:

$$
\begin{aligned}
S(q)=1+2 & \sum_{n=1}^{n=N-1}\left(1-\frac{n}{N}\right) \times \cos (n q D) \\
& \times \exp \left[-\left(\frac{D}{2 \pi}\right)^{2} q^{2} \eta \gamma\right](n \pi)^{-\left(\frac{D}{2 \pi}\right)^{2} q^{2} \eta}
\end{aligned}
$$

$\mathrm{Na}$ equação acima, $N$ representa o número de camadas correlacionadas na estrutura multicamada, $\gamma$ é a constante de Euler e $\eta$ é o parâmetro de Caillé. Esse parâmetro relaciona as constantes elásticas $\bar{B}$ e $K$ [95]: 


$$
\eta=\frac{\pi k_{B} T}{2 D^{2} \sqrt{\bar{B} K}}
$$

onde $K$ é o módulo de curvatura da membrana e $\bar{B}$ o módulo de compressibilidade à potencial químico constante. $\mathrm{O}$ parâmetro de Caillé é proporcional à flexibilidade das membranas. $\mathrm{O}$ parâmetro $D$, chamado periodicidade lamelar, pode ser relacionado com a espessura da bicamada $\delta_{m}$ e da camada aquosa $\delta_{w}$ por meio de $D=\delta_{m}+\delta_{w}$ (Figura 18A).

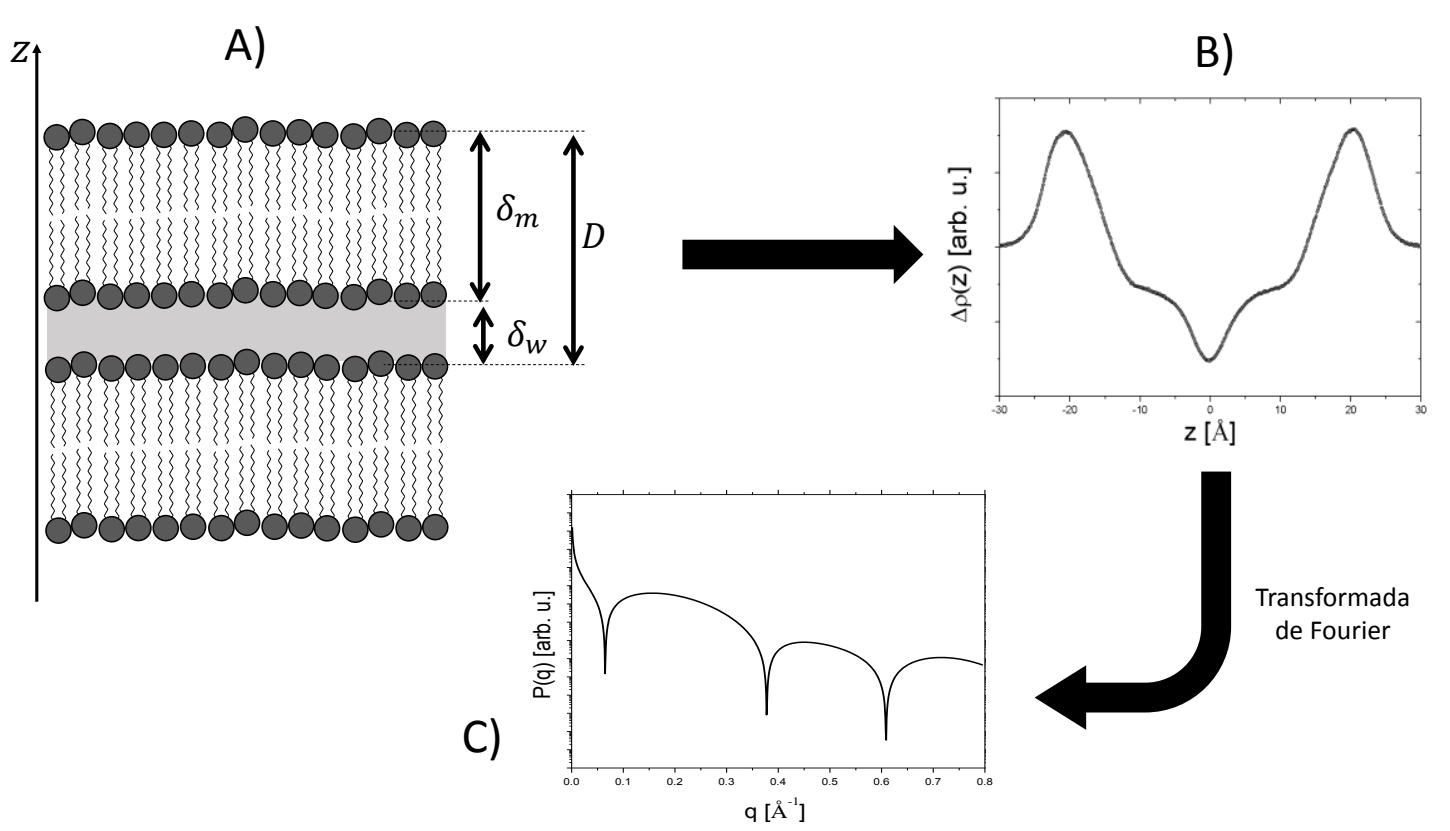

Figura 18: A) Esquema de duas bicamadas adjacentes de espessura $\delta_{m}$, separadas por uma cada aquosa de espessura $\delta_{w}$. A periodicidade lamelar $D$ é tal que $D=\delta_{m}+\delta_{w}$. B) Perfil de contraste de densidade eletrônica $\Delta \rho$ ao longo do eixo $z$, que é a direção perpendicular ao plano da membrana. C) Fator de forma $P(q)$ obtido por meio da Transformada de Fourier de $\Delta \rho$.

Conhecendo-se o perfil de contraste de densidade eletrônica $\Delta \rho$ ao longo da direção perpendicular ao plano de uma bicamada (Figura 18B) é possível se obter a função $P(q)$ uma vez que esta é a transformada de Fourier de $\Delta \rho$ (Figura 18C). Existem modelos que fazem uso de funções degrau para reconstruir o perfil eletrônico da bicamada. Contudo, uma descrição mais detalhada da modulação da densidade eletrônica pode ser obtida utilizando-se funções gaussianas (Figura 18B), visto que o perfil eletrônico apresentará variações mais suaves. 


\subsection{Bicamadas simétricas}

Para a construção de um perfil centrossimétrico, utiliza-se uma gaussiana central, na posição $z=0$, sendo que as demais estarão igualmente espaçadas e também espelhadas com respeito a $z=0$. A gaussiana central representa as caudas carbônicas que compõem a bicamada lipídica, enquanto as demais formam as cabeças polares. O perfil de densidade eletrônica será, então, descrito por

$$
\rho(z)=\sum_{n=1}^{n_{\max }} \frac{a_{n}\left[G_{s}\left(z, z_{n}, \sigma\right)+G_{s}\left(z,-z_{n}, \sigma\right)\right]}{1+\delta_{n 1}}
$$

onde $\delta_{n 1}$ é 1 para $n=1$ e 0 para $n=2,3, \cdots, n_{\text {máx }}$. O parâmetro $a_{n}$ representa a amplitude de cada gaussiana, as quais são dadas pela função $G_{S}$ :

$$
G_{s}\left(z, z_{n}, \sigma\right)=\frac{1}{\sigma \sqrt{2 \pi}} e^{-\frac{\left(z-z_{n}\right)^{2}}{2 \sigma^{2}}}
$$

cujo desvio padrão $\sigma$,

$$
\sigma=\frac{Z}{2 n_{\max } \sqrt{2 \ln 2}}
$$

e as posições $z_{n}$,

$$
z_{n}=2 \sigma(n-1)
$$

são todas pré-definidas em termos de $Z$, que possui relação com a espessura da bicamada $\delta_{m}$ (para o caso em que o perfil de densidade eletrônico é simétrico, $Z=\frac{\delta_{m}}{2}$ ). Como visto antes, a Transformada de Fourier da densidade eletrônica fornece a amplitude de espalhamento $F(q)$ (Eq. 12), a qual se relaciona com o fator de forma, $P(q)=\left\langle F(q)^{2}\right\rangle$. Para bicamadas centrossimétricas, a amplitude de espalhamento será dada por:

$$
F(q)=\sum_{n=1}^{n_{\max }} a_{n} F(q, n)
$$

onde: 


$$
F(q, n)=\sigma \sqrt{2 \pi} e^{-\frac{\sigma^{2} q^{2}}{2}} \cos \left(q z_{n}\right)
$$

\subsection{Bicamadas assimétricas}

O perfil de densidade eletrônico para bicamadas assimétricas será descrito por

$$
\rho(z)=\sum_{n=1}^{n_{\max }} a_{n} G_{s}\left(z, z_{n}, \sigma\right)
$$

onde $a_{n}$ ainda representa a amplitude de cada gaussiana, e a função $G_{s}$ é definida por Eq. 57, com $\sigma$ e $z_{n}$ dados por:

$$
\begin{gathered}
\sigma=\frac{Z}{n_{\max } \sqrt{2 \ln 2}} \\
z_{n}=\sigma(n-1)
\end{gathered}
$$

Para perfis assimétricos, é possível escrever que

$$
P(q)=\left\langle F(q)^{2}\right\rangle=\sum_{k, k^{\prime}}\left\{a_{k} a_{k^{\prime}} \sigma_{k} \sigma_{k^{\prime}} e^{-\frac{\left(\sigma_{k}^{2}+\sigma_{k^{\prime}}^{2}\right) q^{2}}{2}} \cos \left[q\left(z_{k}-z_{k^{\prime}}\right)\right]\right\}
$$

Assim como no caso anterior, $\sigma$ será assumido o mesmo para todas as gaussianas (diminuindo assim a quantidade de parâmetros livres no modelo), de maneira que $\sigma_{k}=\sigma_{k^{\prime}}$ e a equação anterior fica:

$$
P(q)=\left\langle F(q)^{2}\right\rangle=\sigma^{2} e^{-\sigma^{2} q^{2}} \sum_{k, k^{\prime}}\left\{a_{k} a_{k^{\prime}} \cos \left[q\left(z_{k}-z_{k^{\prime}}\right)\right]\right\}
$$

A expressão final de ajuste é dada por:

$$
I(q)=\frac{S c}{q^{2}}\left[P(q) \cdot S(q)+N_{d i f} P(q)\right]+b a c k
$$

onde $P(q)$ pode ser dado para uma bicamada simétrica ou assimétrica e $S(q)$ é dado por Eq. 54. O segundo termo $N_{\text {dif }} P(q)$ descreve o espalhamento difuso que pode surgir da presença de 
bicamadas simples no sistema. O parâmetro $S c$ é um fator de escala geral, e back é um parâmetro de background. 


\section{MICELAS MISTAS}

Neste capítulo serão apresentados os resultados da caracterização por SAXS do sistema surfactante-surfactante formado pela mistura entre os surfactantes SDS e Tween ${ }^{\circledR}$, os quais incluem forma, tamanho e quantificação da interação intermicelar (tanto para micelas carregadas quanto não carregadas).

\subsection{Introdução}

Como mencionado no Capítulo 2, surfactantes em solução aquosa e acima de sua concentração crítica micelar formam agregados de vários tipos, formas e tamanhos cujas características dependem de fatores relacionados a moléculas e de fatores relacionados ao meio [3]. Entre as técnicas usadas para a investigação desses sistemas, como tensão superficial, condutividade elétrica, fluorescência e microscopia eletrônica, estão as de espalhamento a baixo ângulo de luz (SLS), nêutrons (SANS) e de raios X (SAXS). Entre elas, SAXS é uma técnica conveniente para a caracterização estrutural de sistemas em solução aquosa [75] e, em particular, de sistemas de micelas mistas [91,96,97]. Entre os surfactantes modelo tipicamente utilizados nestes trabalhos está o SDS (Figura 19B), aniônico, cujas propriedades já foram extensivamente estudadas e que possui vasta aplicação em vários ramos da sociedade, desde higiene pessoal até processos químicos-petrolíferos [2,37,63], participando também de procedimentos científicos como na técnica de SDS-PAGE. Aproximadamente nas duas últimas décadas a atenção se voltou para a caracterização de surfactantes comerciais, entre eles o Tween ${ }^{\circledR}$ (Figura 19A), nãoiônico, que corresponde a uma série de surfactantes. Essa molécula anfifílica possui um polioxietileno sorbato na região polar (ao todo existem 20 grupos oxietilenos na molécula) enquanto a região apolar é formada por um ácido cujo tipo varia para cada tipo de Tween ${ }^{\circledR}$. Por exemplo, Tween ${ }^{\circledR} 20$ (T20) apresenta um ácido monolaurato, enquanto Tween ${ }^{\circledR} 40$ (T40) possui um ácido monopalmítico [54,55]. Surfactantes da série Tween ${ }^{\circledR}$ não apresentam toxicidade e são estáveis, sendo bastante utilizados como emulsificantes em produtos nutricionais, domésticos, científicos e farmacêuticos [13]. 
Micelas puras formadas por T20, T40 e T80 já foram estudadas por SAXS [98-100], mas até o presente momento as micelas constituídas por T60 ainda não foram caracterizadas por essa técnica. De maneira similar, micelas mistas formadas por SDS e Tween ${ }^{\circledR}$ já foram estudas por técnicas de condutimetria, tensão superficial e fluorescência [16,57,101], mas até o presente momento não existem trabalhos de caracterização estrutural por meio da técnica de SAXS. Nesse sentido, o objetivo deste trabalho é o de preencher essa lacuna, contribuindo com novas informações sobre esse sistema relativamente pouco estudado, ou refinando as informações estruturais já conhecidas na literatura para as micelas formadas por esses surfactantes.

A)

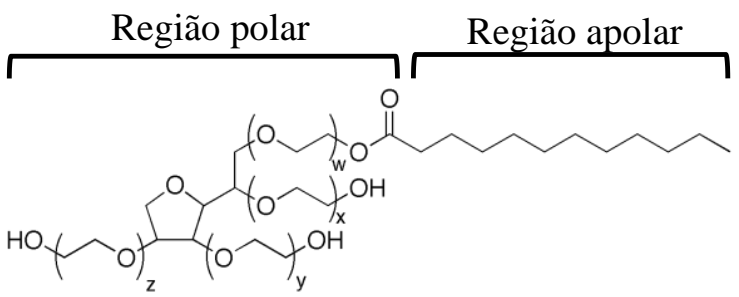

(TW20)

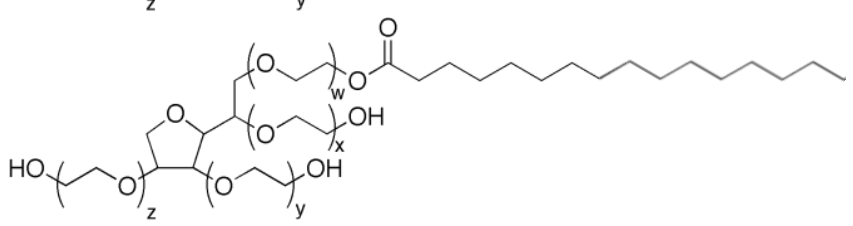

(TW40)

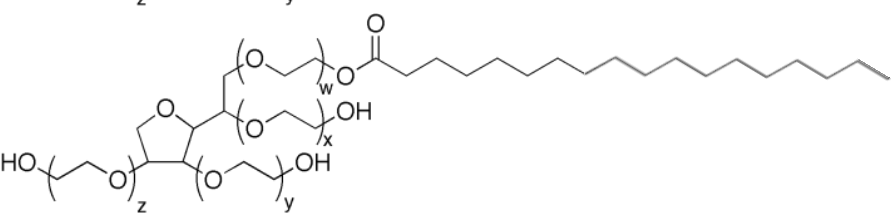

(TW60)

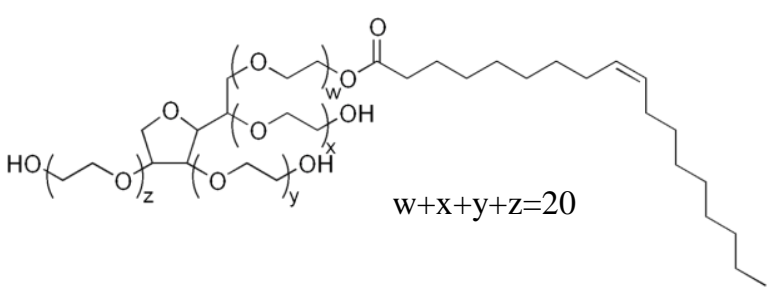

B)

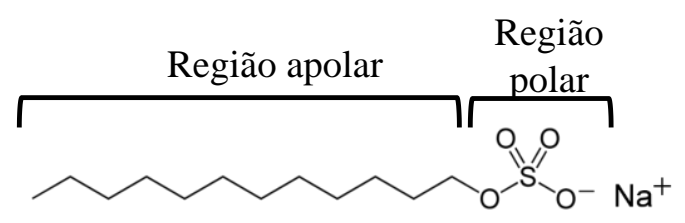

Figura 19: Estrutura molecular dos surfactantes Tween ${ }^{\circledR}$ (A) e SDS (B). 


\subsection{Resultados e Discussão}

A Figura 20A e Figura 21A mostram os dados experimentais de SAXS (símbolos abertos) para as micelas puras e mistas, respectivamente. Como descrito na seção Materiais do Capítulo 2, a concentração total de todas as amostras foi $50 \mathrm{mM}$, e SDS e Tween ${ }^{\circledR}$ foram misturados na razão molar 3:2.
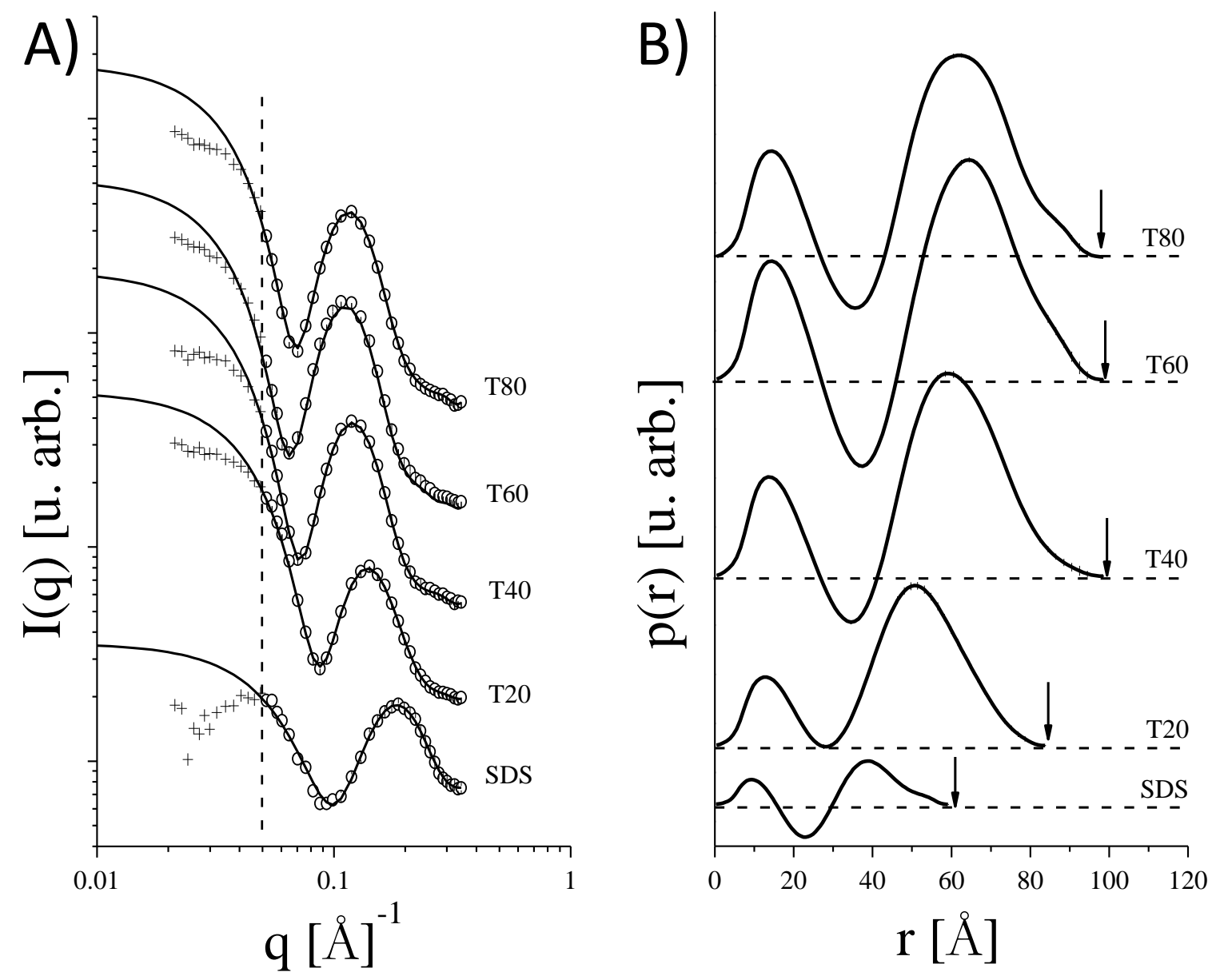

Figura 20: A) Dados experimentais de SAXS para as micelas puras (símbolos abertos), ajustados pelo procedimento IFT (linhas contínuas). Nos ajustes, os pontos atrás da linha vertical tracejada (na posição $q=$ $0,05 \AA^{-1}$ ), representados pelo símbolo de cruz, foram desconsiderados por terem relação com o fator de estrutura. B) Funções $p(r)$ obtidas a partir dos ajustes. As setas indicam os tamanhos máximos das partículas em solução.

É possível notar, em todas as curvas, a presença de um "bump" cuja posição $q$ varia de sistema para sistema. Para micelas puras de T40, T60 e T80 essa posição é de $q \sim 0,12 \AA^{-1}$, enquanto para T20, $q \sim 0,14 \AA^{-1}$. Já para SDS, $q \sim 0,18 \AA^{-1}$. Como foi visto no Capítulo 3 , esse bump possui relação inversa com o tamanho das micelas, de modo que é possível concluir, por essa análise qualitativa, que micelas de SDS são menores que as micelas de T20 que por sua vez são menores que as micelas de T40, T60 e T80. Pela similaridade na posição do bump, pode-se 
afirmar também que estas três últimas micelas possuem tamanhos próximos. Em relação às micelas mistas, a posição do bump diminui de $q \sim 0,17 \AA^{-1}$ (SDS:T20) para $q \sim 0,15 \AA^{-1}$ (SDS:T80), indicando que as micelas formadas por SDS:T80 são as maiores comparadas às micelas formadas por SDS:T20. As demais micelas (razões SDS:T40 e SDS:T60) possuem tamanhos intermediários.

É possível notar que a região inicial das curvas, para aproximadamente $q<0,05 \AA^{-1}$, possui um comportamento ora decrescente (para todas as curvas das micelas mistas e micela pura de SDS) ora crescente (micelas puras de T20, T40, T60 e T80) que está relacionado com a interação entre micelas e, consequentemente, com o fator de estrutura do sistema (seção Fundamentos Teóricos de SAXS, Capítulo 2).
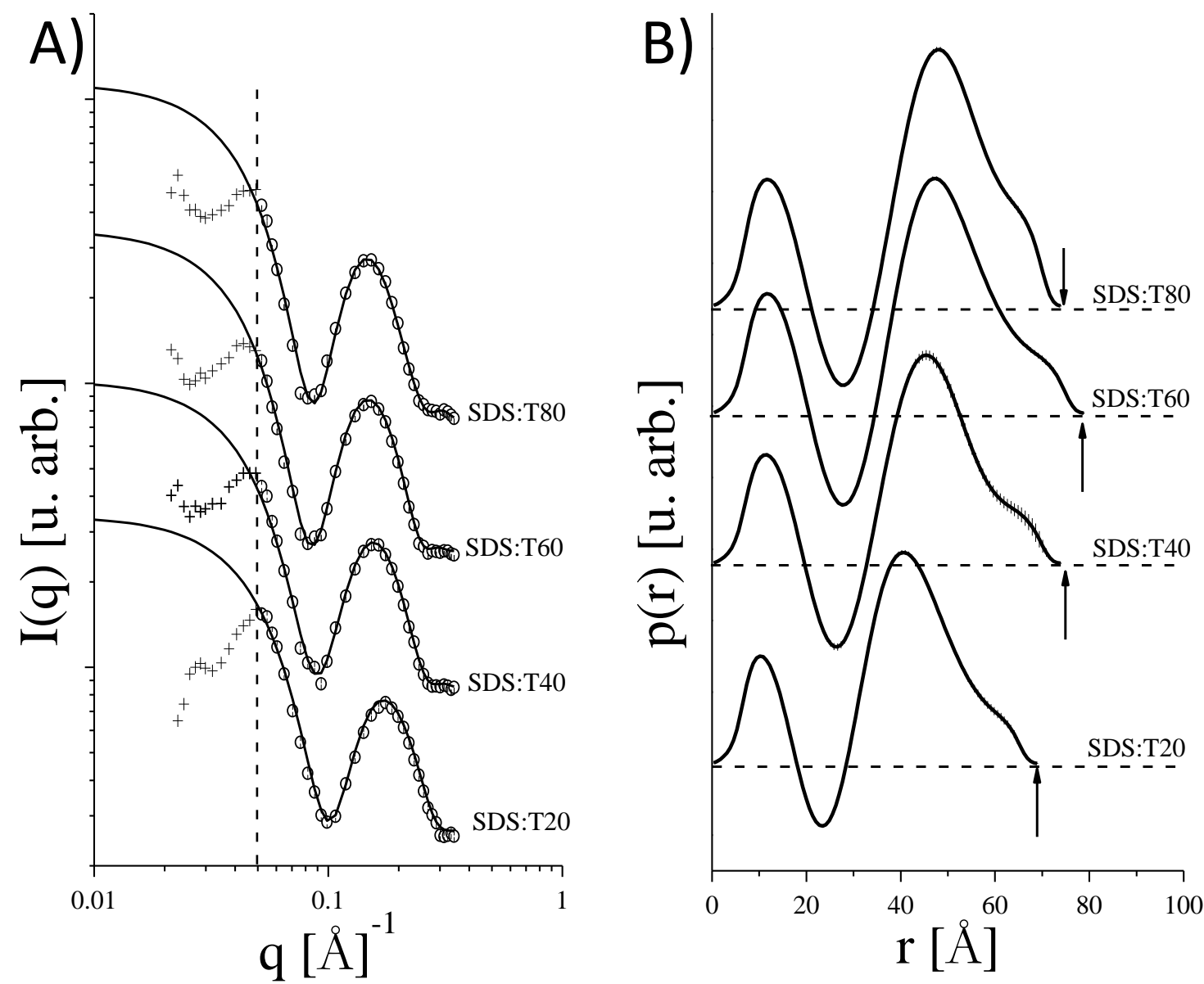

Figura 21: A) Dados experimentais de SAXS para as micelas mistas (símbolos abertos), ajustados pelo procedimento IFT (linhas contínuas). Nos ajustes, os pontos atrás da linha vertical tracejada (na posição $q=$ $0,05 \AA^{-1}$ ), representados pelo símbolo de cruz, foram desconsiderados por terem relação com o fator de estrutura. B) Funções $p(r)$ obtidas a partir dos ajustes. As setas indicam os tamanhos máximos das partículas em solução. 
Micelas de SDS possuem uma carga superficial por causa das cabeças carregadas (grupo sulfato) que são parcialmente neutralizadas pelos contra-íons de sódio correspondentes. Essa combinação iônica, acrescida da camada de solvatação, forma o shell das micelas. Os contraíons restantes encontram-se em solução, dissociados das micelas. Em geral utiliza-se o parâmetro grau de dissociação iônica $\alpha$ (seção Surfactantes e Micelas, Capítulo 2) para caracterizar esse efeito. Logo, essas micelas de SDS interagirão eletrostaticamente (de modo repulsivo) umas com as outras. Naturalmente, micelas mistas entre SDS e Tween ${ }^{\circledR}$ também possuirão carga elétrica por conta, novamente, dos grupos sulfato e contra-íons de sódio. Portanto, em ambos os casos (micelas de SDS e micelas mistas SDS:Tween ${ }^{\circledR}$ ), o comportamento decrescente no começo da curva de espalhamento reflete a interação eletrostática de repulsão entre os agregados. Já as micelas puras de Tween ${ }^{\circledR}$ não possuem carga elétrica superficial uma vez que moléculas de Tween ${ }^{\circledR}$ são neutras. Logo, a interação não é eletrostática, mas, dependendo da concentração, pode ser do tipo esferas rígidas, por exemplo. Essa diferença no tipo de interação, que é traduzida também por um fator de estrutura, possui efeito sobre o início da curva, que é decrescente. Dessa forma, a modelagem dos dados experimentais levará em consideração esse fato a fim de descrever corretamente o comportamento de toda a curva experimental.

A análise inicial das curvas de SAXS foi realizada com a modelagem indireta via procedimento IFT (seção Fundamentos Teóricos de SAXS, Capítulo 2). Embora as curvas experimentais claramente indiquem, como discutido anteriormente, a presença da interação entre as partículas, optou-se por não utilizar o procedimento GIFT (Generalized IFT, [102]), que permite lidar com sistemas onde os efeitos de concentração são relevantes e possibilita a determinação numérica do fator de forma e de estrutura bem como a função $p(r)$. Isso se deve ao fato de que, nessa etapa de análise por GIFT, seria necessário assumir um modelo de interação, por exemplo de esferas rígidas ou de partículas carregadas, a fim de ajustar os dados. Como apontado em [103], mesmo que os ajustes pelo procedimento GIFT sejam satisfatórios, valores dos parâmetros do fator de estrutura considerados pelo usuário podem não possuir significado físico, cabendo portanto ao usuário discernir, com base no seu conhecimento sobre o sistema, se os resultados obtidos são, de fato, satisfatórios. Portanto, mesmo que GIFT seja aplicável neste caso, optouse por utilizar as análises IFT, que ainda fornecerão insights sobre forma e tamanho das partículas, e deixar as considerações sobre o fator de estrutura para a modelagem direta dos dados. 
Os ajustes IFT dos dados experimentais de micelas puras e mistas estão mostrados na Figura 20A e Figura 21A (linhas contínuas). A influência dos efeitos das interações entre as partículas foi eliminado desconsiderando-se os pontos experimentais a baixo ângulo [40] (nas figuras esses pontos foram representados pelo símbolo de cruz). Por meio desses ajustes, que são satisfatórios, obtêm-se as funções $p(r)$, mostradas na Figura 20B e Figura 21B. Como é possível observar, as funções $p(r)$ apresentam "oscilações" características de partículas do tipo core-shell. As setas na figura indicam os tamanhos máximos das partículas. Micelas de SDS possuem um tamanho máximo de $\sim 60 \AA$, compatível com resultados recentes [45,104,105], enquanto as micelas de T20 têm um tamanho de $\sim 85 \AA$, comparável com resultados de medidas de espalhamento dinâmico de luz ${ }^{7}$. As micelas de T40, T60 e T80 possuem uma dimensão máxima similar de $\sim 100 \AA$, corroborando assim as conclusões feitas antes usando-se as informações relativas à posição do bump de cada curva. Essa distância também é compatível com informações da literatura [99,100]. De maneira geral, micelas formadas por Tween ${ }^{\circledR}$ são maiores do que aquelas formadas por SDS. A diferença de até $40 \AA ̊$ em tamanho é bastante apreciável e pode ser associada à junção de dois fatores:

i. Como as moléculas de Tween ${ }^{\circledR}$ são não-iônicas, o número de agregação $N_{a g g}$ tende a ser maior porque não existem interações de repulsão elétrica como no caso dos surfactantes iônicos [3,5];

ii. De acordo com a representação espacial dos átomos que compõem a molécula, nota-se que moléculas de Tween ${ }^{\circledR}$ ocupam um espaço maior do que as de SDS. Como consequência da informação anterior sobre o número de agregação, é esperado que as micelas do surfactante não-iônico sejam, em média, maiores do que as formadas pelo surfactante iônico.

Ainda sobre os sistemas puros, comparando-se as funções $p(r)$ da série Tween ${ }^{\circledR}$, nota-se que o tamanho da micela de T40 é maior do que de T20, ao passo que aquelas constituídas por T40, T60 e T80 possuem tamanhos próximos. Isso pode ser explicado pelo fato de que T20 possui a cadeia hidrocarbonada mais curta (11 carbonos) comparado aos outros $(15,17,17$, respectivamente para $\mathrm{T} 40, \mathrm{~T} 60$ e $\mathrm{T} 80$ ).

\footnotetext{
${ }^{7}$ https://www.malvernpanalytical.com/en/learn/knowledge-center/applicationnotes/AN101104SurfactantMicelleCharacterization.html
} 
Em se tratando dos sistemas mistos, micelas de SDS:T20 possuem dimensão máxima $\sim 70 \AA$, micelas de SDS:T40 e SDS:T80 possuem tamanho de $\sim 75 \AA$, enquanto para SDS:T60, a dimensão máxima é $~ 80 \AA ̊$. Assim, grosso modo, as micelas mistas possuem tamanhos intermediários entre aqueles das micelas puras, compatível com observações da literatura para sistemas similares [91].

Foram realizados testes considerando-se os fatores de forma obtidos com os ajustes IFT para micelas de SDS e Tween ${ }^{\circledR}$. Para uma amostra formada hipoteticamente por micelas individuais de SDS e de Tween ${ }^{\circledR}$, a intensidade espalhada por esse sistema será simplesmente a combinação linear das intensidades espalhadas pelas micelas individuais. Utilizando-se esse "modelo", observou-se que os ajustes das curvas experimentais de micelas mistas não foram satisfatórios, corroborando assim a tese de que a mistura entre SDS e de Tween ${ }^{\circledR}$ forma micelas mistas.

Com as informações obtidas até aqui, procedeu-se com a modelagem direta dos dados. Observou-se que eles são bem descritos por um modelo que considera que as micelas (puras e mistas) são elipsoides de revolução core-shell, sendo o core formado pelas caudas apolares dos surfactantes, e o shell sendo constituído pelas cabeças polares juntamente com contra-íons e as moléculas de água da camada de solvatação (seção Modelos Teóricos de SAXS, Capítulo 2). A interação intermicelar, que causa o comportamento crescente ou decrescente dos pontos experimentais a baixo ângulo da curva de SAXS, como discutido anteriormente, foi modelada por um fator de estrutura de esferas rígidas [89], para o caso das micelas puras não carregadas de Tween ${ }^{\circledR}$, e por um fator de estrutura de esferas carregadas [90] para os demais casos em que as micelas são carregadas. Assume-se no modelo que todas as micelas são mistas. Essa hipótese simplificadora reduz a quantidade de parâmetros livres, aumentando assim a estabilidade do programa de ajuste. Além disso, como o sistema de micelas mistas é carregado, a configuração mais provável é aquela em que SDS e Tween ${ }^{\circledR}$ estão distribuídos de maneira aproximadamente uniforme por toda micela, sem reforço de quantidade de apenas um surfactante em alguma parte da micela [91], embora existam casos na literatura em que isso não se aplica totalmente [106]. Esse mesmo modelo foi utilizado de maneira bem-sucedida para outros sistemas compostos por uma mistura binária entre surfactantes [91,96,97,107].

A modelagem direta dos dados consistiu de duas etapas: Modelagem das micelas puras e, somente depois, modelagem das micelas mistas. Essa abordagem é conveniente porque permite testar o modelo e comparar os resultados iniciais com aqueles disponíveis na literatura bem como determinar a informação sobre volume da cabeça do Tween ${ }^{\circledR}, V_{h(T W)}$, de fundamental 
importância para os cálculos de densidade eletrônica [75,85,104]. Todos os surfactantes da série Tween ${ }^{\circledR}$ possuem a mesma estrutura molecular na cabeça polar (Figura 19). Logo, analisandose as micelas de Tween ${ }^{\circledR}$, é possível determinar essa informação com o modelo de ajuste. Uma vez calculado, esse parâmetro $\left(V_{h(T W)}\right)$ poderá depois ser empregado na modelagem das micelas mistas. Outras informações usadas no modelo estão apresentadas na Tabela 1.

Tabela 1: Informações moleculares dos surfactantes. Massa molecular (MW), concentração micelar crítica (CMC) determinadas entre $23{ }^{\circ} \mathrm{C}$ e $25^{\circ} \mathrm{C}$, em água deionizada, volume da cabeça polar $\left(V_{h}\right)$ e da cauda apolar $\left(V_{t}\right)$, número de elétrons na cabeça polar $\left(N_{e l_{h}}\right)$ e na cauda apolar $\left(N_{e l_{t}}\right)$.

\begin{tabular}{cccccccc}
\hline \hline \multirow{2}{*}{ Surfactante } & $\mathrm{MW}^{\mathrm{a}}[\mathrm{g} / \mathrm{mol}]$ & $\mathrm{CMC}[\mathrm{mM}]$ & $V_{h}\left[\AA^{3}\right]$ & $V_{t}\left[\AA^{3}\right]$ & $N_{e l_{h}{ }^{\mathrm{c}}}$ & $N_{e l_{t}{ }^{\mathrm{c}}}$ \\
\hline \hline & 20 & 1227,5 & $0,058[55]$ & $1667^{\mathrm{b}}$ & $324[108]$ & 581 & 89 \\
\cline { 2 - 8 } & 40 & 1283,6 & $0,0361[54]$ & $1667^{\mathrm{b}}$ & $432[108]$ & 581 & 121 \\
\cline { 2 - 8 } & 60 & 1311,9 & $0,0144[54]$ & $1667^{\mathrm{b}}$ & $487[108]$ & 581 & 137 \\
\cline { 2 - 8 } & 80 & 1309,7 & $0,0126[54]$ & $1667^{\mathrm{b}}$ & $460[108]$ & 581 & 135 \\
\hline \hline & & 288,37 & $8,2[57]$ & $61[109]$ & $355[109]$ & $59^{\mathrm{d}}$ & 97 \\
\hline \hline
\end{tabular}

${ }^{\mathrm{a}}$ Informação disponível no website do fornecedor.

${ }^{\text {b}}$ Valor típico obtido a partir ajuste dos dados de SAXS para as micelas puras.

${ }^{c}$ Valores obtidos a partir da composição química das moléculas.

${ }^{\mathrm{d}}$ Valores obtidos considerando-se o contra-íon $\mathrm{Na}^{+}$.

Os ajustes dos dados de micelas puras com o modelo de elipsoide de revolução core-shell estão mostrados na Figura 22A (linhas contínuas). Como é possível observar, eles são satisfatórios em toda a região de $q$ estudada. Os valores obtidos para os parâmetros do modelo estão mostrados na Tabela 2.

O número de agregação $N_{a g g}$ para a micela de SDS possui uma boa concordância com valores da literatura obtidos por análises de SANS, SAXS e condutimetria [40,67,110]. Já as micelas de T20, T40, T60 e T80 apresentam um valor de $N_{a g g}$ até $30 \%$ mais alto do que aqueles obtidos por medidas de densidade [54,55]. Contudo, deve ser mencionado que a análise feita nesses últimos trabalhos assume que as micelas de Tween ${ }^{\circledR}$ são esféricas, o que não é verdade tendo em vista os valores de anisotropia $\varepsilon$ observados, indicando que as micelas, inclusive as de SDS, são prolatas $(\varepsilon>1)$, conclusões estas condizentes com observações feitas para micelas de SDS 
[40,110] e para micelas de T20 e T80 [98]. Esse fato pode gerar um desvio apreciável no cálculo do volume micelar.
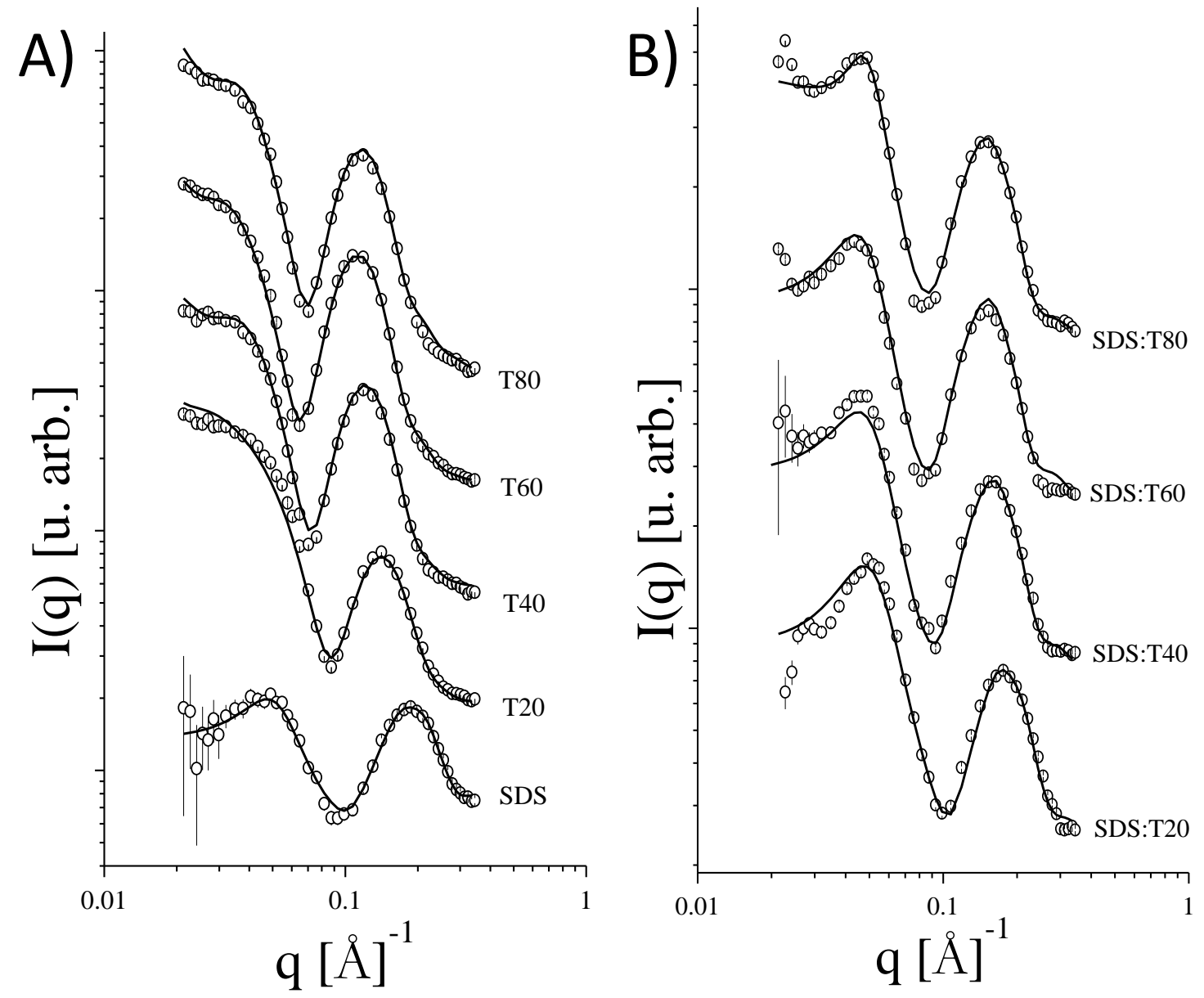

Figura 22: A) e B) correspondem aos dados experimentais (símbolos abertos) para as micelas puras e mistos, respectivamente, ajustados pelo modelo de elipsoide de revolução core-shell (linha contínua).

É interessante mencionar que os valores de anisotropia obtidos para as micelas da série Tween ${ }^{\circledR}$ são compatíveis entre si dentro das barras de erro. Como este parâmetro possui relação com a forma das partículas, pode-se então afirmar que as micelas do surfactante não-iônico possuem um formato similar, conclusões compatíveis com a análise inicial por IFT. Além disso, foi observada uma proporcionalidade entre $N_{a g g}$ e o comprimento da cauda do Tween ${ }^{\circledR}$, de modo que o aumento no comprimento da cauda gera um aumento no número de agregação, compatível com observações da literatura [111]. Adicionalmente, como T40/T60/T80 possuem comprimentos de cauda parecidos $\left(15,17\right.$ e 17 carbonos, respectivamente), os valores de $N_{a g g}$ são próximos. Apesar disso, observando-se a estrutura de T60 e T80 (Figura 19), nota-se a 
presença de uma ligação dupla entre carbonos na cauda apolar do T80. Isso provavelmente se reflete na diferença entre os números de agregação encontrados para T60 e T80 (75 e 63, respectivamente), uma vez que a ligação dupla reduz o CMC de T80 comparado ao T60 ([112] e Tabela 1) e, consequentemente, reduz o número de agregação [111].

Tabela 2: Valores dos parâmetros número de agregação $\left(N_{a g g}\right)$, anisotropia $(\varepsilon)$, volume da cabeça polar do Tween ${ }^{\circledR}$ $\left(V_{h(T W)}\right)$, raio de esfera rígida $\left(R_{H S}\right)$, fração volumétrica de micelas $(\phi)$ e carga elétrica superficial para micelas carregadas $(Z)$ obtidos a partir do ajuste dos dados experimentais das micelas puras. As incertezas dos valores nos últimos algarismos significativos, quando existem, estão mostradas entre parêntesis.

\begin{tabular}{ccccccc}
\hline Amostra & $N_{\text {agg }}$ & $\varepsilon$ & $V_{h(T W)}\left[\AA^{3}\right]$ & $R_{H S}[\AA]$ & $\phi$ & $Z[\mathrm{e}]$ \\
\hline \hline SDS & $54(1)$ & $1,44(15)$ & ----- & $16,5(8)$ & $0,00287(32)$ & $23,6(7)$ \\
T20 & $44(3)$ & $1,65(21)$ & $1651(3)$ & $23,2(3)$ & $0,00646(40)$ & ----- \\
T40 & $64(7)$ & $1,57(16)$ & $1674(5)$ & $27,5(3)$ & $0,0111(14)$ & ----- \\
T60 & $75(1)$ & $1,59(18)$ & $1668(2)$ & $29,0(2)$ & $0,0121(12)$ & ----- \\
T80 & $63(3)$ & $1,64(25)$ & $1676(6)$ & $26,9(5)$ & $0,0107(11)$ & ----- \\
\hline \hline
\end{tabular}

Os valores obtidos para o parâmetro volume da cabeça polar do Tween ${ }^{\circledR}\left(V_{h(T W)}\right)$ variam entre $1651 \AA^{3}$, para T20, e $1676 \AA^{3}$, para T80, mostrando boa concordância entre si e compatíveis com a expectativa de que o volume da cabeça polar deve ser idealmente o mesmo para todos os surfactantes da série trabalhados aqui. Os valores encontrados estão de acordo com aqueles obtidos por estimativas considerando o volume total $V=V_{t}+V_{h}$ da molécula de T80, obtido por dados de volume parcial específico, e do volume da cauda. Os valores estimados são $1638 \AA^{3}$ (considerando-se as referências [54,98]) e $1694 \AA^{3}$ (considerando-se as referências $[56,98])$. Nas análises de micelas mistas será usado o valor $V_{h(T W)}=1667 \AA^{3}$, obtido pela média aritmética simples dos valores de $V_{h(T W)}$ mostrados na Tabela 2.

Avaliando-se os parâmetros do fator de estrutura, nota-se que o raio de esfera rígida $R_{H S}$ para o SDS (comparável com valores da literatura [107]) é menor do que para os surfactantes Tween ${ }^{\circledR}$. Essa constatação pode ser atribuída ao fato das micelas de Tween ${ }^{\circledR}$ serem até, $40 \AA$ maiores (em termos da dimensão máxima) que as micelas de SDS, de acordo com as análises anteriores de IFT. Os valores de fração volumétrica $\phi$ podem ser relacionados com a densidade 
de micelas em solução, $n_{m i c}$, que corresponde ao fator $\frac{c-C M C}{N_{a g g}}$ da Eq. 36 e Eq. 44, e com o volume total da molécula de surfactante $V$, por meio de $\phi=n_{\text {mic }} V$ [107]. A diferença entre os valores de $\phi$ apresentados na Tabela 2 e aqueles estimados por meio das informações experimentais e moleculares (Tabela 1) usadas foi menor que 10\%. Para o caso da micela de SDS, como mencionado anteriormente, existe uma carga superficial devido ao efeito da dissociação iônica do contra-íon $\mathrm{Na}^{+}$. Essa carga, representada por $Z$ e expressa em quantidade de elétrons, está vinculada ao grau de dissociação iônica $\alpha$ por meio de $\frac{Z}{N_{a g g}}$ [107]. Nesse caso, obteve-se $\alpha \cong 0,44$. Nas condições utilizadas neste trabalho, reporta-se na literatura que valores típicos de $\alpha$ para as micelas de SDS estão entre $\sim 0,30$ [57] e 0,40 [113]. Mesmo ligeiramente elevado, o valor de $\alpha$ encontrado é razoável e provavelmente será mais próximo daqueles da literatura caso sejam levados em conta os erros experimentais e/ou de cálculo. É importante mencionar que o parâmetro força iônica $(I)$ foi mantido fixo e igual à $10 \mathrm{mM}$ durante todos os ajustes que envolveram sistemas carregados (micelas de SDS e micelas mistas).

Tabela 3: Valores dos parâmetros número de agregação $\left(N_{a g g}\right)$, anisotropia $(\varepsilon)$, raio de esfera rígida $\left(R_{H S}\right)$, fração volumétrica de micelas $(\phi)$ e carga elétrica superficial para micelas carregadas $(Z)$ obtidos a partir do ajuste dos dados experimentais das micelas mistas. Os parâmetros fração molar de SDS na micela $\left(x_{S D S}\right)$ e concentração micelar crítica da micela mista $\left(C M C_{M}\right)$ foram obtidos pela Teoria de Clint para misturas ideais e foram mantidos fixos nos ajustes. As incertezas dos valores nos últimos algarismos significativos, quando existem, estão mostradas entre parêntesis.

\begin{tabular}{cccccccc}
\hline \hline Amostra & $N_{a g g}$ & $\varepsilon$ & $x_{S D S}{ }^{\mathrm{a}}$ & $\mathrm{CMC}_{\mathrm{M}}^{\mathrm{a}}[\mathrm{mM}]$ & $R_{H S}[\AA]$ & $\phi$ & $Z[\mathrm{e}]$ \\
\hline \hline SDS:T20 & $44(1)$ & $1,52(10)$ & 0,560 & 0,143 & $19,58(2)$ & $0,00448(22)$ & $20,5(2)$ \\
SDS:T40 & $45(2)$ & $1,49(21)$ & 0,560 & 0,090 & $20,30(8)$ & $0,0104(21)$ & $20,1(2)$ \\
SDS:T60 & $45(1)$ & $0,57(19)$ & 0,560 & 0,034 & $28,74(5)$ & $0,0289(13)$ & $18,5(3)$ \\
SDS:T80 & $45(1)$ & $0,49(17)$ & 0,560 & 0,031 & $29,39(5)$ & $0,0321(10)$ & $15,6(2)$ \\
\hline \hline
\end{tabular}

${ }^{a}$ Valores mantidos fixos durante os ajustes.

Para micelas puras, portanto, a aplicação do modelo de elipsoide de revolução core-shell no ajuste dos dados experimentais resultou em parâmetros cujos valores são coerentes com observações presentes na literatura. Assim, ele foi usado para também caracterizar as micelas 
mistas formadas por SDS e Tween ${ }^{\circledR}$. Os ajustes encontram-se na Figura 22B e mostraram-se satisfatórios em todo intervalo de $q$ estudado. Os valores dos parâmetros obtidos encontram-se na Tabela 3.

A fração de $\operatorname{SDS}\left(x_{S D S}\right)$ nas micelas mistas bem como a sua concentração micelar crítica $\left(C M C_{M}\right)$ foram calculadas utilizando-se a Teoria de Clint assumindo que a mistura entre SDS e Tween ${ }^{\circledR}$ seja ideal (ver seção Modelos Teóricos de SAXS, Capítulo 2). Ambos os valores foram deixados fixos durante o processo de ajuste.

Observa-se na Tabela 3 que os valores de $N_{a g g}$ são relativamente menores que aqueles encontrados para as micelas puras (Tabela 2). Isso provavelmente possui relação com a presença de SDS na micela mista, tornando-a carregada. Como observado na literatura, por causa da repulsão eletrostática entre os monômeros, $N_{a g g}$ é, em geral, menor para micelas formadas por surfactantes iônicos do que aquelas constituídas puramente por surfactantes nãoiônicos [3,65]. Esse fato foi constatado também para outros sistemas compostos de uma mistura entre surfactantes iônicos e não-iônicos [114]. Curiosamente, o valor de $N_{a g g}$ é o mesmo (dentro das barras de erro) para as micelas de SDS:T40, SDS:T60 e SDS:T80. Isso provavelmente é reflexo de dois fatores:

i) A cabeça polar é exatamente a mesma para os três surfactantes não-iônicos, de maneira que o grupo sulfato interagirá de maneira similar nos três casos.

ii) As caudas apolares de T40, T60 e T80 são semelhantes entre si, tanto em comprimento quanto em composição, fazendo com que a interação entre as caudas apolares do SDS com o surfactante iônico seja, novamente, similar nos três casos.

Aparentemente a dupla ligação de carbono na cauda do T80 não possui influência sobre o número de agregação da micela mista. A mistura SDS+ Tween ${ }^{\circledR}$ possui a característica, portanto, de formar micelas com $N_{a g g}$ menor do que os valores de $N_{a g g}$ para as micelas puras de T20, T40, T60 e T80. Contudo, de acordo com os valores da Tabela 3, esses novos valores de $N_{a g g}$ para as micelas mistas são menores do que aqueles para as micelas puras de SDS. Esse fato provavelmente ilustra a influência do volume da cabeça polar do Tween ${ }^{\circledR}$ nos complexos: Como o espaço ocupado por ela é $\frac{1667 \AA^{3}}{61 \AA^{3}} \sim 30$ vezes maior que a cabeça de SDS, a estabilização elétrica do agregado formado não precisa, necessariamente, acontecer por conta dos contra-íons $\mathrm{Na}^{+}$. Ao mesmo tempo, é possível que esses contra-íons encontrem alguma dificuldade para "penetrar" a superfície do shell a fim de neutralizarem os íons sulfato. Logo, a micela mista 
pode ser tão carregada quanto uma micela de SDS pura. Essa hipótese é corroborada pelo parâmetro $Z$ que, associado ao valor de $N_{a g g}$, fornece os valores de $\alpha$ de $\sim 0,47, \sim 0,45, \sim 0,42$ e 0,35 para as micelas mistas de SDS:T20, SDS:T40, SDS:T60 e SDS:T80, respectivamente. A diminuição dos valores do parâmetro $Z$ pode ter relação com o fato de micelas de SDS:T20 e SDS:T40 serem prolatas $(\varepsilon>1)$ enquanto aquelas formadas por SDS:T60 e SDS:T80 serem oblatas $(\varepsilon<1)$. Essa transição já foi observada na literatura para alguns sistemas envolvendo uma mistura de surfactantes de classes diferentes [115,116] e aparentemente pode ser desencadeada principalmente pela assimetria entre os comprimentos da cadeia apolar dos constituintes da micela mista [117]. De fato, para os casos da mistura SDS:T60 e SDS:T80, a diferença entre as cadeias polares é maior (5 carbonos) do que nas outras misturas (1 a 3 carbonos). Adicionalmente, a alteração na geometria da partícula de prolata para oblata pode acabar favorecendo a penetração de contra-íons no shell, o que explicaria a diminuição da carga $Z$ para as misturas SDS:T60 e SDS:T80, uma vez que pode influenciar grandemente a disposição dos monômeros que a compõem [106]. Essa alteração na forma se reflete diretamente nos valores de $R_{H S}$, que apresentam um comportamento bem distinto em cada situação: As micelas prolatas apresentam $R_{H S} \sim 20 \AA$, enquanto para as oblatas, $R_{H S} \sim 30 \AA$. Por fim, da mesma maneira que antes, a diferença entre os valores de $\phi$ apresentados na Tabela 3 e aqueles estimados por meio das informações experimentais e moleculares (Tabela 1) usadas foi menor que $10 \%$, o que demonstra, além do exposto acima, a aplicabilidade do modelo para esse caso de estudo.

\subsection{Conclusão}

Neste trabalho foi realizada a caracterização de micelas puras formadas pelo surfactante modelo SDS, aniônico, e daquelas formadas pelos surfactantes comerciais da série Tween ${ }^{\circledR}$, nãoiônicos. A diferença entre T20, T40, T60 e T80 está na cauda apolar, que possui 11, 15, 17 e 17 carbonos, respectivamente, uma vez que a cabeça polar é a mesma em todos os casos. Seu volume, em torno de $1667 \AA^{3}$, foi determinado pelas análises de SAXS e é compatível com estimativas feitas usando-se valores da literatura. Além disso, as micelas mistas obtidas por meio da mistura de SDS com T20/T40/T60/T80 na razão molar 3:2 também foram caracterizadas. Pela análise inicial dos dados de SAXS pelo procedimento IFT concluiu-se que todas as micelas, puras e mistas, correspondem a partículas do tipo core-shell. Micelas de SDS 
possuem um tamanho típico máximo de $\sim 60 \AA$ A enquanto aquelas formadas por Tween ${ }^{\circledR}$ podem chegar a ter $\sim 100$ Å. Já as micelas mistas possuem, em geral, tamanhos intermediários entre $\sim 70 \AA ̊$ e $\sim 80$ Å. Utilizando-se um modelo de elipsoide de revolução core-shell para representar ambas micelas puras e mistas, foi possível ajustar os dados experimentais de maneira satisfatória e, com isso, obter informações sobre forma e tamanho das partículas em solução. Micelas de SDS são prolatas, com número de agregação médio de $\sim 54$, com carga superficial tal que o grau de dissociação iônica é $\sim 0,44$. As micelas de Tween ${ }^{\circledR}$, neutras, também se apresentaram prolatas, possuindo número de agregação tipicamente maior, entre $\sim 60$ e $\sim 80$, exceto para o caso de T20, que apresentou um valor de $\sim 45$ para esse parâmetro. Já as micelas mistas são carregadas eletricamente, com o grau de ionização variando entre $\sim 0,35$ e $\sim 0,50$, de modo que algumas são inclusive mais carregadas que as micelas puras de SDS. Isso provavelmente está associado com o grande volume da cabeça do Tween ${ }^{\circledR}$, que ajuda na estabilização elétrica do agregado, dispensando parcialmente a presença dos contra-íons, ao mesmo tempo que pode dificultar a ação dos contra-íons sobre as cabeças carregadas do SDS. Diferentemente das micelas puras, as micelas mistas se mostraram prolatas para os casos SDS:T20 e SDS:T40 e oblatas para os casos SDS:T60 e SDS:T80. Essa transição de forma provavelmente possui relação com a diferença entre os comprimentos das cadeias apolares dos constituintes micelares. Ao mesmo tempo, esse fenômeno pode estar associado com a maior penetração de contra-íons no shell das micelas oblatas SDS:T60 e SDS:T80, explicando os valores relativamente menores de grau de dissociação comentado antes. As análises feitas aqui para o sistema SDS- Tween ${ }^{\circledR}$ permitiram a obtenção de informações consistentes com aquelas previamente estabelecidas na literatura e outras totalmente novas, segundo nosso conhecimento, relacionadas à caracterização das micelas mistas por meio da técnica de SAXS. 


\section{PROTEÍNAS - SURFACTANTES}

Neste capítulo serão apresentados os resultados para a caracterização por ITC, SAXS e CD do sistema proteina-surfactante. Como será visto, a estratégia de combinar informações oriundas das três técnicas permitiu, por meio de uma análise consistente e sistemática, acompanhar a desnaturação das proteínas lisozima e alfa-lactalbumina sob a ação do surfactante SDS.

\subsection{Estudo de caso: Lisozima e SDS ${ }^{8}$}

\subsubsection{Introdução}

Lisozima, também chamada de muramidase, é uma enzima globular antimicrobiana encontrada em diversos organismos, como pássaros, mamíferos, plantas, bactérias, etc. Particularmente no ser humano, ela é encontrada nas lágrimas, no muco nasal e em secreções gástricas [118]. A sua primeira descrição ocorreu em 1909, e mais tarde, em 1922, identificada em secreções e tecidos biológicos por Alexander Fleming [119,120]. Somente em 1965 sua estrutura tridimensional foi resolvida por cristalografia de raios X [121]. Nos anos 1960 e 1970 o interesse pela enzima cresceu muito dada sua ação antibiótica natural. Nesse sentido, foram encontrados, por exemplo, índices elevados de lisozima em pacientes com leucemia [122]. Essa demanda estimulou a investigação da proteína em diversos aspectos, entre os quais estudos relacionados à interação com ligantes [123-125]. Essas investigações visam tanto o entendimento sobre os processos de interação dessa proteína com outras moléculas [126,127] quanto a compreensão de suas propriedades físico-químicas objetivando aplicações em bioquímica [128]. Dentre todas as lisozimas, a da clara do ovo de galinha tem sido a mais estudada, sendo composta de 129 resíduos, com massa molecular de aproximadamente

\footnotetext{
${ }^{8}$ [45] Y. Sun, P. L. O. Filho, J. C. Bozelli, Jr., J. Carvalho, S. Schreier, and C. L. P. Oliveira, Soft Matter 11, 7769 (2015).
} 
14,3 kDa (Figura 23). Entre os ligantes mais utilizados estão os surfactantes iônicos, como o SDS, que possuem diversas aplicações dentre as quais pode-se citar seu uso em solubilização de proteínas de membranas, de vírus e de ribossomos. Em particular, SDS pode ser empregado na técnica SDS-PAGE, que permite a determinação do peso molecular de proteínas. Para tanto, micelas de SDS, que se ligam aos sítios hidrofóbicos proteicos, induzem a chamada desnaturação reconstrutiva, onde os complexos proteína-surfactante assumem uma estrutura tipo "colar de pérolas” [129]. As micelas (“pérolas”) se ligam às proteínas solúveis em água numa proporção que depende do comprimento da cadeia polipeptídica (e, portanto, proporcional ao peso molecular da proteína analisada [130].

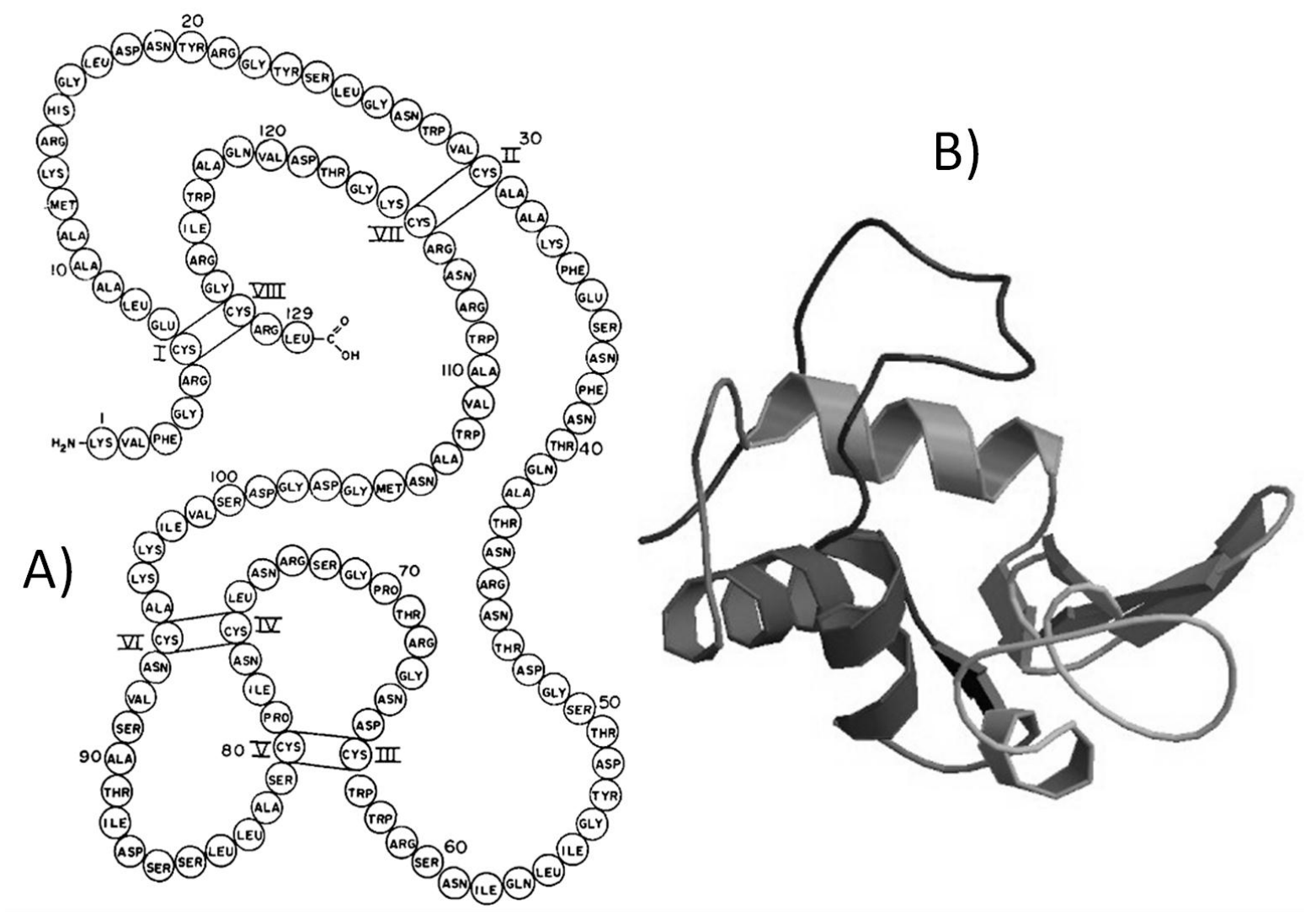

Figura 23: A) Estrutura primária da lisozima (sequência de letras, cada uma representando um resíduo). Retirado de [131]. B) Estrutura secundária e terciaria da lisozima gerada no website https://www.rcsb.org com a entrada 6LYZ.pdb.

É interessante observar que proteínas globulares e solúveis em água, como alfa-lactalbumina [132], pepsina e imunoglobulina G [133] apresentam um conteúdo maior de estruturas secundárias do tipo hélice $\alpha$ na presença de micelas de SDS. O estudo do mecanismo por trás desse efeito pode ajudar a elucidar o mecanismo de enovelamento de proteínas que ainda não são completamente compreendidos. Para tanto, seria interessante: 
1. Analisar como SDS, monomérico e micelar, desnatura proteínas globulares;

2. Caracterizar a estrutura dos complexos em cada etapa de ligação envolvida na desnaturação;

3. Correlacionar o aumento das conformações hélice $\alpha$ com a presença de micelas de SDS. O objetivo deste trabalho é responder essas perguntas por meio do estudo sistemático da interação entre SDS e lisozima que utiliza a combinação de técnicas de ITC, SAXS e CD ${ }^{9}$. As informações obtidas com o estudo poderão auxiliar no entendimento do processo de desnaturação da lisozima induzido pelo SDS assim como revelar o papel das micelas no enovelamento/desenovelamento de proteínas globulares em geral.

\subsubsection{Resultados e Discussão}

Os entalpogramas obtidos da titulação de SDS em diferentes concentrações de lisozima $(0,03$, 0,06, 0,09, 0,12 e 0,15 mM) encontram-se na Figura 24A, e fornecem um panorama geral, do ponto de vista energético, do processo de desnaturação da proteína induzido pelo surfactante.

Como é possível observar, a medida em que a concentração proteica aumenta, as curvas se deslocam para a direita. Esse fato evidencia a característica estequiométrica da ligação entre SDS e lisozima: mais moléculas de surfactante são necessárias para desnaturar mais moléculas de proteína (por isso o deslocamento dos entalpogramas para a direita). Tal relação pode ser escrita matematicamente da seguinte forma $[2,58,134,135]$ :

$$
[S]=[S]_{\text {Livre }}+N_{\text {agg }}[P]
$$

onde $[S]$ e $[P]$ são as concentrações de surfactante e proteína, respectivamente, $[S]_{\text {free }}$ é a concentração de monômeros de surfactante livres em solução e o parâmetro $N_{a g g}$, conhecido como número de ligação, é a quantidade de moléculas de surfactante ligadas à proteína ${ }^{10}$. Logo, a parcela $N_{a g g}[P]$ corresponde à concentração de surfactante ligado às proteínas.

\footnotetext{
${ }^{9}$ No trabalho original foi usada também a técnica de fluorescência.

${ }^{10}$ Propositalmente foi usada a mesma nomenclatura $\left(N_{a g g}\right)$ para simbolizar o número de agregação micelar (ver seção Modelos Teóricos de SAXS, Capítulo 2), de modo que será possível comparar resultados de ITC com os de SAXS.
} 


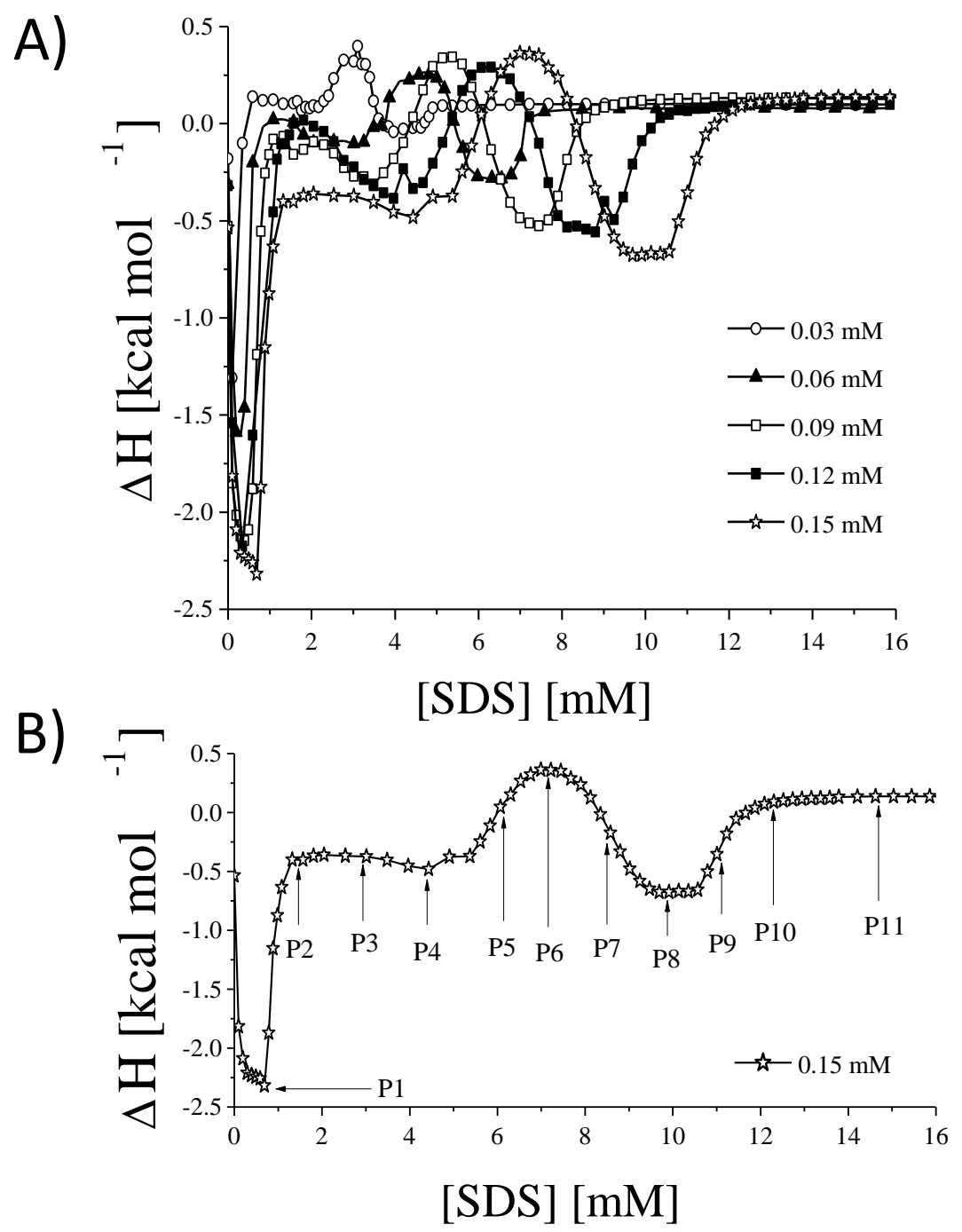

Figura 24: A) Entalpogramas obtidos para a titulação de SDS em diferentes concentrações de lisozima. B) Pontos selecionados para a determinação da estequiometria de ligação.

A fim de acompanhar o processo de ligação, foram selecionados 11 pontos dos entalpogramas (Figura 24B). A maioria deles, matematicamente são ponto crítico ou de inflexão, sendo o restante pontos arbitrários escolhidos de maneira considerar as partes dos entalpogramas representativas. Cada um desses pontos traz informação sobre $[S]$ e $[P]$ que pode ser lida diretamente da tabela de valores gerais fornecida pelo equipamento de medida a partir da qual é gerado cada entalpograma. A organização de toda a informação coletada na forma de um gráfico $[S] \times[P]$ encontra-se na Figura 25. A partir do ajuste da Eq. 7 para cada conjunto de pontos, obtém-se os valores dos parâmetros $N_{a g g}$ e $[S]_{\text {free }}$ (Tabela 4$)$. 


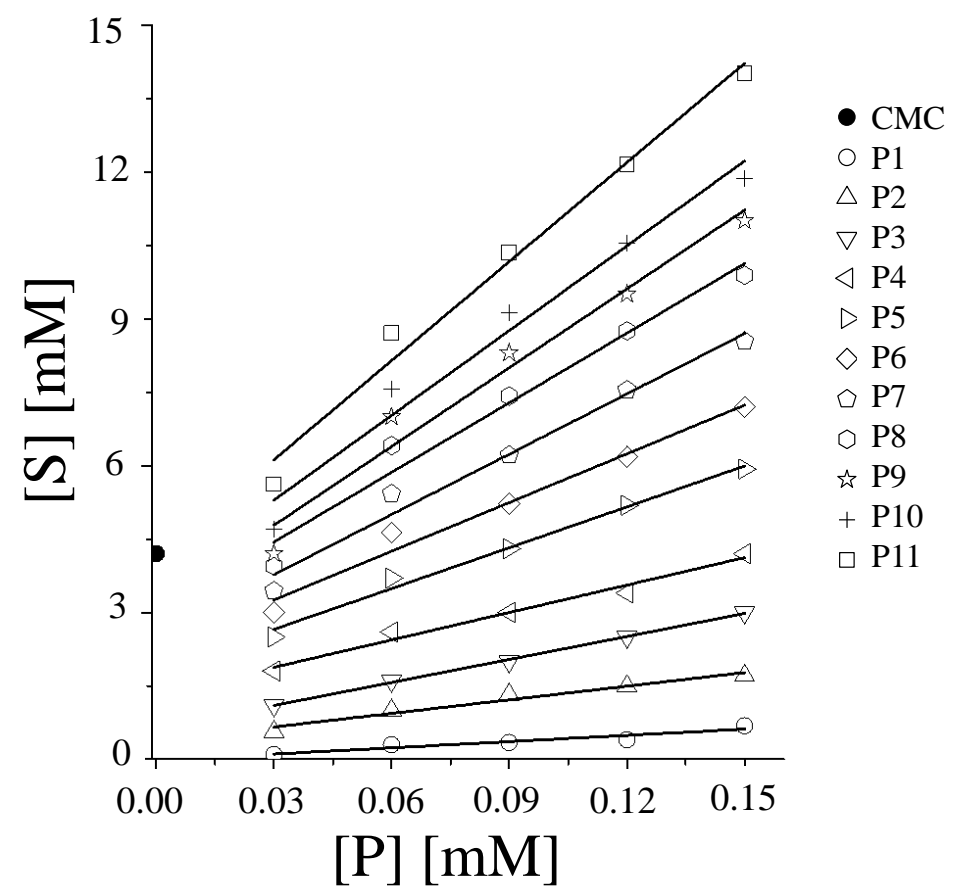

Figura 25: Concentração total de surfactante [S] em função da concentração total de proteína [P] para cada um dos 11 pontos selecionados, para cada entalpograma. As linhas contínuas correspondem aos ajustes feitos com a Eq. 7.

Observa-se que tanto o parâmetro $[S]_{\text {free }}$ quanto $N_{\text {agg }}$ aumentam continuamente conforme a razão $[S]:[P]$ aumenta. Nas condições de temperatura, $\mathrm{pH}$ e força iônica para as quais as amostras foram analisadas, a CMC do SDS foi ${ }^{11} \sim 4 m M$, o que mostra que serão formadas micelas apenas nos pontos P10 e P11, onde $[S]_{\text {free }}>4 \mathrm{mM}$. Portanto, na maior parte da interação entre SDS e lisozima (P1-P9), não há micelas de SDS. Contudo, os complexos formados podem possuir características micelares. Por exemplo, em P5, $N_{a g g} \sim 30$, ou seja, há, em média, cerca de 30 monômeros de SDS ligados em cada molécula de lisozima. Para essa quantidade, é possível que a estrutura desses monômeros seja do tipo micelar, interagindo com a proteína de alguma maneira. Para checar essa possibilidade, foram conduzidos experimentos de SAXS.

Com base no entalpograma para $[P]=0,15 \mathrm{mM}$, foram preparadas amostras com as razões molares $[S]:[P]$ de cada um dos 11 pontos selecionados. Para essas amostras foram realizados

${ }^{11}$ A CMC de SDS no tampão usado nesse trabalho foi obtida usando-se a técnica de condutimetria. 
experimentos de SAXS, e as curvas de espalhamento obtidas encontram-se na Figura 26A (símbolos abertos).

Tabela 4: Valores dos parâmetros $N_{a g g}$ e $[S]_{\text {free }}$ obtidos a partir do ajuste da Eq. 7 para cada conjunto de pontos mostrado na Figura 25.

\begin{tabular}{cccc}
\hline \hline Pontos selecionados & Razão molar $[\mathrm{S}]:[\mathrm{P}]$ & {$[S]_{\text {free }}[\mathrm{mM}]$} & $N_{\text {agg }}$ \\
\hline P1 & 2,0 & 0,0 & 1,9 \\
\hline P2 & 7,3 & 0,8 & 4,9 \\
\hline P3 & 16,7 & 1,3 & 10,8 \\
\hline P4 & 29,3 & 1,8 & 19,1 \\
\hline P5 & 45,3 & 2,2 & 30,1 \\
\hline P6 & 48,0 & 2,4 & 32,3 \\
\hline P7 & 57,3 & 2,7 & 40,0 \\
\hline P8 & 66,0 & 3,2 & 45,5 \\
\hline P9 & 70,7 & 3,5 & 47,1 \\
\hline P10 & 86,0 & 4,3 & 60,5 \\
\hline P11 & 106,0 & 4,9 & 72,7 \\
\hline
\end{tabular}

A curva de espalhamento obtida para a lisozima possui um aspecto típico para esse tipo de sistema [75] e é interessante notar que mesmo uma adição pequena de surfactante já induz alterações significas na curva I(q) correspondente ao ponto P1. Também é possível observar que para os demais pontos, há um "bump" em torno de $q \sim 0,2 \AA^{-1}$, aspecto similar à curva de SAXS para SDS, medido em concentração acima da sua CMC. Com o intuito de se extrair mais informações das curvas de SAXS, seguiu-se com análise inicial por meio do procedimento IFT. Para tanto, empregou-se o programa WIFT [136]. Na Figura 26A as linhas contínuas representam os ajustes, que são satisfatórios para todas as curvas experimentais, enquanto a Figura 26B exibe as funções $p(r)$ encontradas.

O comportamento da função $p(r)$ para lisozima e SDS é muito distinto. No primeiro caso, o formato da curva permite concluir que a proteína é globular alongada (como um elipsoide) de dimensão máxima $\sim 45$ Å. Já a $p(r)$ da micela de SDS apresenta “oscilações”, relacionadas a partículas do tipo core-shell. Além disso, as micelas possuem dimensão máxima de $\sim 70 \AA$ A. Com exceção da curva relativa ao ponto $\mathrm{P} 1$, as demais funções $p(r)$ são também características de partículas do tipo core-shell. É interessante mencionar que os tamanhos máximos dessas 
partículas estão entre $\sim 45 \AA$ e $\sim 70 \AA$ (ou seja, são partículas maiores que a lisozima e menores que as micelas de SDS) e também que as oscilações das funções $p(r)$ são diferentes daquelas observadas para a micela de SDS. Essas duas constatações indicam que as partículas não são nem micelas de surfactante tampouco uma mistura entre essas micelas e a proteína (porque, afinal, só existirão micelas em P10 e P11, de acordo com os resultados de ITC). Tratam-se, portanto, de complexos constituídos de SDS e lisozima cuja estrutura é do tipo core-shell.
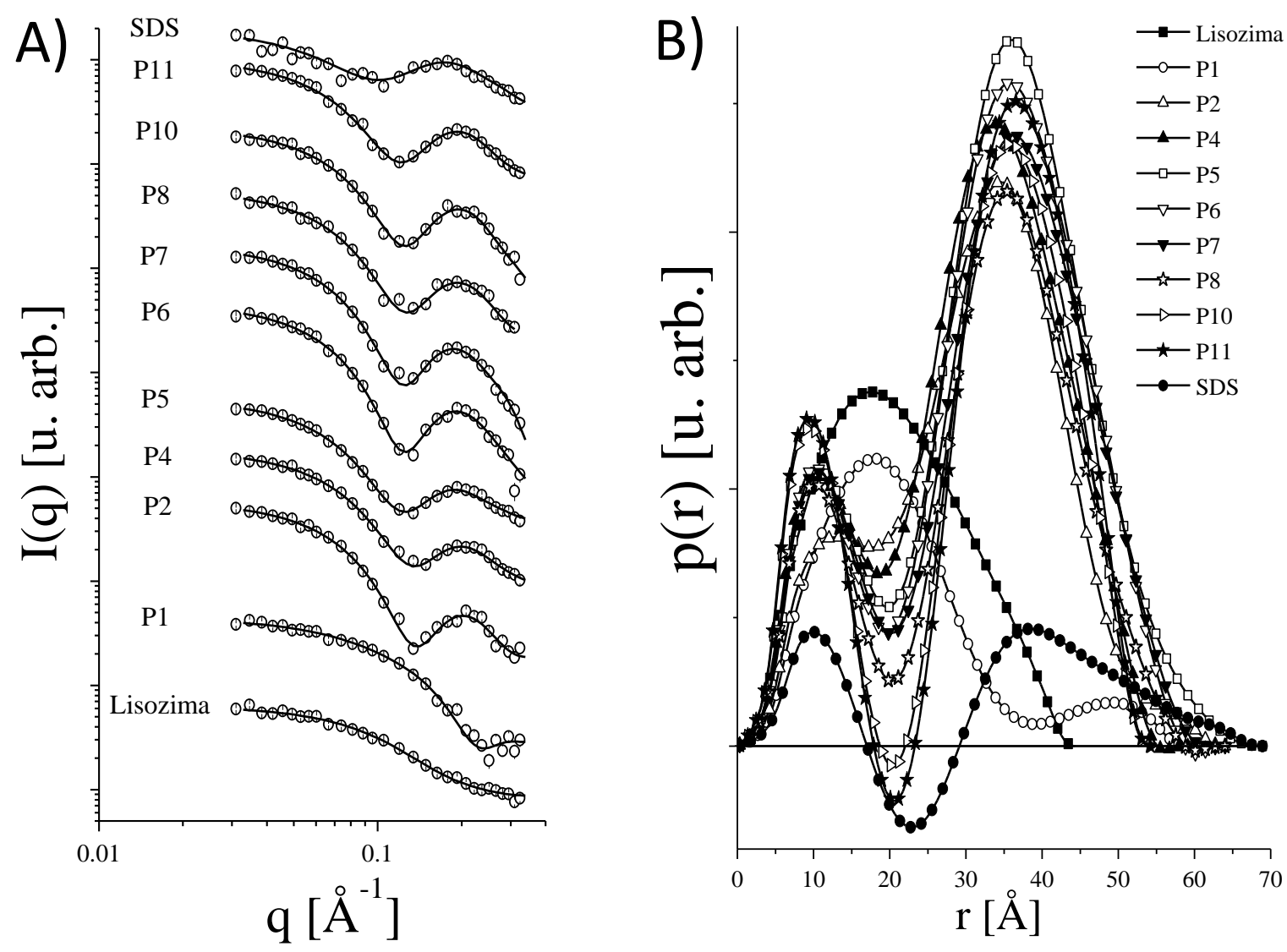

Figura 26: A) Curvas de SAXS (símbolos abertos) obtidas para as soluções de lisozima, SDS e para as amostras P1-P11, com exceção das amostras P3 e P9. As linhas contínuas representam os ajustes IFT. B) Funções $p(r)$ obtidas para as curvas apresentadas em A).

A curva $p(r)$ para a amostra $\mathrm{P} 1$ possui um aspecto diferente das curvas restantes. Nesse sentido, análises feitas a partir da intensidade espalhada teórica da lisozima (calculada a partir do arquivo 6LYZ.pdb utilizando-se o programa CRYSOL [137]) permitiram concluir que o complexo em P1 possui uma estrutura geral muito semelhante à da proteína nativa. Por esse motivo, serão considerados complexos core-shell as partículas nas amostras P2-P11. Vale ressaltar que, para as amostras P10 e P11, a intensidade espalhada resulta da contribuição tanto dos complexos quanto das micelas de SDS. Sendo assim, qualquer tentativa de modelagem do sistema precisará levar em conta esse fato para a correta descrição da intensidade espalhada. 

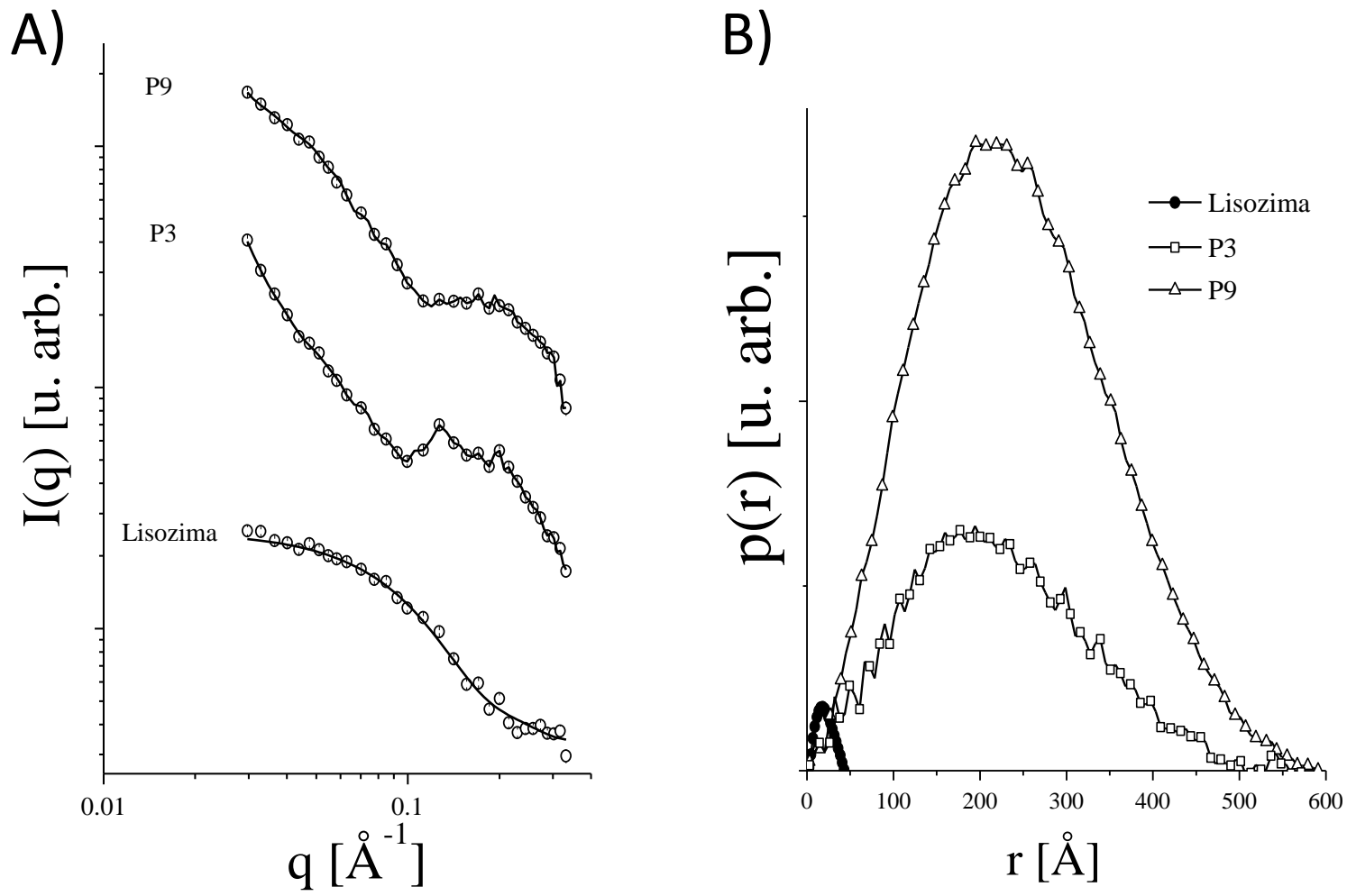

Figura 27: A) Curvas de SAXS (símbolos abertos) obtidos para as amostras P3 e P9. As linhas contínuas representam os ajustes IFT. B) Funções $p(r)$ obtidas para as curvas apresentadas em A).

As curvas de SAXS para os pontos P3 e P9 estão mostradas na Figura 27A (símbolos abertos), enquanto as linhas contínuas novamente são os ajustes IFT, por meio dos quais obteve-se as funções $p(r)$ correspondentes (Figura 27B). As partículas continuam sendo do tipo core-shell, mas nesses casos foi observada agregação, o que faz com que o início das curvas de SAXS apresente uma subida abruta, ou mesmo que o tamanho máximo observado na função $p(r)$ seja muito maior do que os valores típicos observados nos casos restantes. Essa agregação, embora frequentemente observada em sistemas proteicos, é característica particular do sistema lisozima-SDS, por motivos que serão discutidos mais adiante.

Dadas as informações obtidas pela análise das funções $p(r)$, é possível se proceder com a modelagem de SAXS, a qual pode utilizar o modelo de micelas decoradas (ver seção Modelagem Teórica de SAXS, Capítulo 2). Esse tipo de modelo assume, entretanto, que a proteína está distribuída sobre a superfície das micelas, decorando-as. Ou seja, assume-se que a proteína globular perdeu sua estrutura terciária. Para verificar esse fato com a finalidade de proceder com a modelagem dos dados, foram realizados experimentos de CD. 

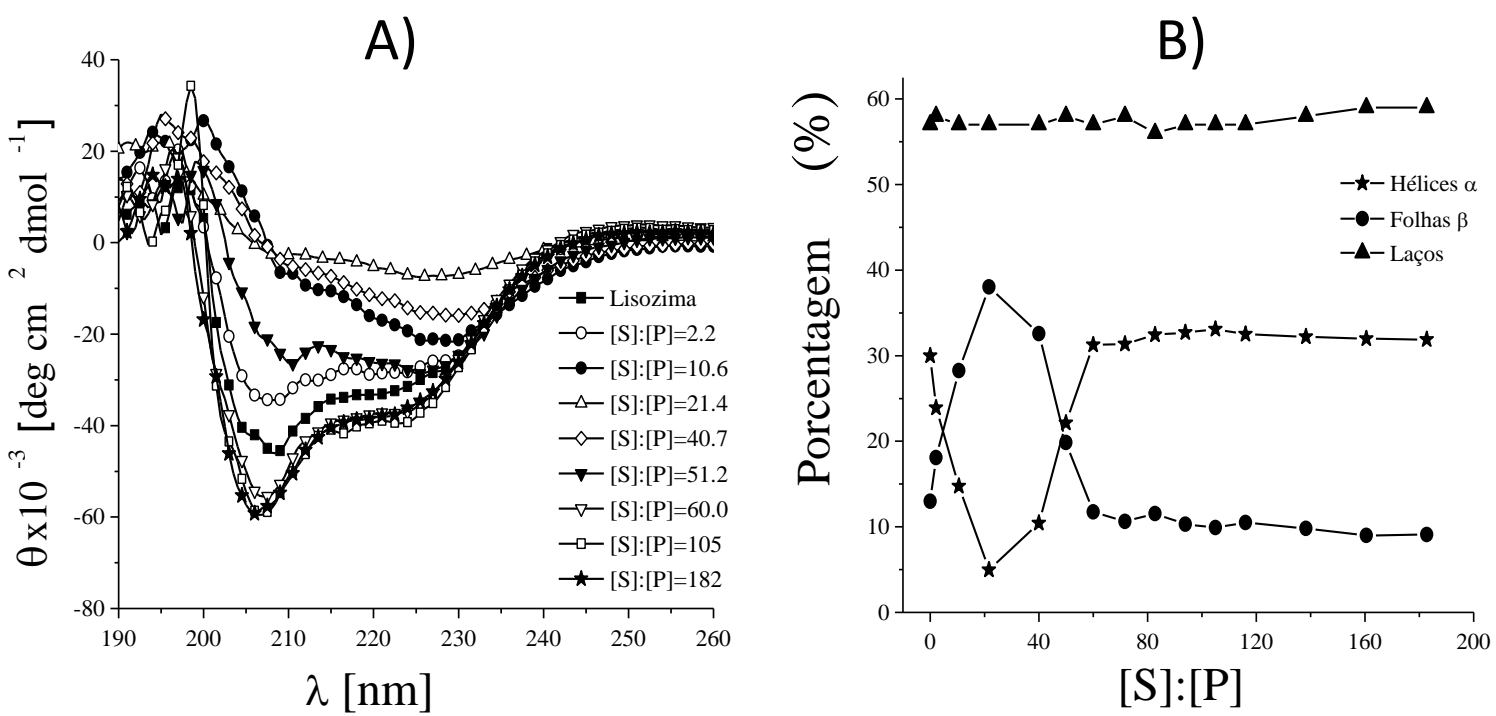

Figura 28: A) Espectros de CD na região $F a r-U V$, que fornecem informações sobre a estrutura secundária da proteína, coletados para diferentes razões $[S]:[P]$. B) Porcentagem de três conformações da estrutura secundária da lisozima em função da razão $[S]:[P]$, obtida a partir do ajuste das curvas de CD usando-se o programa DICHROWEB.

A Figura 28A mostra os resultados de CD para a região Far-UV, relacionada com a estrutura secundária proteica. A fim de se obter informações quantitativas, utilizou-se o programa online DICHROWEB [80] o qual, por meio do ajuste da curva de CD e comparações com banco de dados de proteínas conhecidas, fornece a fração de estruturas hélice $\alpha$, folha $\beta$ e laços presentes na amostra analisada. Como observado na Figura 28B, o conteúdo de hélices $\alpha$ diminui até $[S]:[P] \sim 40$ e depois aumenta até $[S]:[P] \sim 60$, permanecendo aproximadamente constante depois disso. $\mathrm{O}$ contrário ocorre com as folhas $\beta$, que aumentam em porcentagem até $[S]:[P] \sim 40$ e depois diminuem até $[S]:[P] \sim 70$, permanecendo praticamente constante depois disso. A quantidade de laços possui um leve aumento durante todo o processo (de $\sim 57,5 \%$ passa para $\sim 60 \%$ ). É interessante notar que o conteúdo de hélice $\alpha$ e folha $\beta$ da estrutura nativa $([S]:[P]=0)$ é $\sim 30 \%$ e $\sim 12,5 \%$, respectivamente. Ao final do processo, o conteúdo de hélice $\alpha$ é ligeiramente maior ( $232 \%)$ enquanto o de folha $\beta$ é menor ( $8 \%)$. Além disso, o aumento de hélices $\alpha$ observado entre $40<[S]:[P]<60$, aproximadamente, até atingir a porcentagem nativa ocorre para $[S]_{\text {free }}<C M C$, ao passo que o aumento de $\sim 30 \%$ para $\sim 32 \%$ até o final do processo acontece para $[S]:[P]>80$, aproximadamente, ou seja, para $[S]_{\text {free }}>C M C$. Portanto, tanto monômeros quanto micelas de SDS induzem a formação de estruturas hélices $\alpha$. 


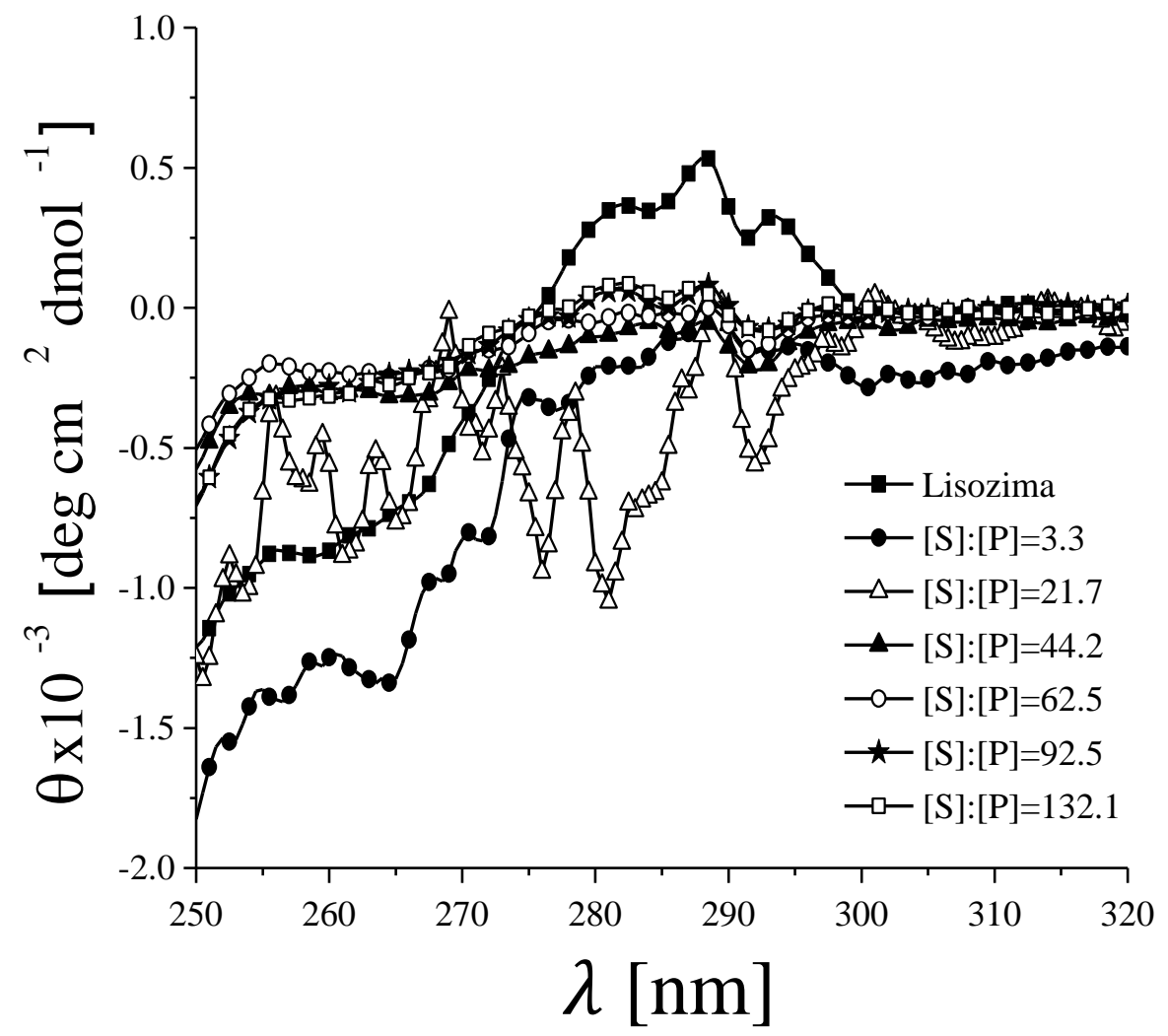

Figura 29: Espectros de CD na região Near-UV, o qual fornece informações sobre a estrutura terciária da proteína, coletados para diferentes razões $[S]:[P]$.

Em relação à estrutura terciária, os dados de CD na região Near-UV (Figura 29) analisados de maneira qualitativa mostram que ocorre uma diminuição de sinal já para razões $[S]:[P]$ pequenas, indicando um desenovelamento parcial com perda da estrutura terciária. Com exceção do ponto $\mathrm{P} 1$, nos demais a proteína encontra-se, portanto, no estado "molten globule", isto é, com pouca ou nenhuma estrutura terciária e alguma estrutura secundária. Com base nessa informação, procedeu-se com a aplicação do modelo de micelas decoradas aos dados de SAXS com a finalidade de caracterizar estruturalmente os complexos formados.

Os ajustes dos dados de SAXS com o modelo de micelas decoradas estão mostrados na Figura 30. Diferente dos demais casos, as amostras P3 e P9 apresentaram agregação (Figura 30B), sendo necessário incluir, na tentativa de descrever o comportamento dos dados experimentais, além do fator de forma de micelas decoradas, um fator de estrutura. Foram testados várias possibilidades e o fator de estrutura que forneceu o melhor ajuste foi o de agregados globulares simples, dado por [138]: 


$$
S(q)=1+S_{C_{2}} e^{-\frac{q^{2} R_{G}^{2}}{3}}
$$

onde $S_{C_{2}}$ é o fator de escala do agregado, relacionado com a fração de estruturas core-shell agregadas, e $R_{G}$ é o raio de giro médio dos agregados. Vale lembrar que todos os ajustes foram feitos em escala absoluta com a inclusão de vínculos moleculares. Para SDS, a partir da sua estrutura molecular, $N_{e l(T)}=97 e$ e $N_{e l(H)}=59 e$. Além disso, $V_{T}=355,1 \AA^{3}$ e $V_{H}=60,5 \AA^{3}$ [109]. A densidade eletrônica calculada para o tampão usado foi $0,333 \frac{e}{\AA^{3}}$ [62], muito próxima da densidade eletrônica da água.
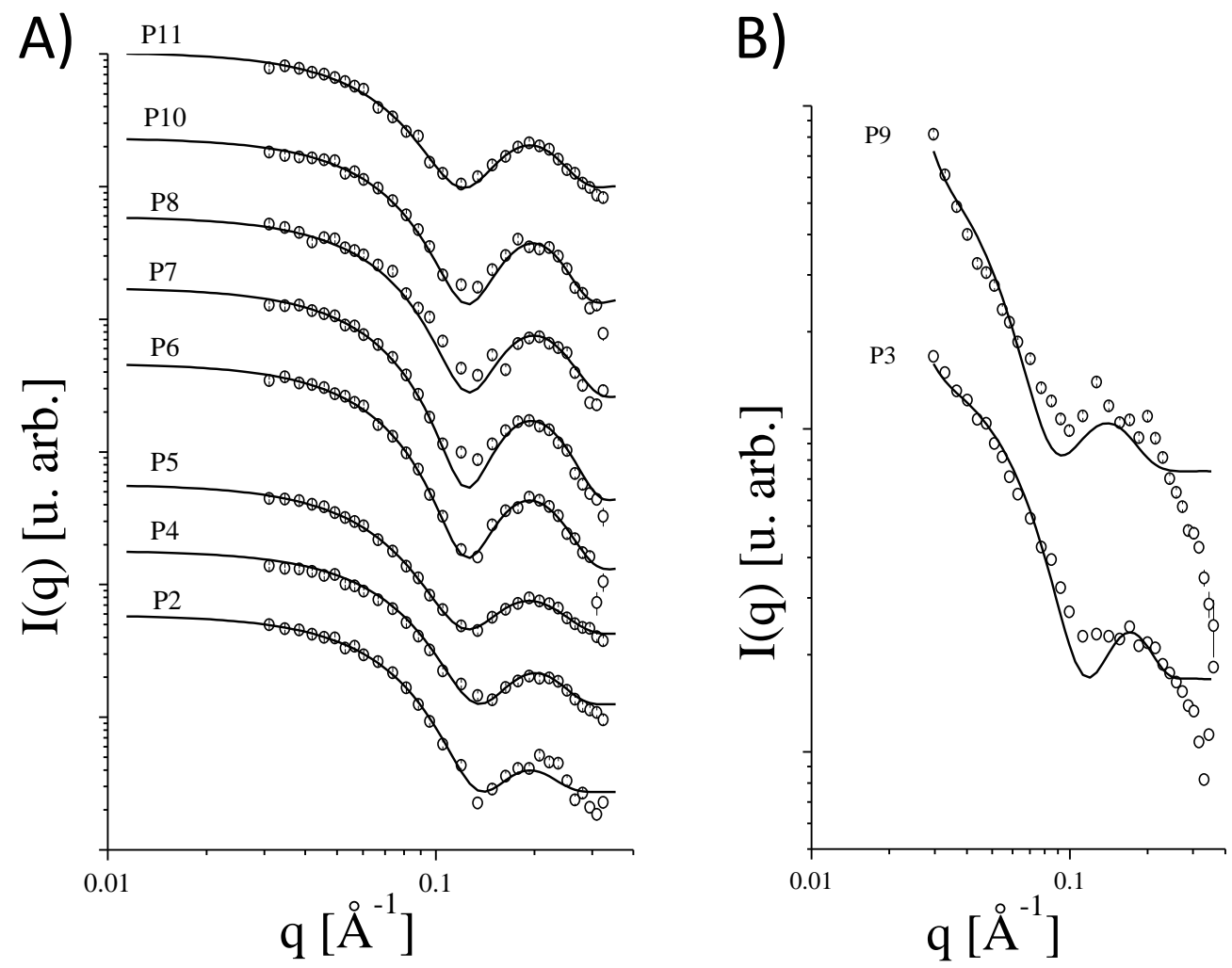

Figura 30: A) Dados de SAXS (símbolos abertos) ajustados com o modelo de micelas decoradas (linhas contínuas) para todos os pontos exceto P3 e P9. B) Ajuste (linhas contínuas) dos dados de P3 e P9 (símbolos abertos) com o modelo de micelas decoradas acrescido do fator de estrutura da pela Eq. 69.

Os parâmetros $D, R_{\text {core }}$, $\varepsilon_{\text {core }}$ e $c_{\text {free }}$ são parâmetros de ajuste do modelo, e seus valores encontram-se na Tabela 5 ( $c_{\text {free }}$ foi mantido fixo, e por esse motivo não possui erro). Já os parâmetros $N_{a g g}, m_{\text {prot }}$ e $x_{w t}$ são calculados a partir dos anteriores e das informações moleculares mencionadas antes usando-se, respectivamente, as equações Eq. 27, Eq. 46 e Eq. 
51. Como os ajustes não foram satisfatórios para os casos P3 e P9, os respectivos valores obtidos para os parâmetros foram omitidos da Tabela 5 por serem discrepantes em relação àqueles para os demais pontos, para os quais os ajustes (Figura 30A) são capazes de descrever bem o comportamento das curvas experimentais.

Observa-se que a espessura do shell, $T$, apresenta o maior valor em P2, no início da desnaturação, e diminui conforme a razão $[S]:[P]$ aumenta, permanecendo em torno de $9 \AA$ na saturação (P10-P11). Isso pode ter relação com as mudanças da estrutura proteica apontadas pelos resultados de CD. Nesse sentido, inicialmente em P2, a proteína ainda possui parte de sua estrutura terciária e principalmente secundária, e ao longo do processo de desnaturação, a sua distribuição sobre superfície micelar é maior, fazendo com que $T$ diminua. Portanto, mesmo que os dados de SAXS sejam de baixa resolução, ainda assim é possível se obter informações médias efetivas sobre alterações estruturais.

Tabela 5: Valores dos parâmetros do modelo de micela decorada obtidos a partir dos ajustes dos dados experimentais de SAXS. Os valores entre parêntesis indicam a incerteza nos últimos algarismos significativos.

\begin{tabular}{cccccccc}
\hline \hline $\begin{array}{c}\text { Pontos } \\
\text { selecionados }\end{array}$ & $T[\AA]$ & $R_{\text {core }}[\AA]$ & $\varepsilon_{\text {core }}$ & {$[S]_{\text {free }}[\mathrm{mM}]$} & $N_{\text {agg }}$ & $x_{w t}[\%]$ & $m_{\text {prot }}[\mathrm{kDa}]$ \\
\hline P2 & $20,4(4)$ & $8,5(2)$ & $1,1(3)$ & 0,03 & 7,8 & 74,1 & 21,6 \\
\hline P4 & $13,3(1)$ & $14,5(2)$ & $0,7(7)$ & 1,9 & 25,5 & 58,4 & 22,5 \\
\hline P5 & $10,7(9)$ & $12,6(1)$ & $1,9(6)$ & 2,5 & 45,7 & 52,3 & 23,4 \\
\hline P6 & $10,5(1)$ & $12,7(1)$ & $1,9(7)$ & 2,6 & 45,7 & 53,1 & 21,8 \\
\hline P7 & $9,4(1)$ & $13,0(2)$ & $1,9(9)$ & 2,9 & 49,3 & 52,0 & 19,0 \\
\hline P8 & $8,1(2)$ & $13,4(2)$ & $1,8(1)$ & 3,8 & 50,6 & 44,1 & 18,3 \\
\hline P10 & $9,0(2)$ & $13,8(3)$ & $1,5(1)$ & 6,0 & 45,1 & 58,0 & 14,4 \\
\hline P11 & $8,5(1)$ & $14,1(2)$ & $1,6(7)$ & 8,0 & 51,7 & 56,1 & 14,4 \\
\hline \hline
\end{tabular}

O parâmetro $R_{\text {core }}$, por outro lado, assume o menor valor em $\mathrm{P} 2$, em torno de 8,5 $\AA$, e o maior valor em P4 ( 14,5 $)$, permanecendo entre $\sim 13 \AA$ e $\sim 14 \AA$ até o final da desnaturação. Isso mostra que inicialmente o core das micelas provavelmente é formado por poucas moléculas de SDS, o que gera um $R_{\text {core }}$ efetivo pequeno. Conforme a razão $[S]:[P]$ aumenta, provavelmente mais monômeros passam a compor o core, o que acarreta um aumento de $R_{\text {core }}$. 
Em P2, as micelas decoradas são aproximadamente esféricas, com $\varepsilon_{\text {core }} \sim 1,1$, as quais passam por uma transição para elipsoides oblatos em P4 e permanecem prolatos até a saturação, onde $\varepsilon_{\text {core }} \sim 1,5$. A concentração de monômeros livres em solução, $[S]_{\text {free }}$, é diretamente proporcional à razão $[S]:[P]$. Além disso, esse parâmetro, assim como aquele de ITC (Eq. 68), indica que são formadas micelas livres de SDS na saturação, pois $[S]_{\text {free }}>C M C$.

O parâmetro número de agregação micelar, $N_{a g g}$, possui o menor valor em P2 ( 8) e aumenta continuamente até P8, permanecendo entre $\sim 45$ e $\sim 52$ na saturação. Esse comportamento justifica as variações observadas para $R_{\text {core }}$ e valida o fato de que o aumento da quantidade de monômeros que formam o core causa um ligeiro aumento das dimensões do mesmo. A diferença entre o parâmetro $N_{a g g}$ obtido por SAXS e ITC (Tabela 4) pode estar relacionado à sensibilidade de ambas as técnicas em fornecer informações sobre este parâmetro, além do fato de que a definição de $N_{a g g}$ é diferente para cada análise (para SAXS, utiliza-se a Eq. 27, enquanto para ITC a Eq. 68).

A fração molar de moléculas de água no shell, $x_{w t}$, apresenta o maior valor em P2 ( 74\%), diminui até P8 ( 44\%) e volta a crescer, permanecendo em torno de 57\% na saturação. Esse comportamento corrobora as observações feitas para $T$. Se, inicialmente, em P2, a proteína está pouco distribuída sobre a superfície micelar, o que gera um valor de $T$ efetivo relativamente alto, então provavelmente haverão mais moléculas de água solvatando o shell (isso explica o valor alto encontrado para $x_{w t}$ em P2) do que se a proteína estiver melhor distribuída. Nessa situação, $T$ e $x_{w t}$ diminuem comparados à $\mathrm{P} 2$. O aumento de $x_{w t}$ observado para os pontos P10-P11 pode ter relação com o aumento das estruturas hélice $\alpha$ e laços observada por CD para $[S]:[P]>80$.

O valor da massa de proteína por complexo, $m_{\text {prot }}$, se inicia em $\sim 22 k D a$, apresenta um leve aumento até P5 ( 23 kDa), e depois diminui continuamente até atingir $\sim 14,4 k D a$ na saturação. Portanto, inicialmente, existem complexos formados por até duas proteínas compartilhando a mesma micela, como já relatado na literatura [40,42]. O aumento da razão $[S]:[P]$ faz com que esse compartilhamento diminua até a saturação, onde existe apenas uma molécula de proteína por micela decorada, fato este corroborado pela proximidade entre o valor de $m_{\text {prot }}$ e a massa molecular da lisozima. 
Combinando os resultados obtidos e correlacionando-os com informações conhecidas da literatura, foi proposto descrever o processo de desnaturação da lisozima induzido por SDS em cinco estágios (Figura 31):

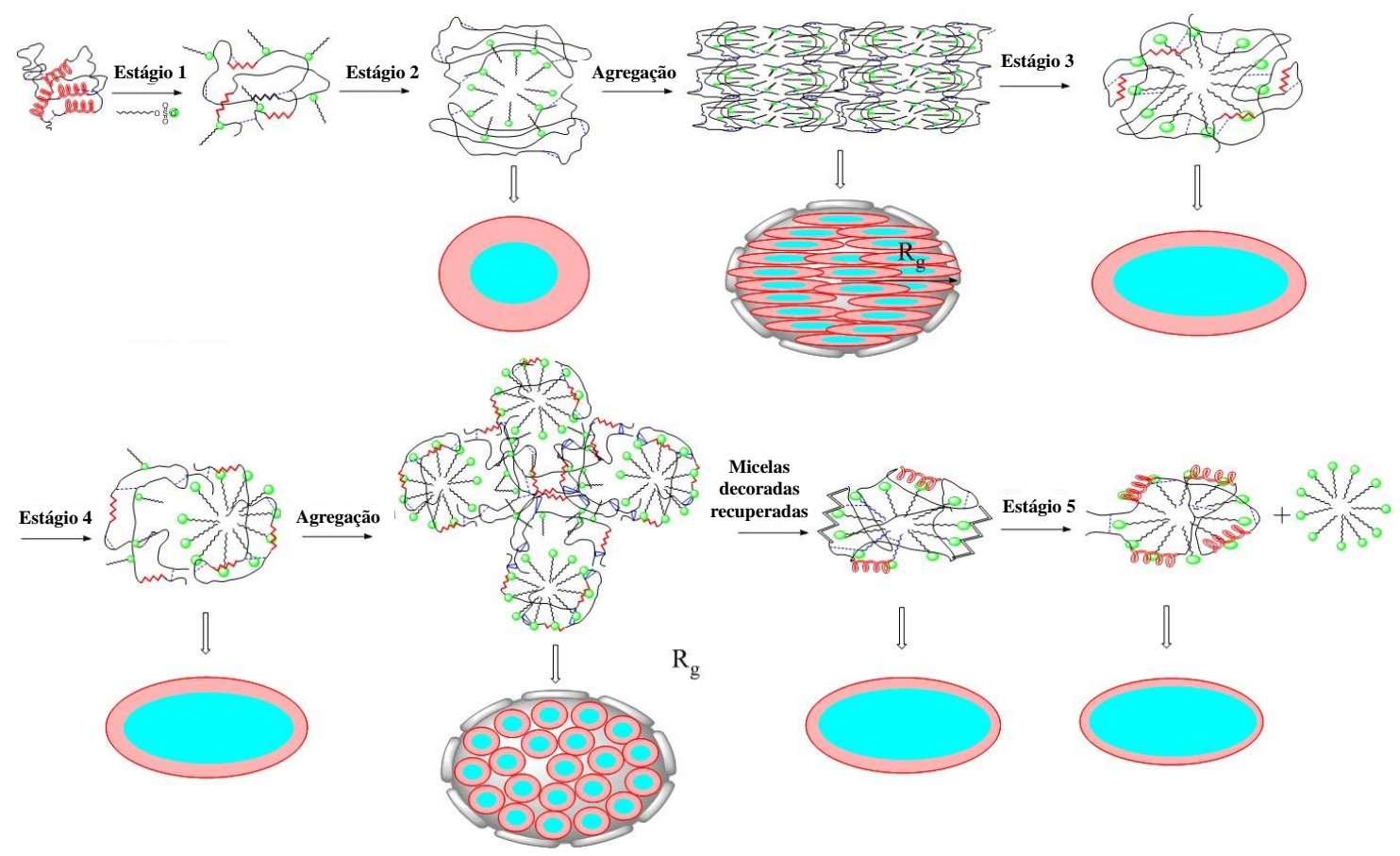

Figura 31: Representação esquemática dos diferentes estágios da ligação de SDS na lisozima, dando origem aos complexos estudados nessa seção. Figura adaptada de [45].

1) (P1-P2) O grupo sulfato (negativo) dos monômeros de SDS se ligam eletrostaticamente às porções positivas da lisozima. A neutralização diminui a repulsão eletrostática entre os complexos, favorecendo a aglomeração, o que contribuiu para o efeito exotérmico [60]. A proteína é parcialmente desenovelada, com perda de hélices $\alpha$ e aumento das folhas $\beta$. Resíduos hidrofóbicos como Trp e Tyr são expostos ao solvente, ficando assim suscetíveis à ligação com as caudas apolares do SDS via interação hidrofóbica.

2) (P2-P4) Há a agregação dos complexos neutralizados e a posterior dissolução, uma vez que a ligação dos mesmos com SDS aumenta assim como a repulsão eletrostática. Isso promove um comportamento levemente endotérmico e então o processo cooperativo de desenovelamento ocorre. A perda/ganho de hélices $\alpha /$ folhas $\beta$ continua, com a exposição de mais resíduos hidrofóbicos para o solvente, o que induz a formação das primeiras micelas decoradas, mesmo que $N_{a g g}$ ainda seja muito menor do que o requerido para a formação de micelas [40]. Contudo, parte da proteína pode estar ligada 
à micela e parte livre em solução. Essa hipótese é corroborada pelos valores altos de espessura do shell encontrados em SAXS.

3) (P4-P6) Nesse estágio há um balanço entre carga e hidrofobicidade onde o aumento da quantidade de moléculas de SDS ligadas propicia um ambiente favorável energeticamente para a reestruturação de hélices $\alpha$ por meio de ligações de hidrogênio internas, interações iônicas e hidrofóbicas com a consequente expulsão de moléculas de água [41]. Isso contribui para o comportamento endotérmico e o máximo de entalpia observada em todo o processo.

4) (P6-P10) O núcleo micelar dos complexos está saturado, de maneira que se inicia a competição de monômeros adicionais de SDS com aqueles que formam as micelas decoradas. O conteúdo de hélices $\alpha$ e folhas $\beta$ é próximo do da estrutura nativa. O shell é mais fino e com menor quantidade de proteína, corroborando a tese de que uma proteína pode compartilhar mais de uma micela. Possivelmente esse efeito de compartilhamento e a consequente exposição de grupos hidrofóbicos para o solvente contribui para o processo de agregação observado em $\mathrm{P} 9$, que é diferente daquele ocorrido em P3 devido à neutralização dos complexos. Com o aumento da quantidade de monômeros de SDS, os agregados (formados devido principalmente às interações hidrofóbicas) são desfeitos e as micelas decoradas são recuperadas. Porém, como a concentração de monômeros livres é maior do que a CMC do SDS, micelas livres e micelas decoradas passam a coexistir. Isso gera uma situação energeticamente favorável para que as porções hidrofóbicas das proteínas antes compartilhadas entre micelas decoradas formem novas hélices $\alpha$ em detrimento à formação de folhas $\beta$.

5) (P10-P11) Ocorre a saturação do processo de ligação. O aumento da concentração de SDS no sistema gera variações pouco perceptíveis na entalpia e também leva ao aumento da quantidade de micelas livres. Já as micelas decoradas atingem sua estrutura final, com cerca de 50 monômeros formando o core, e a proteína espalhada por praticamente toda a superfície micelar (isso é corroborado pelo shell possuir uma espessura menor do que nos estágios anteriores), com um conteúdo de hélices $\alpha$ cerca de $2 \%$ maior do que na estrutura nativa, e um conteúdo de folhas $\beta$ cerca de $5 \%$ menor que no início. 


\subsubsection{Conclusão}

A combinação dos resultados oriundos de diferentes técnicas permitiu acessar informações sobre o processo de desenovelamento e reenovelamento da lisozima induzido pelo surfactante SDS. ITC forneceu um olhar energético sobre toda a desnaturação, desde o início até a saturação do processo de ligação. Desse modo, soube-se exatamente a razão $[S]:[P]$ a ser usada na preparação de amostras para SAXS e CD. Este último forneceu informações sobre alterações nas estruturas secundária e terciária, permitindo concluir que a proteína perde e ganha hélices $\alpha$, ao passo que ganha e perde folhas $\beta$. Ao final, há um leve aumento de hélices $\alpha$ comparado à estrutura nativa da proteína. $\mathrm{O}$ contrário é observado para folhas $\beta$. Além disso, ao longo da interação proteína-surfactante, a estrutura terciária vai sendo perdida. Para $[S]:[P] \sim 40$, por exemplo, já não há praticamente estrutura terciária e a lisozima encontra-se no estado "molten globule". De acordo com as análises de SAXS, conclui-se que a estrutura adotada pelos complexos é do tipo core-shell. Adicionalmente, a técnica foi capaz de identificar dois momentos de agregação que não foram indicados pelos métodos anteriores. Com o auxílio da modelagem quantitativa dos dados em escala absoluta, e com a imposição de vínculos moleculares, foi possível caracterizar a forma e tamanho dos complexos em cada etapa de ligação, tornando também possível propor um esquema (Figura 31) que sintetiza visualmente as etapas mais importantes. A rota de análise adotada neste trabalho pode ser usada para investigar qualquer tipo de complexação entre proteínas globulares e surfactantes. A seguir demonstra-se isso com outro estudo de caso. 


\subsection{Estudo de caso: Alfa-lactalbumina e SDS ${ }^{12}$}

\subsubsection{Introdução}

Alfa-lactalbumina é uma proteína globular de 123 resíduos que apresenta quatro ligações dissulfeto e em seu estado nativo está ligada ao íon $\mathrm{Ca}^{2+}$ (Figura 32). Sua massa molecular é aproximadamente $14 k D a$.

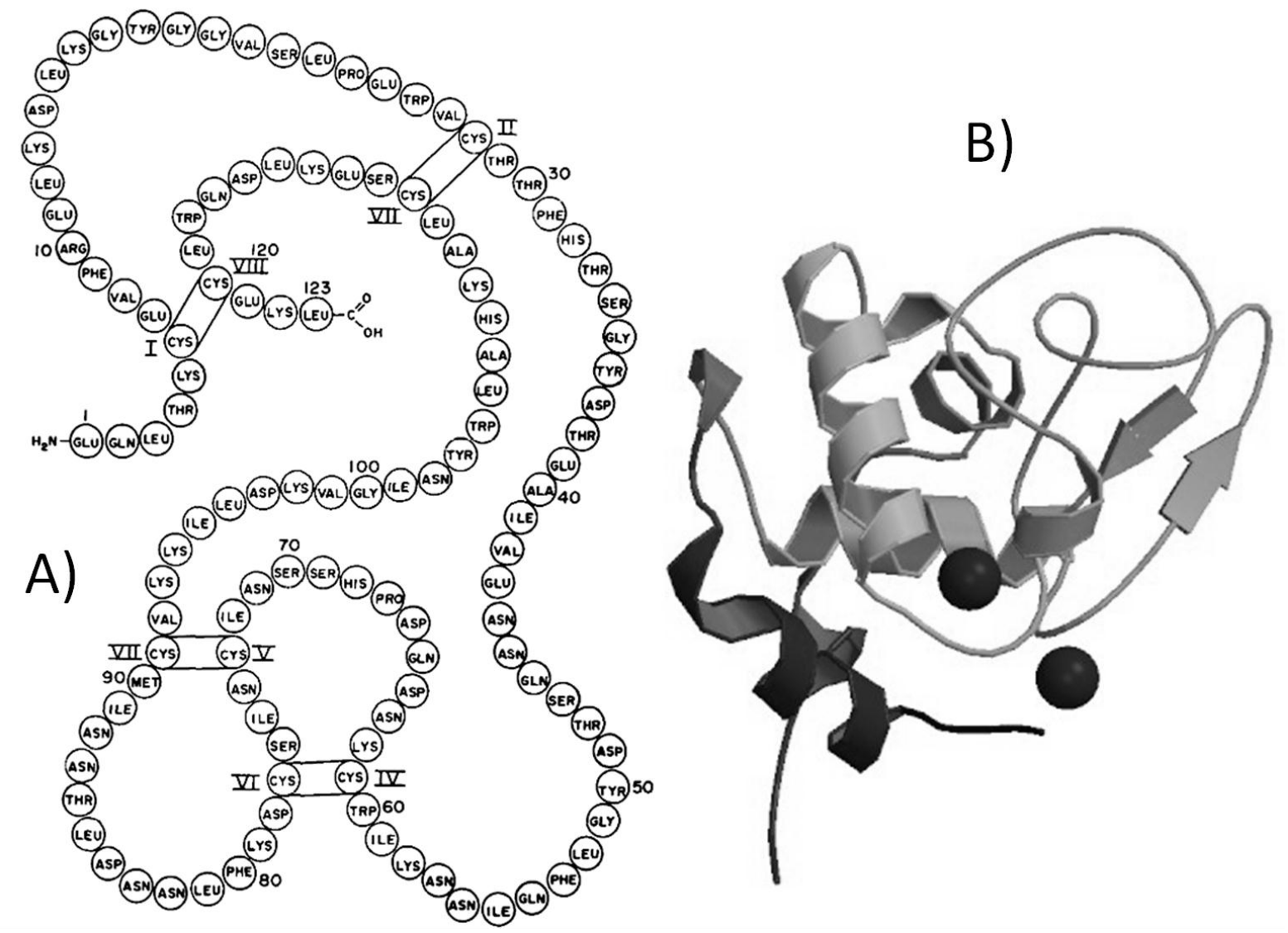

Figura 32: A) Estrutura primária da alfa-lactalbumina (sequência de letras, cada uma representando um resíduo). Retirado de [131]. B) Estrutura secundária e terciaria da alfa-lactalbumina gerada no website https://www.rcsb.org com a entrada 1AV4.pdb. As pequenas esferas representam íons $\mathrm{Ca}^{2+}$.

Assim como a beta-lactoglobulina e a albumina sérica, a alfa-lactalbumina vem do soro do leite, onde atua como reguladora da enzima galactozil transferase, responsável por sintetizar lactose a partir de glucose e galactose $[131,139,140]$. Além disso, descobriu-se que a alfa-lactalbumina humana possui a habilidade de induzir apoptose (isto é, morte celular) em células de câncer [141,142]. Aparentemente, essa característica é também compartilhada com a alfa-lactalbumina

12 [105] Y. Sun, P. L. Oseliero, and C. L. P. Oliveira, Food Hydrocolloids 62, 10 (2017). 
bovina [143]. Por isso, assim como no caso da lisozima, estudos relacionados à sua estrutura, às propriedades físico-químicas e à ligação da proteína com outras moléculas são altamente relevantes. Neste último aspecto, a interação de alfa-lactalbumina com moléculas anfifílicas tais como SDS mostrou que a proteína sofre grandes alterações em sua estrutura [59]. Inclusive existem na literatura modelos esquemáticos que procuram descrever a interação entre as duas moléculas mas que até o presente estudo não haviam sido validados [58].

Com o intuito de estudar a interação entre proteína e surfactantes é necessário combinar técnicas e correlacionar informações estruturais e termodinâmicas, abordagem esta adotada em trabalhos recentes [42,109,144,145] e também no estudo de caso apresentado na seção anterior [45]. Seguindo essa estratégia, será investigada a complexação entre a proteína alfa-lactalbumina bovina e o surfactante SDS tendo como objetivo a caracterização estrutural e termodinâmica do processo de ligação.

\subsubsection{Resultados e Discussão}

A Figura 33A mostra os entalpogramas obtidos para a titulação do surfactante em diferentes concentrações de proteína $(0,0,02,0,04,0,06,0,08$ e 0,1 mM). Notam-se grandes diferenças entre os entalpogramas relativos à titulação de SDS em tampão (entalpograma $0 \mathrm{mM}$ ) e em proteína (as demais curvas). Isso evidencia que há interação entre ambas as moléculas, pois do contrário todos os entalpogramas restantes seriam similares ao entalpograma $0 \mathrm{mM}$. Além disso, há um certo deslocamento das curvas (exceto para o entalpograma $0 \mathrm{mM}$ ) para a direita conforme aumenta-se a concentração de proteína, o que se traduz em uma estequiometria de ligação, expressa matematicamente pela Eq. 7. Visando determiná-la, foram selecionados 11 pontos de cada entalpogramas que foram atribuídos a mudanças energéticas importantes (Figura $33 B)$. A Figura 34 mostra um gráfico $[S] \times[P]$ que organiza toda a informação obtida por essa análise (símbolos abertos). O comportamento linear de cada conjunto de dados é aquele previsto pela Eq. 7. Usando-a para o ajuste, obtém-se os valores dos parâmetros $[S]_{\text {free }}$ e $N_{a g g}$, mostrados na Tabela 6.

Ambos os parâmetros são diretamente proporcionais à razão molar $[S]:[P]$. Além disso, como a CMC do surfactante nesse tampão é $\sim 4 m M^{13}$, somente existirão micelas livres de SDS com $[S]_{\text {free }}>4 \mathrm{mM}$, ou seja, nos três últimos pontos P9, P10 e P11 escolhidos. Assim como no

\footnotetext{
${ }^{13}$ Assim como no estudo de caso anterior, a CMC foi obtida usando-se a técnica de condutimetria.
} 
estudo de caso anterior, a maior parte da interação proteína-surfactante evidenciada pelo ITC ocorre na região submicelar. Com o intuito e analisar forma e tamanho dos complexos, procedeu-se com os experimentos de SAXS.

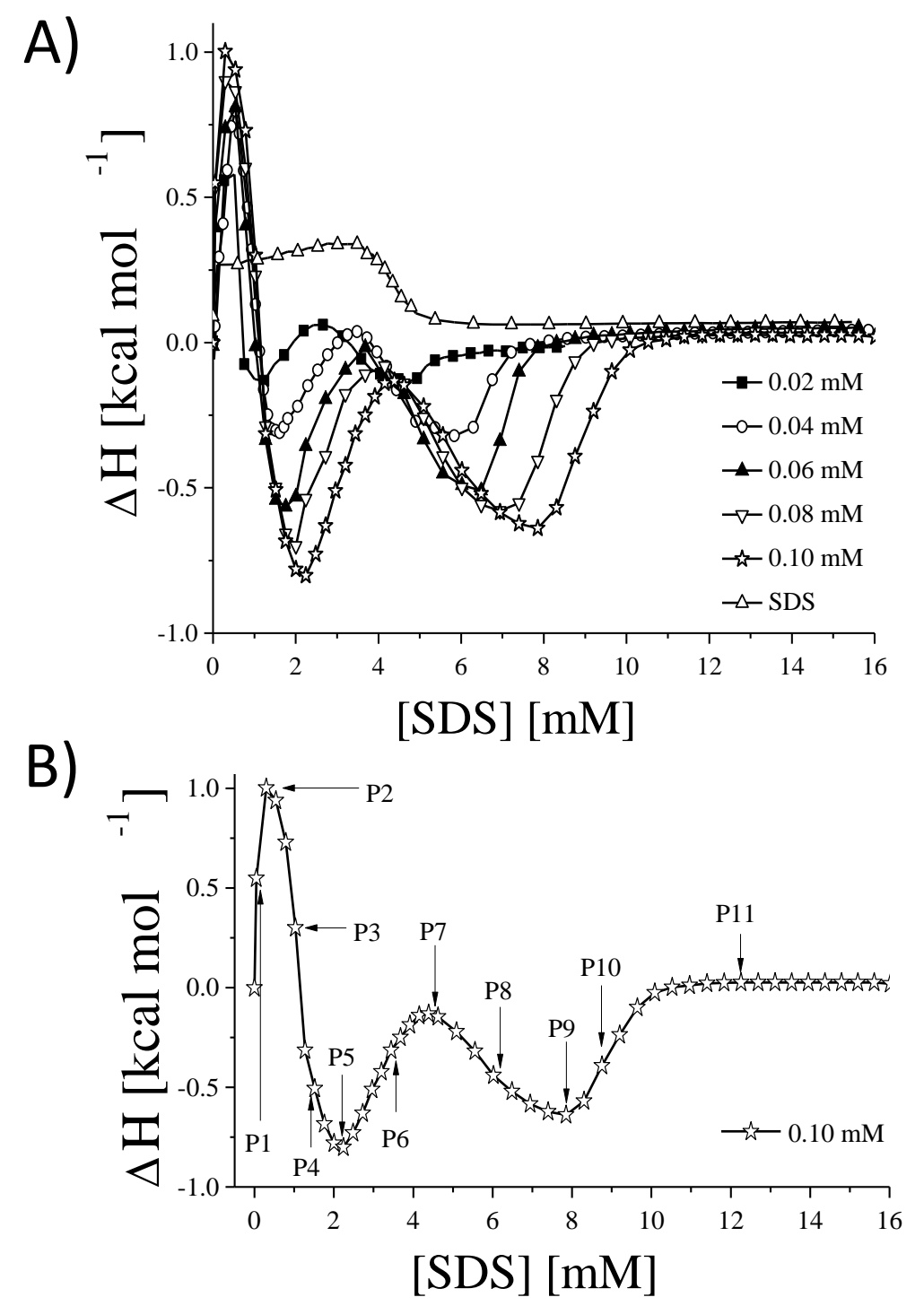

Figura 33: A) Entalpogramas obtidos para a titulação de SDS em diferentes concentrações de alfa-lactalbumina. B) Pontos selecionados para a determinação da estequiometria de ligação.

Para cada ponto selecionado no ITC, foram preparadas amostras com a mesma razão molar $[S]:[P]$, as quais foram medidas pela técnica de SAXS. Os resultados encontram-se na Figura 35A (símbolos abertos). 


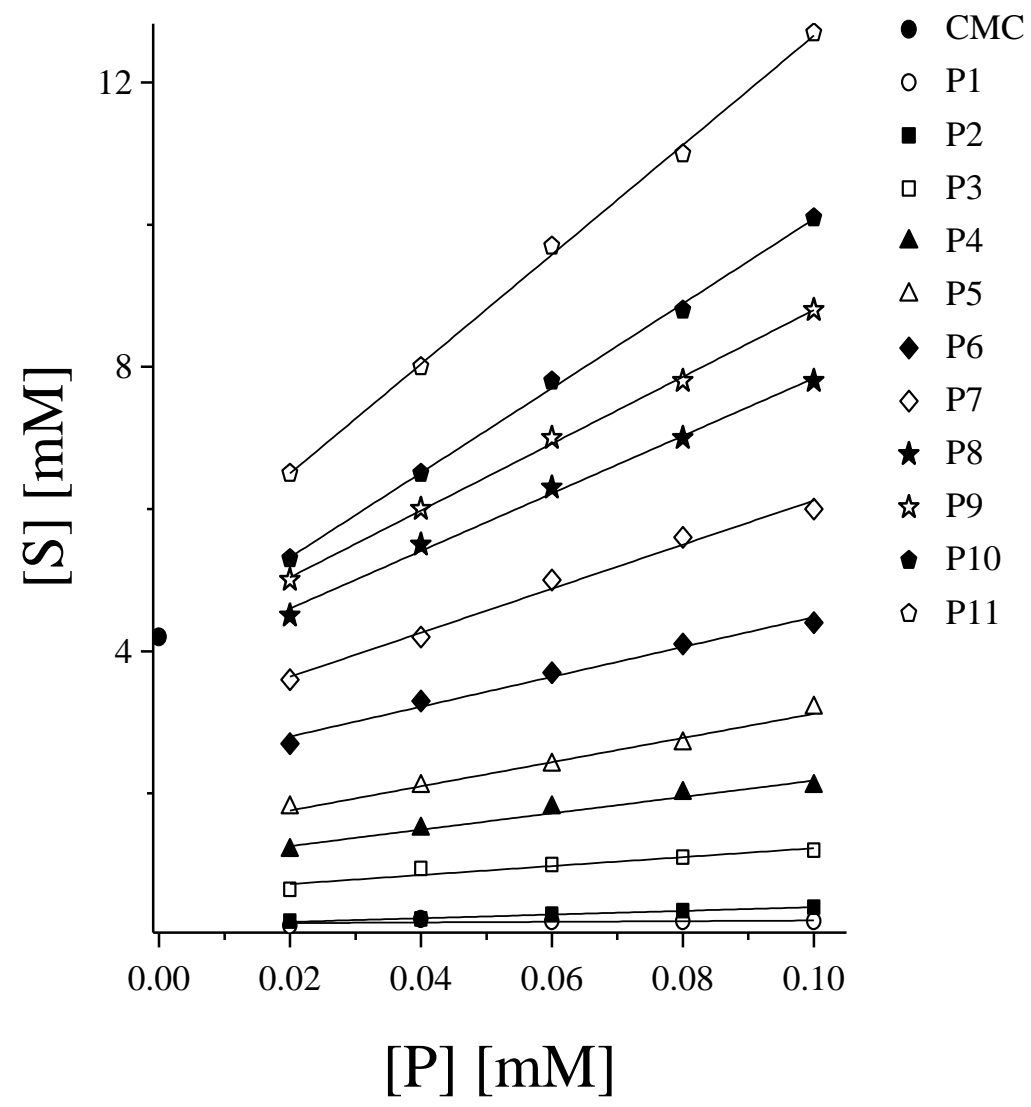

Figura 34: Concentração total de surfactante [S] em função da concentração total de proteína [P] para cada um dos 11 pontos selecionados, para cada entalpograma. As linhas contínuas correspondem aos ajustes feitos com a Eq. 7.

Nota-se que as curvas referentes aos pontos P1, P2 e P3 são semelhantes entre si e não apresentam um "bump" em torno de $q \sim 0,2 \AA^{-1}$, ao contrário das curvas restantes. A fim de se extrair mais informações das curvas sem necessitar, para tanto, assumir algo do sistema formado, procedeu-se com os ajustes das curvas experimentais (Figura 35A, linhas contínuas) por meio do procedimento IFT, que fornecem as funções $p(r)$ (Figura 35B). Conclui-se pelo comportamento dessas funções que alfa-lactalbumina é uma partícula globular alongada (por exemplo, um elipsoide), de dimensão máxima $\sim 50 \AA ̊$, enquanto SDS forma micelas de tamanho máximo $\sim 60 \AA$ A, do tipo core-shell, por a sua $p(r)$ apresenta "oscilações".

Para as amostras P1-P3, o tamanho máximo é $\sim 40 \AA ̊$ (menor do que o tamanho da proteína nativa), enquanto para os demais a dimensão máxima é $\sim 50$ Å. Essas informações sugerem que pequenas quantidades de surfactante $([S]:[P]$ de $\sim 0,6$ até $\sim 8)$ deixam a estrutura proteica mais compacta. Testes usando o espalhamento teórico da proteína (calculados com o programa 
CRYSOL a partir da estrutura cristalográfica 1A4V.pdb) sugerem que nas amostras P1-P3 a proteína mantém sua estrutura nativa (embora mais compacta), diferente das amostras P4-P11, cujas partículas são do tipo core-shell por causa das oscilações nas funções $p(r)$. Em princípio pode-se empregar o mesmo modelo de micelas decoradas usado no estudo de caso anterior. Antes disso, entretanto, é necessário investigar as alterações nas estruturas secundária e terciária decorrentes da presença do surfactante a fim de checar se é possível a proteína estar distribuída pela superfície das micelas, decorando-as, como requerido pelo modelo. Por conta disso, procedeu-se com os experimentos de CD.

Tabela 6: Valores dos parâmetros $N_{a g g}$ e $[S]_{\text {free }}$ obtidos a partir do ajuste da Eq. 7 para cada conjunto de pontos mostrado na Figura 25.

\begin{tabular}{cccc}
\hline Pontos selecionados & Razão molar $[\mathrm{S}]:[\mathrm{P}]$ & {$[S]_{\text {free }}[\mathrm{mM}]$} & $N_{\text {agg }}$ \\
\hline \hline P1 & 0,6 & 0,0 & 0,5 \\
\hline P2 & 3,4 & 0,1 & 2,6 \\
\hline P3 & 8,1 & 0,4 & 6,3 \\
\hline P4 & 15,0 & 0,9 & 11,5 \\
\hline P5 & 21,7 & 1,4 & 17,0 \\
\hline P6 & 30,6 & 2,4 & 21,0 \\
\hline P7 & 43,2 & 3,0 & 31,0 \\
\hline P8 & 58,0 & 3,8 & 40,5 \\
\hline P9 & 78,3 & 4,1 & 47,0 \\
\hline P10 & 87,8 & 4,5 & 59,5 \\
\hline P11 & 114,5 & 5,0 & 77,0 \\
\hline \hline
\end{tabular}

A Figura 36A mostra os dados de CD na região Far-UV. A fim de avaliar quantitativamente o que acontece com a estrutura secundária, utilizou-se novamente o programa online DICHROWEB. O resultado (Figura 36B) revela que, diferentemente do estudo de caso anterior, tanto laços quanto folhas $\beta$ diminuem continuamente até $[S]:[P] \sim 100$ ao passo que hélices $\alpha$ aumentam continuamente. Para $[S]:[P]>100$, a porcentagem dessas três estruturas permanece constante. Considerando que micelas livres de SDS ocorrem a partir de P9 ([S]: $[P] \sim 78$ ), conclui-se que o aumento de hélices $\alpha$ é um efeito causado tanto por SDS monomérico quanto micelar, da mesma forma que observado para o sistema lisozima-SDS. 

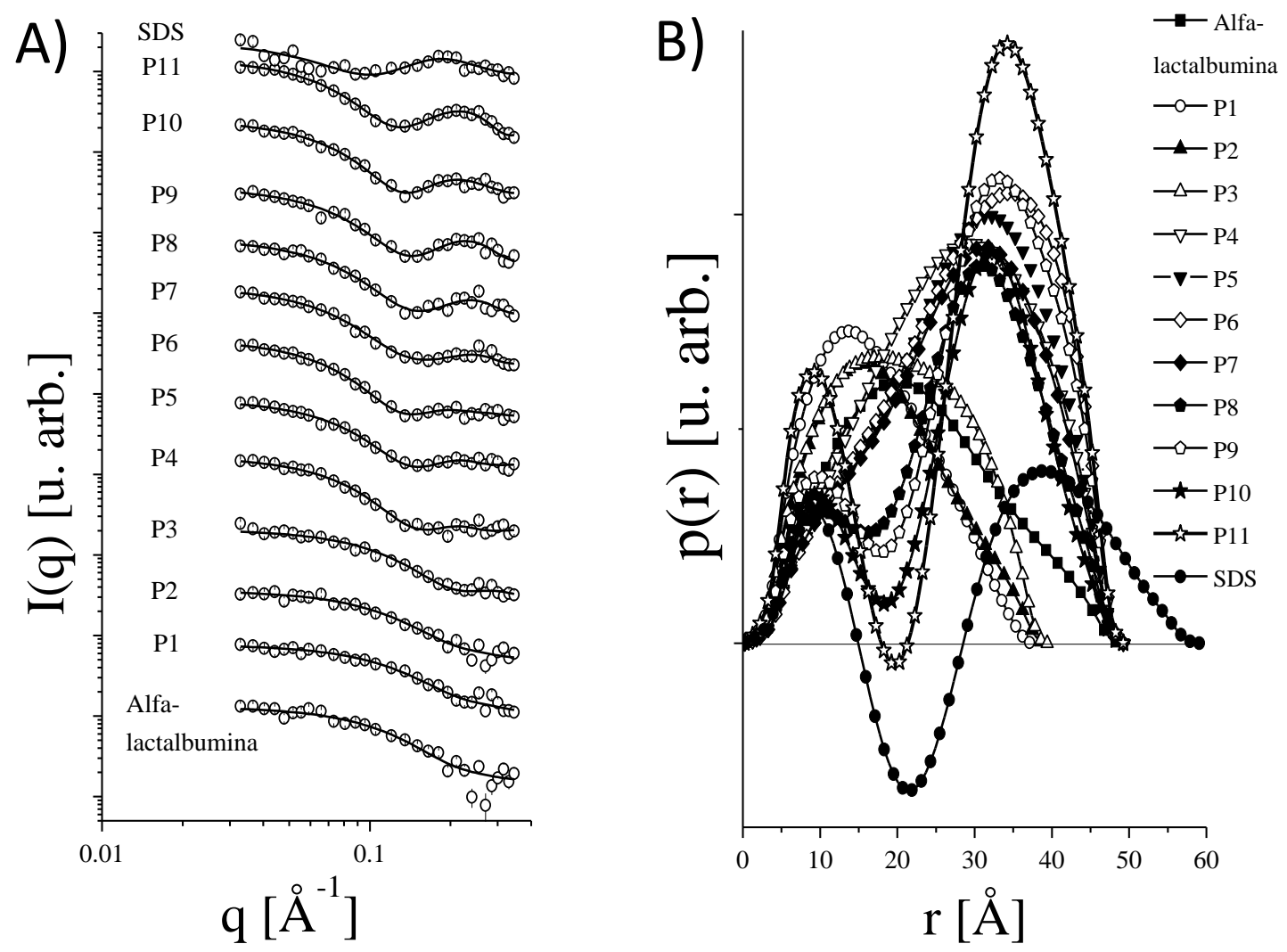

Figura 35: A) Curvas de SAXS (símbolos abertos) obtidas para as soluções de alfa-lactalbumina, SDS e para as amostras P1-P11. As linhas contínuas representam os ajustes IFT. B) Funções $p(r)$ obtidas para as curvas apresentadas em A).

Em relação à estrutura terciária, os dados de CD na região Near-UV (Figura 37), analisados de maneira qualitativa, mostram que o aumento da razão $[S]:[P]$ gera uma perda de sinal correspondente à perda de estrutura terciária. Curiosamente, o sinal em $270 \mathrm{~nm}$ e $290 \mathrm{~nm}$ aumenta um pouco durante o processo de ligação, indicando uma estrutura terciária levemente mais rígida comparada ao estado nativo. Provavelmente isso pode ser relacionado com a estrutura mais compacta observada por SAXS nos casos P1-P3. Em resumo, o processo de ligação de SDS em alfa-lactalbumina acarreta a perda de estrutura terciária, de laços e de folhas $\beta$, comparadas ao estado nativo, ao passo que propicia o aumento de hélices $\alpha$. Logo, o processo de ligação faz com que a alfa-lactalbumina se encontre no estado "molten globule", indicação esta que permite usar o modelo de micelas decoradas para os dados de SAXS. 


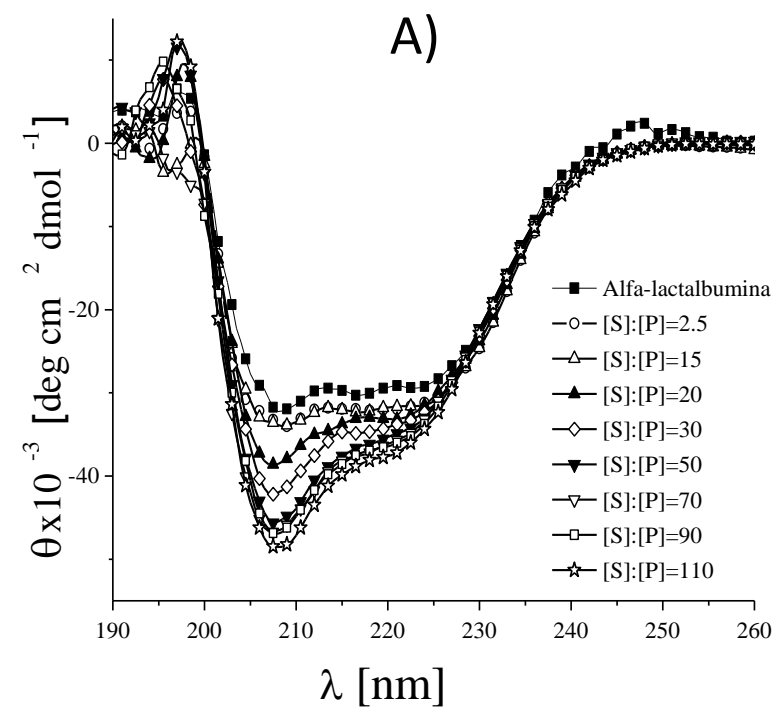

B)

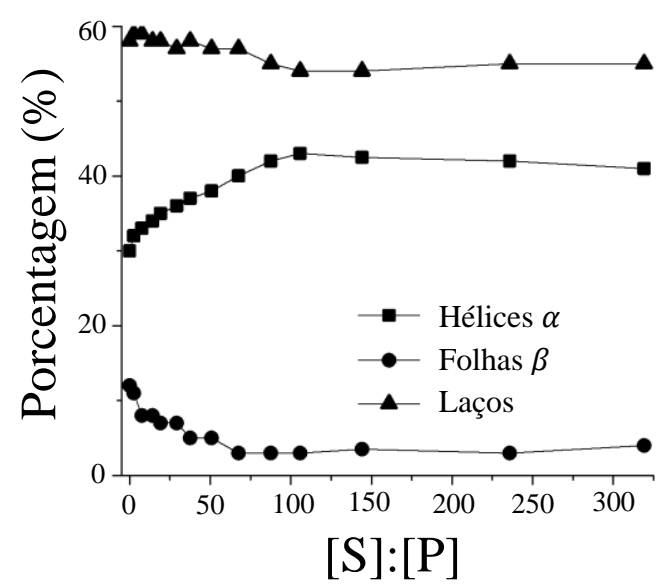

Figura 36: A) Espectros de CD na região Far-UV, que fornecem informações sobre a estrutura secundária da proteína, coletados para diferentes razões $[S]:[P]$. B) Porcentagem de três conformações da estrutura secundária da alfa-lactalbumina em função da razão $[S]:[P]$, obtida a partir do ajuste das curvas de CD usando-se o programa DICHROWEB.

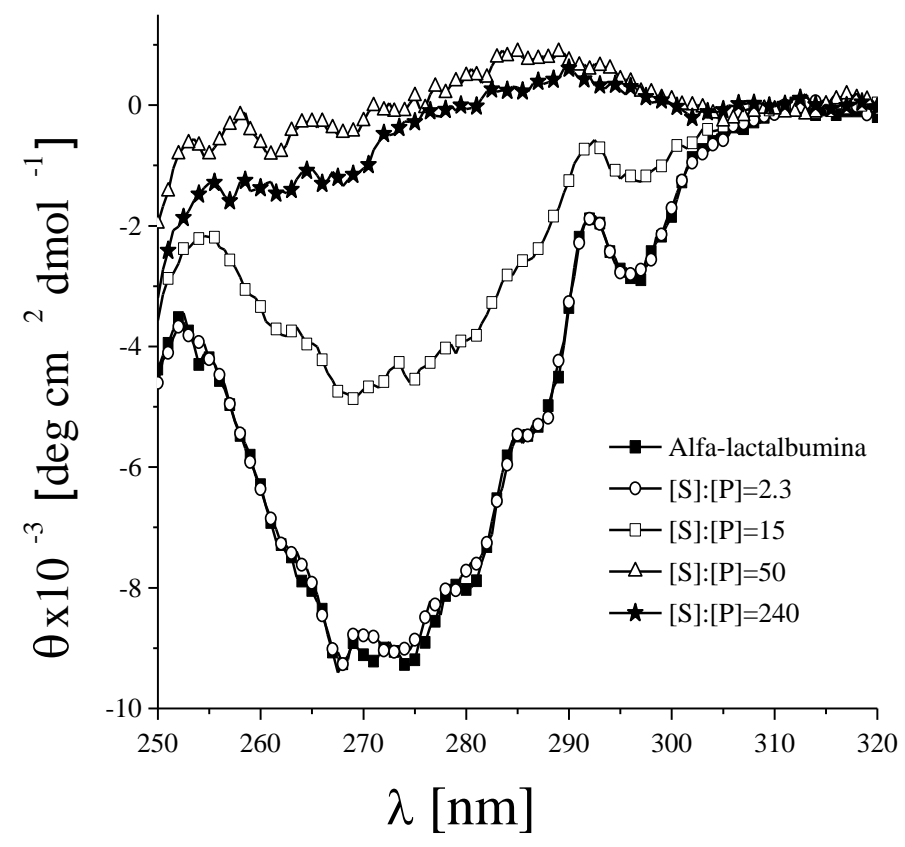

Figura 37: Espectros de CD na região Near-UV, o qual fornece informações sobre a estrutura terciária da proteína, coletados para diferentes razões $[S]:[P]$.

O modelo de micelas decoradas foi usado para o ajuste (linhas contínuas) dos dados experimentais de SAXS (Figura 38, símbolos abertos), que se mostraram satisfatórios. Os valores dos parâmetros obtidos encontram-se na Tabela 7. 


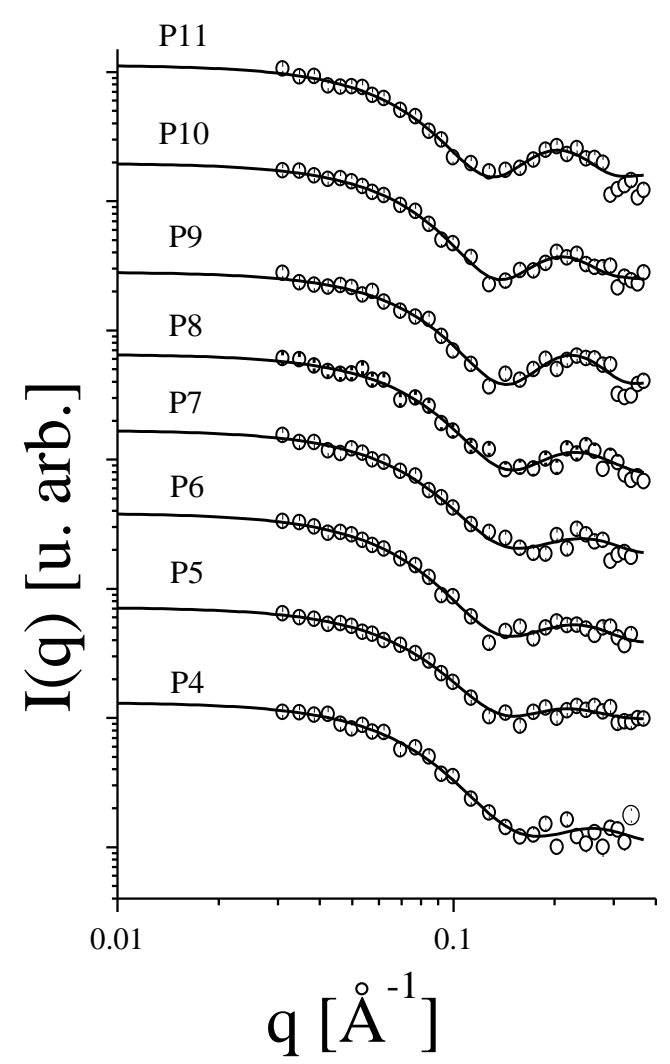

Figura 38: Dados de SAXS (símbolos abertos) ajustados com o modelo de micelas decoradas (linhas contínuas).

Observa-se que $T$ apresenta o maior valor em P4, no início da desnaturação, e diminui conforme a razão $[S]:[P]$ aumenta, permanecendo em torno de $6 \AA$ na saturação (P11). Isso pode ter relação com as mudanças da estrutura proteica apontadas pelos resultados de CD. Assim, inicialmente em P4, a proteína ainda possui parte de sua estrutura terciária e principalmente secundária, e ao longo do processo de desnaturação, a sua distribuição sobre superfície micelar é maior, fazendo com que $T$ diminua. Embora a quantidade de estruturas hélice $\alpha$ aumente, isso acaba sendo provavelmente compensado pela diminuição considerável da quantidade de folhas $\beta$. O parâmetro $R_{\text {core }}$, por outro lado, assume o menor valor em $\mathrm{P} 4$, em torno de $7 \AA$, e aumenta até o final da desnaturação, sugerindo que provavelmente mais monômeros passam a compor o core conforme a razão $[S]:[P]$, o que acarreta um aumento de $R_{\text {core }}$.

Em todos os casos, as micelas decoradas são prolatas, possuindo maior anisotropia no início da desnaturação, em P4 ( $\left.\varepsilon_{\text {core }} \sim 3\right)$, a qual diminui continuamente até a saturação, atingindo valores em torno de $\sim 1,5$. Dessa maneira, o aumento da razão $[S]:[P]$ deixa a micelas decoradas menos alongadas. 
O parâmetro $[S]_{\text {free }}$ é diretamente proporcional à razão $[S]:[P]$. De acordo com seus valores, conclui-se que são formadas micelas livres de SDS a partir de P8, o que é apenas ligeiramente diferente da constatação, via análises de ITC, de que as micelas livres ocorrem a partir de P9. Além disso, o parâmetro $[S]_{\text {free }}$ obtido por SAXS e ITC para P8 valem, respectivamente, 4,0 e 3,8. Talvez haja equivalência entre eles caso as barras de erro estivessem disponíveis. De toda maneira, eles são muito próximos entre si, o que evidencia a boa concordância entre as duas técnicas.

Tabela 7: Valores dos parâmetros do modelo de micela decorada obtidos a partir dos ajustes dos dados experimentais de SAXS. Os valores entre parêntesis indicam a incerteza no último algarismo significativo.

\begin{tabular}{cccccccc}
\hline \hline $\begin{array}{c}\text { Pontos } \\
\text { selecionados }\end{array}$ & $T[\AA]$ & $R_{\text {core }}[\AA]$ & $\varepsilon_{\text {core }}$ & {$[S]_{\text {free }}[\mathrm{mM}]$} & $N_{\text {agg }}$ & $x_{w t}[\%]$ & $m_{\text {prot }}[\mathrm{kDa}]$ \\
\hline P4 & $13,1(5)$ & $7,1(4)$ & $3,0(6)$ & 0,6 & 13,6 & 51,2 & 22,6 \\
\hline P5 & $12,7(2)$ & $9,0(3)$ & $2,2(2)$ & 0,9 & 30,8 & 51,5 & 22,8 \\
\hline P6 & $8,7(2)$ & $10,9(2)$ & $2,5(2)$ & 2,0 & 31,0 & 36,8 & 23,8 \\
\hline P7 & $8,4(3)$ & $10,3(3)$ & $2,5(3)$ & 3,6 & 32,9 & 37,5 & 20,6 \\
\hline P8 & $7,6(3)$ & $11,2(3)$ & $2,0(2)$ & 4,0 & 34,2 & 38,6 & 15,0 \\
\hline P9 & $7,0(3)$ & $13,1(3)$ & $1,5(2)$ & 4,5 & 39,0 & 30,3 & 14,0 \\
\hline P10 & $7,0(2)$ & $13,7(3)$ & $1,4(2)$ & 6,5 & 42,9 & 32,7 & 17,6 \\
\hline P11 & $6,1(3)$ & $14,8(7)$ & $1,5(2)$ & 8,5 & 56,6 & 16,1 & 18,7 \\
\hline \hline
\end{tabular}

O parâmetro número de agregação micelar, $N_{a g g}$, possui o menor valor em P4 $(\sim 13,6)$ e aumenta continuamente até P11, atingindo o valor em torno de $\sim 57$. Esse comportamento justifica as variações observadas para $R_{\text {core }}$ e corrobora o fato de que o aumento da quantidade de monômeros que formam o core causa um aumento das dimensões do mesmo.

A fração molar de moléculas de água no shell apresenta o maior valor no início, em P4-P5 ( $~ 51 \%)$, diminui para $\sim 37 \%$ e permanece em torno desse valor em P6-P8. Antes de atingir em P11 o valor $\sim 16 \%, x_{w t}$ assume o valor em torno de 31\% para P9-P10. Portanto, de maneira geral, $x_{w t}$ tente a diminuir conforme o aumento de $[S]:[P]$. Esse comportamento corrobora as observações feitas para $T$, no sentido de que, inicialmente, em P4, a proteína está pouco distribuída sobre a superfície micelar, o que gera um valor de $T$ efetivo relativamente alto. Nesse caso, haverão provavelmente mais moléculas de água solvatando o shell, o que explica 
o alto valor encontrado para $x_{w t}$ em P4, do que se a proteína estiver melhor distribuída, situação que ocorre na saturação.

O valor da massa de proteína por complexo, $m_{\text {prot }}$, se inicia em $\sim 23 k D a$, em $\mathrm{P} 4$, e apresenta um leve aumento até P6 ( 24kDa), e depois diminui até P9, atingindo algo em torno de $\sim 14 \mathrm{kDa}$. Na saturação o $m_{\text {prot }}$ aumenta para $19 \mathrm{kDa}$. Considerando que a massa molecular da alfa-lactalbumina ( $14 k D a)$, conclui-se que em P4-P7 e P10-P11 existem complexos formados por até duas proteínas compartilhando a mesma micela, diferentemente de P8-P9.

Sintetizando os resultados obtidos de todas as técnicas e análises, foi possível descrever a interação entre alfa-lactalbumina e SDS em quatro estágios (Figura 39):

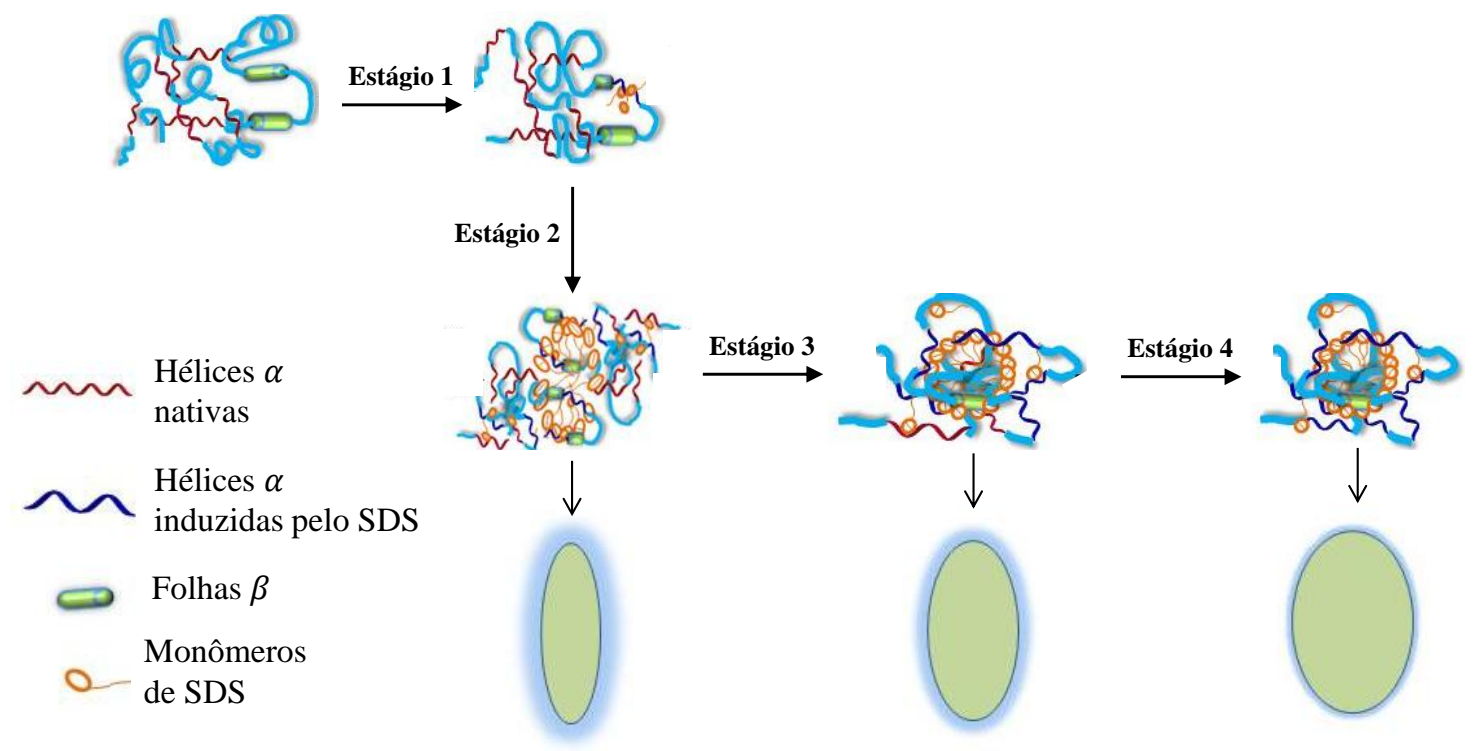

Figura 39: Representação esquemática dos diferentes estágios da ligação de SDS na lisozima, dando origem aos complexos estudados nessa seção. Figura adaptada de [105].

1) (P1-P3) No pH 6,9, ambos alfa-lactalbumina e SDS estão carregados negativamente, tornando as interações hidrofóbicas mais relevantes nesta etapa [146]. Nesse caso, as cadeias apolares do surfactante se associam muito provavelmente com as porções hidrofóbicas da proteína que se encontram do lado oposto ao sítio de ligação de cálcio [147], trazendo como consequência a exposição de resíduos Trp [148]. Além disso, a interação iônica entre os grupos sulfato e os aminoácidos carregados negativamente pode induzir uma maior compactação de toda a estrutura proteica, como observado nos resultados de SAXS e CD. Todo o processo gera o maior efeito endotérmico observado nos entalpogramas. 
2) (P4-P7) As cadeias apolares dos monômeros de SDS adicionais se associam com os resíduos Trp expostos [149], enquanto os grupos sulfatos podem estabelecer interações iônicas do tipo atrativas e repulsivas com as cadeias laterais de outros resíduos carregados [150]. A ligação cooperativa favorece a estabilização das cadeias laterais que foram expostas ao solvente no estágio anterior, o que pode induzir a conversão folhas $\beta$ e laços em hélices $\alpha$ [151]. Os complexos formados podem ser descritos como micelas decoradas com 11 a 30 monômeros de SDS formando o core e quase duas proteínas formando o shell (essa associação dimérica em micelas decoradas já foi reportada antes na literatura e não é uma situação incomum [42,144]).

3) (P7-P9) Nessa etapa 40 monômeros de SDS se ligam à proteína. $[S]_{\text {free }}$ é suficiente para a formação de micelas livres de surfactante. Passa a existir, portanto, uma competição entre monômeros adicionais para constituírem ou micelas livres ou micelas decoradas. Essa situação favorece o rearranjo da estrutura dos complexos, aumentando a exposição de porções hidrofóbicas e diminuindo levemente a fração de conformações hélices $\alpha$. Essas alterações contribuem com o comportamento exotérmico detectado pelos entalpogramas de ITC.

4) (P9-P11) Há coexistência entre micelas decoradas e micelas livres de SDS. Nessa situação, que corresponde à saturação observada com os entalpogramas de ITC, uma molécula de proteína, em média, está cobrindo toda a superfície do complexo, que contém cerca de 55 monômeros de SDS.

\subsubsection{Conclusão}

A estratégia adotada no estudo de caso lisozima e SDS permitiu, de maneira bem-sucedida, ter acesso a informações sobre a interação entre alfa-lactalbumina e SDS, possibilitando caracterizar os complexos formados de maneira sistemática e consistente, tanto estrutural quanto termodinamicamente. Conclui-se que os complexos proteína-surfactante podem ser interpretados como micelas decoradas, com formato elipsoidal de revolução prolato, onde o core é formado pelas cadeias apolares e o shell é constituído pelas cabeças polares juntamente com a proteína (uma ou aproximadamente duas, dependendo do estágio da ligação) em seu estado "molten globule", como observado pelos dados de $\mathrm{CD}$, cobrindo toda a superfície micelar. Os resultados obtidos foram sintetizados em quatro estágios e representados 
esquematicamente na Figura 39. Por tudo isso, ficou verificado que a abordagem adotada pode ser usada com sucesso para o estudo das interações entre proteínas globulares e surfactantes. 


\section{LIPOSSOMAS - (BIO)ATIVOS}

Neste Capitulo serão apresentados os resultados das análises de SAXS de três sistemas formados por lipossomas e (bio)ativos usando o Método da Deconvolução Gaussiana. Como será visto, a abordagem permitiu a caracterização das alterações na bicamada lipídica devido à presença dos (bio)ativos. No contexto da colaboração com outros grupos de pesquisa, as informações obtidas aqui contribuíram(rão) para compor um panorama mais geral sobre os sistemas envolvendo outras técnicas e análises.

\subsection{Estudo de caso: Lipossomas e curcumina/vitamina $D_{3}{ }^{14}$}

\subsubsection{Introdução}

A busca crescente por hábitos de vida mais saudáveis por parte dos consumidores levou ao aumento da demanda por alimentos cada vez mais naturais e funcionais. Consequentemente, há a necessidade do desenvolvimento de técnicas que possibilitem uma adição mais efetiva de ingredientes naturais/funcionais em matrizes alimentícias. Dentre esses ingredientes está a curcumina (Figura 40A), um bioativo de cor amarela encontrado no açafrão-da-terra (também conhecido como curcuma, turmérico, raiz-de-sol, açafrão-da-índia, açafroa e gengibre amarelo [152] e que, por ser natural e possuir diversas propriedades associadas a efeitos antioxidante, anti-inflamatório e imunomodulatório [153,154], corresponde a um excelente substituto para corantes artificiais na indústria alimentícia.

Por outro lado, a vitamina $\mathrm{D}_{3}$ (também conhecida como colecalciferol, calcitriol, dihidroxicolecalciferol, 7-deidrocolesterol ativado e oleovitamina $\mathrm{D}_{3}$ ) (Figura 40B), que possui vários benefícios associados à absorção de cálcio [155], é um ingrediente funcional sintetizado naturalmente a partir da transformação do composto 7-deidrocolesterol, presente na epiderme humana, devido à incidência dos raios solares (particularmente, da radiação UVB) [156,157].

\footnotetext{
14 [73] M. A. Chaves, P. L. Oseliero, C. G. Jange, R. Sinigaglia-Coimbra, C. L. P. Oliveira, and S. C. Pinho, Colloids and Surfaces a-Physicochemical and Engineering Aspects 549, 112 (2018).
} 
Grande parte da população hoje é deficiente desse tipo de vitamina, seja por causa da perda natural de 7-deidrocolesterol ao longo dos anos, seja porque as pessoas não ficam tão mais expostas ao Sol quando antes [158,159]. A fim de contornar essa situação, que pode levar a doenças como raquitismo (principalmente na infância) e osteoporose (já na fase adulta), podese fortificar alguns alimentos com a vitamina $\mathrm{D}_{3}$ em detrimento ao uso de medicações.

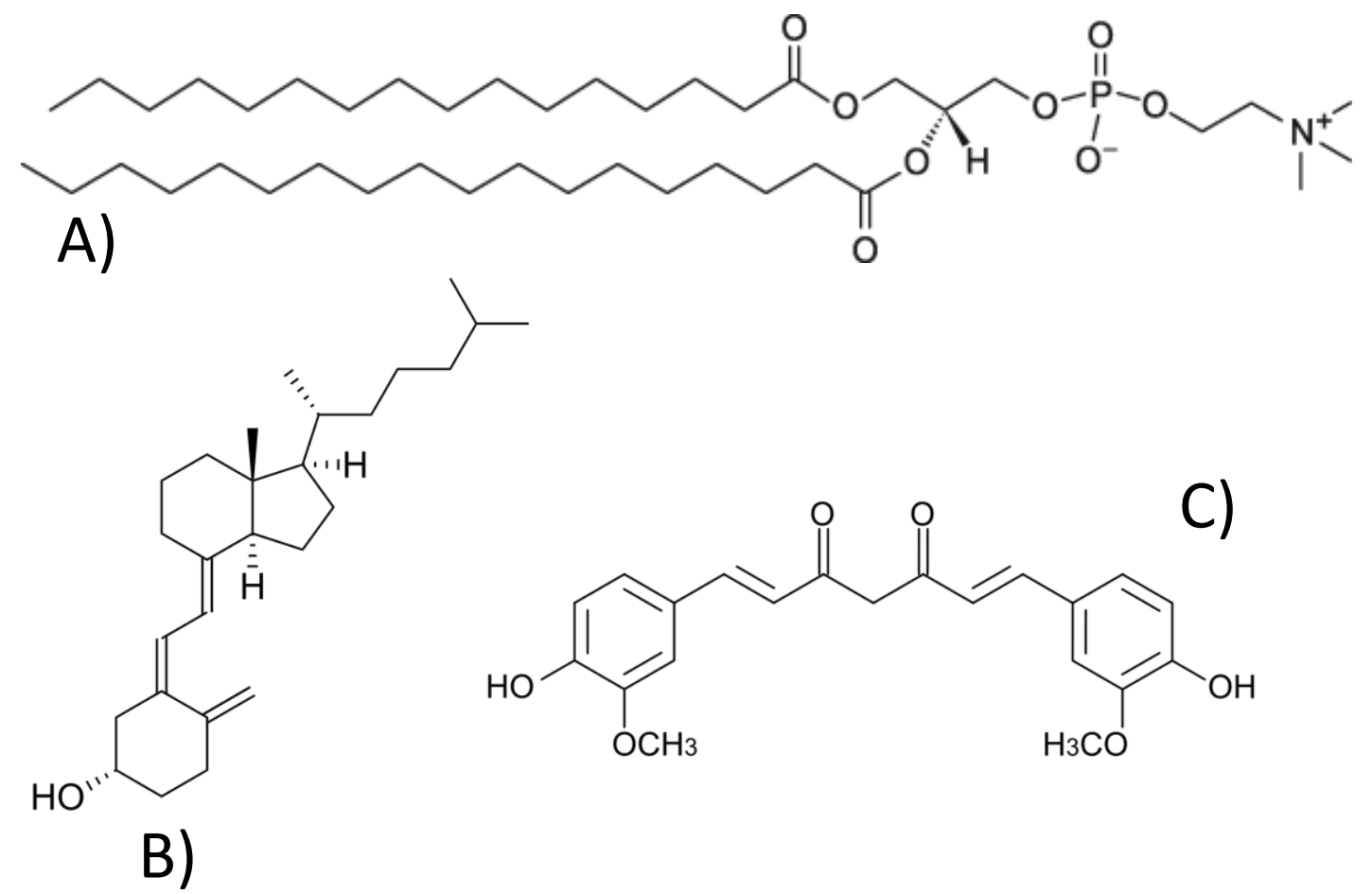

Figura 40: Estrutura química do Phospholipon ${ }^{\circledR} 90 \mathrm{H}$ (A), da vitamina $\mathrm{D}_{3}$ (B) e da curcumina (C)

Em ambos os casos, tanto a curcumina quanto a vitamina $\mathrm{D}_{3}$ são compostos hidrofóbicos, de maneira que a frequente e necessária dispersão dessas substâncias em formulações aquosas se torna bastante limitada. Felizmente, o uso de lipossomas, em particular aquele formado por Phospholipon $^{\circledR} 90 \mathrm{H}$ (Figura 40A), pode resolver esse problema, e já existem na literatura exemplos bem-sucedidos da encapsulação individual de curcuminoides [160] e vitamina $\mathrm{D}_{3}$ [161] que empregam esse tipo de nanocarreador.

Além da encapsulação usual, existe a chamada coencapsulação [25,162,163], técnica largamente utilizada na indústria farmacêutica (mas que também pode ser usada em outras áreas, como a alimentícia) a qual consiste na encapsulação de duas ou mais moléculas no mesmo nanocarreador visando: i) aumentar a disponibilidade dos compostos no ambiente-alvo; ii) utilizar melhor o nanocarreador, uma vez que ele transportará mais de uma única molécula; 
iii) aplicação em tratamentos que demandam o uso de vários fármacos. Para o aumento da estabilidade dos lipossomas produzidos podem ser empregadas, individualmente ou misturadas, as chamadas gomas (como a goma xantana e goma guar), que agem formando uma rede polimérica no meio disperso, impedindo dessa forma a coalescência ou quebra das vesículas e, ao mesmo tempo, garantindo homogeneidade do sistema [164].

Nesse contexto, o objetivo deste trabalho foi o de caracterizar, por meio da análise quantitativa de dados de SAXS, alterações estruturais na bicamada lipídica dos lipossomas devido à coencapsulação da curcumina e vitamina $\mathrm{D}_{3}$ bem como devido ao aumento de temperatura.

\subsubsection{Resultados e Discussão}

As curvas obtidas estão mostradas na Figura 41A (símbolos abertos). Há cinco grupos de curvas, nomeados de FC, F5V, F8V, FC5V e FC8V. A primeira sigla corresponde a lipossomas contendo apenas curcumina, usada aqui como referência para checar as eventuais alterações estruturais nas bicamadas lipídicas introduzidas pela presença da vitamina $\mathrm{D}_{3}$. Já F5V e F8V dizem respeito a lipossomas contendo apenas vitamina $\mathrm{D}_{3}$ nas quantidades 50000 UI e 80000 UI, respectivamente. "UI", que vem de "Unidades Internacionais", é como em geral são medidas as doses dessa substância. Por fim, as siglas FC5V e FC8V representam, respectivamente, lipossomas contendo curcumina e vitamina $\mathrm{D}_{3}$ nas quantidades mencionadas anteriormente. Visando maior clareza na apresentação dos resultados, as curvas correspondentes às temperaturas $30^{\circ} \mathrm{C}$ e $50{ }^{\circ} \mathrm{C}$ foram omitidas por serem muito similares às curvas de $20^{\circ} \mathrm{C} \mathrm{e} 40{ }^{\circ} \mathrm{C}$.

Devido à presença de picos de Bragg na razão $q_{0}: q_{1}$ de $1: 2$, onde $q_{0}$ e $q_{1}$ são as posições do primeiro e segundo picos, respectivamente, conclui-se que as curvas são características de sistemas contendo vesículas multilamelares ou mesmo uma mistura de vesículas uni- e multilamelares. Além disso, independentemente da presença ou quantidade de curcumina e vitamina $\mathrm{D}_{3}$, todos os conjuntos de curvas de SAXS são muito similares entre si, indicando qualitativamente que nenhum dos bioativos induzem mudanças estruturais significativas na bicamada. Em termos do efeito da temperatura, nota-se que os picos ficam mais finos e intensos quando se passa de $50{ }^{\circ} \mathrm{C}$ para $60^{\circ} \mathrm{C}$. Essa mudança ocorre por causa da transição da fase gel para a fase líquido-cristalina, fato este corroborado por experimentos de Calorimetria Diferencial de Varredura (DSC) por meio dos quais conclui-se que $T_{C} \sim 53{ }^{\circ} \mathrm{C}$ [73], um pouco 
menor do que a temperatura de transição para o Phopholipon ${ }^{\circledR} 90 \mathrm{H}\left(\sim 55^{\circ} \mathrm{C}^{15}\right)$. Essa informação é bastante importante para a aplicação desses lipossomas na indústria alimentícia, uma vez que a temperatura de estocagem é da ordem de $10^{\circ} \mathrm{C}$. Desse modo, com uma temperatura de transição alta, é possível garantir e integridade estrutural dos lipossomas [72,164,165]. É interessante notar a mudança estrutural provocada na bicamada devido à transição térmica fica muito evidente nas curvas de SAXS.
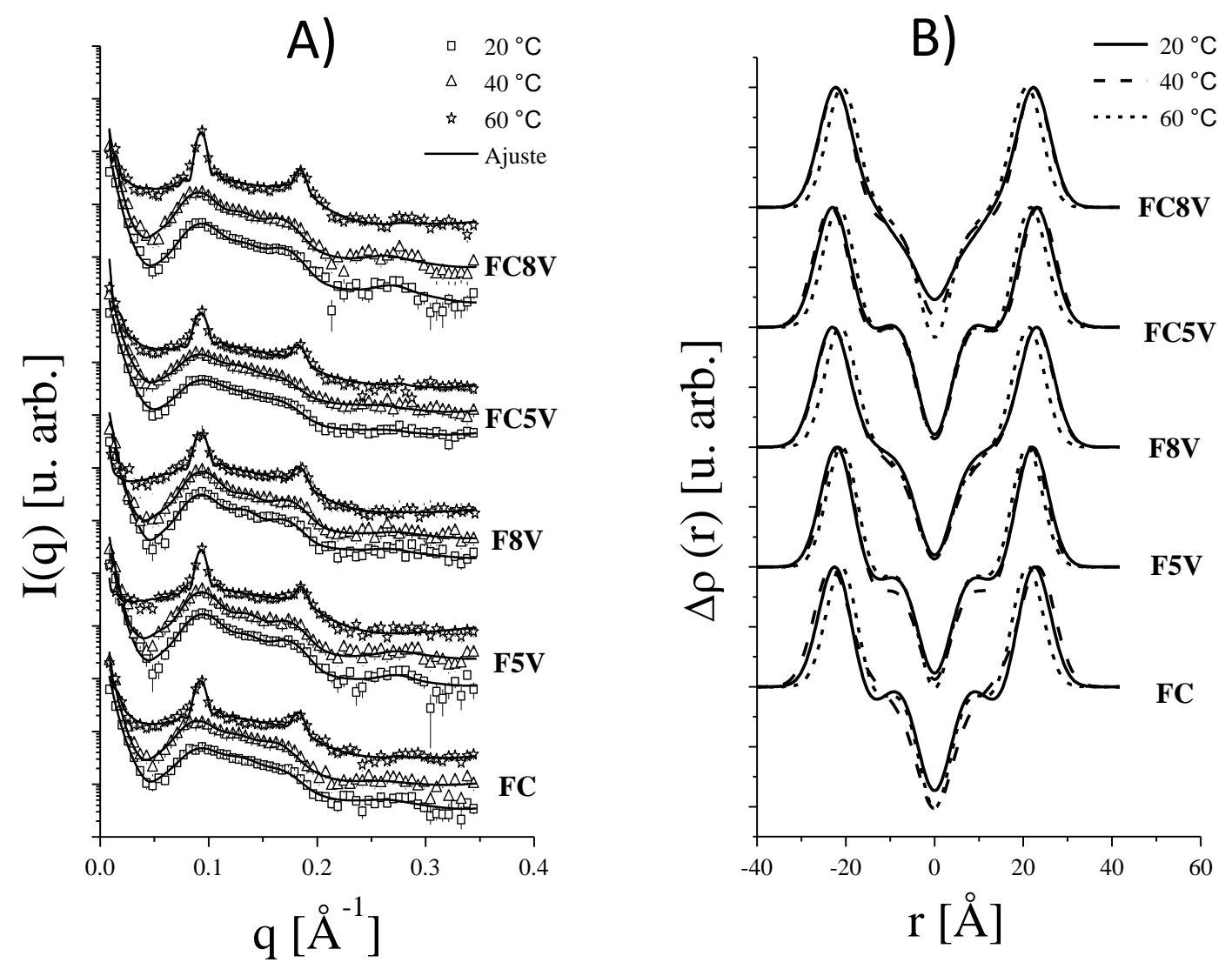

Figura 41: A) Dados de SAXS (símbolos abertos) correspondentes a dispersões de lipossomas contendo apenas curcumina (FC), apenas vitamina $\mathrm{D}_{3}$ na concentração 50000 UI (F5V), apenas vitamina $\mathrm{D}_{3}$ na concentração 80000 $\mathrm{UI}(\mathrm{F} 8 \mathrm{~V})$, curcumina + vitamina $\mathrm{D}_{3}$ na concentração $50000 \mathrm{UI}(\mathrm{FC} 5 \mathrm{~V})$, curcumina + vitamina $\mathrm{D}_{3}$ na concentração 80000 UI (FC8V), em diferentes temperaturas. As curvas de SAXS relativas às temperaturas $30{ }^{\circ} \mathrm{C}$ e $50^{\circ} \mathrm{C}$ estão ausentes pois são muito semelhantes às curvas para $20^{\circ} \mathrm{C} \mathrm{e} 40^{\circ} \mathrm{C}$. As linhas sólidas correspondem aos ajustes usando o Método de Deconvolução Gaussiana. B) Perfis de contraste de densidade eletrônico obtidos a partir dos ajustes dos dados experimentais.

Com a finalidade de se obter informações quantitativas, as curvas de SAXS foram ajustadas segundo o Método da Deconvolução Gaussiana (ver seção Fundamentos Teóricos, Capítulo 2),

${ }^{15}$ De acordo com http://www.americanlecithin.com. 
o qual permite a modelagem simultânea de ambos o fator de forma, relacionado nesse caso com informações sobre a bicamada lipídica, e o fator de estrutura, que traz dados sobre o empilhamento dessas bicamadas para o caso de lipossomas multilamelares.

Os resultados dos ajustes (Figura 41A (linhas cheias)) incluem os perfis de contraste de densidade eletrônica, $\Delta \rho(r)$ (Figura 41B). Como observado, eles indicam a presença de bicamadas simétricas, comuns em lipossomas compostos de fosfolipídios zwieteriônicos $[93,166]$. Isso é justificado para este caso, uma vez que o Phopholipon ${ }^{\circledR} 90 \mathrm{H}$ é majoritariamente constituído de fosfatidilcolina (> $85 w t \%$ ) [167]. Apesar da semelhança, é possível observar pequenas diferenças de contraste eletrônico entre os perfis, principalmente para o sistema FC8V, em relação ao qual o perfil sofreu uma variação um pouco mais pronunciada na sua região central com o aumento da temperatura. Essas modificações podem, muito provavelmente, serem associadas com a presença dos bioativos na bicamada. Mesmo pouco perceptíveis, talvez porque a concentração relativa de curcumina $(0,025 w t \%)$ e vitamina $\mathrm{D}_{3}$ (menos de 0,002 wt\%) seja baixa, a técnica de SAXS possui sensibilidade suficiente para indicá-las. Além disso, as moléculas de curcumina e vitamina $\mathrm{D}_{3}$ são menores do que o lipídio, de maneira que a acomodação de ambos os bioativos no interior da mesma matriz lipídica é perfeitamente possível sem que isso gere alterações estruturais.

Na Tabela 10 (Apêndice 1) e Figura 42 são apresentados os parâmetros estruturais obtidos pelos ajustes descritos anteriormente. A adição dos bioativos parece não alterar o número de bicamadas correlatas $N$, que permanece entre 2 e 3 para todos os casos, exceto quando a temperatura do sistema é superior à $T_{c}$. Nesse caso, $N$ apresenta um aumento abrupto e atinge valores entre 7 e 8 bicamadas. Sendo assim, nessa situação, embora as caudas apolares dos lipídeos se apresentem em um estado desorganizado (fase líquido-cristalina), o sistema de bicamadas passa a ser mais organizado. Isso é compatível com o fato da curva de SAXS relativa à temperatura de $60^{\circ} \mathrm{C}$ apresentar picos mais intensos e finos. 

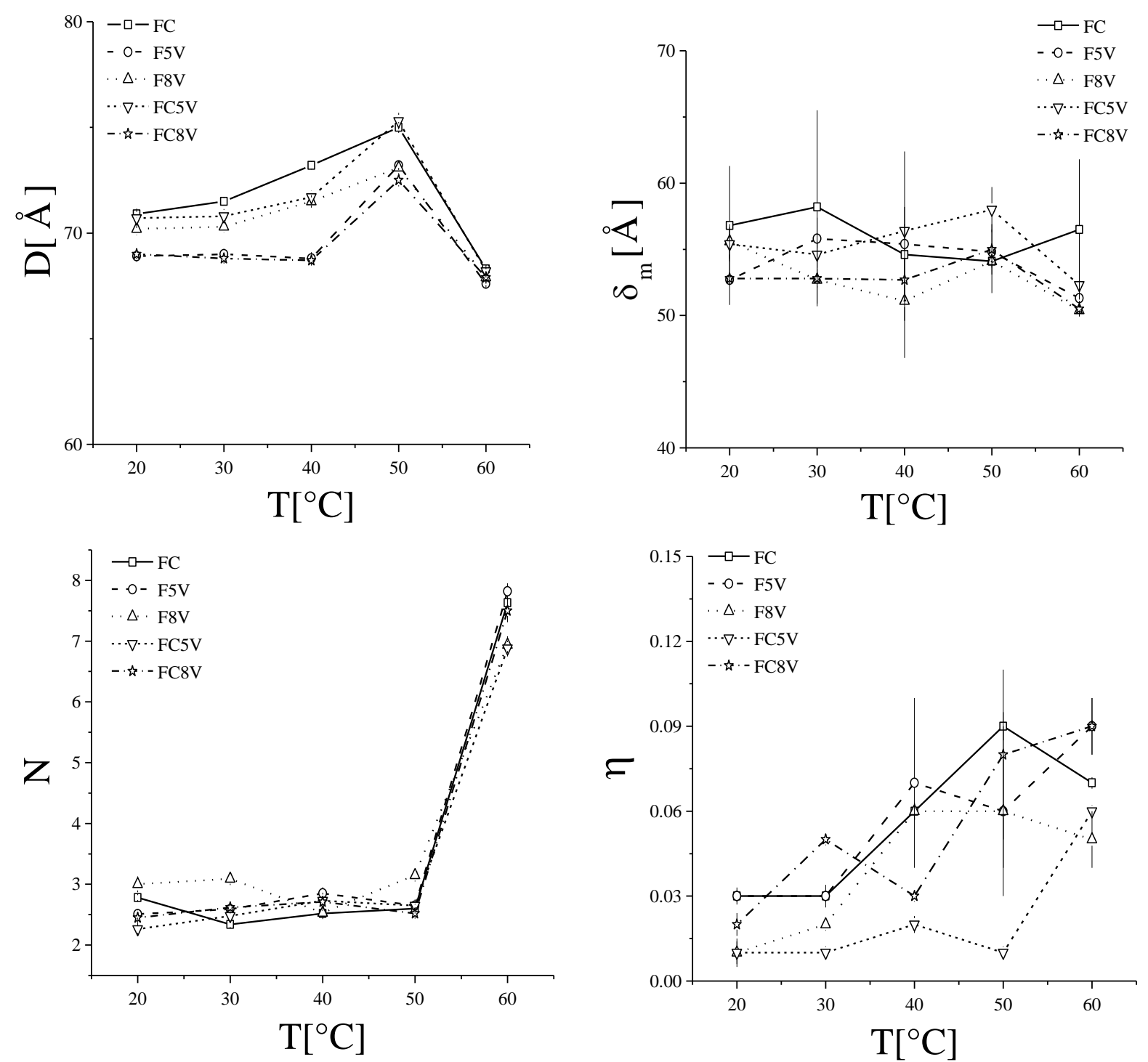

Figura 42: Valores dos parâmetros obtidos para as composições FC, F5V, F8V, FC5V e FC8V em função da temperatura.

O parâmetro de Caillé $\eta$ tende a aumentar de maneira mais gradual conforme o aumento de temperatura exceto para o caso $\mathrm{FC} 5 \mathrm{~V}$, que possui um comportamento mais abrupto similar ao do parâmetro $N$. Em todos os casos, $\eta$ é maior ao final do aquecimento do que no começo, sugerindo que as membranas se tornam mais flexíveis. Por outro lado, a periodicidade lamelar $D$ tende a aumentar conforme o aumento da temperatura e, na temperatura de transição, apresenta uma diminuição abrupta. Essa observação já foi reportada na literatura por Takeda et al. [168], que concluiu que $D$ na fase gel é maior do que na fase líquido-cristalina. A espessura da bicamada $\delta_{m}$ permanece constante, dentro das barras de erro, para todas as formulações e temperaturas estudadas, sugerindo novamente que a encapsulação dos bioativos não traz mudanças estruturais profundas na matriz lipídica. 


\subsubsection{Conclusões}

As análises de SAXS indicaram que não há mudanças estruturais significativas na estrutura da bicamada lipídica com a adição de vitamina $\mathrm{D}_{3}$, nas quantidades 50000 e 80000 UI, em lipossomas contendo curcumina. Esse fato é muito importante considerando as aplicações dos lipossomas produzidos, uma vez que é possível encapsular vitamina $\mathrm{D}_{3}$ em quantidades muito maiores do que àquelas recomendadas para dose diária $\left(\sim 1000 \mathrm{UI}^{16}\right)$. Além disso, o procedimento de análise usado permitiu acompanhar as modificações nos parâmetros que caracterizam as membranas com o aumento da temperatura. De maneira geral, a espessura da bicamada permanece constante (dentro das barras de erro), enquanto a membrana se torna mais flexível com o aumento de temperatura. Em relação à estrutura do lipossoma, o aumento de temperatura o torna mais multilamelar depois da temperatura de transição ao passo que a distância entre as bicamadas diminui.

${ }^{16}$ De acordo com https://www.hospitalsiriolibanes.org.br. 


\subsection{Estudo de caso: Lipossomas e ácido láurico}

\subsubsection{Introdução}

Acne vulgar é uma das doenças de pele humana mais comuns, e começa quando o folículo piloso é bloqueado pelo excesso de sebo e pele morta [169]. Como grande parte do sebo não consegue ultrapassar a abertura do poro e ali se acumula, formam-se os chamados comodões abertos (cravos pretos) ou fechados (cravos brancos) [170].

A acne vulgar ocorre com maior frequência em regiões do corpo humano com maior quantidade de glândulas sebáceas, como o rosto e a parte superior do peito e das costas. Além dos vários fatores que podem levar ao aparecimento e persistência da acne vulgar, tais como fatores genéticos, tabagismo e dieta, o acúmulo de sebo retido no interior dos folículos, principalmente na fase da puberdade, favorece a infestação por bactérias como a Propionibacterium acnes, as quais desempenham papel importante na doença [171], uma vez que os poros bloqueados (cravos pretos ou brancos) e contaminados por bactérias dão origem às espinhas (pústulas, pápulas e cistos). É conhecido que a $P$. acnes possui efeitos positivos na pele normal, protegendo-a de outras bactérias patogênicas. Contudo, ela se torna patogênica em pele doente [172]. Nos casos mais leves de acne vulgar, a aplicação tópica de medicamentos contendo ativos como a tretinoína, ácido retinoico, salicílico ou peróxido de benzoíla pode ser suficiente para desobstruir os folículos pilosos, controlar a oleosidade e impedir o desenvolvimento de bactérias [173]. Já para os casos mais graves, de acne inflamatória e purulenta, os antibióticos por via oral ou tópica ou, ainda, sob a forma de injeções no interior das lesões, representam uma opção de tratamento mais intensivo [174].

Tratamentos usando antibióticos são bem-sucedidos na maioria dos casos, ao menos reduzindo a área de pelo afetada. Contudo, essas abordagens podem levar à resistência microbiana [175]. Terapias alternativas contra o P. acnes, especialmente usando ácidos graxos como o ácido láurico (LA) têm sido propostos uma vez que se mostraram bastante eficientes [176]. Contudo, essas moléculas possuem baixíssima solubilidade em formulações aquosas, problema este que pode ser contornado com a encapsulação de LA em lipossomas, os quais têm sido largamente usados como nanocarreadores de fármacos e com grande potencial para aplicações tópicas (Maghraby et al., 2008; Elsayed et al., 2007). Já é conhecido que ácidos graxos alteram propriedades estruturais e termodinâmicas dos lipossomas, tais como temperatura de transição, lamelaridade, diâmetro das vesículas, etc. [177], que não foram ainda extensivamente exploradas [178]. Nesse sentido, o objetivo deste trabalho foi o de, assim como no estudo de 
caso anterior, caracterizar, por meio da análise quantitativa de dados de SAXS, alterações estruturais na bicamada lipídica dos lipossomas formados por DPPC (Figura 43A) devido à presença de LA (Figura 43B) em diferentes pH's.

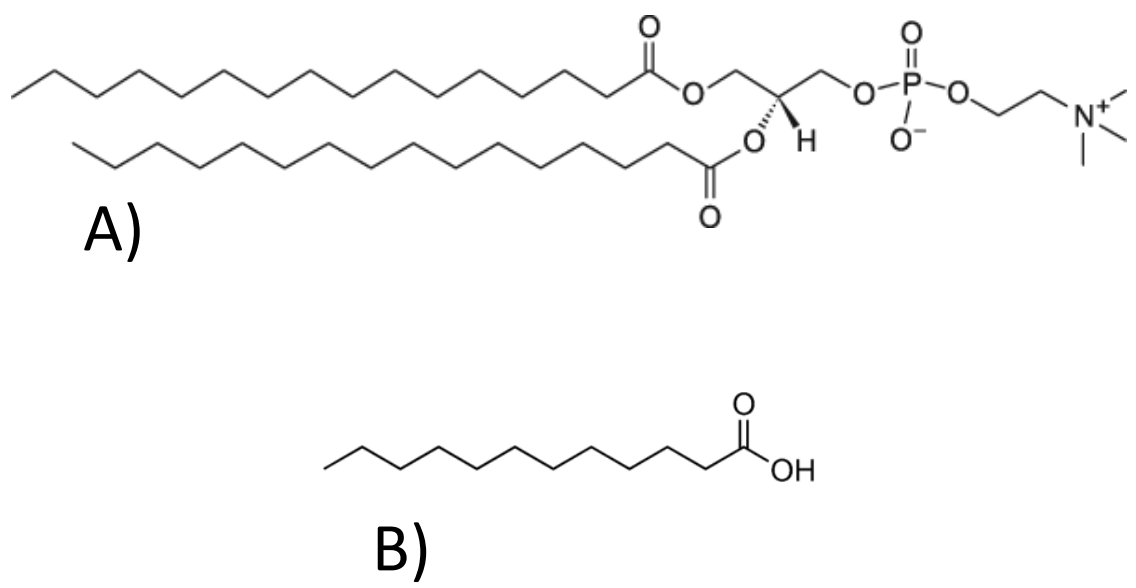

Figura 43: Estrutura química da dipalmitoilfosfatidilcolina de soja (A) e do ácido láurico (B).

\subsubsection{Resultados e Discussão}

Os dados tratados estão exibidos na Figura 44A (símbolos abertos), são característicos de vesículas uni- ou multilamelares. A principal diferença entre elas está relacionada ao fato de que vesículas multilamelares exibem uma oscilação no "bump" na região $0,06 \AA^{-1}<q<$ $0,2 \AA^{-1}$, o que indica um número de bicamadas lipídicas correlacionadas $(N)$ maior que 1 . Por exemplo, considerando a Figura 44A, esquerda ( $\mathrm{pH} 5,0)$, as curvas correspondentes a 40\% e $50 \%$ de LA são relacionadas à predominância de vesículas unilamelares, uma vez que não há oscilação no "bump" na região $0,06 \AA^{-1}<q<0,2 \AA^{-1}$, diferentemente do restante das curvas, relacionadas à presença de vesículas multilamelares. Como observado na Figura 44A, vesículas formadas apenas por DPPC (0\% de LA), ambas em pH 5,0 e 7,4, são multilamelares. Já que o aspecto geral das curvas de SAXS é similar, é possível concluir qualitativamente que as vesículas possuem estruturas semelhantes no intervalo de $q$ analisado. Entretanto, aumentandose a quantidade de LA até $10 \%$, há uma transição de vesículas multi- para unilamelares quando o pH é 7,4. A mesma transição é observada para o pH 5,0, a qual acontece somente com $40 \%$ de LA. Esse resultado indica qualitativamente a importância do $\mathrm{pH}$ na nanoestrutura do sistema estudado. 

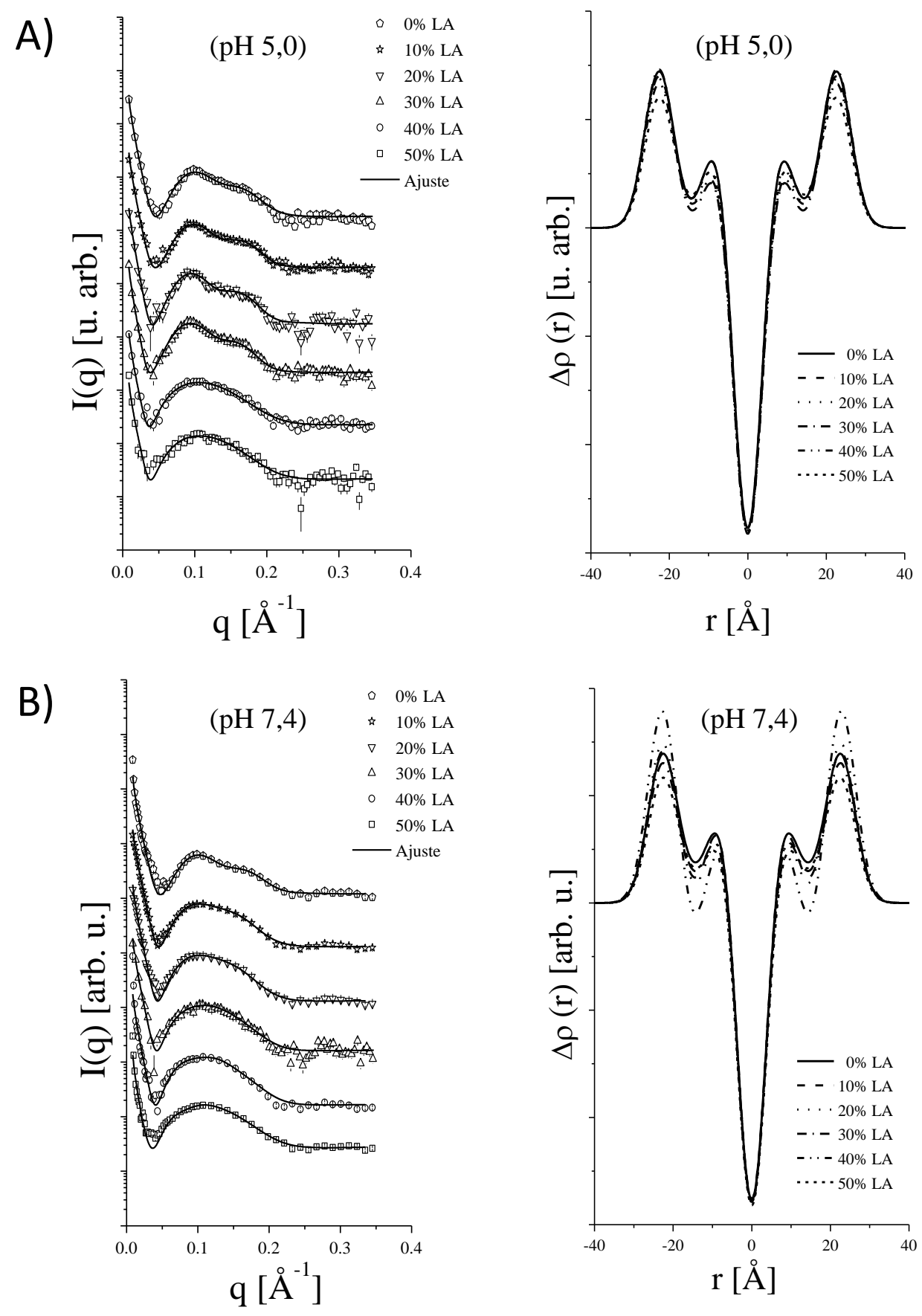

Figura 44: A) Dados experimentais (símbolos abertos) correspondentes a vesículas em presença de LA em diferentes pH's. As linhas sólidas correspondem aos ajustes usando o Método da Deconvolução Gaussiana. B) Perfil de contraste de densidade eletrônico obtido a partir dos ajustes dos dados experimentais.

A fim de se obter informação quantitativa sobre as mudanças estruturais do sistema, as curvas experimentais de SAXS foram ajustadas com o Método da Deconvolução Gaussiana. Os ajustes estão mostrados na Figura 44A (linhas sólidas) e descrevem satisfatoriamente o comportamento dos dados experimentais. O resultados dos ajustes incluem o perfil de contraste de densidade 
eletrônico $\Delta \rho(r)$, mostrados na Figura 44B, e os valores dos outros parâmetros de ajuste, sumarizados na Tabela 8. É importante mencionar que todos os valores mostrados correspondem a valores médios. Por exemplo, $N$ igual a 1,3 \pm 0,1 não significa uma vesícula com 1,3 bicamadas, mas apenas que as vesículas possuem, em média, 1,3 bicamadas. Além disso, para vesículas cujo valor de $N$ é próximo de 1 (considerando as barras de erro), ou seja, vesículas unilamelares, os parâmetros relativos ao fator de estrutura ( $D$ e $\eta$ ) não puderam ser determinados e/ou não fazem sentido. Para esses casos, seus valores na Tabela 8 aparecem como "NA" (não se aplica).

Tabela 8: Valores dos parâmetros obtidos a partir dos ajustes das curvas experimentais (Figura 44A) usando o Método da Deconvolução Gaussiana. Para vesículas unilamelares (valor de $N$ próximo de 1), os parâmetros relativos ao fator de estrutura ( $D$ e $\eta$ ) não se aplicam ("NA"). Os valores entre parêntesis indicam a incerteza no último algarismo significativo.

\begin{tabular}{|c|c|c|c|c|c|}
\hline $\mathrm{pH}$ & $\%$ LA & $D[\AA ̊]$ & $\delta_{m}[\AA]$ & $N$ & $\eta$ \\
\hline \multirow{6}{*}{5,0} & 0 & $68(9)$ & $51(5)$ & $1,3(1)$ & $0,04(5)$ \\
\hline & 10 & $69(1)$ & $51(5)$ & $1,3(1)$ & $0,02(1)$ \\
\hline & 20 & $70(2)$ & $53(9)$ & $1,4(1)$ & $0,3(1)$ \\
\hline & 30 & $70(9)$ & $51(7)$ & $1,3(1)$ & $0,23(3)$ \\
\hline & 40 & NA & $52(2)$ & $1,0(1)$ & NA \\
\hline & 50 & NA & $51(6)$ & $1,0(1)$ & NA \\
\hline \multirow{6}{*}{7,4} & 0 & $68(8)$ & $52(3)$ & $1,3(2)$ & $0,08(2)$ \\
\hline & 10 & NA & $52(7)$ & $1,1(1)$ & NA \\
\hline & 20 & NA & $53(3)$ & $1,0(1)$ & NA \\
\hline & 30 & NA & $51(4)$ & $1,0(1)$ & NA \\
\hline & 40 & NA & $51(7)$ & $1,1(1)$ & NA \\
\hline & 50 & NA & $51(5)$ & $1,1(1)$ & NA \\
\hline
\end{tabular}

Como observado na Figura 44A, os perfis $\Delta \rho(r)$ possuem o mesmo aspecto geral para todos os casos, mas mudanças significativas foram encontradas na parte mais externa das curvas associadas às cabeças polares do fosfolipídeo, indicando que LA interage predominantemente com a porção hidrofílica das bicamadas lipídicas. Aparentemente essa interação possui efeito 
desprezível sobre a espessura membranar, uma vez que os valores de $\delta_{m}$, aproximadamente $50 \AA ̊$ Å, são similares (dentro das barras de erro) para todos os casos investigados. Além disso, os resultados para o parâmetro $N$ confirmaram a transição de vesículas multi- para unilamelares comentado anteriormente para ambos os pH's. Para pH 5,0, essa transição acontece a partir de $40 \%$ de LA (já que, a partir dessa porcentagem, $N \approx 1$ ), mas para $\mathrm{pH} 7,4$ acontece a partir de apenas $10 \%$ de LA. Para o pH 7,4 é importante mencionar que o "bump" na região $0,06 \AA^{-1}<$ $q<0,2 \AA^{-1}$ exibe uma pequena oscilação para as curvas relativas a 10\%, 20\%, 30\%, 40\% e $50 \%$ de LA, de modo que o valor de $N$ obtido a partir dos ajustes não é perfeitamente igual a 1 , mas perto o suficiente. Isso acontece porque, como em todos os casos, há uma coexistência entre vesículas uni- e multilamelares, especialmente quando $N$ é baixo [167].

Como observado para $\delta_{m}$, a periodicidade lamelar $D$ (para vesículas multilamelares) permanece aproximadamente constante e igual a $70 \AA$ (dentro das barras de erro). Por outro lado, o parâmetro de Caillé $\eta$ aumenta conforme a quantidade de LA aumenta, em ambos os pH's, indicando que a membrana lipídica se torna mais flexível, provavelmente devido a defeitos topológicos criados pela presença do LA [179].

\subsubsection{Conclusões}

Uma caracterização das bicamadas de lipossomas de DPPC em presença de LA em diferentes concentrações foi realizada por meio da análise quantitativa que empregou o Método da Deconvolução Gaussiana. LA interage preferencialmente com as cabeças polares do fosfolipídeo. Além disso, foi observada uma transição de lipossomas multilamelares para unilamelares a qual é dependente tanto da quantidade de LA no sistema quanto do pH utilizado. Para o pH 5,0, essa transição ocorre para concentrações de LA da ordem de 10\% ou maiores. Já para pH 7,4 é necessário maior quantidade LA, ocorrendo apenas para concentrações de, no mínimo, 40\% de LA. Em todos os casos estudados, a espessura da bicamada permanece constante (dentro das barras de erro), enquanto a membrana se torna mais flexível com o aumento da quantidade de LA. Nos casos em que há vesículas multilamelares (principalmente no $\mathrm{pH} 5,0)$, o espaçamento entre bicamadas parece aumenta conforme a quantidade de LA aumenta. 


\subsection{Estudo de caso: Lipossomas e sumatriptano ${ }^{17}$}

\subsubsection{Introdução}

A cefaleia, designação para dores de cabeça em geral, é uma queixa bastante comum entre as pessoas. A sociedade internacional de cefaleia reconhece mais de 300 tipos, e as distingue entre as primárias (que correspondem a uma doença) e secundárias (que são consequência de outra desordem onde a relação causal é bem estabelecida) [181].

A enxaqueca, também conhecida como migrânea, é um tipo de cefaleia primária, com sintomas que variam entre os pacientes, mas que traz uma dor recorrente, unilateral e pulsátil, de intensidade moderada a intensa, sendo agravada por atividade física rotineira e que pode durar de 4 a 72 horas. Além da dor, as crises podem ser associadas à fotofobia, fonofobia, vertigem, náusea e vômito, [182].

A fisiopatologia da enxaqueca, a exemplo da acne vulgaris discutida no estudo de caso anterior, ainda não é compreendida completamente. Acreditava-se antes que a enxaqueca seria uma doença vascular, onde a modulação da contração dos vasos sanguíneos aliviaria seus sintomas. Contudo, estudos mostraram que a enxaqueca seria uma doença com causas vasculares, relacionadas aos vasos sanguíneos intracranianos, mas também neurológicas, influenciada pela modulação de neurotransmissores e peptídeos [183]. A terapia de primeira linha é feita com anti-inflamatórios do tipo não-esteroidais, entre os quais pode haver o uso do ácido acetilsalicílico associado ou não à metoclopramida, ibuprofeno, naproxeno e ácido tolfenâmico, bem como uma associação entre ácido acetilsalicílico, paracetamol e cafeína [184]. Já para tratamento específico, onde os casos são mais graves ou os fármacos acima não possuem resposta, são utilizadas as classes dos derivados de ergotaminas, como a di-hidroergotamina, e os triptanos, como sumatriptana, zolmitriptana, naratriptana, eletriptana, rizatriptana, almotriptana e frovatriptana $[185,186]$.

A eficácia do tratamento está relacionada à rapidez em se iniciar a medicação uma vez diagnosticada a enxaqueca e principalmente à concentração do fármaco no sangue após sua administração no decorrer da crise [187]. Sobre esse último aspecto, sumatriptana (SMT), também chamado de sumatriptano (Figura 45B), é o mais frequentemente usado para o tratamento dessa doença porque pode ser administrado tanto oral quanto subcutaneamente.

\footnotetext{
17 [180] I. Wood, J. M. R. Albano, P. L. O. Filho, V. M. Couto, M. A. de Farias, R. V. Portugal, E. de Paula, C. L. P. Oliveira, and M. Pickholz, European Biophysics Journal with Biophysics Letters 47, 561 (2018).
} 
Infelizmente, trata-se de um fármaco hidrofóbico o que dificulta seu acesso ao sistema nervoso central bem como sua disponibilidade no meio [188,189]. Nesse sentido, o desenvolvimento de nanocarreadores poderia ser uma estratégia promissora visando minimizar efeitos colaterais pela diminuição da concentração de SMT no sangue, manter a liberação do fármaco por mais tempo, bem como facilitar a permeação de SMT na barreira sangue-cérebro. Recentemente, tentativas foram feitas para encapsular SMT em nanopartículas, entre eles os lipossomas [190,191]. Contudo, poucas resultaram em soluções farmacêuticas minimamente viáveis gerando, assim, a demanda por maior pesquisa sobre esse tema.
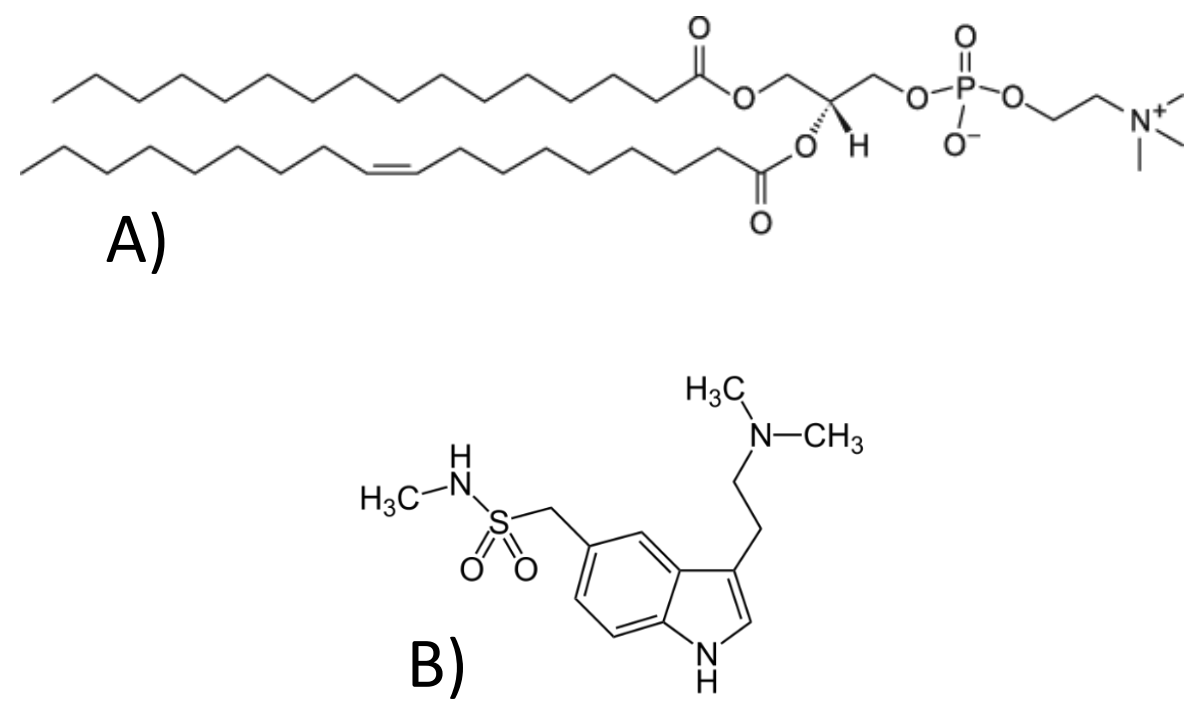

Figura 45: Estrutura química da fosfatidilcolina de ovo (A) e do sumatriptano (B).

Nesse contexto, o objetivo deste trabalho foi o de, assim como nos estudos de caso anteriores, caracterizar, por meio da análise quantitativa de dados de SAXS, alterações estruturais na bicamada lipídica dos lipossomas formados por fosfatidilcolina de ovo (EPC) (Figura 45A) devido à presença SMT em diferentes razões molares.

\subsubsection{Resultados e discussão}

A Figura 46A mostra os dados experimentais tratados (símbolos abertos). Embora pouco pronunciados, é possível notar nas curvas a presença de picos, na razão 1:2, indicando estruturas lamelares. Nesse caso, assim como nos estudos de caso anteriores, tratam-se de lipossomas multilamelares. 
Procedeu-se com o ajuste das curvas com o Método de Deconvolução Gaussiana. As primeiras tentativas assumiram que as bicamadas eram simétricas, o que gerava ajustes insatisfatórios, principalmente na região de $q<0,1 \AA^{-1}$. Utilizando-se, entretanto, um perfil $\Delta \rho$ assimétrico, como mostra a Figura 46B, os ajustes (Figura 46A, linhas contínuas) passaram a ser satisfatórios, sendo capazes de descrever toda a curva experimental.
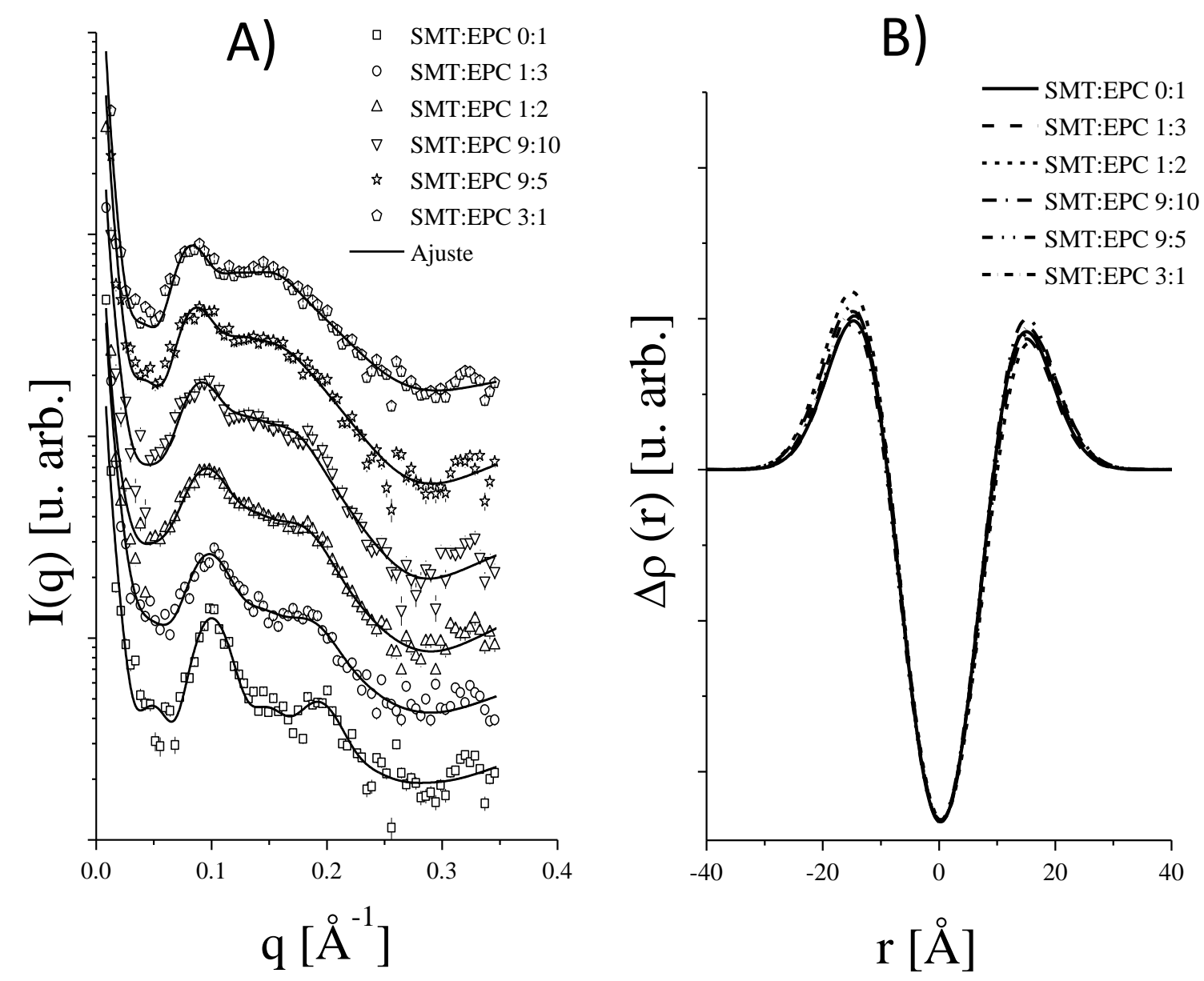

Figura 46: A) Dados experimentais (símbolos abertos) para lipossomas de EPC com SMT em diferentes razões molares. As linhas sólidas correspondem aos ajustes usando o Método da Deconvolução Gaussiana (seção Fundamentos Teóricos do Capítulo 2). B) Perfis de contraste de densidade eletrônica obtidos a partir dos ajustes das curvas experimentais.

É interessante mencionar que os perfis mostrados na Figura 46B são aparentemente mais simples e com menos detalhes do que os perfis utilizados nos estudos de caso anteriores. Isso acontece porque, como visto na seção Fundamentos Teóricos do Capítulo 2, são usadas quatro funções gaussianas para cada lado do perfil simétrico. Logo, são utilizadas no total oito gaussianas, o que confere um nível grande de detalhamento ao desenho do perfil sem, 
necessariamente, aumentar a quantidade de parâmetros do modelo. Caso fosse necessário o mesmo grau de detalhamento para um perfil assimétrico, seria necessário o dobro de parâmetros. No caso da Figura 46B foram usadas cinco funções gaussianas para construir cada perfil, o qual consegue ajustar satisfatoriamente os dados experimentais. Testes foram feitos e o aumento do número de gaussianas não representou melhora significativa dos ajustes tampouco mudanças grandes nos valores dos parâmetros. Portanto, optou-se por utilizar o perfil apresentado que, embora menos detalhado do que aqueles nos estudos de caso anteriores, é capaz de fornecer as mesmas informações fundamentais. Os valores dos parâmetros obtidos encontram-se na Tabela 9, os quais foram usados para construir a Figura 47.

Tabela 9: Valores dos parâmetros obtidos a partir do ajuste dos dados experimentais de SAXS (Figura 46). Os valores entre parêntesis indicam a incerteza no último algarismo significativo.

\begin{tabular}{ccccc}
\hline $\begin{array}{c}\text { Razão molar } \\
\text { SMT:EPC }\end{array}$ & $D[\AA ̊]$ & $\delta_{m}[\AA]$ & $N$ & $\eta$ \\
\hline $0: 1=0,0$ & $62,1(4)$ & $43(5)$ & $2,8(2)$ & $0,15(6)$ \\
\hline $1: 3=0,3$ & $63,4(5)$ & $41(2)$ & $2,5(1)$ & $0,21(6)$ \\
\hline $1: 2=0,5$ & $65,8(4)$ & $42(9)$ & $2,3(1)$ & $0,18(5)$ \\
\hline $9: 10=0,9$ & $69,3(8)$ & $43(1)$ & $2,5(2)$ & $0,24(8)$ \\
\hline $9: 5=1,8$ & $71,7(9)$ & $42(5)$ & $2,8(4)$ & $0,40(9)$ \\
\hline $3: 1=3,0$ & $76,0(9)$ & $42(4)$ & $2,7(2)$ & $0,35(9)$ \\
\hline \hline
\end{tabular}

Observa-se que o parâmetro de Caillé $\eta$ apresentou um leve aumento comparado o seu valor para o EPC puro, o que traduz um aumento da flexibilidade membranar. A periodicidade lamelar $D$ aumenta e a quantidade de camadas correlatas $N$ diminui com a adição do fármaco, enquanto a espessura da bicamada $\delta_{m}$, assim como nos casos anteriores, tende a permanecer constante dentro das barras de erro. Observando o perfil de densidade eletrônica mostrado na Figura 46B, é possível perceber mudanças principalmente na região do gráfico correspondente às cabeças polares dos lipídeos que foram a bicamada, mostrando que a interação SMT e lipossomas acontece preferencialmente nessa parte, compatível com resultados de simulações utilizando Dinâmica Molecular [192]. 

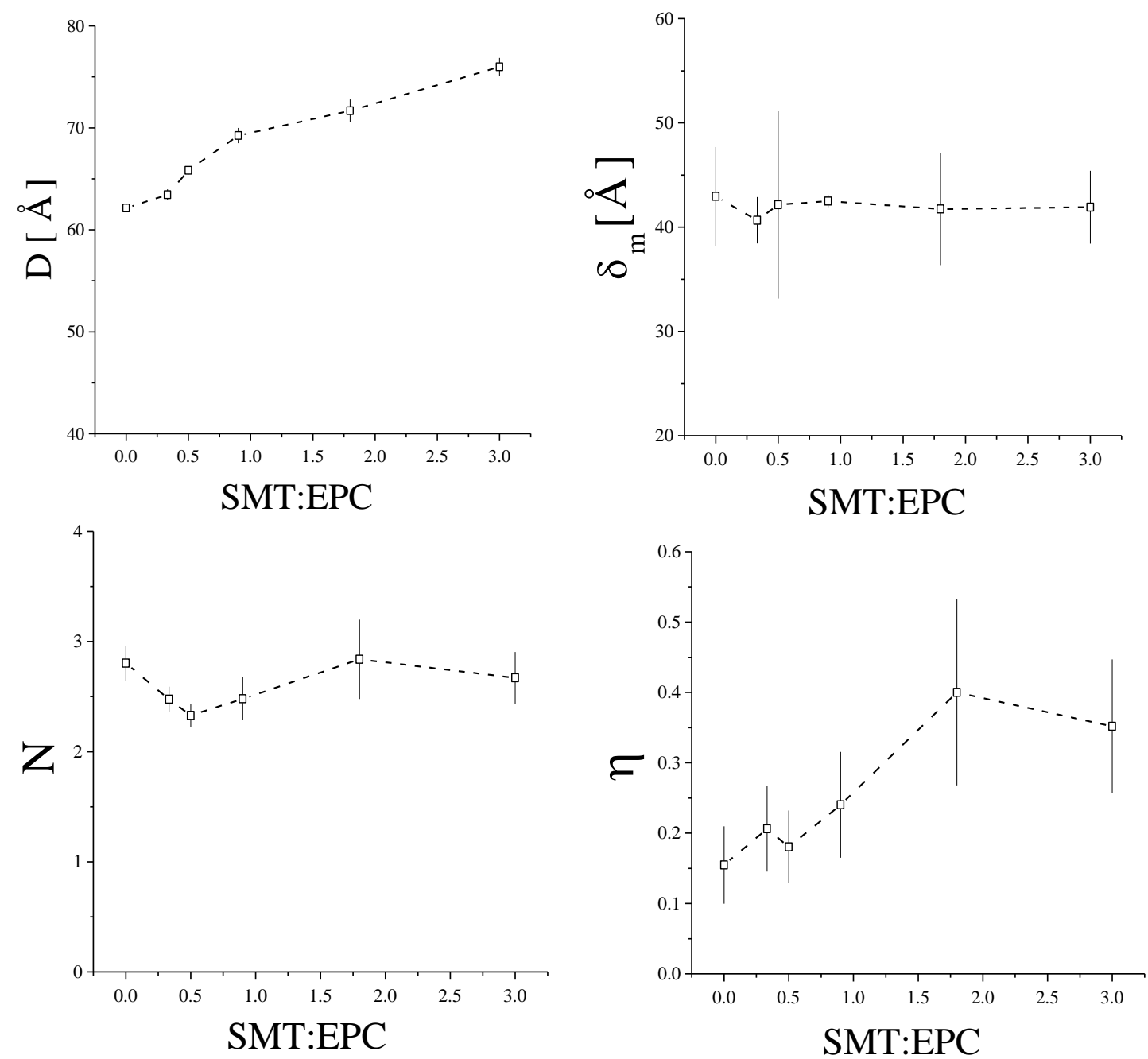

Figura 47: Valores dos parâmetros da Tabela 9 em função do valor numérico da razão STM:EPC.

\subsubsection{Conclusão}

Uma caracterização das bicamadas de lipossomas de EPC em presença de SMT em diferentes concentrações foi realizada por meio da análise quantitativa que empregou o Método da Deconvolução Gaussiana. SMT interage preferencialmente com as cabeças polares do fosfolipídeo. Além disso, os resultados das análises mostraram que as bicamadas com fármaco possuem um perfil de densidade eletrônico assimétrico, diferentemente das bicamadas sem fármaco. Em todos os casos estudados, a espessura da bicamada permanece constante (dentro das barras de erro), enquanto a membrana se torna mais flexível com o aumento da quantidade de SMT. Em relação à estrutura dos lipossomas, todos são multilamelares, com 2 a 3 bicamadas, valor este que não se altera muito com a adição do SMT, diferente da periodicidade lamelar, que aumenta conforme a quantidade de SMT aumenta. 


\section{CONCLUSÕES E PERSPECTIVAS}

Neste capítulo são apresentadas as principais conclusões obtidas a partir dos estudos discutidos anteriormente sobre os sistemas de diferentes classes surfactante-surfactante, proteina-surfactante e lipossomas-(bio)ativos. Também serão apresentadas brevemente as perspectivas de continuação dos trabalhos assim como o estabelecimento de outras colaborações.

\subsection{Conclusões gerais}

Este trabalho teve como objetivo caracterizar estruturalmente os sistemas surfactantesurfactante, proteína-surfactante e lipossomas-(bio)ativos discutidos no texto. Em relação ao primeiro, a principal contribuição desta tese foi a proposição de um modelo que integra características estruturais das micelas (puras e mistas) com vínculos moleculares dos surfactantes que as formam, reduzindo assim a ambiguidade dos valores dos parâmetros ajustáveis. Isso foi possível porque a intensidade espalhada estava em escala absoluta. A partir da implementação computacional do modelo, os dados experimentais foram ajustados satisfatoriamente, o que possibilitou a caracterização estrutural das micelas mistas formadas por SDS e Tween ${ }^{\circledR}$. Com isso, concluiu-se que as micelas podem ser entendidas como elipsoides de revolução, do tipo core-shell. Todas as micelas puras são prolatas. Uma das principais constatações desse estudo, que só foi possível por causa do tipo de modelagem empregada, refere-se ao fato de que, diferentemente das micelas puras, as micelas mistas podem ser prolatas ou oblatas dependendo do tipo de Tween ${ }^{\circledR}$ utilizado. Com o auxílio da Teoria de Clint para misturas ideais, integrada ao modelo, foi possível determinar, teoricamente, a fração de SDS e Tween ${ }^{\circledR}$ na micela mista, bem como calcular a CMC da micela mista para cada composição de amostra.

Já para o sistema proteína-surfactante, foi elaborada uma estratégia de analise de tais sistemas que permite correlacionar o estudo estrutural e termodinâmico dos complexos proteínasurfactante podendo acompanhar os estágios do processo de ligação do surfactante à proteína, 
aliado à modelagem de dados de SAXS em escala absoluta de intensidade com imposição de vínculos moleculares. A técnica de ITC, ao fornecer um panorama geral sobre a desnaturação das proteínas lisozima e alfa-lactalbumina sob ação do SDS, bem como informações sobre a quantidade de monômeros livres e número de ligação em cada estágio de interação, indicou pontos de mudanças termodinâmicas relevantes para os experimentos seguintes de SAXS e CD que permitem observar a estrutura do complexo em diferentes escalas de tamanho. Pela análise inicial dos dados de SAXS, concluiu-se que os complexos formados são do tipo core-shell. Já a técnica de CD mostrou que as proteínas perdem quase que totalmente sua estrutura terciária, mas não a secundária (estado "molten globule"). No caso da desnaturação da lisozima, a quantidade de hélices $\alpha$ diminui e volta a aumentar conforme o processo ocorre, diferentemente da quantidade de folhas $\beta$, que aumenta e volta a diminuir. Por outro lado, para a desnaturação da alfa-lactalbumina, a quantidade de hélices $\alpha$ aumenta até atingir um platô, enquanto o contrário acontece para as folhas $\beta$. Em ambos os casos, tanto para uma proteína quanto para outra, a quantidade de laços não sofre alterações significativas. Com base nas informações de $\mathrm{CD}$, procedeu-se com a modelagem de SAXS. No caso, os complexos proteína-surfactante foram interpretados com micelas decoradas. Em todas as situações investigadas, o tamanho e forma das micelas evoluíram com o processo de ligação, os quais foram caracterizados sistematicamente. De maneira geral, a quantidade de SDS no core dos agregados foi diretamente proporcional ao aumento da razão surfactante:proteína, ao passo que a espessura do shell diminuiu, indicando que a proteína se encontra mais distribuída próximo da saturação, estágio em que também passam a existir micelas livres de SDS. Por fim, em várias ocasiões concluiu-se que a mesma micela foi partilhada por até duas proteínas, fato este compatível com a literatura. Os resultados apresentados aqui compuseram até o presente momento duas publicações, [45] e [105].

Em relação ao sistema lipossomas-(bio)ativos, a análise dos dados de SAXS com o Método da Deconvolução Gaussiana permitiu acompanhar mudanças na estrutura da bicamada ocasionadas pela presença dos (bio)ativos. No caso da coencapsulação de curcumina e vitamina $\mathrm{D}_{3}$ em lipossomas formados por Phospholipon ${ }^{\circledR} 90 \mathrm{H}$, concluiu-se que ambos bioativos não alteraram significativamente a membrana lipídica, o que é um resultado bastante promissor visando aplicações em larga escala. O efeito do aumento da temperatura aumenta também o parâmetro de Caillé o que se traduz em uma maior flexibilidade da membrana, a ponto de, na temperatura de transição $\left(\sim 53{ }^{\circ} \mathrm{C}\right)$ os lipossomas, que já eram multilamelares, apresentarem um aumento abrupto do número de bicamadas correlatas, acompanhado da diminuição da 
periodicidade lamelar, isto é, da distância entre bicamadas adjacentes. Durante a variação térmica, não foi observada alteração perceptível na espessura das bicamadas. Essa mesma conclusão vale para a interação de lipossomas de EPC com o ativo sumatriptano e para a interação entre lipossomas formados por DPPC com o bioativo ácido láurico. Em ambos os casos, os compostos interagem preferencialmente com as cabeças polares dos fosfolipídeos que constituem os lipossomas, haja vista as alterações no perfil de contraste de densidade eletrônico. Também, para ambos os sistemas, as membranas ficam mais flexíveis quanto maior a presença dos (bio)ativos, indicando que a interferência deles na região polar dos lipossomas pode criar defeitos topológicos, como já demostrado na literatura. O ácido láurico, diferentemente do sumatriptano, induz uma transição de lipossomas multilamelares para unilamelares, e esse fenômeno é grandemente influenciado pelo $\mathrm{pH}$ do meio. Em particular, para pH 5,0, a transição acontece antes do que para $\mathrm{pH}$ 7,4, para as mesmas concentrações de ácido láurico. Por fim, verificou-se que uso de modelo de bicamadas simétricas foi perfeitamente capaz de descrever os dados de SAXS para os sistemas Phospholipon ${ }^{\circledR} 90 \mathrm{H}$ - curcumina/ vitamina $\mathrm{D}_{3}$ e DPPC ácido láurico, diferentemente do caso EPC - sumatriptano. Os resultados apresentados aqui compuseram até o presente momento duas publicações, [73] e [180].

\subsection{Perspectivas}

A investigação feita para o sistema surfactante-surfactante e para o sistema lipossomas/ácido láurico será usada para a redação de artigos para publicação em revistas internacionais indexadas.

Além disso, uma das colaborações feitas durante meu doutoramento trabalhou com investigação de SAXS de microemulsões. O resultados dessa parte, ainda que iniciais, resultaram na publicação [193]. Como perspectiva, serão aprofundadas as análises de modelagens de SAXS para esse sistema.

No final do meu doutorado, participei de uma missão científica pelo projeto USP-COFECUB. Na ocasião, trabalhei 21 dias no Centre de Recherche Paul-Pascal (CRPP), em Pessac, França, sob orientação do Prof. Frédéric Nallet. O tema do meu estudo foi relacionado com a teoria termodinâmica de sistemas contendo fases lamelares de lipídios (ver Apêndice) e sua correlação com dados experimentais de SAXS e pressão osmótica. Como perspectiva, esse trabalho bem como a colaboração serão ambos continuados. Ainda sobre essa colaboração, existem vários dados de SAXS coletados no Brasil e na França para sistemas lipídicos contendo DNA que 
mostram coexistência de estruturas hexagonais de DNA com fases lamelares. Até agora a análise dos dados consistiu essencialmente da análise padrão por indexação de picos de Bragg. Como perspectiva, será feita a modelagem desses dados, incluindo no modelo tanto informações da fase lamelar quanto da fase hexagonal. 


\section{APÊNDICE 1}

Tabela 10: Parâmetros de SAXS obtidos a partir do ajuste das curvas experimentais das dispersões de lipossomas (Figura 41A) usando o Método de Deconvolução Gaussiana. Os valores entre parêntesis indicam a incerteza no último algarismo significativo.

\begin{tabular}{|c|c|c|c|c|c|}
\hline Formulação & $T\left[{ }^{\circ} \mathrm{C}\right]$ & $D[\AA ̊]$ & $\left.\delta_{m}[\AA]\right]$ & $N$ & $\eta$ \\
\hline \multirow{5}{*}{$\mathrm{FC}$} & 20 & $70,9(2)$ & $57(5)$ & $2,78(4)$ & $0,032(3)$ \\
\hline & 30 & $71,5(2)$ & $58(7)$ & $2,34(4)$ & $0,021(2)$ \\
\hline & 40 & $73,2(2)$ & $55(8)$ & $2,52(4)$ & $0,064(3)$ \\
\hline & 50 & $75,0(3)$ & $54(2)$ & $2,60(8)$ & $0,087(5)$ \\
\hline & 60 & $68,3(2)$ & $55(5)$ & $7,63(4)$ & $0,073(2)$ \\
\hline \multirow{5}{*}{ F5V } & 20 & $68,9(3)$ & $53(2)$ & $2,51(6)$ & $0,031(3)$ \\
\hline & 30 & $69,0(3)$ & $56(2)$ & $2,59(7)$ & $0,027(4)$ \\
\hline & 40 & $68,8(3)$ & $55(3)$ & $2,85(9)$ & $0,07(3)$ \\
\hline & 50 & $73,2(1)$ & $55(1)$ & $2,65(9)$ & $0,06(3)$ \\
\hline & 60 & $67,6(1)$ & $51(1)$ & $7,82(9)$ & $0,09(1)$ \\
\hline \multirow{5}{*}{ F8V } & 20 & $70,2(3)$ & $56(1)$ & $3,00(9)$ & $0,011(5)$ \\
\hline & 30 & $70,3(3)$ & $53(2)$ & $3,09(8)$ & $0,017(2)$ \\
\hline & 40 & $71,5(2)$ & $51(2)$ & $2,53(6)$ & $0,062(3)$ \\
\hline & 50 & $73,1(3)$ & $54(1)$ & $3,15(9)$ & $0,06(2)$ \\
\hline & 60 & $67,9(1)$ & $50(1)$ & $6,94(9)$ & $0,05(1)$ \\
\hline \multirow{5}{*}{ FC5V } & 20 & $70,7(5)$ & $55(1)$ & $2,26(6)$ & $0,012(4)$ \\
\hline & 30 & $70,8(3)$ & $55(1)$ & $2,48(8)$ & $0,014(2)$ \\
\hline & 40 & $71,7(3)$ & $56(1)$ & $2,73(9)$ & $0,023(3)$ \\
\hline & 50 & $75,3(4)$ & $58(2)$ & $2,65(9)$ & $0,014(3)$ \\
\hline & 60 & $68,2(1)$ & $52(1)$ & $6,88(9)$ & $0,058(2)$ \\
\hline \multirow{5}{*}{ FC8V } & 20 & $69,0(2)$ & $53(1)$ & $2,45(5)$ & $0,024(4)$ \\
\hline & 30 & $68,8(1)$ & $53(1)$ & $2,62(6)$ & $0,049(2)$ \\
\hline & 40 & $68,7(2)$ & $53(2)$ & $2,71(7)$ & $0,032(2)$ \\
\hline & 50 & $72,5(3)$ & $55(2)$ & $2,52(6)$ & $0,08(3)$ \\
\hline & 60 & $67,9(1)$ & $51(1)$ & $7,5(2)$ & $0,09(1)$ \\
\hline
\end{tabular}




\section{APÊNDICE 2}

\section{MISSÃO CIENTÍFICA NA FRANÇA}

\subsection{Resumo}

Eu visitei o Professor Frédéric Nallet no Centre de Recherche Paul-Pascal (CRPP), Pessac, França, para trabalhar no projeto USP-COFECUB sob o título:

\section{"Development of theoretical and modeling tools for structural and thermodynamic investigation of self-assembly in lipidic lamelar systems"}

de autoria do Prof. Dr. Cristiano Luis Pinto de Oliveira e a Profa. Dra. Elisabeth Andreoli de Oliveira (lado brasileiro). A missão científica aconteceu no período entre 2 e 23 de Julho de 2018, e o plano de atividades foi o seguinte:

1. Compreender o modelo termodinâmico para empilhamentos lamelares proposto em [194];

2. Escrever um programa que implementa equação de estado do empilhamento lamelar descrita em [194] bem como um procedimento automático de otimização para o ajuste dos dados;

3. Executar testes usando dados experimentais;

4. Estudar as principais caraterísticas termodinâmicas de sistemas em coexistência de fase (por exemplo, sistemas lamelares+hexagonais apresentados em [195] e [196]);

5. Desenvolver um modelo e escrever um programa para análise de dados de SAXS dos sistemas lamelares+hexagonais apresentados em [195] e [196];

6. Executar testes usando dados experimentais.

O tempo disponível nos permitiu tratar dos itens 1, 2 e 3 da lista acima (incorporando também um estudo da chamada equação de estado da bicamada), e isso gerou uma maior compreensão 
do modelo termodinâmico desenvolvido em [194] bem como forneceu ferramentas eficientes para a análise dos dados experimentais.

Nas próximas linhas o modelo termodinâmico proposto em [194] será brevemente introduzido, incluindo as principais equações e definições, acompanhado da apresentação do procedimento de análise dos dados desenvolvido durante minha missão científica.

\subsection{Introdução}

No trabalho [194] é apresentado um modelo para a quantidade termodinâmica fundamental (densidade de excesso de energia livre $-f_{\text {exc }}$ ) de um empilhamento lamelar fluido (como em sistemas multilamelares auto organizados), dado por:

$$
f_{\text {exc }}=\frac{3 \pi^{2}}{128} \frac{\left(k_{B} T\right)^{2}}{\kappa} \frac{1}{\ell} \frac{1}{(\ell-\delta)^{2}}-k_{B} T \chi \phi^{2}+\frac{1}{\ell}\left(\frac{k_{B} T}{\bar{\Sigma}} \ln \left(\frac{\Sigma_{0}}{e\left(\bar{\Sigma}-\Sigma_{0}\right)}\right)+\frac{1}{2} k_{B} T \frac{b_{2}}{\bar{\Sigma}^{2}}\right) \quad \text { Eq. } 70
$$

onde

- $\quad k_{B}$ é a constante de Boltzmman, $1,38064852 \times 10^{-23} \frac{\mathrm{J}}{\mathrm{K}}$;

- $\quad T$ é a temperatura (assumida $298,15 K$ para todos os dados analisados aqui);

- $\quad \kappa$ é o módulo de torção da bicamada;

- $\quad \ell$ é a periodicidade lamelar, obtida experimentalmente a partir do pico de Bragg de primeira ordem nas curvas de SAXS, $q_{0}$, por meio da relação $\ell=\frac{2 \pi}{q_{0}}$;

- $\delta$ é a espessura da bicamada;

- $\chi$ é o segundo coeficiente virial que representa as interações diretas inter-bicamadas de acordo com Milner e Roux [197];

- $\phi$ é a fração volumétrica da bicamada (ou seja, quanto volume a bicamada ocupa em relação ao todo), experimentalmente acessível a partir da preparação das amostras;

- $\bar{\Sigma}$ é a área interfacial por molécula anfifílica;

- $\bar{\Sigma}_{0}$ é a "área excluída” no fluido bidimensional de moléculas anfifílicas (semelhante ao volume excluído na teoria de van der Waals); 
- $\quad b_{2}$ é o segundo coeficiente virial que representa as interações intra-bicamada entre as moléculas anfifílicas.

Algumas definições úteis:

- $\ell=\frac{\delta}{\phi}$, conhecida como "Lei de Diluição";

- $\delta=\frac{2 \bar{v}}{\bar{\Sigma}}$, onde $\bar{v}$ é o volume molecular efetivo;

- $\bar{v}=x_{S} v_{S}+\left(1-x_{S}\right) v_{L}$, onde $x_{S}$ é a fração molar de Simulsol na bicamada, $v_{S}$ e $v_{L}$ são, respectivamente, os volumes moleculares de Simulsol e lecitina. Estimativas destes volumes feitas com valores conhecidos de densidade de peso molecular nos levaram aos valores $v_{S}=1,18 \times 10^{-27} \mathrm{~m}^{3}$ e $v_{L}=1,28 \times 10^{-27} \mathrm{~m}^{3}$. Assim, para cada dado analisado, com o valor de $x_{S}$ conhecido, pode-se calcular o valor de $\bar{v}$ correspondente;

- $\bar{\Sigma}=x_{S} \Sigma_{S}+\left(1-x_{S}\right) \Sigma_{L}$, onde $\Sigma_{S}$ e $\Sigma_{L}$ são, respectivamente, as áreas interfaciais do Simulsol e da lecitina por molécula anfifílica;

- $\phi=\frac{N_{l} \bar{v}}{N_{w} v_{w}+N_{l},}$, onde $N_{l}$ e $N_{w}$ são, respectivamente, o número total (médio) de moléculas de lecitina/Simulsol e água, e $v_{w}$ é o volume molecular da molécula de água.

OBS: 1) $\phi$ e $\bar{\Sigma}$ são as variáveis independentes escolhidas em [194] para o desenvolvimento da base termodinâmica do modelo. Portanto, todo o restante é função delas. Nesse sentido, $\delta=$ $\delta(\bar{\Sigma}), \ell=\ell(\phi, \bar{\Sigma})$, e $f_{\text {exc }}=f_{\text {exc }}(\phi, \bar{\Sigma})$. 2) Já que $v_{S}$ e $v_{L}$ são considerados parâmetros constantes, então $\bar{v}$ também será constante de acordo com sua definição.

\subsubsection{As equações de estado}

De $f_{\text {exc }}(\phi, \bar{\Sigma})$ é possível derivar a equação de estado da bicamada e a equação de estado do empilhamento lamelar que poderão ser comparadas com os dados experimentais disponíveis de maneira a testar o modelo. Nas próximas linhas ambas as equações serão deduzidas e todas as hipóteses serão evidenciadas. Antes disso, entretanto, vamos colocar a Eq. 70 na forma $f_{\text {exc }}(\phi, \bar{\Sigma})$. Usando $\ell=\frac{\delta}{\phi}$ e $\delta=\frac{2 \bar{v}}{\bar{\Sigma}}$, teremos:

$$
f_{e x c}=\frac{3 \pi^{2}}{128} \frac{\left(k_{B} T\right)^{2}}{\kappa} \frac{1}{8 \bar{v}^{3}} \frac{\phi^{3}}{(1-\phi)^{2}} \bar{\Sigma}^{3}-k_{B} T \chi \phi^{2}+\phi \frac{k_{B} T}{2 \bar{v}}\left(\ln \left(\frac{\Sigma_{0}}{e\left(\bar{\Sigma}-\Sigma_{0}\right)}\right)+\frac{b_{2}}{2 \bar{\Sigma}}\right)
$$


1. Equação de estado da bicamada: É a equação $\frac{\partial f_{e x c}}{\partial \bar{\Sigma}}=0$, da qual é possível obter a "Lei de Diluição" apresentada anteriormente. Considerando a Eq. 71 , teremos:

$$
\begin{gathered}
\frac{\partial f_{\text {exc }}}{\partial \bar{\Sigma}}=0 \\
\frac{\partial}{\partial \bar{\Sigma}}\left(\frac{3 \pi^{2}}{128} \frac{\left(k_{B} T\right)^{2}}{\kappa} \frac{1}{8 \bar{v}^{3}} \frac{\phi^{3}}{(1-\phi)^{2}} \bar{\Sigma}^{3}-k_{B} T \chi \phi^{2}+\phi \frac{k_{B} T}{2 \bar{v}}\left(\ln \left(\frac{\Sigma_{0}}{e\left(\bar{\Sigma}-\Sigma_{0}\right)}\right)+\frac{b_{2}}{2 \bar{\Sigma}}\right)\right)=0
\end{gathered}
$$

Assumindo $\kappa, \chi$ e $b_{2}$ independentes de $\bar{\Sigma}$, então:

$$
\frac{3 \pi^{2}}{128} \frac{\left(k_{B} T\right)^{2}}{\kappa} \frac{1}{8 \bar{v}^{3}}\left(\frac{\phi}{1-\phi}\right)^{2} 3 \bar{\Sigma}^{2}-\frac{k_{B} T}{2 \bar{v}}\left(\frac{1}{\bar{\Sigma}-\Sigma_{0}}+\frac{b_{2}}{2 \bar{\Sigma}^{2}}\right)=0
$$

Assim, dado $\phi$, e conhecendo-se os valores de $\kappa, \Sigma_{0}$ e $b_{2}$, e resolvendo-se a última equação, é possível encontrar a raiz $\bar{\Sigma}=\bar{\Sigma}_{o p t}$, a qual corresponde à área ótima por molécula anfifílica. Pelo menos duas questões podem surgir nesse momento:

- Questão 01: Como saber $\kappa, \Sigma_{0}$ e $b_{2}$ ?

- Questão 02: Uma vez que $\kappa, \Sigma_{0}$ e $b_{2}$ são conhecidos, como encontrar $\bar{\Sigma}_{\text {opt }}$ para um dado $\phi$ (ou seja, como exatamente resolver a Eq. 72 a fim de achar $\bar{\Sigma}_{\text {opt }}$ )?

Essas questões serão respondidas posteriormente, mas por agora note que embora $\phi$ e $\bar{\Sigma}$ sejam variáveis independentes, $\bar{\Sigma}_{o p t}$ é dependente de $\phi$, ou seja, $\bar{\Sigma}_{o p t}=\bar{\Sigma}_{o p t}(\phi)$.

2. Equação de estado do empilhamento lamelar: é a equação $\Pi=\phi \frac{\partial f_{e x c}}{\partial \phi}-f_{\text {exc }}$. Novamente, assumindo $\kappa, \chi$ e $b_{2}$ independentes de $\phi$, tem-se que:

$$
\Pi=\frac{3 \pi^{2}}{128} \frac{\left(k_{B} T\right)^{2}}{\kappa} \frac{1}{8 \bar{v}^{3}}\left(\frac{\phi}{1-\phi}\right)^{3} 2 \bar{\Sigma}^{3}-k_{B} T \chi \phi^{2}
$$

Os dados de pressão osmótica apresentados em [194] foram medidos no estado de equilíbrio termodinâmico, no qual os parâmetros estão otimizados. Nesse sentido, para comparação com os dados experimentais, a variável $\bar{\Sigma}$ apresentada na última equação deve ser substituída por $\bar{\Sigma}_{\text {opt }}$. Dessa maneira, temos:

$$
\Pi_{o p t}=\frac{3 \pi^{2}}{128} \frac{\left(k_{B} T\right)^{2}}{\kappa} \frac{1}{8 \bar{v}^{3}}\left(\frac{\phi}{1-\phi}\right)^{3} 2 \bar{\Sigma}_{o p t}{ }^{3}-k_{B} T \chi \phi^{2}
$$


Note que $\kappa$ e $\bar{\Sigma}_{\text {opt }}$, assim como $\phi$, são os mesmos que na equação de estado da bicamada (Eq. 72). Uma vez que $\bar{\Sigma}_{o p t}=\bar{\Sigma}_{o p t}(\phi), \Pi_{\text {opt }}$ é unicamente dependente de $\phi$, ou seja, $\Pi_{o p t}=\Pi_{o p t}(\phi)$.

\subsubsection{Objetivos}

A partir dos experimentos de SAXS e pressão osmótica, temos os dados $\Pi_{o p t}(\phi) \times \phi$ e $\bar{\Sigma}_{o p t}(\phi) \times \phi$. O objetivo da minha missão científica é usar as equações de estado apresentadas anteriormente para ajustar os dados experimentais disponíveis e extrair os valores dos parâmetros $\kappa, \chi, \Sigma_{0}$ e $b_{2}$ para cada composição $x_{S}$ estudada. Com esses valores, será possível no futuro construir a função $f_{\text {exc }}$ e possuir assim toda a informação termodinâmica do sistema, o que nos possibilitaria fazer previsões importantes acerca, por exemplo, da coexistência de fases lamelares.

\subsection{Métodos}

Métodos que empregam Mínimos Quadrados são frequentemente usados para otimizar os parâmetros de um modelo de maneira a ajustar os dados disponíveis. A maioria deles unicamente considera o erro nas variáveis dependentes assim como exige que estas sejam função explícita das variáveis independentes, enquanto o procedimento conhecido como Orthogonal Distance Regression (ODR) pode superar esses dois empecilhos [198]. Aqui nós usamos o pacote scipy.odr ${ }^{18}$ para o ajuste dos dados, o qual oferece uma interface orientada a objeto para o ODRPACK, originalmente escrito em Fortran-77 [199]. Visando o cálculo de $\bar{\Sigma}_{\text {opt }}$ por meio da equação de estado da bicamada (Eq. 72), nós usamos o método scipy.optimize.fsolve ${ }^{19}$. Todo o código foi escrito em linguagem Python e executado no ambiente Jupyter Notebook ${ }^{20}$.

\footnotetext{
${ }^{18}$ https://docs.scipy.org/doc/scipy/reference/odr.html

${ }^{19}$ https://docs.scipy.org/doc/scipy-0.14.0/reference/generated/scipy.optimize.fsolve.html.

${ }^{20} \mathrm{https://jupyter.org}$
} 


\subsection{Resultados e Discussão}

Foram utilizadas duas abordagens para ajustar os dados disponíveis, as quais foram chamadas de "Teste 01 " e "Teste 02 ". Na primeira, os dados foram ajustados independentemente, tendo em vista verificar 1) se o modelo termodinâmico poderia ajustar os dados de maneira satisfatória dependendo da escolha dos parâmetros e 2) se o procedimento de ajuste seria capaz de fornecer automaticamente estes parâmetros (no artigo original os parâmetros foram escolhidos manualmente). Todos os ajustes usando essa abordagem foram bastante satisfatórios, o que mostra o potencial do modelo em descrever os dados assim como o do procedimento de ajuste em retornar os valores dos parâmetros automaticamente. Contudo, ao checar os valores dos parâmetros, encontramos alguns problemas. O principal está relacionado ao parâmetro $\kappa$, que deve ser o mesmo tanto na equação de estado da bicamada (Eq. 72) e na equação de estado do empilhamento lamelar (Eq. 74). Em vários casos as diferenças são bastante consideráveis, podendo chegar a duas ordens de grandeza.

Na tentativa de impor alguma restrição para o parâmetro $\kappa$, procedemos com o Teste 02 . Nesse sentido, já que $\Pi_{o p t}$ é uma quantidade experimental diretamente medida (em vez de $\bar{\Sigma}_{o p t}$, que é indiretamente determinada e modelo-dependente, como apontado em [194]), nós escolhemos primeiramente ajustar os dados de pressão osmótica (nessa ocasião usamos os valores $\bar{\Sigma}_{\text {opt }}$ experimentais em vez dos valores calculados). Seguindo essa estratégia, teremos uma primeira estimativa para o valor $\kappa$ que pode ser usada para ajustar os dados de $\bar{\Sigma}_{o p t}(\kappa$ permanecerá fixo). Depois disso, ajustaremos os dados de pressão osmótica novamente, mas desta vez usando os valores de $\bar{\Sigma}_{\text {opt }}$ calculados (assim como antes, $\kappa$ permanecerá fixo para garantir que se trata do mesmo valor usado para ajustar os dados de $\bar{\Sigma}_{o p t}$ ). O objetivo do Teste 02 é verificar se o mesmo valor de $\kappa$ pode levar a ajustes satisfatórios para ambos conjuntos de dados $\left(\Pi_{o p t}(\phi) \times \phi\right.$ e $\left.\bar{\Sigma}_{o p t}(\phi) \times \phi\right)$. A Figura 48 mostra os resultados obtidos para o Teste 02 usando todos os conjuntos de dados disponíveis. Concluímos que é possível obter ajustes satisfatórios, embora, em algumas situações, eles não sejam tão bons quanto no Teste 01 . Vale ressaltar que o Teste 02 provavelmente não é a melhor abordagem, uma vez que, ao fixar o parâmetro $\kappa$, estamos forçando os outros parâmetros a mudar a fim de ajustar os dados, e isso não é ideal, mesmo que eles continuem tendo significado físico. Um aprimoramento do Teste 02 (possivelmente levando ao Teste 03) seria realizar os ajustes de ambas equações de estado ao mesmo tempo. Dessa maneira, $\kappa$ ainda seria um parâmetro ajustável, e o valor que assumiria seria tal que garantisse o melhor ajuste global. 

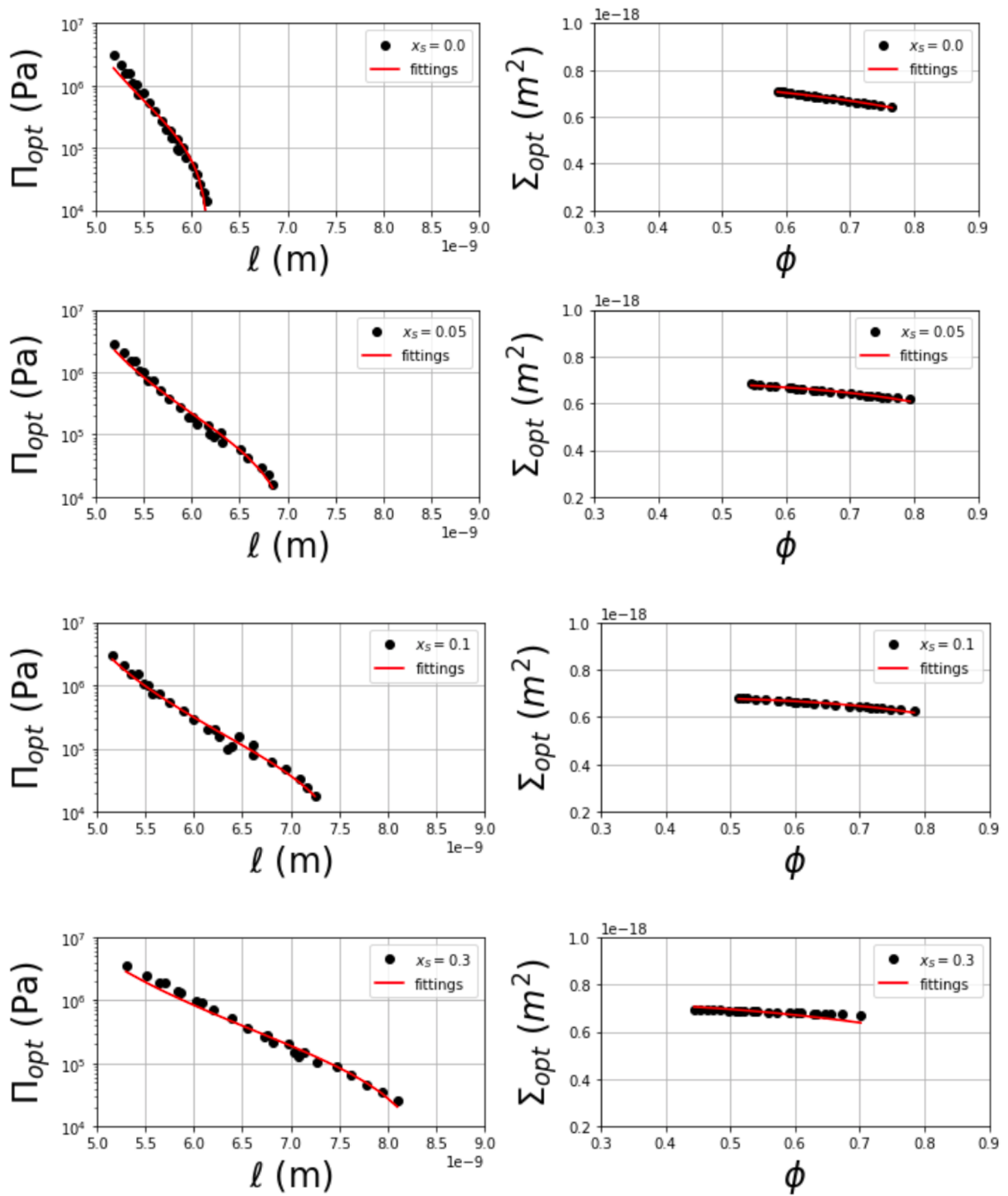

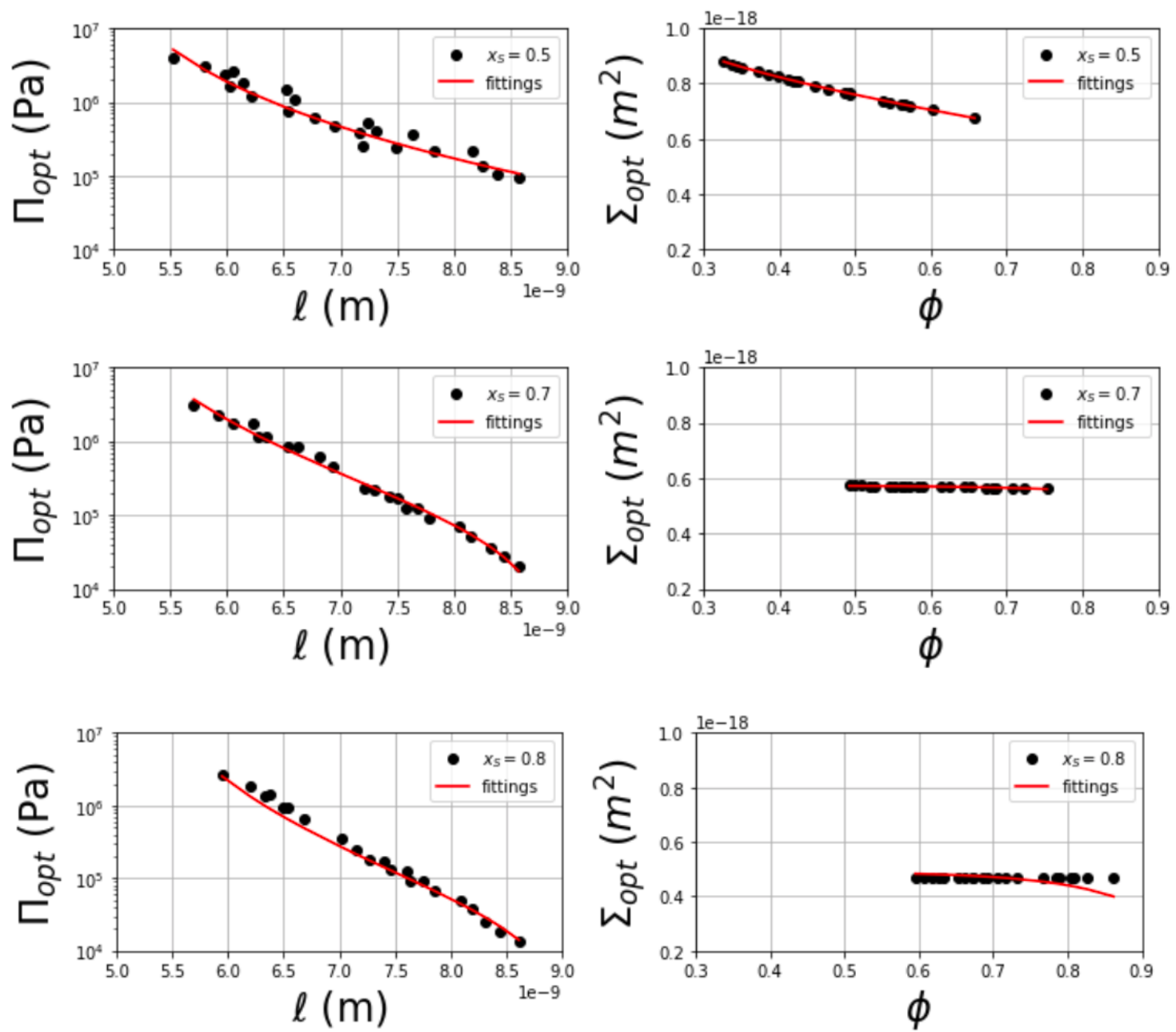

Figura 48 - Resultados do Teste 02 para todos os conjuntos de dados analisados.

Na Figura 49 é feita uma comparação entre os valores dos parâmetros, para cada composição $x_{S}$ estudada, obtidos pelo artigo [194] e pelo procedimento de ajuste automático. Como é possível observar, os valores em geral são próximos entre si, exceto para a composição $x_{S}=$ 0,8 . Neste caso, ambos $b_{2}$ e $\Sigma_{0}$ são muito diferentes dos valores da referência. Uma vez que eles são obtidos a partir da equação de estado da bicamada, a qual é comparada com os dados $\bar{\Sigma}_{\text {opt }}(\phi) \times \phi$, podemos investigar os ajustes obtidos. De fato, os ajustes não são satisfatórios (embora o ajuste dos dados de pressão osmótica esteja bom). Em conversa particular com o Professor Nallet, talvez isso tenha acontecido porque $\bar{\Sigma}_{\text {opt }}(\phi)$ assume um comportamento perfeitamente constante (ou seja, os valores $\bar{\Sigma}_{o p t}(\phi)$ são exatamente os mesmos), o que é “estranho" considerando os muito prováveis erros experimentais. Portanto, neste caso, é possível que seja necessário checar os dados originais para esta composição. 

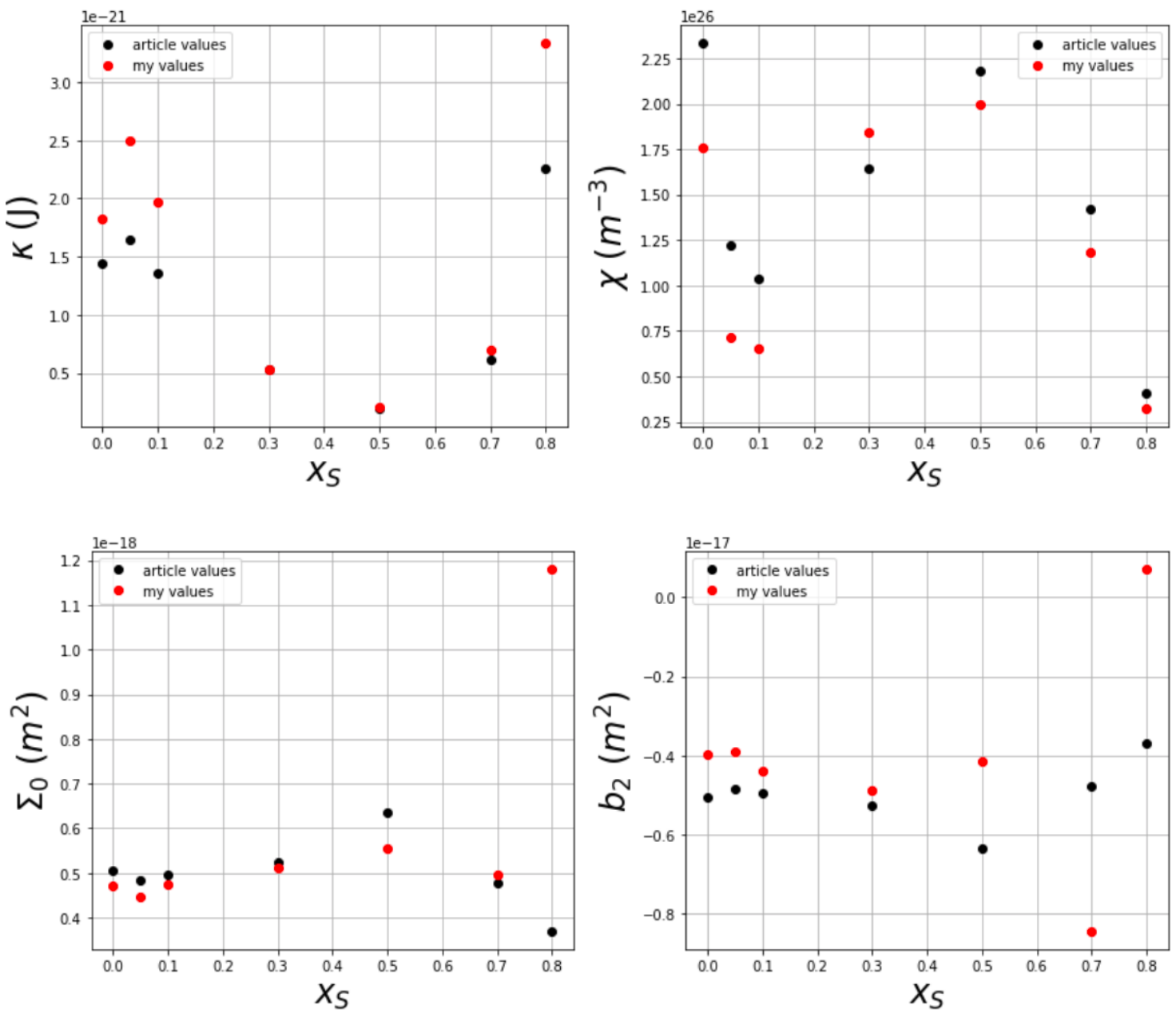

Figura 49 - Comparação entre os valores dos parâmetros apresentados no artigo original [194] (círculos pretos) e os valores obtidos via procedimento automático de ajuste (círculos vermelhos).

É importante mencionar que, embora cada parâmetro possua seu erro, estimado por meio dos procedimentos computacionais adotados aqui, ele não está mostrado na Figura 49 porque, até esse ponto, não podemos confiar neles já que 1) os dados originais de $\bar{\Sigma}_{o p t}$ não possuem incerteza, 2) é necessário checar os erros atribuídos aos dados originais de $\Pi_{\text {opt }}$ e 3) precisamos saber como a rotina ODR faz a estimativa dos erros. Provavelmente, sobre este último ponto, será necessário fornecer ao procedimento ODR mais informação (por exemplo, as funções jacobianas relacionadas às derivadas da função tanto em relação aos parâmetros quanto em relação às entradas) de maneira a obter estimativas de erro confiáveis.

\subsection{Conclusão}

Do planejamento de 21 dias, foi possível cumprir os seguintes itens: 
1. Compreender o modelo termodinâmico para empilhamentos lamelares proposto em [194] (aqui temos que tomar cuidado com a expressão "compreender", uma vez que o entendimento completo de todas as características e consequências do modelo complexo apresentado em [194] demandaria muito mais tempo que apenas 21 dias...);

2. Escrever um programa que implementa equação de estado do empilhamento lamelar [194] bem como um procedimento automático de otimização para o ajuste dos dados (como comentado acima, levamos em consideração também a chamada equação de estado da bicamada);

3. Executar testes usando dados experimentais (foram executados dezenas de testes...); Enquanto existem indicativos de que os procedimentos desenvolvidos/usados aqui funcionem bem, uma vez que os ajustes são satisfatórios, há melhoramentos que podem ser implementados no futuro. Em particular, o Teste 02 pode ser substituído por um ajuste global simultâneo de $\bar{\Sigma}_{o p t}$ e $\Pi_{o p t}$. Adicionalmente, melhoramentos podem ser feitos na parte concernente à estimação dos erros, primeiramente para a sua atribuição aos dados experimentais, e depois para o seu cálculo e atribuição aos valores dos parâmetros obtidos por meio dos ajustes. 


\section{REFERÊNCIAS BIBLIOGRÁFICAS}

[1] J. Kotz, S. Kosmella, and T. Beitz, Progress in Polymer Science 26, 1199 (2001).

[2] D. Otzen, Biochimica Et Biophysica Acta-Proteins and Proteomics 1814, 562 (2011).

[3] Y. Moroi, Micelles: Theoretical and applied aspects (Plenum Press, New York, 1992).

[4] D. Attwood and A. T. Florence, Surfactant systems: Their chemistry, pharmacy and biology (Chapman \& Hall, London, 1983).

[5] D. F. Evans and H. Wennerström, The colloidal domain: Where physics, chemistry, biology, and technology meet (Wiley-VCH, New York, 1999), 2nd ed. edn.

[6] R. Zana, S. Yiv, C. Strazielle, and P. Lianos, Journal of Colloid and Interface Science 80, 208 (1981).

[7] M. D. Graciani, M. Munoz, A. Rodriguez, and M. L. Moya, Langmuir 21, 3303 (2005).

[8] P. D. Galgano and O. A. El Seoud, Journal of Colloid and Interface Science 345, 1 (2010).

[9] P. D. Galgano and O. A. El Seoud, Journal of Colloid and Interface Science 361, 186 (2011).

[10] J. L. Anderson, V. Pino, E. C. Hagberg, V. V. Sheares, and D. W. Armstrong, Chemical Communications, 2444 (2003).

[11] C. Holt, C. G. de Kruif, R. Tuinier, and P. A. Timmins, Colloids and Surfaces aPhysicochemical and Engineering Aspects 213, 275, Pii s0927-7757(02)00520-4 (2003).

[12] J. Lipfert, L. Columbus, V. B. Chu, S. A. Lesley, and S. Doniach, Journal of Physical Chemistry B 111, 12427 (2007).

[13] Reisshus.F and V. Luzzati, Journal of Colloid and Interface Science 21, 534 (1966).

[14] S. H. Chen, Annual Review of Physical Chemistry 37, 351 (1986).

[15] R. Zana, C. Picot, and R. Duplessix, Journal of Colloid and Interface Science 93, 43 (1983).

[16] D. M. Cirin, M. M. Posa, V. S. Krstonosic, and M. L. Milanovic, Hemijska Industrija 66, 21 (2012).

[17] B. Kanoje, S. Padshala, J. Parikh, S. K. Sahoo, K. Kuperkar, and P. Bahadur, Physical Chemistry Chemical Physics 20, 670 (2018).

[18] A. Cid, J. Morales, J. C. Mejuto, N. Briz-Cid, R. Rial-Otero, and J. Simal-Gandara, Food Chemistry 151, 358 (2014).

[19] L. Zhang et al., Colloids and Surfaces B-Biointerfaces 163, 125 (2018).

[20] P. A. Bhat, G. M. Rather, and A. A. Dar, Journal of Physical Chemistry B 113, 997 (2009).

[21] S. J. Singer and G. L. Nicolson, Science 175, 720 (1972).

[22] F. M. Goñi, Biochimica et Biophysica Acta (BBA) - Biomembranes 1838, 1467 (2014). 
[23] R. M. Capito, H. S. Azevedo, Y. S. Velichko, A. Mata, and S. I. Stupp, Science 319, 1812 (2008).

[24] S. M. Standley et al., Cancer Res 70, 3020 (2010).

[25] M. Halwani, B. Yebio, Z. E. Suntres, M. Alipour, A. O. Azghani, and A. Omri, Journal of Antimicrobial Chemotherapy 62, 1291 (2008).

[26] G. L. Nicolson, Bba-Biomembranes 1838, 1451 (2014).

[27] A. Catala, Biochimie 94, 101 (2012).

[28] S. M. Murray, R. A. O'Brien, K. M. Mattson, C. Ceccarelli, R. E. Sykora, K. N. West, and J. H. Davis, Jr., Angew Chem Int Edit 49, 2755 (2010).

[29] B. B. Gerbelli, E. R. da Silva, B. M. Soares, W. A. Alves, and E. A. de Oliveira, Langmuir 34, 2171 (2018).

[30] W. Wang, L. Yang, and H. W. Huang, Biophysical Journal 92, 2819 (2007).

[31] A. Siddhanta and D. Shields, Journal of Biological Chemistry 273, 17995 (1998).

[32] D. Luo and W. M. Saltzman, Nature Biotechnology 18, 33 (2000).

[33] A. S. Angelatos, K. Katagiri, and F. Caruso, Soft Matter 2, 18 (2006).

[34] D. L. NELSON and M. M. COX, Princípios de bioquímica de Lehninger (Artmed, Porto Alegre, 2011), $5^{\text {a }}$ ed. edn.

[35] B. Z. Chowdhry and S. E. Harding, in Protein-Ligant Interactions: hydrodynamics and calorimetry (Oxford University Press, 2001).

[36] R. A. L. Jones, Soft Condensed Matter (Oxford University Press, Oxford, 2002), Vol. Vol. 6, Oxford Master Series in Condensed Matter Physics.

[37] D. E. Otzen, Biochimica Et Biophysica Acta-Biomembranes 1859, 639 (2017).

[38] N. Yoshii, K. Iwahashi, and S. Okazaki, Journal of Chemical Physics 124, 184901 (2006).

[39] C. A. Rohl, C. E. M. Strauss, K. M. S. Misura, and D. Baker, Numerical Computer Methods, Pt D 383, 66 (2004).

[40] K. K. Andersen, C. L. Oliveira, K. L. Larsen, F. M. Poulsen, T. H. Callisen, P. Westh, J. S. Pedersen, and D. Otzen, Journal of Molecular Biology 391 (2009).

[41] M. D. Lad, V. M. Ledger, B. Briggs, R. J. Green, and R. A. Frazier, Langmuir 19, 5098 (2003).

[42] K. K. Andersen and D. E. Otzen, Journal of Physical Chemistry B 113, 13942 (2009).

[43] B. Shweitzer, D. Zanette, and R. Itri, Journal of Colloid and Interface Science 277, 285 (2004).

[44] R. C. Lu, A. N. Cao, L. H. Lai, B. Y. Zhu, G. X. Zhao, and J. X. Xiao, Colloids and Surfaces B-Biointerfaces 41, 139 (2005).

[45] Y. Sun, P. L. O. Filho, J. C. Bozelli, Jr., J. Carvalho, S. Schreier, and C. L. P. Oliveira, Soft Matter 11, 7769 (2015).

[46] S. Chodankar, V. K. Aswal, P. A. Hassan, and A. G. Wagh, Physica B-Condensed Matter 398, 112 (2007). 
[47] M. N. Jones, in Surface Activity of Proteins: Chemical and Physicochemical Modifications (Marcel Dekker, Inc., 1996).

[48] S. Ghosh and A. Banerjee, Biomacromolecules 3, 9 (2002).

[49] M. C. Wiener, Current Opinion in Colloid \& Interface Science 6, 412 (2001).

[50] E. L. Gelamo, C. Silva, H. Imasato, and M. Tabak, Biochimica Et Biophysica ActaProtein Structure and Molecular Enzymology 1594, 84 (2002).

[51] M. M. Nielsen, K. K. Andersen, P. Westh, and D. E. Otzen, Biophysical Journal 92, 3674 (2007).

[52] E. L. Gelamo, R. Itri, A. Alonso, J. V. da Silva, and M. Tabak, Journal of Colloid and Interface Science 277, 471 (2004).

[53] Y. L. Wang, B. X. Han, H. K. Yan, and J. C. T. Kwak, Langmuir 13, 3119 (1997).

[54] K. M. Glenn, S. Moroze, S. C. Bhattacharya, and R. M. Palepu, Journal of Dispersion Science and Technology 26, 79 (2005).

[55] C. C. Ruiz, J. A. Molina-Bolivar, J. Aguiar, G. MacIsaac, S. Moroze, and R. Palepu, Colloid and Polymer Science 281, 531 (2003).

[56] K. Szymczyk and A. Taraba, Journal of Thermal Analysis and Calorimetry 126, 315 (2016).

[57] M. Munoz, A. Rodriguez, M. D. Graciani, and M. L. Moya, Langmuir 20, 10858 (2004).

[58] D. E. Otzen, P. Sehgal, and P. Westh, Journal of Colloid and Interface Science 329, 273 (2009).

[59] S. Hamada and K. Takeda, Journal of Protein Chemistry 12, 477 (1993).

[60] A. Valstar, W. Brown, and M. Almgren, Langmuir 15, 2366 (1999).

[61] C. Tanford, The hydrophobic effect: Formation of micelles and biological membranes (Wiley-Interscience, New York, 1980), p.^pp. 233.

[62] P. L. Oseliero Filho, Universidade de São Paulo, 2013.

[63] D. E. Otzen, Biophysical Journal 83, 2219 (2002).

[64] J. D. Kaspersen, A. Sondergaard, D. J. Madsen, D. E. Otzen, and J. S. Pedersen, Biophysical Journal 112, 1609 (2017).

[65] K. Holmberg, B. Jönsson, and B. Kronberg, Surfactants and polymers in aqueous solution (John Wiley \& Sons, LTD, 2003), Segunda edição edn.

[66] J. N. Israelachvili, Intermolecular and surface forces (Academic Press, London, 1991), 2nd edition. edn.

[67] P. H. Elworthy, A. T. Florence, and C. B. Macfarlane, Solubilization by surface-active agents and its applications in chemistry and the biological sciences (Chapman \& Hall, London, 1968).

[68] C. M. Batista, C. M. B. d. Carvalho, and N. S. S. Magalhães, Revista Brasileira de Ciências Farmacêuticas 43, 167 (2007).

[69] D. L. N. M. M. Cox, Princípios de Bioquímica de Lehninger (. . 2012), 6 edn., Vol. 1, . .p.^pp. .

[70] R. A. L. Jones, Soft Condensed Matter (. . 2002), 6 edn., Vol. 1, . p.^pp. . 
[71] J. Li, X. L. Wang, T. Zhang, C. L. Wang, Z. J. Huang, X. Luo, and Y. H. Deng, Asian Journal of Pharmaceutical Sciences 10, 81 (2015).

[72] G. S. Silva, C. G. Jange, J. S. S. Rocha, M. A. Chaves, and S. C. Pinho, International Journal of Food Science and Technology 52, 772 (2017).

[73] M. A. Chaves, P. L. Oseliero, C. G. Jange, R. Sinigaglia-Coimbra, C. L. P. Oliveira, and S. C. Pinho, Colloids and Surfaces a-Physicochemical and Engineering Aspects 549, 112 (2018).

[74] C. M. S. Cereda, G. B. Brunetto, D. R. de Araujo, and E. de Paula, Canadian Journal of Anaesthesia-Journal Canadien D Anesthesie 53, 1092 (2006).

[75] C. L. P. Oliveira, in Current Trends in X-Ray Crystallography, edited by A. Chandrasekaran (InTech, 2011), pp. 367.

[76] C. L. P. Oliveira, M. A. Behrens, J. S. Pedersen, K. Erlacher, D. Otzen, and J. S. Pedersen, Journal of Molecular Biology 387 (2009).

[77] H. B. Callen, Thermodynamics and an Introduction to Themostatistics (John Wiley \& Sons, New York, 1985).

[78] A. Chatterjee, S. P. Moulik, S. K. Sanyal, B. K. Mishra, and P. M. Puri, Journal of Physical Chemistry B 105 (2001).

[79] M. M. Pierce, C. S. Raman, and B. T. Nall, Methods-a Companion to Methods in Enzymology 19 (1999).

[80] L. Whitmore and B. A. Wallace, Nucleic Acids Research 32, W668 (2004).

[81] J. D. Jackson, Classical Electrodynamics (John Wiley \& Sons Ltd., 1962).

[82] O. Glatter, Acta Physica Austriaca 36 (1972).

[83] O. Glatter, Journal of Applied Crystallography 10 (1977).

[84] A. Guinier and G. Fournet, Small-Angle Scattering of X-rays (Wiley, New York, USA, 1955).

[85] J. S. Pedersen, Advances in Colloid and Interface Science 70 (1997).

[86] S. Vass, J. S. Pedersen, J. Plestil, P. Laggner, E. Retfalvi, I. Varga, and T. Gilanyi, Langmuir 24, 408 (2008).

[87] F. J. Rogers and D. A. Young, Physical Review A 30 (1984).

[88] L. Rayleigh, Proceedings of the Royal Society of London Series a-Containing Papers of a Mathematical and Physical Character 84 (1910).

[89] D. J. Kinning and E. L. Thomas, Macromolecules 17, 1712 (1984).

[90] J. P. Hansen and J. B. Hayter, Molecular Physics 46, 651 (1982).

[91] V. K. Aswal and P. S. Goyal, Physica B 245, 73 (1998).

[92] S. Manet et al., Journal of Physical Chemistry B 115, 11318 (2011).

[93] C. L. P. Oliveira, B. B. Gerbelli, E. R. T. Silva, F. Nallet, L. Navailles, E. A. Oliveira, and J. S. Pedersen, Journal of Applied Crystallography 45, 1278 (2012).

[94] O. Glatter and O. Kratky, Small Angle X-ray Scattering (Academic Press London, 1982). 
[95] R. T. Zhang, R. M. Suter, and J. F. Nagle, Physical Review E 50, 5047 (1994).

[96] P. C. Griffiths, M. L. Whatton, R. J. Abbott, W. Kwan, A. R. Pitt, A. M. Howe, S. M. King, and R. K. Heenan, Journal of Colloid and Interface Science 215, 114 (1999).

[97] J. Penfold, E. Staples, and I. Tucker, Journal of Physical Chemistry B 106, 8891 (2002).

[98] R. K. Mahajan, J. Chawla, K. K. Vohra, and V. K. Aswal, Journal of Applied Polymer Science 117, 3038 (2010).

[99] H. Aizawa, Journal of Applied Crystallography 42, 592 (2009).

[100] M. Bester-Rogac, Acta Chimica Slovenica 54, 452 (2007).

[101] S. Ghosh and S. P. Moulik, Journal of Colloid and Interface Science 208, 357 (1998).

[102] J. BrunnerPopela and O. Glatter, Journal of Applied Crystallography 30, 431 (1997).

[103] A. Bergmann, G. Fritz, and O. Glatter, Journal of Applied Crystallography 33, 1212 (2000).

[104] H. G. Mortensen, J. K. Madsen, K. K. Andersen, T. Vosegaard, G. R. Deen, D. E. Otzen, and J. S. Pedersen, Biophysical Journal 113, 2621 (2017).

[105] Y. Sun, P. L. Oseliero, and C. L. P. Oliveira, Food Hydrocolloids 62, 10 (2017).

[106] A. Moller, P. Lang, G. H. Findenegg, and U. Keiderling, Journal of Physical Chemistry B 102, 8958 (1998).

[107] H. Pilsl, H. Hoffmann, S. Hofmann, J. Kalus, A. W. Kencono, P. Lindner, and W. Ulbricht, Journal of Physical Chemistry 97, 2745 (1993).

[108] Y. Chevalier and T. Zemb, Reports on Progress in Physics 53 (1990).

[109] L. Giehm, C. L. Pinto Oliveira, G. Christiansen, J. S. Pedersen, and D. E. Otzen, Journal of Molecular Biology 401, 115 (2010).

[110] D. Bendedouch, S. H. Chen, and W. C. Koehler, The Journal of Physical Chemistry 87, 2621 (1983).

[111] R. C. Oliver, J. Lipfert, D. A. Fox, R. H. Lo, S. Doniach, and L. Columbus, Plos One 8, e62488 (2013).

[112] M. W. Samaha and V. F. Naggar, International Journal of Pharmaceutics 42, 1 (1988).

[113] E. Dutkiewicz and A. Jakubowska, Colloid and Polymer Science 280, 1009 (2002).

[114] T. P. Goloub, R. J. Pugh, and B. V. Zhmud, Journal of Colloid and Interface Science 229, 72 (2000).

[115] M. Bergstrom and J. S. Pedersen, Langmuir 15, 2250 (1999).

[116] M. Bergstrom and J. S. Pedersen, Physical Chemistry Chemical Physics 1, 4437 (1999).

[117] P. Koshy, V. K. Aswal, M. Venkatesh, and P. A. Hassan, Soft Matter 7, 4778 (2011).

[118] J. Newman, A. Cacatian, A. Josephson, and A. Tsang, The Lancet 304, 756 (1974).

[119] T. Imoto, K. Hayashi, and M. Funatsu, Journal of Biochemistry 64, 387 (1968).

[120] T. Imoto, Y. Doi, K. Hayashi, and M. Funatsu, Journal of Biochemistry 65, 667 (1969).

[121] C. C. F. Blake, D. F. Koenig, G. A. Mair, A. C. T. North, D. C. Phillips, and V. R. Sarma, Nature 206, 757 (1965). 
[122] E. F. Osserman and D. P. Lawlor, Journal of Experimental Medicine 124, 921 (1966).

[123] K. Nitta, H. Tsuge, K. Shimazaki, and S. Sugai, Biological chemistry Hoppe-Seyler 369, 671 (1988).

[124] J.-P. Perraudin and J.-P. Prieels, Biochimica et Biophysica Acta (BBA) - General Subjects 718, 42 (1982).

[125] P. G. Schmidt and I. D. Kuntz, Biochemistry 23, 4261 (1984).

[126] S. Roy and J. W. Rhim, Journal of Molecular Structure 1171, 1 (2018).

[127] Y. L. Gu, Y. Q. Wang, and H. M. Zhang, Spectrochimica Acta Part a-Molecular and Biomolecular Spectroscopy 202, 260 (2018).

[128] M. Hubner, C. Lodziak, H. T. J. Do, and C. Held, Fluid Phase Equilibria 472, 62 (2018).

[129] A. Rath, M. Glibowicka, V. G. Nadeau, G. Chen, and C. M. Deber, Proceedings of the National Academy of Sciences of the United States of America 106, 1760 (2009).

[130] K. Shirahama, K. Tsujii, and T. Takagi, Journal of Biochemistry 75, 309 (1974).

[131] T. C. Vanaman, K. Brew, and R. L. Hill, The Journal of biological chemistry 245, 4583 (1970).

[132] W. L. Mattice, J. M. Riser, and D. S. Clark, Biochemistry 15, 4264 (1976).

[133] W. Parker and P. S. Song, Biophysical Journal 61, 1435 (1992).

[134] K. K. Andersen, P. Westh, and D. E. Otzen, Langmuir 24, 399 (2008).

[135] J. G. Hansted, P. L. Wejse, H. Bertelsen, and D. E. Otzen, Biochimica Et Biophysica Acta-Proteins and Proteomics 1814, 713 (2011).

[136] C. L. P. Oliveira, M. A. Behrens, J. S. Pedersen, K. Erlacher, D. Otzen, and J. S. Pedersen, Journal of Molecular Biology 387, 147 (2009).

[137] D. Svergun, C. Barberato, and M. H. J. Koch, Journal of Applied Crystallography 28, 768 (1995).

[138] C. L. P. Oliveira, A. M. Monteiro, and A. M. F. Neto, Brazilian Journal of Physics 44, 753 (2014).

[139] K. Kuwajima, Journal of Molecular Biology 114, 241 (1977).

[140] Z. Y. Peng and P. S. Kim, Biochemistry 33, 2136 (1994).

[141] C. Svanborg et al., Advances in Cancer Research, Vol 88 88, 1 (2003).

[142] M. Svensson, H. Sabharwal, A. Hakansson, A. K. Mossberg, P. Lipniunas, H. Leffler, C. Svanborg, and S. Linse, Journal of Biological Chemistry 274, 6388 (1999).

[143] M. Svensson et al., Protein Science 12, 2794 (2003).

[144] J. D. Kaspersen et al., Chembiochem 15, 2693 (2014).

[145] J. D. Kaspersen, C. M. Jessen, B. S. Vad, E. S. Sorensen, K. K. Andersen, M. Glasius,

C. L. P. Oliveira, D. E. Otzen, and J. S. Pedersen, Chembiochem 15, 2113 (2014).

[146] M. F. M. Engel, C. P. M. van Mierlo, and A. Visser, Journal of Biological Chemistry 277, 10922 (2002).

[147] A. C. W. Pike, K. Brew, and K. R. Acharya, Structure 4, 691 (1996). 
[148] D. A. Kelkar, A. Chaudhuri, S. Haldar, and A. Chattopadhyay, European Biophysics Journal with Biophysics Letters 39, 1453 (2010).

[149] V. Nanda and L. Brand, Proteins-Structure Function and Genetics 40, 112 (2000).

[150] A. I. P. Dekroon, M. W. Soekarjo, J. Degier, and B. Dekruijff, Biochemistry 29, 8229 (1990).

[151] O. Halskau, J. Underhaug, N. A. Froystein, and A. Martinez, Journal of Molecular Biology 349, 1072 (2005).

[152] P. Anand et al., Biochemical Pharmacology 76, 1590 (2008).

[153] H. Ahsan, N. Parveen, N. U. Khan, and S. M. Hadi, Chemico-Biological Interactions 121, 161 (1999).

[154] A. Rahman, R. F. Angawi, and A. A. Kadi, Food Chemistry 173, 489 (2015).

[155] A. Caroli, A. Poli, D. Ricotta, G. Banfi, and D. Cocchi, Journal of Dairy Science 94, 5249 (2011).

[156] M. F. Holick, New England Journal of Medicine 357, 266 (2007).

[157] J. H. Lee, J. H. O'Keefe, D. Bell, D. D. Hensrud, and M. F. Holick, Journal of the American College of Cardiology 52, 1949 (2008).

[158] T. Kulie, A. Groff, J. Redmer, J. Hounshell, and S. Schrager, Journal of the American Board of Family Medicine 22, 698 (2009).

[159] J. Maclaughlin and M. F. Holick, Journal of Clinical Investigation 76, 1536 (1985).

[160] N. Ghalandarlaki, A. M. Alizadeh, and S. Ashkani-Esfahani, Biomed Research International, 394264 (2014).

[161] C. J. H. Porter, N. L. Trevaskis, and W. N. Charman, Nature Reviews Drug Discovery 6, 231 (2007).

[162] A. Gursoy, E. Kut, and S. Ozkirimli, International Journal of Pharmaceutics 271, 115 (2004).

[163] S. G. Ingebrigtsen, N. Skalko-Basnet, C. D. C. Jacobsen, and A. M. Holsaeter, European Journal of Pharmaceutical Sciences 97, 192 (2017).

[164] T. Toniazzo, I. F. Berbel, S. Cho, C. S. Favaro-Trindade, I. C. F. Moraes, and S. C. Pinho, Lwt-Food Science and Technology 59, 1265 (2014).

[165] M. Moraes, J. M. P. Carvalho, C. R. Silva, S. Cho, M. R. Sola, and S. C. Pinho, International Journal of Food Science and Technology 48, 274 (2013).

[166] M. C. Blok, L. L. M. van Deenen, and J. de Gier, Biochimica et Biophysica Acta (BBA) - Biomembranes 433, 1 (1976).

[167] A. Nasedkin, J. Davidsson, and M. Kumpugdee-Vollrath, Journal of Synchrotron Radiation 20, 721 (2013).

[168] T. Takayoshi Takeda and Kozo Akabori and Yoshinori Toyoshima and Shigehiro Komura and Yumi, Japanese Journal of Applied Physics 26, 1791 (1987).

[169] N. Benner and D. Sammons, Osteopathic Family Physician 5, 185 (2013).

[170] P. Hsu, G. I. Litman, and R. T. Brodell, Postgraduate Medicine 123, 153 (2011). 
[171] I. Aslam, A. Fleischer, and S. Feldman, Expert Opinion on Emerging Drugs 20, 91 (2015).

[172] S. Knutsen-Larson, A. L. Dawson, C. A. Dunnick, and R. P. Dellavalle, Dermatologic Clinics 30, 99 (2012).

[173] P. V. Chernyshov, L. Tomas-Aragones, L. Manolache, A. Svensson, S. E. Marron, A. W. M. Evers, V. Bettoli, G. B. Jemec, and J. C. Szepietowski, Journal of the European Academy of Dermatology and Venereology 32, 1410 (2018).

[174] A. Kang, A. Lyons, J. Herrmann, and R. Moy, Journal of the American Academy of Dermatology 79, AB302 (2018).

[175] A. L. Zaenglein et al., Journal of the American Academy of Dermatology 74, 945 (2016).

[176] D. Yang, D. Pornpattananangkul, T. Nakatsuji, M. Chan, D. Carson, C.-M. Huang, and L. Zhang, Biomaterials 30, 6035 (2009).

[177] G. M. Maghraby, B. W. Barry, and A. C. Williams, European Journal of Pharmaceutical Sciences 34, 203 (2008).

[178] M. M. A. Elsayed, O. Y. Abdallah, V. F. Naggar, and N. M. Khalafallah, International Journal of Pharmaceutics 332, 1 (2007).

[179] L. S. Hirst, A. Ossowski, M. Fraser, J. Geng, J. V. Selinger, and R. L. B. Selinger, Proceedings of the National Academy of Sciences of the United States of America 110, 3242 (2013).

[180] I. Wood, J. M. R. Albano, P. L. O. Filho, V. M. Couto, M. A. de Farias, R. V. Portugal, E. de Paula, C. L. P. Oliveira, and M. Pickholz, European Biophysics Journal with Biophysics Letters 47, 561 (2018).

[181] C. J. Schankin and A. Straube, The Journal of Headache and Pain 13, 263 (2012).

[182] R. Hargreaves, Headache 47, S26 (2007).

[183] B. N. Mason and A. F. Russo, Frontiers in Cellular Neuroscience 12, 233 (2018).

[184] V. Snow, K. Weiss, E. M. Wall, C. Mottur-Pilson, P. Amer Acad Family, and P. Amer Coll, Annals of Internal Medicine 137, 840 (2002).

[185] R. B. Lipton and M. E. Bigal, American Journal of Medicine 118, 3S (2005).

[186] R. B. Lipton and M. E. Bigal, Headache 47, S2 (2007).

[187] J. F. Rothrock, Headache 49, 635 (2009).

[188] S. Law, S. Derry, and R. A. Moore, Cochrane Database of Systematic Reviews, Cd008541 (2016).

[189] P. C. Tfelt-Hansen, The Journal of Headache and Pain 11, 5 (2010).

[190] G. P. Hansraj, S. K. Singh, and P. Kumar, International Journal of Biological Macromolecules 81, 467 (2015).

[191] P. Girotra and S. K. Singh, Pharmaceutical Research 33, 1682 (2016).

[192] I. Wood and M. Pickholz, European Biophysics Journal with Biophysics Letters 42, 833 (2013). 
[193] M. N. Yukuyama, P. L. Oseliero, E. T. M. Kato, R. Lobenberg, C. L. P. de Oliveira, G. L. B. de Araujo, and N. A. Bou-Chacra, Colloids and Surfaces a-Physicochemical and Engineering Aspects 554, 296 (2018).

[194] R. L. Rubim, B. B. Gerbelli, K. Bougis, C. L. P. de Oliveira, L. Navailles, F. Nallet, and E. A. de Oliveira, European Physical Journal E 39, 3 (2016).

[195] E. Andreoli de Oliveira, E. R. Teixeira da Silva, A. Fevrier, E. Grelet, F. Nallet, and L. Navailles, Epl 91, 28001 (2010).

[196] E. R. T. da Silva, E. A. de Oliveira, A. Fevrier, F. Nallet, and L. Navailles, European Physical Journal E 34, 83 (2011).

[197] S. T. Milner and D. Roux, Journal De Physique I 2, 1741 (1992).

[198] P. T. Boggs, R. H. Byrd, and R. B. Schnabel, Siam Journal on Scientific and Statistical Computing 8, 1052 (1987).

[199] P. T. Boggs, J. R. Donaldson, R. H. Byrd, and R. B. Schnabel, Acm Transactions on Mathematical Software 15, 348 (1989). 